\title{
Real and Financial
}

Asymmetries in

the Euro Area 

Real and Financial Asymmetries in the Euro Area 
Manuscript committee: Prof. dr. J.A. Bikker

Prof. dr. M. Koetter

Prof. dr. O.C.H.M. Sleijpen

Prof. dr. C.N. Teulings

Prof. dr. C. van Marrewijk

ISBN 978-94-91870-44-6

Tjalling Koopmans Institute dissertation series

USE 059

Printed by Ridderprint BV | www.ridderprint.nl

(C) 2021 Katharina Weddige-Haaf

All rights reserved. No part of this book may be reproduced or transmitted in any form by any electronic or mechanical means without the permission in writing from the author. 


\title{
Real and Financial Asymmetries in the Euro Area
}

\author{
Reële en Financiële Asymmetrieën in de Eurozone
}

(met een samenvatting in het Nederlands)

\section{Proefschrift}

ter verkrijging van de graad van doctor aan de Universiteit Utrecht

op gezag van de

rector magnificus, prof.dr. H.R.B.M. Kummeling, ingevolge het besluit van het college voor promoties

in het openbaar te verdedigen op

vrijdag 9 april 2021 des middags te 12.45 uur

door

\section{Katharina Weddige-Haaf}

geboren op 3 februari 1974

te Quedlinburg, Duitsland 
Promotor:

Prof. dr. C.J.M. Kool 
To Emma, Alma and Clara 



\section{Acknowledgements}

Life takes unexpected turns sometimes. I was invited to the inauguration ceremony of my dear former colleague Dr. Jaap Bikker from De Nederlandsche Bank at Utrecht University. On this occasion, I met the supervisor of my Master's thesis, Dr. Clemens Kool, again. We had been out of touch for a while. At the time, my PhD project at McGill university faltered after several terms of parental leave as well as due to the geographic distance between Belgium (where I lived with my family) and Canada. Clemens offered: "If you need a supervisor, let me know." I do not remember how long it took me to take the decision. But I never regretted that I did. Clemens, by nature, questions everything. He never returned a document without suggestions for improvement. He was a master in condensing when my writings got too wordy. In a nutshell, he kept challenging me from beginning to end. Sometimes, his comments left me desperate mostly at times when I thought that a paper was finished. But Clemens has this incredible talent of always combining his points of criticism or suggestions for improvement with simultaneous encouragement. He knows exactly when it is time to push and when it is time to hold. This kept my spirits. I could not have wished for a more patient and supportive supervisor. It was a true pleasure working with him.

A big thank you to Dr. Lenard Lieb from Maastricht University for his spontaneous support with Matlab during the Growth at Risk project. He re-arranged the code and thus made the program accessible and easy to use. I am grateful to the reading committee, Prof. dr. J.A. Bikker, Prof. dr. M. Koetter, Prof. dr. O.C.H.M. Sleijpen, Prof. dr. C.N. Teulings and Prof. dr. C. van Marrewijk, for reading and commenting on my thesis. Further, I thank the administrative staff at Utrecht University, above all Mariska van Dort and Marianne de Jonge, for helping me with all administrative issues along the way. And I am grateful to Dr. Andrea Schleu for her enduring support.

I thank my parents, family, relatives, friends, and acquaintances who supported me in many ways throughout the years and who share my joy of completing this thesis. However, those who did not believe that pursuing the thesis was worthwhile were sometimes my biggest motivation to finish it. I am particularly grateful for the special relationship I had with my deceased 
grandparents. They were always loyal and supportive, and they took great interest in all my endeavours.

I thank my former partner, Dr. Hans-Jörn Weddige, for his encouragement and support. The biggest thanks definitely go to our three girls, Emma, Alma and Clara. They grew up with their mother striving to finish a $\mathrm{PhD}$ project and closely experienced and endured all associated ups and downs of the research and writing process. Thank you for all the treats and crafts and special notes. Ihr seid toll!

Katharina Weddige-Haaf

Mülheim, April 2021 


\section{Contents}

$\begin{array}{lc}\text { List of Tables } & \text { xiii }\end{array}$

List of Figures $\quad$ xv

1 Introduction 1

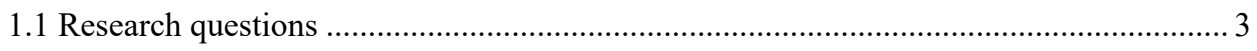

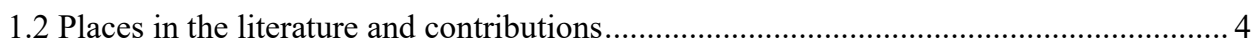

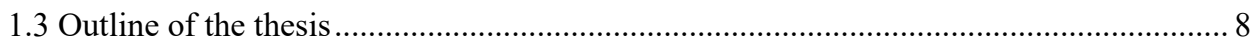

1.4 Summary of results and policy recommendations.................................................. 12

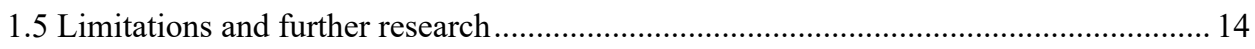

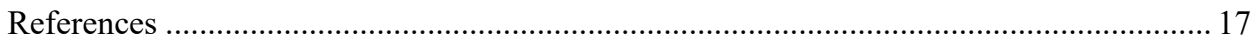

2 Synchronisation and Spillovers between Financial and Business Cycles in the Euro Area

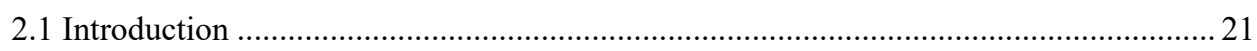

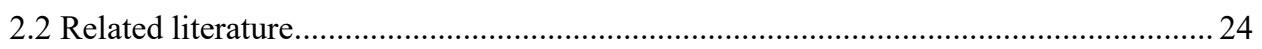

2.2.1 Economic cycles - computation and general characteristics................................... 24

2.2.2 Economic cycles - (bilateral) synchronisation .................................................... 27

2.2.3 Economic cycles - macro-financial linkages....................................................... 28

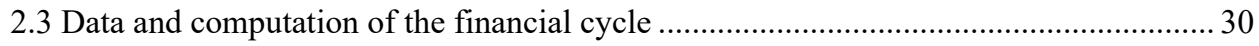

2.4 Stylised statistics of financial and business cycles ..................................................... 33

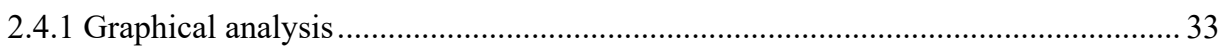

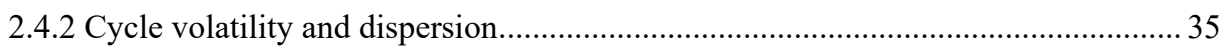

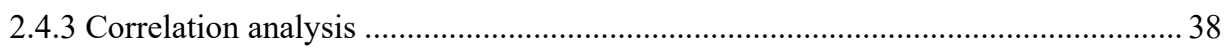

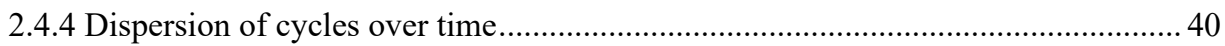

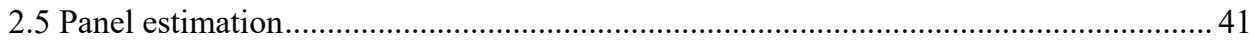

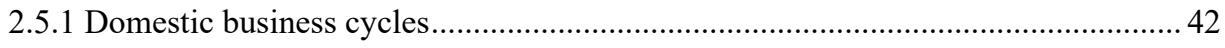




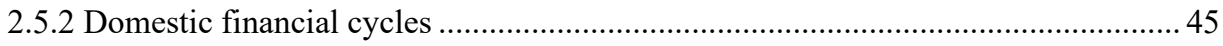

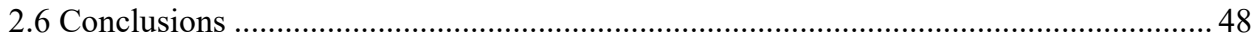

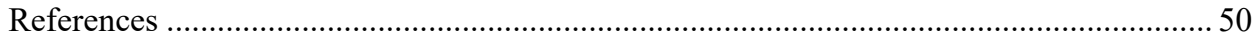

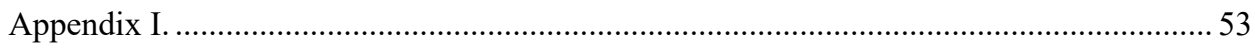

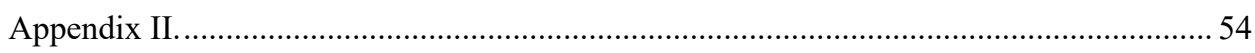



3 Growth at Risk and Financial Cycles in Euro Area Countries 61

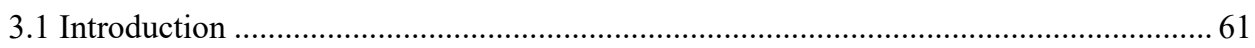

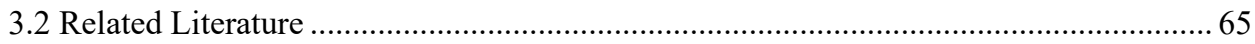

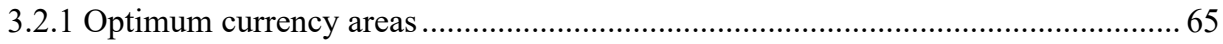

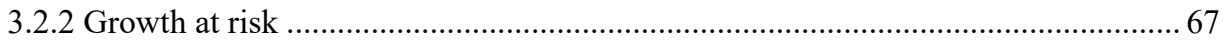

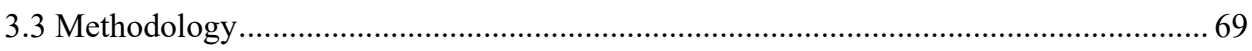

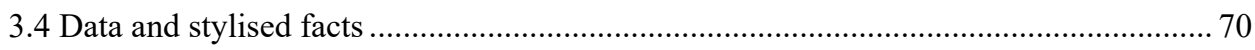

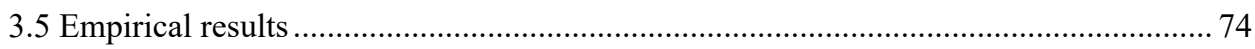

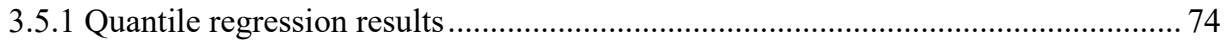

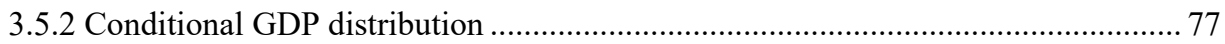

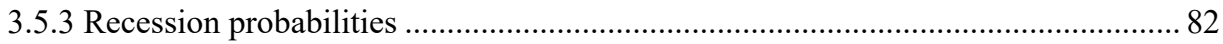

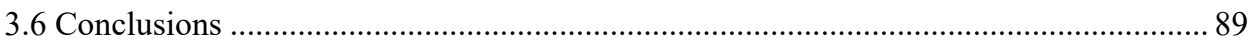

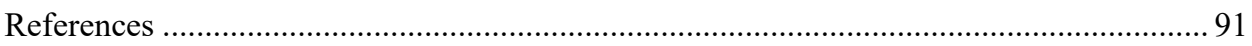





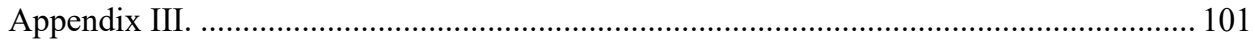

4 Trade Imbalances in the Euro Area: A GVAR Analysis 103

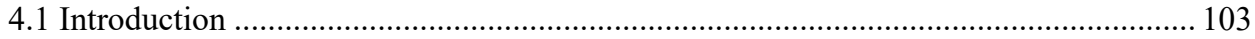

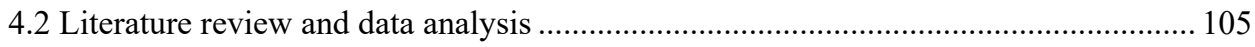



4.2.2 Competitiveness and the real effective exchange rate ....................................... 109

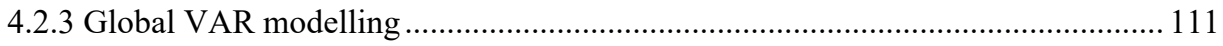

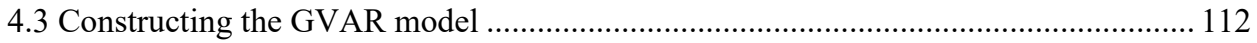

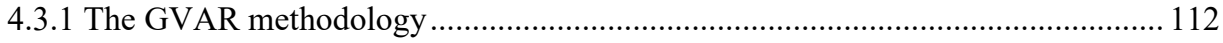

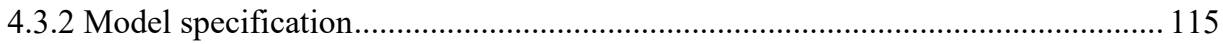

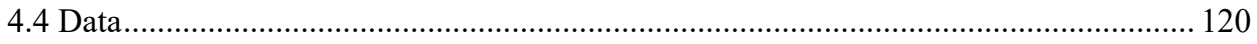




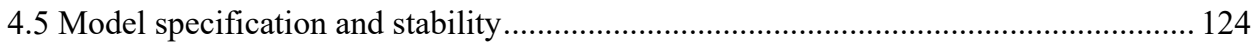

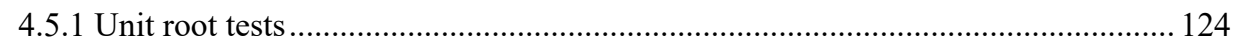

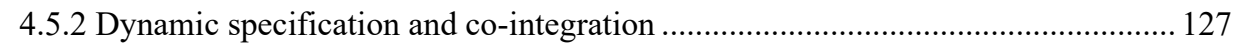

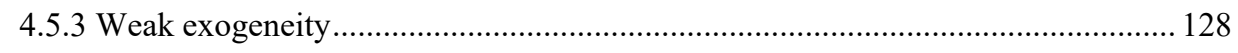

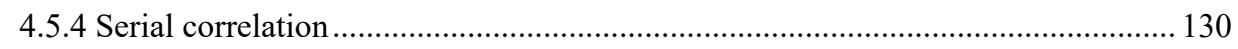

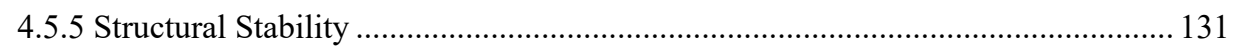

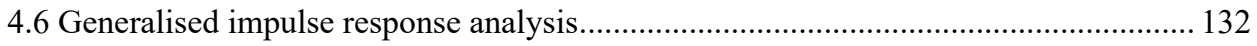

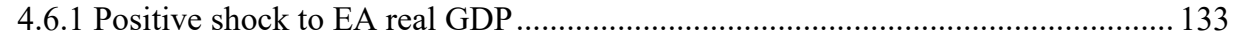



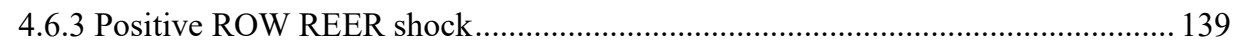

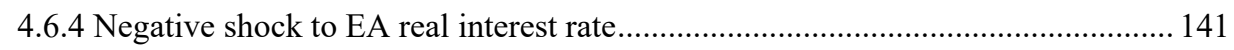

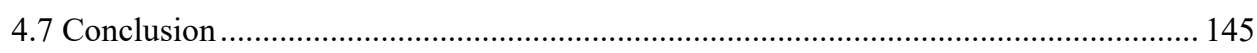

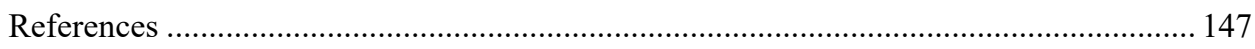

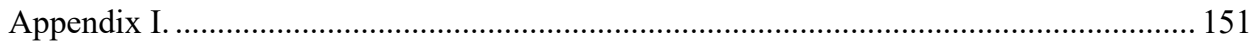

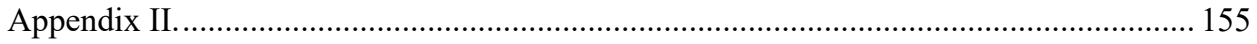

5 Regional Growth and Convergence in Germany, 1995-2014 157

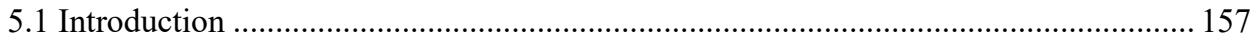

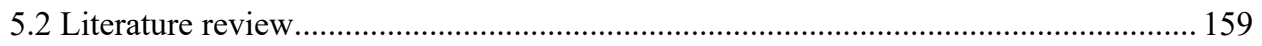

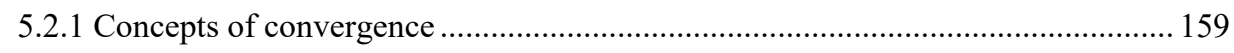

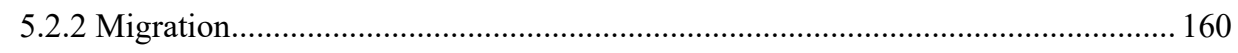

5.2.3 Federal financial equalisation system (Länderfinanzausgleich) ........................... 161

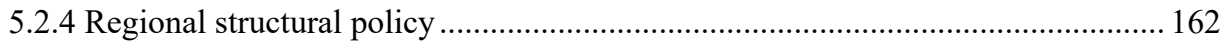



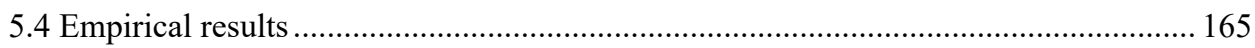



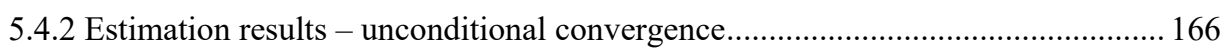

5.4.3 Empirical results - Conditional convergence ….............................................. 174

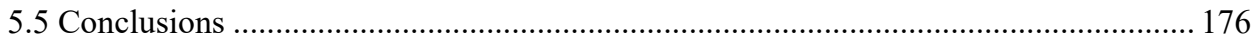

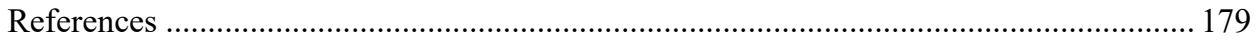

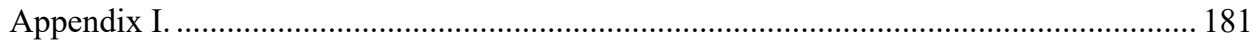





\section{List of Tables}

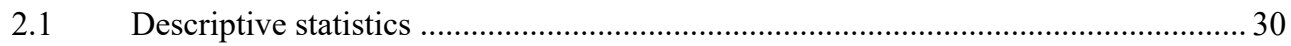

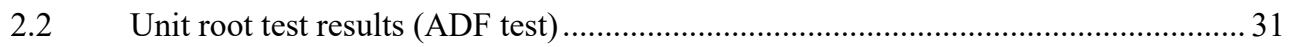

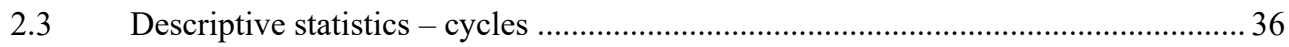

$2.4 \quad$ F-test results for standard deviations of various cycles ........................................ 37

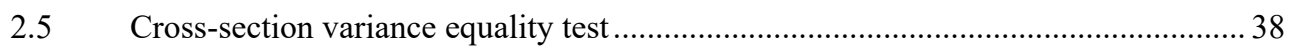

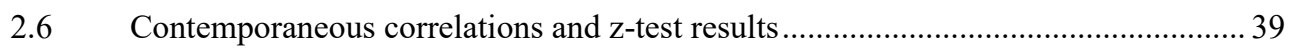

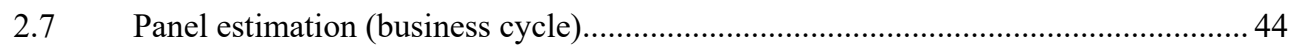

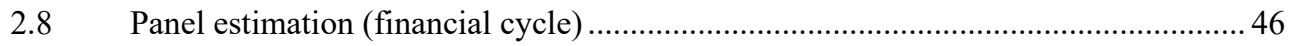



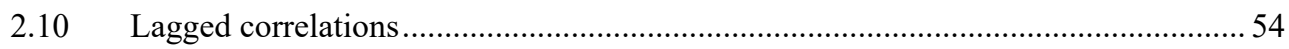

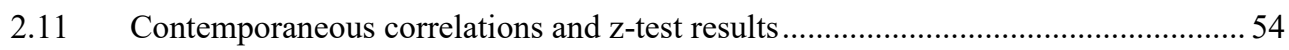

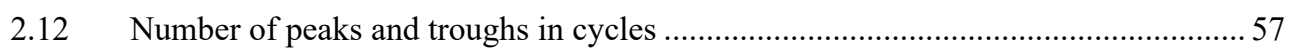

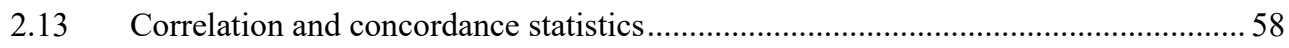

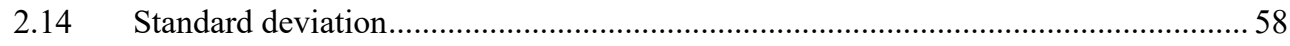

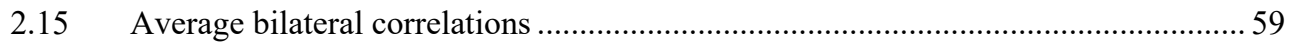

2.16 Correlations and concordance with the EA8 cycle ............................................. 60

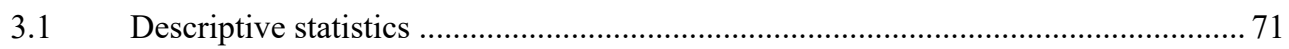

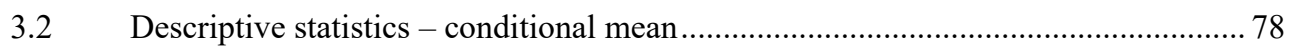

3.3 Cross-country correlations of conditional mean ..................................................... 79

3.4 Descriptive statistics and realised recession percentages........................................... 85

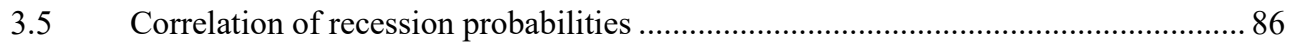

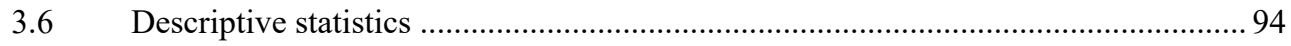

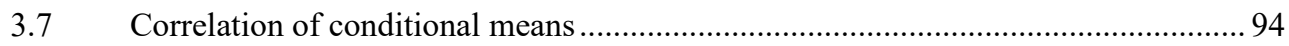

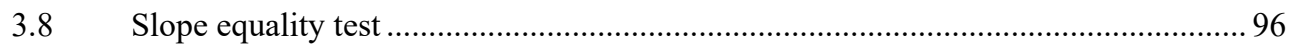

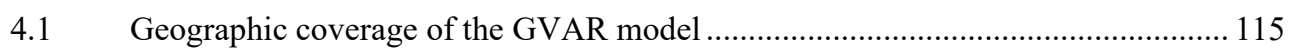

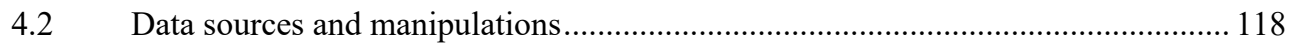




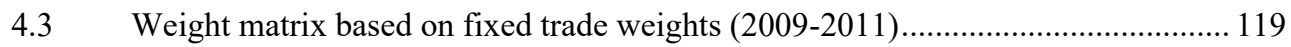

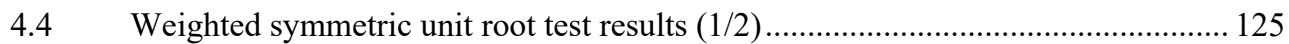

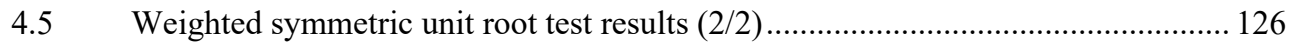

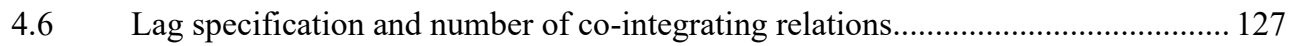

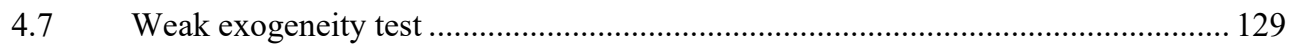

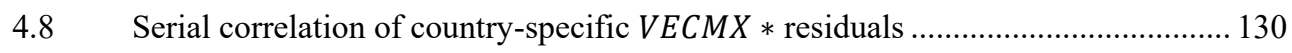

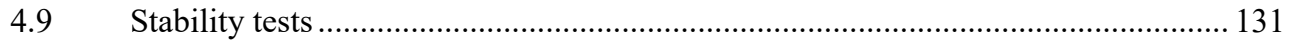

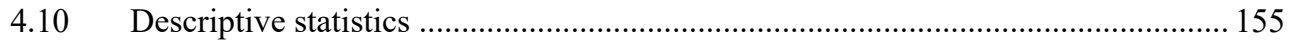

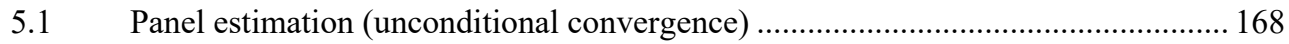

5.2 Panel estimation (cross-section and period fixed effects) ......................................... 175



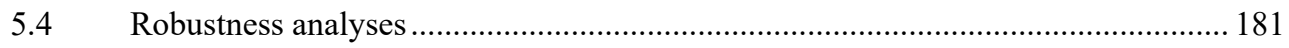




\section{List of Figures}

2.1 Business and financial cycles - domestic vs. EA aggregates .................................... 34

2.2 Cross-country standard deviation of domestic business and financial cycles ........... 41



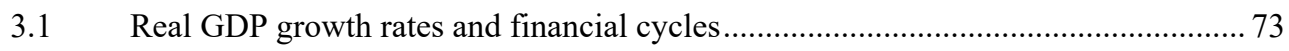

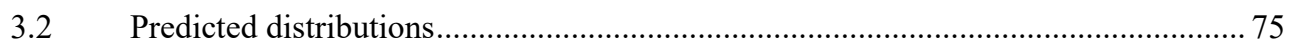

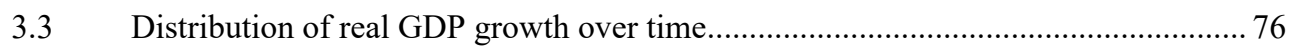



3.5 Cross-country standard deviation of conditional mean growth ................................ 80

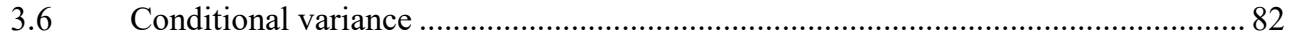

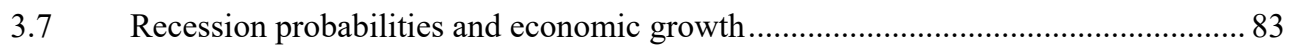

3.8 Standard deviation of recession probabilities ...................................................... 87

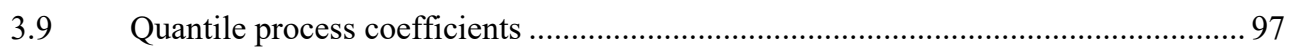





4.2 Intra-EA and extra-EA real effective exchange rates .......................................... 123

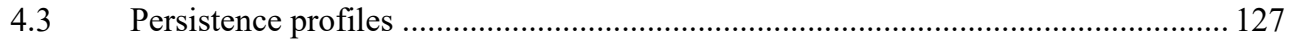

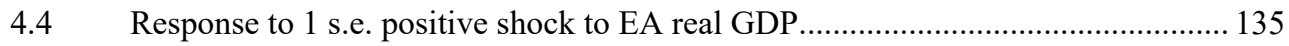

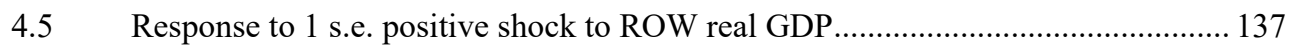

4.6 Response to 1 s.e. positive shock to ROW REER ................................................. 140

4.7 Response to 1 s.e. negative shock to EA real interest rate ..................................... 142

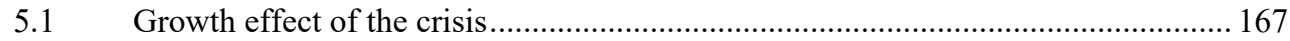

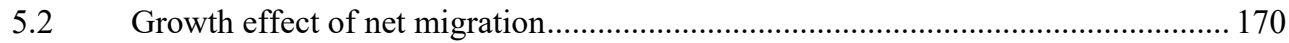

5.3 Growth effect of fiscal equalisation (Federal supplementary grants) ...................... 171







\section{Chapter 1}

\section{Introduction}

It is indeed a challenge to write the introduction to a thesis about asymmetries in the European Economic and Monetary Union (EMU) which was written in over almost a decade. In particular when the underlying economic structures it takes for granted in its analysis are challenged by the appearance of a tiny virus which shakes the world in its foundations. A virus that has the power to bring to an almost complete standstill this huge machine called the global economy. The global health crisis translated into an unprecedented global demand and supply shock. It is clear already that the shock is asymmetrically transmitted into the different countries of the world, not least into euro area (EA) economies. As a result, international trade relations may need to be reconsidered. The mere existence of the euro area is once again put to the test. Positively though, in response to the crisis, the European Union (EU) has made some overdue progress in terms of risk sharing to cope with the crisis impact. The recent events thus underline the relevance of the topics and approaches of this thesis.

Even prior to the covid-19 pandemic, the EA had to cope with at least two major challenges, namely the financial crisis and the European debt crisis which evolved in its aftermath. The challenges are related to the common finding that the EA does not fulfil the conditions of an optimum currency area (OCA). From a conceptual perspective, a currency union should meet several preconditions to compensate for the loss in monetary autonomy and exchange rate policy for each of the participating countries. Long before its actual implementation, the idea of a European Economic and Monetary Union triggered the debate on economic motivations for the introduction of a common currency in Europe. With a common currency, national authorities can no longer use monetary policy and exchange rate adjustments as tools to 
accommodate disturbances - either common or idiosyncratic - that the national economy might face. Instead, a central monetary authority designs a common monetary policy and strives to optimise its policy at union level. Successful common monetary policy calls for a sufficient degree of similarity between participating economies. If the countries are sufficiently similar in economic structure, or, alternatively, if other adjustment mechanisms are in place to compensate for structural differences, the cost of renouncing monetary policy independence and exchange rate adjustment will be outweighed by the benefits of using a single currency. ${ }^{1}$ In practice, empirical research on EMU and its OCA properties often focuses on the symmetry of shocks and the synchronisation of short-term (business cycle) fluctuations to assess the degree of synchronisation and convergence over time (Hessel, 2019). Hence, the focus of the analysis has for long been on the real side of the economy. The severity of the recent financial crisis has renewed research interest in the linkages between financial markets and the real economy in general. Studies like Borio (2012) and Drehmann et al. (2012), for instance, emphasise the role of financial factors in amplifying and prolonging economic fluctuations via movements in asset prices, credit and private debt and house prices. Macro-financial linkages have not generally been the focus of OCA studies in the past. Yet, as a result of European economic integration and the introduction of the euro as the common currency, both an increase in bilateral trade and an overall deepening of EA financial markets can be observed. Also, the international ties of the EA as a whole have intensified in the course of globalisation. These complex real and financial interactions within member states, between member states and between the EA and its international trading partners transmit shocks across national borders as well as between the real and financial sectors. The 2008/2009 financial crisis has shown that symmetric shocks can become a real test to the union's viability if they are transmitted asymmetrically across EA economies and if the EA is lacking the policy tools or alternative adjustment mechanisms to appropriately respond to them. The same holds a fortiori for asymmetric shocks.

In order to accommodate shocks of various types, it is crucial to understand the real and financial transmission channels as well as the existing asymmetries in the EA. My thesis intends to contribute to this understanding. In Chapter 2 and Chapter 3 I examine macro-financial linkages within and between EA member states. Specifically, in Chapter 2 I investigate the degree of interaction between business and financial cycles within and between EA member states as well as the importance of EA business and financial cycles for country-specific cycles.

\footnotetext{
${ }^{1}$ See De Grauwe (2007) for a thorough analysis of the costs and benefits related to currency unions.
} 
In Chapter 3 I explore the importance of the financial cycle in predicting future growth and the synchronisation between countries based on the predicted distributions. Chapter 4 is dedicated to EA trade (im-)balances and the transmission of symmetric shocks through trade links. I examine the impact of symmetric shocks on intra-EA and extra-EA trade balances. In the last chapter, I shift the geographic focus of the analysis to German federal states which can be considered a currency union of a smaller scale. Despite initial structural differences between the East and the West, it is plausible that the preconditions for an OCA, such as labour mobility and wage and price flexibility, are more likely met between German states than between EA countries. Germany has put in place a fiscal policy scheme, including the redistribution of tax revenues across federal states and some measures of structural funding to support poorer regions and to promote their convergence. I investigate if migration, fiscal equalisation and structural funding between regions are effective in supporting the convergence between German regions.

This introductory chapter is structured as follows. In section 1.1, I present the research questions of my thesis. Section 1.2 presents the relevant literature and the contributions of my research. Section 1.3 gives an outline of the thesis with a summary of the chapters. Section 1.4 briefly summarises the results of the thesis and presents policy recommendations. I discuss the limitations of my work and the suggestions for further research in section 1.5.

\subsection{Research questions}

The first question relates to the synchronisation of real and financial markets in the EA and is discussed in Chapter 2 and Chapter 3. Based on country-specific business and financial cycles I investigate the degree of cross-country synchronisation as well as the presence of macrofinancial linkages within and between EA countries. I compare the pre-euro and euro periods (Chapter 2) and the pre-crisis and post-crisis periods (Chapter 3).

The second question relates to the transmission of shocks in the EA. In Chapter 4 I specifically ask how symmetric shocks affect external balances and the competitiveness of individual EA countries. In the light of increasing macroeconomic imbalances my conjecture is that shock transmission is asymmetric across countries. Further, I distinguish between intra-EA and extraEA external balances and competitiveness for EA countries. The underlying assumption is that intra-EA and extra-EA external balances of a country might move into opposite directions, posing a challenge to domestic fiscal policy. 
The third question relates to the convergence between German federal states. Germany has put in place a fiscal policy scheme to promote convergence between regions. In Chapter 5 I investigate if these measures are successful in reaching the intended goal of convergence unconditional or conditional - between the federal states, postulating that the results depend on the states' initial conditions.

\subsection{Places in the literature and contributions}

All chapters in this thesis are related to the theory and literature of optimum currency areas. Given the rather loose connection between the chapters, there is only limited overlap in the remaining referenced literature. I will start off this section with an introduction to OCA theory as the unifying framework and then, for each chapter, point out the relevant literature.

OCA theory has guided the research on currency unions ever since its introduction by Mundell (1961). ${ }^{2}$ The traditional OCA criteria define adjustment mechanisms that can compensate for the loss of monetary independence. They are formulated as prerequisites for currency unions to evaluate (ex ante) the costs and benefits for countries attempting to create or join a monetary union. These conditions include wage and price flexibility, labour market integration, factor market integration, financial market integration, diversification in production and consumption, similarities of inflation rates, fiscal integration, political integration, and similarity of shocks. In its origins, the theory lacked a unifying framework as well as a clear ranking of these criteria. It was difficult to unambiguously measure and to evaluate the properties against each other, as they often yielded contradictory results. The similarity of economic shocks was advanced as a "meta-property" of OCA theory as it captures the interaction between several of its properties (Mongelli, 2002). The underlying assumption of this proposition is that if countries face similar shocks, a common monetary policy response is sufficient to accommodate them. This proposition implicitly assumes that countries resemble in structure and that therefore monetary policy affects real variables in a similar way across countries. If, on the other hand, disturbances are distributed asymmetrically or if the transmission of symmetric shocks or monetary policy is asymmetric across countries, asymmetric policy responses are required. In the latter case, countries participating in a monetary union are left with fiscal policy as the only policy measure

\footnotetext{
${ }^{2}$ See Mongelli (2002) for a review of the OCA literature.
} 
to accommodate the disturbances. ${ }^{3}$ Alternatively, other - more market oriented - mechanisms, such as wage and price flexibility or international risk sharing via financial markets, need to be put in place to make up for the loss of policy independence and to cope with this type of asymmetries.

Frankel (1999) singles out the degree of openness and the correlation of income as the two most crucial properties in assessing the net benefits from a currency union. He further argues that OCA properties evolve over time and stresses the endogenous effect that currency unions might have, i.e. countries that do not satisfy the OCA criteria ex ante, might converge as a result of the single currency and become an OCA ex post. Most authors agree that reciprocal trade and openness increase among countries sharing a single currency and a common monetary policy (Frankel and Rose, 2000). However, the effect of monetary integration and the effective increase in reciprocal trade on income correlation is disputed (Mongelli, 2002). Two opposite views on the effect are put forward: the "Krugman specialisation hypothesis" (Krugman, 1993) and the "endogeneity of OCA" hypothesis (Frankel and Rose, 1998; Frankel, 1999). The specialisation approach asserts that monetary unions promote trade integration which fosters inter-industry trade specialisation to exploit economies of scale and therefore increases the asymmetry of industrial structures between countries, even if the OCA conditions are met ex ante. The likelihood of country-specific sectoral shocks increases, and incomes become less correlated. The endogeneity hypothesis postulates a positive link between income correlation and trade integration. Monetary integration reduces trading costs and promotes reciprocal trade, economic and financial integration and business cycle synchronisation through the cross-border transmission of shocks.

In the light of the OCA theory, a large body of literature evolved to empirically assess the costs and benefits associated with monetary unification in Europe. This literature primarily focuses on the symmetry of shocks (Bayoumi and Eichengreen, 1992; Bayoumi and Eichengreen, 2017) and the synchronisation of short-term (business cycle) fluctuations (Hessel, 2019). When the OCA theory was originally developed in the middle of the 20th century, banks were more strictly regulated and financial markets were less internationalised than in later decades (Eichengreen, 2014). Hence, the role of cross-border financial flows as a destabilising mechanism within a currency union was mostly disregarded in the empirical analysis.

\footnotetext{
${ }^{3}$ In the case of the European countries, the EMU with its internal market programme and the Stability and Growth Pact (SGP) imposes limits on the use of fiscal policies by the participating economies. In addition, the loss of seigniorage to finance budget deficits and the tax constraints imposed on the fiscal authorities by increasingly mobile factors of production restrict the use of fiscal policy.
} 
Chapter 2 is related to the literature on economic cycles and the synchronisation of economic cycles, in the spirit of OCA theory. The chapter also relates to the literature on (bi-directional) spillovers between the real economy and the financial sector (macro-financial linkages). A classification of economic cycles in general is presented in Harding and Pagan (2005). The research by Borio (2014), Claessens et al. (2011) and Drehmann et al. (2012) focuses on the definition of the financial cycle. Gächter et al. (2012) and Gächter et al. (2013) review multiple ways to model and analyse the synchronicity of cycles. An overview of the literature on macrofinancial linkages is presented for instance in Claessens and Kose (2018). In the first part of Chapter 2, I compute financial and business cycles following the approach presented in Drehmann et al. (2012) for individual EA countries and EA aggregates. I chose the same medium-term frequency for both, the business and financial cycles, to explore their relationship. The importance of the medium-term component in business cycles was stressed by Comin and Gertler (2006) and Rünstler and Vlekke (2016). While there is an abundant literature on the synchronisation of EA business cycles, the literature with prime focus on the synchronisation of EA financial cycles is rather limited (Alcidi, 2017; Granville and Hussain, 2017; Merler, 2015). Also, there is only limited evidence regarding the synchronisation between domestic business and financial cycles for EA countries (Alcidi, 2017; Granville and Hussain, 2017). In Chapter 2 I contribute to this literature. In the second part of the chapter, I move away from the - symmetric - cross-country analysis on a bilateral basis and contribute to the literature by investigating how individual EA countries' financial and business cycles are affected by one another as well as their EA equivalents in a panel framework.

In Chapter 3 I apply a different approach to relate the concepts of macro-financial linkages and OCA. Specifically, I make use of the developing growth at risk literature (GaR) along the lines of Adrian et al. (2019). The theory of GaR links a measure of financial conditions to the probability distribution of future GDP growth (Adrian et al., 2019; IMF, 2017). Specifically, the approach uses quantile regression to estimate the full distribution of future GDP. A parametric form skewed t-distribution is then fit to smooth the empirical quantile function. The chapter contributes to both the literature on GaR and OCA. First, I contribute to the GaR literature by using the financial cycles from Chapter 2 instead of a financial conditions index (FCI) as conditioning variable for GDP prediction. Second, the geographic scope - the exclusive focus on individual EA countries - differs from earlier research. Third, I use the time series of the conditional moments and recession probabilities from smoothing of the empirical 
quantile function to assess the degree of economic synchronisation between EA countries using measures of co-movement and dispersion.

In OCA theory, the similarity of shocks is considered a precondition for the successful functioning of the monetary union. In Chapter $4 \mathrm{I}$ investigate if symmetric shocks are transmitted symmetrically into EA countries. The chapter is related to the literature on current account (CA) imbalances and the global vector autoregression (GVAR) framework. The GVAR model is composed of a large number of unit-specific models. It was initially developed as a tool for credit risk analysis, but the approach was later applied to a variety of questions, including international transmissions (di Mauro and Pesaran, 2013). In the context of multicountry macroeconomic models, core domestic variables (such as real output, trade balance, interest rate, exchange rate) are related to observed global variables (such as international energy prices and foreign specific variables). Within this framework, I model individual EA countries instead of treating the EA as a single region to allow for heterogeneity across countries. Further, my model specification treats EA countries differently from non-EA countries. Specifically, following the research of Bayoumi et al. (2011), Nieminen (2015), Nieminen and Junttila (2015) and Schmitz and Von Hagen (2011), I argue that additional insights into the development of external balances and their determinants can be gained from differentiating between countries' intra-EA and extra-EA trade balances. I contribute to the GVAR literature by assessing the degree of asymmetry resulting from the transmission of symmetric shocks to intra-EA and extra-EA trade balances and to intra-EA and extra-EA real effective exchange rates (REER).

Chapter 5 is related to the literature on growth and convergence in general and between the regions of a monetary union in particular. The geographic focus of the chapter is on Germany as a monetary union. I investigate the - unconditional and conditional - beta convergence between German states using the growth-initial income equation (Barro and Sala-i-Martin, 1992; Barro and Sala-i-Martin, 2004). I include in turn net migration, fiscal redistribution and structural policy as additional explanatory variables into the estimating equation. Scheufele and Ludwig (2009) argue that migratory flows between the Eastern and the Western states in Germany have a significant impact on the growth rates of per capita incomes. There is generally no empirical support for a growth promoting or convergence effect of fiscal equalisation in Germany (Baskaran et al., 2017). The study by Eggert et al. (2007) suggests that structural funding promotes convergence between German states, but that the overall impact on macroeconomic growth is negative. The contribution of the chapter is threefold and related to 
estimation technicalities. I use comparatively long time series to analyse the impact of the financial crisis on convergence. Second, I use a time trend in our specification to explicitly account for potential misspecification due to ongoing technology growth. Third, in contrast to the majority of earlier studies, I hypothesise that the effect of additional explanatory variables on growth depends on initial conditions using interaction effects.

\subsection{Outline of the thesis}

This thesis consists of four self-contained chapters addressing macro-financial linkages (Chapter 2 and Chapter 3), trade imbalances (Chapter 4) and the convergence between German states (Chapter 5). Each chapter contains an introduction followed by a literature review, data and methodology, empirical results and a conclusion.

In Chapter 2 I examine macro-financial linkages between medium-term financial and business cycles for eight EA countries. The analysis is based on quarterly credit, house prices and real GDP data over the period 1975-2017. I compute a synthetic financial cycle measure for each country based on credit and house price data in the spirit of Drehmann et al. (2012) as well as a corresponding business cycle. Cross-country aggregation of financial and business cycles yields their EA aggregates. First, I investigate the synchronisation of the cycles in terms of comovement, volatility and dispersion. Second, in a panel ordinary least squares (OLS) framework, I explore how the domestic financial and business cycles are affected by one another as well as their EA equivalents. In particular, I investigate the lagged impact of domestic and EA cycles on changes in domestic business and financial cycles. I introduce euro dummies to examine if these relationships have changed with the introduction of the single currency. The preliminary analysis of the cycles shows that financial cycles and business cycles across euro area countries are closely related and that the synchronising effect of the euro is stronger in real than in financial markets. I confirm earlier findings in the literature that financial cycles are typically more volatile than business cycles, but their relative volatility decreases over time. Further, I identify a generally positive co-movement between business and financial cycles at the country level. However, cross-country differences in amplitudes between financial cycles as well as business cycles are persistent over time. The results of the panel estimations show the importance of domestic macro-financial linkages and the positive impact of the euro on this relationship. In addition, changes in the domestic cycles are significantly influenced by the state of their EA counterparts. Overall, EA cycles add to the explanatory power of the regression and 
indicate the importance of spillovers between countries and markets. However, my results also show that there are multiple channels of seemingly opposing impact affecting domestic business and financial cycles with implications for the conduct and the transmission of common monetary policy. In particular, given the various interactions, the overall impact of common monetary policy can be expected to be affected via macro-financial linkages. An optimal policy response needs to take the various transmission channels into account.

In Chapter 3 I use the domestic financial cycles and data on real GDP from Chapter 2 in a GaR framework (Adrian et al., 2019). First, I apply quantile regression to estimate the full distribution of future (one year ahead) real GDP growth conditional on current economic conditions and the financial cycle for each country. I closely follow the approach presented in Adrian et al. (2019), but replace the financial conditions index by the domestic financial cycle as explanatory variable. Second, I fit a parametric form skewed t-distribution to smooth the empirical quantile function. This optimisation process yields the time series of the first four moments of the skewed t-distribution. In addition, I compute the time series of the one year ahead recession probability. The aim of the analysis is two-fold. First, I investigate the importance of domestic macro-financial linkages for each of the eight EA countries. Second, I assess the degree of cross-country synchronisation of the conditional distributions in the spirit of OCA theory. Specifically, I examine the co-movement and dispersion of conditional mean and variance as well as the related recession probabilities before and after the 2008/2009 financial crisis. I identify two groups of countries: a 'core' and a 'periphery'. My analysis shows that the financial crisis loomed for a long time in periphery countries without being reflected in actual economic performance. I find that booming financial cycles in the early euro period translated into continuously declining conditional means, increasing conditional variances and rising recession probabilities in periphery countries. I do not identify similar trends for the core countries prior to the financial crisis. Overall, the empirical results suggest that countries tend to differ in both conditional mean growth and recession probabilities. Asymmetries between countries arise from both differences in size (dispersion of mean growth rates) and from a lack of co-movement.

In Chapter 4 I investigate the diverging external positions of EA countries as well as changes in EA countries' competitiveness. The analysis is based on quarterly data over the period 19752013. I take account of the complex international trade environment of EA economies by estimating a GVAR model for a subset of nine EA countries and nine of their most important international trading partners. I am particularly interested in knowing if the separate assessment 
of intra-EA and extra-EA trade balances within this framework adds to the understanding of EA external imbalances. The aim of the chapter is to examine how four symmetric shocks namely a positive region-specific shock to EA real GDP, a positive region-specific shock to real GDP in all non-EA countries, an exchange rate shock mimicking a euro appreciation and a negative region-specific shock to EA interest rates simulating the effects of an expansionary monetary policy - affect the intra-EA and extra-EA trade balances and competitiveness of EA economies. Thereby I investigate specifically if these shocks are transmitted symmetrically or asymmetrically into the various EA countries, if the impact of shocks differs in size and significance, and if either intra-EA or extra-EA trade balances or both are primarily affected by the shocks. Overall, I detect a large amount of heterogeneity in the responses of trade balances and REER to symmetric shocks both across and within EA countries. I find that shocks to real GDP are important drivers of intra-EA and extra-EA trade balances and that these shocks significantly affect the internal and external competitiveness of individual EA countries. The responses to domestic GDP shocks are more heterogeneous than the responses to international GDP shocks. An appreciation of the euro leads to a permanent change in the external competitive position of the various EA countries but has no long-run effect on trade balances. Expansionary monetary policy affects the internal and external competitiveness of some countries, but their impact on trade balances is only temporary. The overall heterogeneity of the responses suggests that the reduction of external imbalances might not be a straightforward policy task. There are several reasons. First, policy measures themselves might possibly be transmitted non-uniformly into intra-EA and extra-EA trade balances. Second, if countryspecific intra-EA and extra-EA imbalances are of different signs, policy makers might need to prioritise between the imbalances in their policy choices. Third, as intra-EA trade balances across EA countries need to be offsetting, the reduction of intra-EA deficits must inevitably be accompanied by an intra-EA surplus reduction of equal size in some other country.

In Chapter $5 \mathrm{I}$ attempt to assess the degree of $\beta$-convergence between German federal states in the aftermath of German reunification. The analysis is based on the growth-initial income equation in which the growth rate of average per capita income over some period is related to the level of per capita income in the starting period (Barro and Sala-i-Martin, 1992). To take account of ongoing technological change and the financial crisis, I include a time trend and a crisis dummy. I extend this basic equation to include in turn measures of migration, fiscal equalisation and regional structural policy and their interaction with initial income to investigate the impact on per capita growth. I estimate the growth-initial income equation in a panel OLS 
framework using annual data for the period 1991-2014 and proceed in two steps. In the first step, I assume unconditional convergence between German states. This assumption is based on the findings in the empirical literature that regional data sets typically offer more support for unconditional convergence - and therefore a single steady state for all regions - than crosscountry research. In the second step, I relax the assumption of unconditional convergence and estimate a fixed effects (FE) model to allow each state to converge to its own steady state. I thereby acknowledge possible differences in terms of technology and preferences between the German states. In addition to the more obvious differences between Eastern and Western states, one might also expect differences between the more rural areas in the North as compared to the industrialised South and between city and area states, hence justifying the assumption of conditional convergence. The empirical results provide support for rather slow unconditional convergence between East and West and suggest a very long convergence path. The crisis itself caused an extra one-time convergence effect. The automatic convergence effect becomes insignificant when the additional explanatory variables - net migration, fiscal equalisation and structural funding - are included into the benchmark equation. The estimations show that netmigration, vertical fiscal equalisation and structural policy variables contribute to unconditional convergence between East and West, while horizontal fiscal equalisation does not. Our empirical evidence supports the relevance of non-linear interaction effects. Estimation of the fixed effects model supports the hypothesis of conditional convergence between German states. The speed of convergence increases compared to the unconditional convergence specification. The impact of all other explanatory variables is insignificant in the conditional specification, suggesting that conditional convergence is quasi automatic and that additional variables do not succeed in speeding up the convergence process. What are the conclusions of these findings in view of the EA? The findings suggest that unconditional convergence between regions within a monetary union more generally is by no means either automatic or fast. Rather, it seems even more likely that income differences between EA regions could prevail in the long-run and that the regions converge to a region-specific rather than common steady state. In the light of these findings, the effectiveness of EA convergence policy, its extent and desirability need separate evaluation in view of the expected length of the convergence process. 


\subsection{Summary of results and policy recommendations}

The proper functioning of a currency union presupposes a sufficient degree of similarity of the participating economies or alternative mechanisms to make up for the lack of similarity. In this thesis, I measure these similarities in a number of ways. The results of the various chapters in this thesis show that asymmetries between countries in the EA continue to exist, both in real and financial markets. Differences in economic structures and institutions furthermore result in the asymmetric transmission of symmetric shocks. The example of Germany shows that convergence of incomes within a currency union will be a lengthy process despite migration and fiscal transfer schemes and suggests that income differences between EA countries and regions are likely to exist in the longer run.

The empirical analyses in Chapter 2 and Chapter 3 are based on business and financial cycles. Chapter 2 indicates that financial and business cycles are tightly interlinked in the EA, yet differences in volatility continue to persist. Panel analysis reveals that both domestic and EA cycles explain changes in the domestic business and financial cycles in EA economies. For a deeper understanding of cross-country differences related to financial and business cycles, Chapter 3 turns to a cross-country analysis. Here, I investigate if the financial cycle includes information for upside or downside risk to future economic growth. The results show that while in the periphery countries booming financial cycles translated into declining conditional means, increasing conditional variances and rising recession probabilities, similar developments are not identified in the core countries. As both groups of countries experienced severe economic contraction during the financial crisis, the results suggests that other (cross-border) channels such as the interactions between cycles within the EA identified in Chapter 2 - cannot be underestimated in their importance for spreading crises across countries within the EA. Chapter 4 shows that symmetric shocks are heterogeneously transmitted into the trade balances of EA economies and thus have the potential to further increase imbalances and the divergence of external positions in the EA. The German example in Chapter 5 demonstrates that real income differences are very likely to persist in the long term. Labour mobility and fiscal redistribution cannot be expected to lead to hoped-for convergence in income in the near future.

As structural, institutional and income differences continue to exist, the EA remains vulnerable to shocks which common monetary policy cannot accommodate sufficiently. Mechanisms supplementing monetary policy are needed to mitigate shocks, to ensure economic stability, 
and to promote income convergence. This leaves scope for some kind of mutualisation and policy coordination at the EA level.

An increase in private sector risk sharing can be a powerful channel in insulating households against country-specific shocks. Internationally diversified portfolios, i.e. cross-border asset holdings, are more resilient to local and global shocks and can mitigate the impact of this type of adverse scenarios. However, the findings in the literature suggest that, so far, the levels of private risk sharing in the EA have generally been low. Private sector risk sharing can take place via credit and capital markets, but the prevailing fragmentation of these markets at the EA level reduces the attractiveness of cross-border investments. The banking union and the capital market union affect different parts of the financial system but follow the common objective of achieving a more efficient and stable financial system. According to Hoffmann et al. (2018), real banking integration and capital market union are complements and robust risk sharing requires both. In particular, the paper shows that real banking integration, i.e. crossborder lending to the real sector, has proven more resilient than interbank lending in the aftermath of the financial crisis. The paper furthermore claims that the nature of banking integration is of first order importance for patterns and channels of risk sharing. Completing the banking union by a third pillar, namely a common EA deposit insurance, can strengthen depositors' confidence through a common level of depositor protection across the EA and help prevent self-fulfilling panics on banks in individual member states. Capital market integration aiming at less fragmented and, hence, deeper and more liquid equity markets encourage crossborder investments and portfolio diversification. This presupposes an increase in information transparency, more efficient insolvency regimes as well as simplified and harmonised tax rules. Sørensen et al. (2007) show more generally that risk sharing increases with the decline in the home bias of international asset investments. Hence, a more effective banking union and a capital market union should help to improve private risk sharing in the EA.

In the past, the homogeneous fiscal rules of the Stability and Growth Pact (SGP) which are to ensure sound fiscal systems left governments too little scope to boost public spending to mitigate economic crises. While automatic stabilisers have worked counter-cyclically in the euro period, discretionary fiscal policy has been primarily pro-cyclical, given the lack of fiscal space (Fatas, 2019). Strong fiscal policy would require the strengthening of automatic stabilisers as well as the provision of a framework that encourages counter-cyclical discretionary policy. So far, the Eurozone governance fails to induce fiscal tightening in good times. A European fiscal capacity with clearly defined activation and contribution rules as well 
as measures to reign in moral hazard can prove useful to complement national automatic stabilisers and have a meaningful stabilisation effect (Dolls et al., 2019). Further, some form of fiscal insurance at the supranational level might prove necessary to safeguard the stability of the EA and increase overall welfare. Important advances in this respect have recently been made by the European Commission within the Multiannual Financial Framework (MFF) of the EU budget, integrating a recovery plan to deal with the immediate, medium and long-term impact of the Covid-19 pandemic on national economies and the single market. This plan gives the Commission the ability to raise funds from the financial markets backed by the Union as a whole. The revenues will be allocated to the EU budget to manage asymmetric economic impacts in member states and presents a first attempt of risk sharing at the EU supranational level.

The convergence literature suggests that convergence between countries at different economic levels requires moderate $\mathrm{CA}$ deficits in poorer countries and capital inflows from more prosperous countries. Public policy needs to ensure that CA positions do not translate into excessive capital flows and into unproductive uses of capital. Further, the coordination of fiscal policies of both deficit and surplus countries at the union level can help contain imbalances: while surplus countries partially compensate demand shortfalls by increased public investment and incentives for private investment, deficit countries implement countercyclical fiscal policies in order not to exacerbate overheating. Consistent labour market reforms and structural policies might furthermore prove useful to reduce the imbalances.

\subsection{Limitations and further research}

The analyses in this thesis are subject to a number of limitations. Recognising these limitations helps understand the results and provides a basis for future research.

In empirical analysis, data limitations are generally an issue of concern. The analyses in this thesis could benefit from data extension along both the cross-sectional and the time dimensions. Constraints in the latter were the main reason for the focus on a small number of EA countries in Chapter 2 to Chapter 4. As time proceeds and more (time series) data becomes available, it could be beneficial to extend the present research to a more complete set of EA countries.

The main empirical analyses in both, Chapter 2 and Chapter 5, rely on OLS panel estimation. In the analysis of chapter 2 , I point to the complex interdependencies between real and financial markets and the joint (contemporaneous) determination between the dependent and explanatory 
variables which raises the issues of endogeneity and simultaneity in the estimated equations. Likewise, in Chapter 5, dynamic endogeneity, i.e. some degree of feedback from the dependent variable to the regressors, might be an issue of concern. To approach the issue of endogeneity, I include the explanatory variables in both chapters with a lag. A recent study by Barros et al. (2020) on the endogeneity in panel regressions shows that simultaneity and dynamic endogeneity (feedback effects) might result in inconsistent OLS estimates. The authors illustrate that estimation methods for panel data based on the general method of moments (GMM) approach using assumptions of sequential exogeneity of the regressors present alternatives that are capable of overcoming the abovementioned concerns. The GMM estimations approach, such as the Arellano-Bond estimator could be a possible extension of the econometric approach in this thesis.

My analysis in Chapter 2 could furthermore be extended in two directions. First, my results show that the relative business and financial cycle conditions - and, hence, their net effect explain the changes in the domestic cycles. This observation needs further investigation. Second, my analysis is based on panel estimation and the results give an average picture of the presence and strength of macro-financial linkages in the EA. Possible asymmetries between countries - in particular concerning the strength of domestic macro-financial linkages - are averaged out with this estimation approach. A cross-country analysis based on individual country regressions could provide further insights.

In the computation of the conditional GDP growth in Chapter 3 I use the financial cycles from Chapter 2 which summarise the developments in the credit and residential real estate markets. The development in equity market can provide additional information about future economic developments and including them into the analysis can add further insights into growth at risk and recession probabilities.

The model in Chapter 4 can potentially be modified in various directions. I only highlight three possible extensions. First, my analysis focuses on nine EA countries and their nine most important trading partners outside the EA. This way, the analysis has a focus on the EA core and, from an international perspective, largely on developed market economies. A richer set of both - EA and non-EA countries - could give a more detailed picture and provide a deeper understanding of the shock dynamics. In particular, including emerging markets into the analysis would acknowledge their rising importance for global trade. Second, since the focus of the analysis is on both intra-EA and extra-EA trade relations, the analysis concentrates on a small number of variables but leaves out credit and other financial variables as explanatory 
variables. The research in this thesis highlights the importance of macro-financial linkages. To take account of the importance of financial markets, including credit and other financial variables could potentially increase the explanatory power of the model. A third improvement of the model would be to include export and import volumes instead of trade balances. As a result, the model could take account of absolute and relative changes in overall in trade volumes which would help to better understand the dynamics at work.

As the number of observations in the analysis of Chapter 5 is small, any statistical inference needs to be interpreted with caution. The issue could be solved along various dimensions. A first option would be to add to the analysis more recent observations (beyond 2014). A second option could be to look at economic growth over shorter time horizons, for instance one year or two years. Though this approach increases the number of observations by a multiple, the likelihood of cyclical disturbances would also increase. A larger number of observations would allow us to compute heteroscedasticity adjusted standard errors to the very least. The number of observations is furthermore limited by the choice of regional aggregation. For migration and structural funding an easy increase in the number of observations can be achieved by considering smaller geographic areas, such as NUTS 2, NUTS 3 or German labour market regions. The choice of regional aggregation is limited by the data on fiscal redistribution. 


\section{References}

Adrian, T., Boyarchenko, N., Giannone, D., 2019. Vulnerable Growth. American Economic Review 109 (4), 1263-1289.

Alcidi, C., 2017. Fiscal policy stabilisation and the financial cycle in the euro area. European economy Discussion Paper 052. European Commission, Luxembourg.

Barro, R.J., Sala-i-Martin, X., 1992. Regional Growth and Migration: A Japan-United States Comparison. Journal of the Japanese and International Economies 6, 312-346.

Barro, R.J., Sala-i-Martin, X., 2004. Economic growth, 2nd ed. MIT Press, Cambridge, Massachusetts.

Barros, L., Castro, F.H., da Silveira, A., Bergmann, D., 2020. Endogeneity in panel data regressions: methodological guidance for corporate finance researchers. RBGN 22 (Special Issue), 437-461.

Baskaran, T., Feld, L.P., Necker, S., 2017. Depressing dependence?: Transfers and economic growth in the German states, 1975-2005. Regional Studies 51 (12), 1815-1825.

Bayoumi, T., Eichengreen, B., 1992. Shocking Aspects of European Monetary Unification. NBER Working Paper 3949.

Bayoumi, T., Eichengreen, B., 2017. Aftershocks of monetary unification: Hysteresis with a financial twist. NBER Working Paper 23205.

Bayoumi, T., Harmsen, R., Turunen, J., 2011. Euro Area Export Performance and Competitiveness. IMF Working Paper WP/11/140. IMF.

Borio, C., 2012. The financial cycle and macroeconomics: What have we learnt? BIS Working Papers 395. Bank for International Settlements.

Borio, C., 2014. The financial cycle and macroeconomics: What have we learnt? Journal of Banking \& Finance 45, 182-198.

Claessens, S., Kose, M.A., 2018. Frontiers of macrofinancial linkages. BIS papers 95. BIS, Monetary and Economic Department, Basel.

Claessens, S., Kose, M.A., Terrones, M.E., 2011. Financial Cycles: What? How? When? International Monetary Fund. IMF Working Paper WP/11/76.

Comin, D., Gertler, M., 2006. Medium-Term Business Cycles. The American Economic Review 96 (3), 523-551.

De Grauwe, P., 2007. Economics of Monetary Union, 7th ed. Oxford University Press, Oxford.

di Mauro, F., Pesaran, M.H. (Eds.), 2013. The GVAR Handbook. Structure and Applications of a Macro Model of the Global Economy for Policy Analysis. Oxford University Press.

Dolls, M., Fuest, C., Peichl, A., Schleef, F., 2019. Are the current "automatic stabilisers" in the Euro Area Member States sufficient to smooth economic cycles? Euro Area Scrutiny PE 634.400. European Parliament.

Drehmann, M., Borio, C., Tsatsaronis, K., 2012. Characterising the financial cycle: don't lose sight of the medium term!, June 2012. Bank for International Settlements. BIS Working Papers 380. 
Eggert, W., von Ehrlich, M., Fenge, R., König, G., 2007. Konvergenz- und Wachstumseffekte der europäischen Regionalpolitik in Deutschland. Perspektiven der Wirtschaftspolitik 8 (2), $130-146$.

Eichengreen, B., 2014. The eurozone crisis: The theory of optimum currency areas bites back. Notenstein White Paper Series.

Fatas, A., 2019. Are the current "automatic stabilisers" in the Euro Area Member States sufficient to smooth economic cycles? Euro Area Scrutiny PE 634.399. European Parliament.

Frankel, J.A., 1999. No single currency regime is right for all countries or at all times. NBER Working Paper 7338.

Frankel, J.A., Rose, A.K., 1998. The Endogeneity of the Optimum Currency Area Criteria. Economic Journal 108 (449), 1009-1025.

Frankel, J.A., Rose, A.K., 2000. Estimating the effect of currency unios on trade and output. NBER Working Paper 7857.

Gächter, M., Riedl, A., Ritzberger-Grünwald, D., 2012. Business Cycle Synchronization in the Euro Area and the Impact of the Financial Crisis. Monetary Policy \& The Economy Q2/12, $33-60$.

Gächter, M., Riedl, A., Ritzberger-Grünwald, D., 2013. Business cycle convergence or decoupling? Economic adjustment in CESEE during the crisis. BOFIT Discussion Papers 3. Bank of Finland.

Granville, B., Hussain, S., 2017. Eurozone cycles: An analysis of phase synchronization. International Journal of Finance and Economics) 22 (2), 83-114.

Harding, D., Pagan, A., 2005. A Suggested Framework for Classifying the Modes of Cycle Research. Journal of Applied Econometrics 20 (2), 151-159.

Hessel, J., 2019. Medium-term Asymmetric Fluctuations and EMU as an Optimum Currency Area. DNB Working Paper 644.

Hoffmann, M., Maslov, E., Sørensen, B.E., Stewen, I., 2018. Are banking and capital markets union complements? Evidence from channels of risk sharing in the eurozone. Working paper series 311 . University of Zurich.

IMF, 2017. Financial Conditions and Growth at Risk, in: International Monetary Fund (Ed.), Global Financial Stability Report: Is growth at risk?, Chapter 3, pp. 91-118.

Krugman, P., 1993. Lessons of Massachusetts for EMU, in: Torres, F., Giavazzi, F. (Eds.), The Transition to Economic and Monetary Union in Europe. Cambridge University Press, New York.

Merler, S., 2015. Squaring the cycle: Financial cycles, capital flows and macroprudential policy in the Euro area. Bruegel Working Paper 2015/14.

Mongelli, F.P., 2002. "New" Views on the Optimum Currency Area Theory: What is EMU telling us? ECB Working Paper Series 138.

Mundell, R., 1961. A Theory of Optimum Currency Areas. American Economic Review 51, $657-665$.

Nieminen, M., 2015. Trade imbalances within the euro area and with respect to the rest of the world. Economic Modelling 48, 306-314. 
Nieminen, M., Junttila, J.P., 2015. The euro's effect on trade balance dynamics. https://www.researchgate.net/publication/282217733.

Rünstler, G., Vlekke, M., 2016. Business, housing and credit cycles. ECB Working Paper Series 1915.

Scheufele, R., Ludwig, U., 2009. Der lange Weg der Konvergenz. Wirtschaft im Wandel 10, 400-407.

Schmitz, B., Von Hagen, J., 2011. Current account imbalances and financial integration in the euro area. Journal of International Money and Finance 30 (8), 1676-1695.

Sørensen, B.E., Wu, Y.-T., Yosha, O., Zhu, Y., 2007. Home bias and international risk sharing: Twin puzzles separated at birth. Journal of International Money and Finance 26 (4), 587605. 



\section{Chapter 2}

\section{Synchronisation and Spillovers between Financial and Business Cycles in the Euro Area}

\subsection{Introduction}

The 2007-2009 financial crisis originated in US credit markets and spread internationally across financial and real markets. In the euro area (EA), extensive capital flows and the misallocation of capital in several southern EA countries following the euro's introduction fed into property bubbles and private debt overhang. In the wake of the crisis, private sector debt was transferred to sovereign debt as a result of banking system bailouts. In combination with the global developments, these factors translated into severe contractions in both financial and real markets in all EA countries.

The global dimension of the crisis suggests that financial and real markets are tightly intertwined at an international level. This observation has renewed research interest in financial cycles in general and macro-financial linkages in particular. Macro-financial linkages centre on the two-way interactions between the real economy and the financial sector. Specifically, shocks arising in the real economy can be propagated through financial markets and thereby amplify business cycles. Likewise, financial markets can be the source of shocks leading to more pronounced macroeconomic fluctuations. Global dimensions of these linkages can result in cross-border spillovers through real and financial channels (Claessens and Kose, 2018). 
Previous empirical research shows that financial cycles - in particular their booms and busts tend to affect both the duration and strength of recessions and recoveries. Recessions associated with financial disruptions tend to be longer and deeper, and recoveries combined with booms in financial markets, especially in housing and credit markets, are slightly shorter and stronger (Claessens et al., 2012; Drehmann et al., 2012). These findings are the results of countryspecific or cross-country studies which typically do not account for external developments that potentially influence domestic cycles. A prime example is the role of external capital that often plays an important role in unsustainable domestic credit booms, amplifying movements in credit aggregates (BIS, 2014). The related literature with prime focus on the EA studies the synchronisation of cycles across and within EA countries. Cross-country analyses mostly focus on the bilateral relationships of country-specific financial cycles and on the bilateral relationships of country-specific business cycles, respectively (Ahmed et al., 2018; Franks et al., 2018; Granville and Hussain, 2017). Alcidi (2017); Belke et al. (2016), for instance, relate country-specific cycles to EA aggregates.

Already since the 1980s, real and financial markets in Europe have become increasingly related. The introduction of the euro gave an extra stimulus to this integration for the EA countries. Hence, in addition to influencing each other, domestic business and financial cycles are not insulated from broader EA macroeconomic and financial market developments. Shocks to the domestic financial markets can affect domestic consumption and investment through wealth effects, changes in funding costs and the financial accelerator. In addition, the decline in real activity in one or several other EA countries and the associated decline in import demand may have negative economic effects on the domestic economy, as a result of close EA trade relations. Further, financial shocks spill over to other countries via financial integration: while countries' portfolio exposure to foreign assets can result in better risk sharing and help buffer shocks, it might as well reinforce spillovers between EA financial markets. Changes in financial conditions abroad as well as the resulting portfolio adjustments of international investors would then, through the channels presented above, affect the real sides of the domestic economy (Abbate, 2016).

In this chapter, I investigate financial cycles (FC) and business cycles (BC) for eight EA countries. ${ }^{1}$ In particular, I contribute to the literature by analysing how individual EA countries' (domestic) financial and business cycles are affected by one another and by their EA equivalents (EA7) in a panel framework. In addition, I analyse, if these relationships have changed with the

\footnotetext{
${ }^{1}$ The term "financial" related to the research results in this chapter refers to credit and house prices.
} 
introduction of the single currency. Doing so, I move away from the - symmetric - crosscountry analysis on a bilateral basis and for each country define the relevant external environment as the "rest" of the EA.

At first, some preliminary work is required. I define a synthetic financial cycle measure in the spirit of Drehmann et al. (2012) and a corresponding business cycle measure. I extensively discuss issues related to the computation of economic cycles and compute country-specific financial and business cycle aggregates. In a second step, I present a cross-country empirical analysis documenting the main features of synchronisation - co-movement and dispersion between domestic and EA financial and business cycles. Third, the main empirical analysis of the chapter investigates the two-way relationship between domestic business and financial cycles as well as the contribution of EA conditions to domestic cycles in a panel framework. It relates domestic financial (business) cycles to domestic business (financial) and EA business and financial cycles.

In the preliminary analysis, I investigate co-movement, volatility and dispersion of the cycles. I find that that financial cycles and business cycles across EA countries are closely related and that the synchronising effect of the euro is stronger in real than in financial markets. Further, I find positive co-movement between business and financial cycles at the country level, but the strength of this co-movement varies across countries. The volatility of the cycles differs across countries and it significantly and heterogeneously changes over time. Specifically, domestic cycles tend to be more volatile than EA cycles, and financial cycles are typically more volatile than business cycles. Domestic financial cycles have become comparatively less volatile compared with domestic business cycles in the euro period. There is no clear trend towards cross-country convergence in the amplitudes of either business cycles or financial cycles over time. I find that the cross-country dispersion of cycles is largest just before the onset of a financial crisis and that cycles converge as the crisis develops.

The panel estimations reveal that domestic and EA7 business and financial cycles can explain roughly 50 percent of the domestic business and financial cycle dynamics. Financial cycle effects on business cycle dynamics are negative while the business cycles effects are positive. The coefficients are similar in absolute size and it is their net effect that explains domestic business cycle dynamics. External conditions contribute about 10 percent to the explanation of domestic business cycle dynamics. Similarly, the state of the domestic and EA7 business and financial cycles significantly explains domestic financial cycle dynamics. Financial cycle effects are negative and business cycle effects are positive. The business cycle effect is larger 
than the financial cycle effect. The EA contribution is only half as large as it is for the domestic business cycle.

The remainder of the chapter is structured as follows. Section 2.2 summarises the related literature. In section 2.3 I present the data and compute the relevant business and financial cycles. Section 2.4 gives the stylised statistics of the financial and business cycles. The results of the panel estimations are discussed in section 2.5. Section 2.6 concludes.

\subsection{Related literature}

In this section, I briefly summarise the literature on economic cycles in general, and financial and business cycles in particular. I discuss issues related to the computation of economic cycles in section 2.2.1. Section 2.2.2 summarises the literature on the synchronisation of cycles and in section 2.2.3 I briefly review the results from the literature on macro-financial links.

\subsubsection{Economic cycles - computation and general characteristics}

The literature presents and applies various methods to compute economic cycles in general, and financial and business cycles in particular. Harding and Pagan (2005) intend to classify the various approaches in the cycle literature. Briefly, their suggested framework involves distinguishing two issues: first, the choice of the series to be included as input variables in the analysis and second, the methods to measure the cycle. The first issue not only concerns the choice of one or more appropriate series that contain the relevant cyclical information, but also their form. Cycles can then be measured as classical cycles that are fluctuations in the $(\log )$ level of an economic variable, as growth cycles by removing a permanent component from the level series under study, and as cycles in the growth rates where the underlying time series is first transformed into growth rates.

I first focus on the computation of financial cycles. No natural cycle measure is available for the financial sector (Stremmel, 2015) and, hence, there is no consensus in the literature on the choice of variables when measuring the financial cycle (Borio, 2014). In general, the related literature identifies financial cycles in one or more of three distinct but interdependent market segments, namely credit, residential real estate and equity prices (Granville and Hussain, 2017). BIS (2014) suggests that financial cycles are best measured by a combination of credit aggregates and property prices, representing the "smallest set of variables needed to replicate adequately the mutually reinforcing interactions between financing constraints (credit) and 
perceptions of value and risk (property prices)" (Borio, 2014). Financial cycles can be derived from (log) levels of financial (credit) series (Drehmann et al., 2012), credit growth ${ }^{2}$ (Alcidi, 2017; Cagliarini and Price, 2017; Drehmann et al., 2012; Stremmel, 2015) or the credit to GDP ratio (Alcidi, 2017; Franks et al., 2018; Stremmel, 2015). The growth rate of house prices (or property prices in a broader sense) is used for instance by Cagliarini and Price (2017), Drehmann et al. (2012), Hiebert et al. (2014) and Merler (2015) and house-prices in log-levels are used by Alcidi (2017). Equity prices are used by Ahmed et al. (2018), Granville and Hussain (2017) and Hiebert et al. (2014). All series are generally studied at the quarterly frequency except for equity prices, which are studied at a monthly frequency.

The two most commonly used approaches for the computation of the financial cycle are the turning point method and frequency-based filters. Ahmed et al. (2018), Claessens et al. (2011), Granville and Hussain (2017) and Hiebert et al. (2014) apply the turning point analysis to identify financial cycles in euro area countries. The Christiano-Fitzgerald (CF) bandpass filter is the most frequently applied frequency filter in the financial cycle literature. This two-sided moving average filter isolates certain frequencies in the time series. ${ }^{3}$ The approach is applied to euro area countries by, for instance, Alcidi (2017), Franks et al. (2018), Merler (2015) and Stremmel (2015).

An additional choice, which is specific to financial cycles, needs to be made between univariate and multivariate financial cycle measures. Univariate financial cycle measures are computed for a single financial variable. They make it possible to compare the characteristics of various financial variables or the characteristics of individual financial variables across countries (Drehmann et al., 2012; Galati et al., 2016). But these measures may neglect important developments in other financial market segments (Claessens et al., 2012; Schüler et al., 2017; Stremmel, 2015).

The literature proposes a number of methods to combine information from individual variables into an aggregate (multivariate) measure of the financial cycle. Drehmann et al. (2012) aggregate cycles which are computed with frequency-based filters by taking the average of the filtered series. This is possible since the individual cycles are continuous series (of comparable units of measurement). The peaks and troughs identified by the turning-point methodology can be aggregated using a measure of the median distance of the individual series from a turning

\footnotetext{
${ }^{2}$ Growth rates are generally computed as quarter over quarter or as four-quarter differences of log levels.

${ }^{3}$ Moving average filters are prone to the Slutsky-Yule effect: oscillatory movements may be generated when no oscillations exist in the original data Slutzky (1937) leading to spurious correlations between cycles.
} 
point (Drehmann et al., 2012; Harding and Pagan, 2006). Merler (2015) uses Principal Component Analysis (PCA) and Cagliarini and Price (2017) apply the Bry-Boschan quarterly algorithm for multiple time series to compute cycles in financial variables. Stremmel (2015) identifies the key ingredients and the most appropriate financial cycle measure for Europe using the approach suggested by Drehmann et al. (2012).

I only briefly discuss the computation of business cycles. The most prominent measure of economic activity used in business cycle studies is quarterly real GDP (Alcidi et al., 2017; Belke et al., 2016; Furceri and Karras, 2008; Gächter et al., 2012; Grigoraş and Stanciu, 2016). Other measures of economic activity include the industrial production index at the monthly frequency (Gächter et al., 2012; Gayer, 2007; Granville and Hussain, 2017; Massmann and Mitchell, 2005) and unemployment (Alcidi et al., 2017; Furceri and Karras, 2008) or employment (Duran and Ferreira-Lopes, 2016) at the quarterly frequency. The Hodrick-Prescott filter is generally applied to extract the business cycle (Belke et al., 2016; Duran and Ferreira-Lopes, 2016; Furceri and Karras, 2008; Gächter et al., 2012; Gogas, 2013; Gonçalves et al., 2009; Massmann and Mitchell, 2005; Weyerstrass et al., 2011). Some papers use the Baxter-King bandpass filter (Alcidi et al., 2017; Furceri and Karras, 2008; Gouveia and Correia, 2008; Massmann and Mitchell, 2005; Weyerstrass et al., 2011) or the Christiano-Fitzgerald bandpass filter (Franks et al., 2018; Weyerstrass et al., 2011). Occasionally, research is based on the classical cycle (Granville and Hussain, 2017; Grigoraş and Stanciu, 2016; Massmann and Mitchell, 2005).

The computation of both - financial and business cycles - requires a choice about the frequencies to be extracted from the data. Empirical evidence suggests that financial cycles have a longer duration (10 to 20 years) than business cycles (6 quarters to 8 years) (Drehmann et al., 2012). This implies that, in general, different frequencies are extracted from the data for financial and business cycles. Specifically, for the Hodrick-Prescott filter this translates into the multiplier $\lambda=1600$ for quarterly business cycles. Drehmann et al. (2012) follow the suggestions of Harding and Pagan (2002) and present different censoring rules for the turningpoint algorithm. Their approach guarantees a minimum cycle length of 5 quarters for business cycles and a minimum cycle length of 20 quarters for financial cycles. The CF filter extracts short-term frequencies (8-32 quarters) for business cycles and medium-term frequencies (32120 quarters) for financial cycles (Aikman et al., 2015; Drehmann et al., 2012).

By contrast, some authors stress the importance of the medium-term component in business cycles. Comin and Gertler (2006) show that the aforementioned conventional decomposition of the data with the band pass filter produces a trend which reflects the presence of significant 
cyclical activity at the medium-term frequencies. Multivariate estimates by Rünstler and Vlekke (2016) emphasise the presence of medium-term fluctuations in GDP, which are longer than the traditional business cycle. Drehmann et al. (2012) show the relative importance of the mediumterm cyclical component relative to the short-term component in shaping the dynamics of the GDP series. Alcidi (2017) uses the medium-term component of both - the financial and the business cycles - to eliminate the noise in the business cycle driven by small fluctuations.

This review shows that economic cycles are the outcome of a multitude of ex ante decisions and choices. As a result, cyclical features of an economy can vary depending on how the cycle is measured (Égert and Sutherland, 2012) and influence research results and policy suggestions. In addition, cross-study comparisons require special care. "Many problems arise in being unclear as to what cycle is being studied. A particular pernicious one is that many of the 'stylised facts' about cycles that are cited come from a category combination that is not that maintained by the citer." (Harding and Pagan, 2005) Nevertheless, some general findings are recurrent in the literature: Financial cycles are generally found to be longer and more volatile than business cycles; peaks tend to coincide with banking crises or considerable financial stress; financial cycles are often synchronised across countries as many drivers of the financial cycle have an important global component; financial cycles are found to change with the macroeconomic environment and policy frameworks (BIS, 2014).

\subsubsection{Economic cycles - (bilateral) synchronisation}

In this section, I summarise the literature on the synchronisation of business and financial cycles in the EA. Generally, three measures of synchronisation are applied in this literature: the correlation coefficient and the concordance statistic as measures of co-movement, and the standard deviation as a measure of dispersion. Gächter et al. (2012) and Gächter et al. (2013) review multiple ways to model and analyse the synchronicity of cycles. The concordance statistic was originally advocated by Harding and Pagan (2002).

Synchronisation can be investigated between (1) business cycles, (2) financial cycles and (3) business and financial cycles. (1) and (2) are generally computed bilaterally between countries or country aggregates. There is an abundant literature on the synchronisation of business cycles in the EA suggesting that business cycle correlation is generally high across EA12 member states (Alcidi, 2017; Belke et al., 2016; Gayer, 2007; Gogas, 2013; Weyerstrass et al., 2011). The literature with prime focus on the synchronisation of EA financial cycles is rather limited; it includes Alcidi (2017), Granville and Hussain (2017) and Merler (2015). (3) focuses on the synchronisation between business and financial cycles within countries (Alcidi, 2017; Granville 
and Hussain, 2017). The relationship between univariate cycles in credit, house prices, equity and the business cycle at both, the country level and across countries, presents a combination of (1) - (3) and is investigated by Claessens et al. (2011) and Hiebert et al. (2014). In addition, some authors split the investigated sample period to study the synchronisation of cycles over time (Ahmed et al., 2018; Alcidi, 2017; Franks et al., 2018; Merler, 2015).

The results of the studies establish some general trends in terms of co-movement and dispersion for EA financial and business cycles. First, both financial cycles and business cycles are highly synchronised across EA countries, before and after the introduction of the euro (Ahmed et al., 2018; ${ }^{4}$ Alcidi, 2017; Franks et al., 2018). However, further division of the sub-periods shows that the degree of financial synchronisation fell in the initial phase of the euro, but then rose again in the wake of the crisis (Franks et al., 2018; Merler, 2015). Germany is a well-known exception to these findings: its financial cycle is increasingly delinked from the rest of the EA. Second, Alcidi (2017) and Franks et al. (2018) show that the synchronisation between domestic business and financial cycles increased on average, but that this development is heterogeneous across countries. Third, Claessens et al. (2011) and Hiebert et al. (2014) compute univariate cycles in credit, housing and equity as well as business cycles. They find that the co-movement of domestic credit, housing and business cycles is generally high. Cross-country synchronisation of business cycles, credit cycles and equity cycles, respectively, is higher than the synchronisation of housing cycles, indicating idiosyncrasies in European housing markets. Fourth, Alcidi (2017) finds that financial cycles are generally more volatile than business cycles. Volatility in financial cycles decreased between the pre-euro and euro periods in some, but not all countries (Franks et al., 2018). Fifth, Stremmel (2015) investigates the dispersion of EA countries' financial cycles over time using cross-country standard deviations. The paper does not find a clear tendency towards lower dispersion of cycles over time, but it shows that the financial cycle dispersion tends to decrease, and financial cycle synchronicity tends to increase in the wake of cross-border financial stress events.

\subsubsection{Economic cycles - macro-financial linkages}

While the review in section 2.2.2 focuses on the (bilateral) synchronisation of business cycles and financial cycles, respectively, this section directs the attention to the empirical evidence of (bi-directional) spillovers between the real economy and the financial sector (macro-financial linkages). Claessens and Kose (2018) present an overview of cross-country studies

\footnotetext{
${ }^{4}$ This paper uses a probit framework rather than the conventional correlation approach to investigate synchronisation.
} 
investigating general patterns of aggregate macro-financial linkages for advanced and emerging market economies. At the international level, Claessens et al. (2012) and Drehmann et al. (2012), for instance, find strong linkages between the different phases of business and financial cycles. Financial cycles play an important role in shaping business cycle recessions and recoveries. In particular, recessions associated with financial disruptions are often longer and deeper than other recessions. Conversely, recoveries associated with rapid growth in credit and house prices tend to be stronger than other recoveries. Helbling et al. (2011) present a brief survey of studies investigating the role of credit markets in driving business cycles. Credit markets are strongly intertwined with the real economy. While bank credit can amplify movements in the real economy, cycles in the real economy can also introduce cyclicality in bank lending (Égert and Sutherland, 2012) suggesting two-way interaction between prevailing financial conditions and real economic activity (Tsatsaronis, 2005). Antonakakis et al. (2015) examine spillovers between credit and output growth within and between G7 countries using a vector autoregression (VAR) model. The analysis confirms the bidirectional nature of those spillovers and their larger impact during financial turmoil and economic recessions. International spillovers appear to be quantitatively pronounced, and the strength and direction of spillover effects are found to evolve heterogeneously across G7 countries. Ha et al. (2020) apply a dynamic factor model to G7 countries to jointly characterize global macroeconomic and financial cycles and the spillovers between them. The paper distinguishes between global, variable and country specific factors of macroeconomic aggregates and financial variables. Global macro factors are found to play an important role in explaining business cycle fluctuations, and there are sizeable spillovers from shocks to specific financial variables to macroeconomic variables. Some spillovers of financial variables operate mainly through the global macro factor rather than the country-specific macro factors. There is little evidence in the paper of spillovers from macroeconomic cycles to financial cycles. I am not aware of studies investigating macro-financial linkages with particular focus on the EA.

This literature review suggests that business and financial cycles in the euro area are highly synchronised. In addition, the literature provides evidence of the bidirectional nature of spillovers between real and financial markets at the national and international level. 


\subsection{Data and computation of the financial cycle}

My analysis includes eight EA countries: Belgium (BE), Finland (FI), France (FR), Germany (GE), Ireland (IR), Italy (IT), Netherlands (NE) and Spain (SP) and covers the period 1975Q12017Q3. I use credit, credit to GDP and real house price data to compute medium-term financial cycles. Nominal credit data are deflated by the CPI. I present the descriptive statistics of the data - namely real credit (c), credit per GDP (cgdp), real house prices (hp) and real GDP (y) in Table 2.1.

Table 2.1 Descriptive statistics ${ }^{5}$

\begin{tabular}{|c|c|c|c|c|c|c|c|c|}
\hline$c$ & BE & FI & FR & GE & IR & IT & NE & SP \\
\hline mean & 26.51 & 25.78 & 28.29 & 28.47 & 25.40 & 27.60 & 27.35 & 27.33 \\
\hline median & 26.41 & 25.79 & 28.28 & 28.58 & 24.97 & 27.57 & 27.39 & 27.01 \\
\hline $\max$ & 27.47 & 26.64 & 29.03 & 28.81 & 27.43 & 28.38 & 28.04 & 28.51 \\
\hline $\min$ & 25.63 & 24.81 & 27.58 & 27.82 & 23.91 & 26.86 & 26.14 & 26.47 \\
\hline std & 0.60 & 0.56 & 0.44 & 0.30 & 1.18 & 0.52 & 0.58 & 0.75 \\
\hline$c g d p$ & $\mathbf{B E}$ & FI & FR & GE & IR & IT & NE & SP \\
\hline mean & 0.20 & 0.20 & 0.25 & 0.08 & 0.21 & -0.24 & 0.53 & 0.08 \\
\hline median & 0.08 & 0.19 & 0.22 & 0.07 & -0.13 & -0.33 & 0.59 & -0.19 \\
\hline $\max$ & 0.81 & 0.67 & 0.65 & 0.27 & 1.39 & 0.27 & 0.89 & 0.78 \\
\hline $\min$ & -0.25 & -0.23 & 0.00 & -0.15 & -0.41 & -0.66 & -0.21 & -0.40 \\
\hline std & 0.35 & 0.25 & 0.20 & 0.11 & 0.56 & 0.29 & 0.31 & 0.42 \\
\hline$h p$ & $\mathbf{B E}$ & FI & FR & GE & IR & IT & NE & SP \\
\hline mean & 4.15 & 4.27 & 4.15 & 4.73 & 4.06 & 4.39 & 4.13 & 3.96 \\
\hline median & 4.07 & 4.28 & 4.00 & 4.74 & 3.81 & 4.38 & 4.13 & 3.98 \\
\hline $\max$ & 4.66 & 4.61 & 4.65 & 4.86 & 4.98 & 4.69 & 4.68 & 4.76 \\
\hline $\min$ & 3.60 & 3.83 & 3.77 & 4.59 & 3.36 & 4.07 & 3.51 & 3.19 \\
\hline std & 0.34 & 0.26 & 0.31 & 0.07 & 0.49 & 0.17 & 0.40 & 0.47 \\
\hline$y$ & BE & FI & FR & GE & IR & IT & NE & SP \\
\hline mean & 26.34 & 25.62 & 28.07 & 28.36 & 25.22 & 27.92 & 26.85 & 27.33 \\
\hline median & 26.33 & 25.58 & 28.07 & 28.40 & 25.17 & 27.99 & 26.86 & 27.31 \\
\hline $\max$ & 26.71 & 26.03 & 28.40 & 28.71 & 26.34 & 28.16 & 27.27 & 27.77 \\
\hline $\min$ & 25.87 & 25.10 & 27.59 & 27.89 & 24.26 & 27.45 & 26.34 & 26.83 \\
\hline std & 0.25 & 0.29 & 0.24 & 0.23 & 0.62 & 0.20 & 0.29 & 0.31 \\
\hline
\end{tabular}

Sample period: 1975Q1-2017Q3. Number of observations: 171. The marginal difference in the means of cgdp and the difference between the means of $\mathrm{c}$ and $\mathrm{y}$ result from the fact that I have download cgdp from the BIS and not computed it from the individual credit and GDP series.

All series are in log levels. The table reveals that the characteristics of the series are heterogenous across countries. For all three financial variables, the German series show the

\footnotetext{
${ }^{5}$ Data sources are given in Table 2.9 in Appendix I.
} 
lowest and the Irish series the largest standard deviation. The amount of outstanding credit increases over time and on average exceeds the level of GDP. The only exception is Italy with an average credit-to-GDP ratio of roughly $80 \%$. The differences in mean and median of the credit-to-GDP ratio in Ireland and Spain, and to a lesser extent in Italy, reflect the remarkable increase in this ratio since the late 1990s. In Ireland, outstanding credit reaches an overall peak of about $400 \%$ of GDP. Whereas most countries were confronted with continuously rising house prices since the mid-1990s, Germany's house prices declined until roughly 2010. Developments in real GDP are more homogeneous across countries, except for Ireland which displays the largest standard deviation of all countries. ${ }^{6}$

Table 2.2 Unit root test results (ADF test)

\begin{tabular}{|c|c|c|c|c|c|c|c|c|}
\hline & $c$ & $\Delta c$ & $\operatorname{cgdp}$ & $\Delta c g d p$ & hp & $\Delta h p$ & $y$ & $\Delta y$ \\
\hline $\mathbf{B E}$ & $\begin{array}{l}-1.62 \\
(0.78)\end{array}$ & $\begin{array}{c}-\mathbf{6 . 1 6}^{\text {****}} \\
(0.00)\end{array}$ & $\begin{array}{l}-1.91 \\
(0.64)\end{array}$ & $\begin{array}{c}-\mathbf{6 . 5 0} 0^{* * *} \\
(0.00)\end{array}$ & $\begin{array}{l}-3.30^{*} \\
(0.07)\end{array}$ & $\begin{array}{c}\mathbf{- 3 . 5 3}^{* * * *} \\
(0.01)\end{array}$ & $\begin{array}{l}-2.04 \\
(0.57)\end{array}$ & $\begin{array}{c}\mathbf{- 9 . 5 4}^{* * * *} \\
(0.00)\end{array}$ \\
\hline FI & $\begin{array}{l}-1.50 \\
(0.83)\end{array}$ & $\begin{array}{c}-\mathbf{9 . 0 5} \\
(0.00)\end{array}$ & $\begin{array}{l}-1.86 \\
(0.67)\end{array}$ & $\begin{array}{c}\mathbf{- 8 . 1 3}^{* * *} \\
(0.00)\end{array}$ & $\begin{array}{l}\mathbf{- 3 . 6 8}^{* * *} \\
(0.03)\end{array}$ & $\begin{array}{c}\mathbf{- 3 . 8 9}^{* * * *} \\
(0.00)\end{array}$ & $\begin{array}{l}-2.29 \\
(0.44)\end{array}$ & $\begin{array}{c}-\mathbf{4 . 5 5} \\
(000)\end{array}$ \\
\hline FR & $\begin{array}{c}\mathbf{- 3 . 4 8}^{* * *} \\
(0.05)\end{array}$ & $\begin{array}{c}-3.75^{* * *} \\
(0.00)\end{array}$ & $\begin{array}{l}-2.69 \\
(0.24)\end{array}$ & $\begin{array}{c}-4.39^{* * * *} \\
(0.00)\end{array}$ & $\begin{array}{l}-2.73 \\
(0.23)\end{array}$ & $\begin{array}{c}-3.44 * * \\
(0.01)\end{array}$ & $\begin{array}{l}-1.79 \\
(0.70)\end{array}$ & $\begin{array}{c}-\mathbf{5 . 3 8} \\
(0.00)\end{array}$ \\
\hline GE & $\begin{array}{l}-1.49 \\
(0.82)\end{array}$ & $\begin{array}{l}-2.84^{*} \\
(0.06)\end{array}$ & $\begin{array}{l}-0.91 \\
(0.95)\end{array}$ & $\begin{array}{c}-\mathbf{4 . 4 0} \\
(0.00)\end{array}$ & $\begin{array}{l}-2.12 \\
(0.53)\end{array}$ & $\begin{array}{c}-3.07^{* * *} \\
(0.03)\end{array}$ & $\begin{array}{l}-1.87 \\
(0.67)\end{array}$ & $\begin{array}{c}-11.85^{* * * *} \\
(0.00)\end{array}$ \\
\hline IR & $\begin{array}{l}-1.89 \\
(0.65)\end{array}$ & $\begin{array}{c}\mathbf{- 1 1 . 0 6}^{* * * *} \\
(0.00)\end{array}$ & $\begin{array}{l}-2.16 \\
(0.51)\end{array}$ & $\begin{array}{c}-11.31^{* * * *} \\
(0.00)\end{array}$ & $\begin{array}{l}-2.00 \\
(0.60)\end{array}$ & $\begin{array}{c}\mathbf{- 4 . 1 8}^{* * * *} \\
(0.00)\end{array}$ & $\begin{array}{l}-1.34 \\
(0.88)\end{array}$ & $\begin{array}{c}\mathbf{- 5 . 2 0}^{* * * *} \\
(0.00)\end{array}$ \\
\hline IT & $\begin{array}{l}-2.34 \\
(0.41)\end{array}$ & $\begin{array}{c}-\mathbf{3 . 0 4} 4^{* * *} \\
(0.03)\end{array}$ & $\begin{array}{c}-\mathbf{3 . 7 7 ^ { \kappa * * }} \\
(0.02)\end{array}$ & $\begin{array}{l}-\mathbf{2 . 9 8 * * *} \\
(0.04)\end{array}$ & $\begin{array}{l}-3.39^{*} \\
(0.06)\end{array}$ & $\begin{array}{c}-\mathbf{- 4 . 3 0}^{* * * * *} \\
(0.00)\end{array}$ & $\begin{array}{l}-1.66 \\
(0.76)\end{array}$ & $\begin{array}{c}-7.64^{* * * *} \\
(0.00)\end{array}$ \\
\hline NE & $\begin{array}{l}-1.83 \\
(0.69)\end{array}$ & $\begin{array}{l}-2.59^{*} \\
(0.10)\end{array}$ & $\begin{array}{l}-1.75 \\
(0.72)\end{array}$ & $\begin{array}{c}\mathbf{- 3 . 5 1}^{* * * *} \\
(0.01)\end{array}$ & $\begin{array}{l}-3.07 \\
(0.12)\end{array}$ & $\begin{array}{l}-2.72^{*} \\
(0.07)\end{array}$ & $\begin{array}{l}-1.10 \\
(0.93)\end{array}$ & $\begin{array}{c}-15.32^{* * * *} \\
(0.00)\end{array}$ \\
\hline SP & $\begin{array}{l}-2.38 \\
(0.39)\end{array}$ & $\begin{array}{l}-2.20 \\
(0.21)\end{array}$ & $\begin{array}{l}-2.26 \\
(0.46)\end{array}$ & $\begin{array}{l}-2.49 \\
(0.12)\end{array}$ & $\begin{array}{l}-2.60 \\
(0.29)\end{array}$ & $\begin{array}{c}\mathbf{- 3 . 6 7}^{* * * *} \\
(0.01)\end{array}$ & $\begin{array}{l}-2.24 \\
(0.47)\end{array}$ & $\begin{array}{c}-3.67^{* * * *} \\
(0.01)\end{array}$ \\
\hline
\end{tabular}

Unit root tests on log of the series over the period 1975Q1-2017Q3. $x$ presents results for level series, $\Delta x$ presents results for first differences. P-values of the ADF test statistic in parentheses. ${ }^{* * *} /{ }^{* *} /{ }^{*}$ indicate significance of the test statistic at the $1 \% / 5 \% / 10 \%$ level. Numbers in bold indicate significance at $5 \%$ or lower.

I compute financial and business cycles from my data. First, I need to investigate the integration properties of the series for the application of the frequency-based Christiano-Fitzgerald (CF) filter. The results of the unit root test are presented in Table 2.2. The table shows that most of the series are (marginally) I(1). I normalise all series by their respective value in 1985Q1 and use log levels. I extract medium-term fluctuations (32-120 quarters) from the log level financial

\footnotetext{
${ }^{6}$ The Irish real GDP series show a one-time structural break between 2014Q4 and 2015Q1. This increase in real GDP is related to the relocation of economic activities of a number of large multinational corporations to Ireland as a result of low corporation taxes (OECD, 2016). I did not correct for this break. As it is a one-time increase, I expect the influence on the medium-term cycle to be minor.
} 
Series $^{7}$ using the CF filter, taking account of the unit root and the drift in the series. I apply the same filter settings to all data series.

For each country, I compute the domestic composite financial cycle as simple average over the three market-specific financial cycles.

$$
F C_{i, t}=\frac{1}{3}\left(F C_{i, t}^{c}+F C_{i, t}^{c g d p}+F C_{i, t}^{h p}\right)
$$

where $F C_{i, t}$ is the financial cycle composite of country $i, F C_{i, t}^{c}$ is country $i$ 's credit cycle, $F C_{i, t}^{c g d p}$ is country $i$ 's credit-per-GDP cycle and $F C_{i, t}^{h p}$ is country $i$ 's house price cycle. I use simple averaging at the country level to allow differences in volatility in the various financial markets to be reflected in the domestic composite financial cycle. Later in this chapter, I will investigate the relationship between the domestic financial cycles and the EA average. I therefore compute,

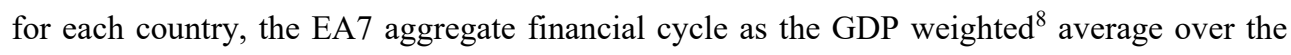
country specific cycles excluding the reference country. ${ }^{9}$

$$
F C_{E A 7, t}=\sum_{j} \omega_{j} F C_{j, t} \quad j \epsilon E A 8 \backslash i ; \sum_{j} \omega_{j}=1
$$

where $F C_{E A 7, t}$ is the EA7 (EA8 excluding the reference country $i$ ) financial cycle, $\omega_{j}$ is the GDP weight of country $j$ in EA7 and $F C_{j, t}$ is the composite financial cycle of country $j$. GDP weights are used as a proxy for market size in order not to overestimate (underestimate) the impact of small (large) volatile countries on the EA7 cycle.

Likewise, I use real GDP to compute the medium-term domestic business cycles as well as the corresponding EA7 aggregates. I chose the same frequency range for the computation of business and financial cycles as I am interested in exploring their relationship. This choice relates in particular to the findings of Drehmann et al. (2012) who argue that business and financial cycles in the traditional frequency ranges are different phenomena. As the filter bands do not overlap, the estimates are uncorrelated by construction (Rünstler and Vlekke, 2016). ${ }^{10}$

\footnotetext{
${ }^{7}$ In the literature, the composite financial cycle is generally a combination of cycles from both annual growth rates and log levels (Alcidi, 2017; Drehmann et al., 2012; Stremmel, 2015). Following Borio et al. (2018), I chose to use log levels for all the series. In Appendix III, I compare the level financial cycles to the financial cycles prepared by the Bank for International Settlements (BIS) and financial cycles based on annual growth rates of my data.

${ }^{8}$ GDP share of individual countries in EA7. I use the average share over the period 1975Q1-2017Q3 as GDP shares tend to vary across time.

${ }^{9}$ I exclude the reference country $i$ from the EA7 aggregate to minimise simultaneity issues.

${ }^{10}$ Please refer to section 2.2.1 for an overview of papers using medium-term business cycles and the arguments in their favour.
} 


\subsection{Stylised statistics of financial and business cycles}

In this section, I analyse the main characteristics of the domestic and EA7 financial and business cycles. In section 2.4.1 I visually analyse their graphs. Section 2.4.2 investigates cycle volatility. In section 2.4.3, I examine the co-movement between domestic financial and business cycles and their EA7 counterparts, respectively, as well as the co-movement between domestic financial and business cycles. Section 2.4.4 analyses the dispersion of domestic financial and business cycles over time.

\subsubsection{Graphical analysis}

I visually inspect the country-specific financial and business cycles, which are displayed in Figure 2.1. I observe between one and three complete business and financial cycles over the sample period. ${ }^{11}$ This similarity in the periodicity of financial and business cycles reflects my choice of pre-specified frequency bands of the CF-filter. For comparison, the bandpass-filtered short-term business cycles presented by Stremmel (2015) display much higher frequency than his medium-term financial cycles. Likewise, the presentation of both - GDP and credit cycles - by Aikman et al. (2015) confirm this finding. Studies like Alcidi (2017) and Drehmann et al. (2012) compute and present medium-term business cycles. Differences in cycle length are much less obvious at first sight in the latter two papers. By construction, my results do not support the generally held view that the periodicity of financial and business cycles is fundamentally different. Other recent studies have also questioned the empirical support for the differences in periodicity. Cagliarini and Price (2017) apply multivariate spectral analysis but cannot find supportive evidence that financial cycles are longer than business cycles. Multispectral analysis in Hiebert et al. (2014) suggests that financial cycles are longer than business cycles, but the turning point method applied in the same paper reveals that the components of the financial cycle are equally long or even shorter than the business cycle.

The graphs furthermore suggest that the business cycle tends to lead the financial cycle in all countries. Formal lead-lag correlations show that the business cycle leads the financial cycle by between 2 (Belgium) and 13 (Finland) quarters over the sample period. ${ }^{12}$ Cagliarini and Price (2017) also find that the cycles in GDP growth positively lead cycles in credit growth in shorter

\footnotetext{
${ }^{11}$ The number of cycles might change depending on whether they are counted from trough to trough or from peak to peak.

${ }^{12}$ For more detailed results, please refer to Table 2.10 in Appendix II.
} 
Figure 2.1 Business and financial cycles - domestic vs. EA aggregates
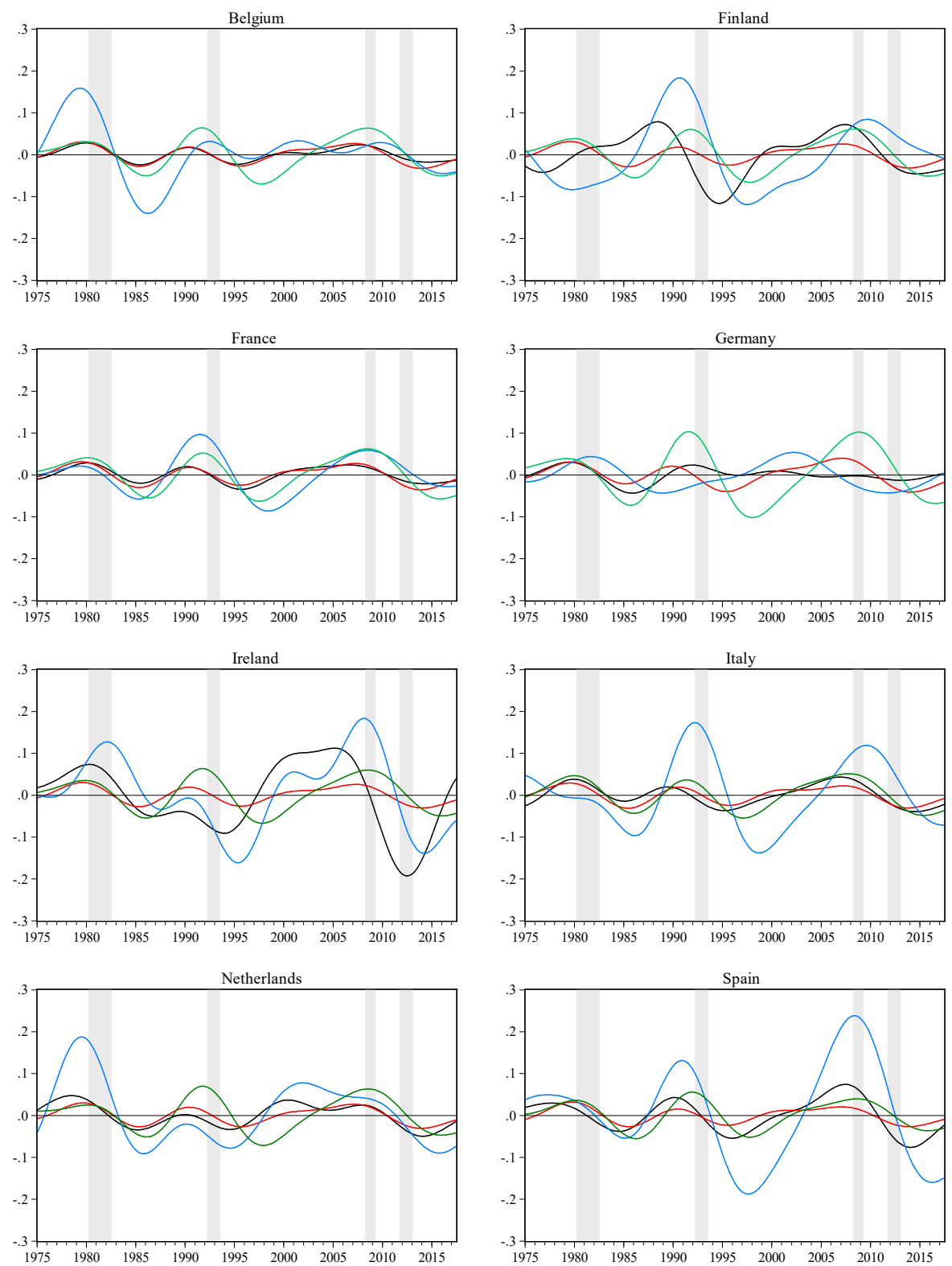

$-\mathrm{BC} \longrightarrow$ EA7_BC

FC - EA7_FC

$\mathrm{BC}$ and $\mathrm{FC}$ are, respectively, the domestic business cycle and the domestic financial cycle. EA7_BC and EA7_FC are, respectively, the EA7 aggregate business cycle and the aggregate financial cycle, excluding the reference country. The shaded areas give the CEPR based recession indicator for the EA business cycle. The shading follows the trough method used by FRED to compute NBER recessions indicators for the US. It shows a recession from the quarter following the peak through the quarter of the trough, i.e. the peak is not included in the recession shading, but the trough is.

Sources: OECD, BIS, IMF-IFS, CEPR; own computations 
lags, but some longer leads/lags are found to be negatively correlated with credit growth cycles. The shaded areas in Figure 2.1 give the CEPR-based recession indicator for the EA business cycle. All EA financial cycle aggregates and most country-specific financial cycles tend to boom ahead of CEPR recessions, but not all recessions are preceded by financial cycle peaks. These findings are in line with the conclusions in Borio et al. (2018) and Claessens and Kose (2018).

\subsubsection{Cycle volatility and dispersion}

Figure 2.1 furthermore suggests that the amplitudes of the financial cycles typically exceed the amplitudes of the business cycle. Comparable with Table 2.1, I compute the descriptive statistics for the various cycles, for the pre-euro and euro periods. The results are presented in Table 2.3. This table shows that the standard deviation of the financial cycles for both the domestic and EA7 cycles is generally larger than the standard deviation of the corresponding business cycles, and this holds in both the pre-euro and euro periods. This result is in line with the findings of other studies like Aikman et al. (2015), Alcidi (2017), Cagliarini and Price (2017) and Drehmann et al. (2012). Figure 2.1 and Table 2.3 furthermore reveal that the volatility of the cycles changes over time. In Belgium, the financial cycle becomes less volatile since the beginning of the 1990s and matches the amplitude of the country-specific business cycle towards the end of the sample period. In contrast, the amplitude of the Spanish financial cycle increases over the sample period. The volatility of both - business and financial - cycles increases in Ireland, while the swings in the German cycles are comparatively small throughout the sample period. To formalise these findings, I test for the equality of the standard deviations in the two periods $\left(H_{0}\right)$. The results of the F-test are also presented in Table 2.3. I generally reject the hypothesis that the volatility of both - the domestic financial cycles and the domestic business cycles - does not significantly change between the two periods. However, the changes are heterogeneous across countries. While cycle volatility increases in some countries, like for instance the financial cycle in Spain and the business cycle in Ireland, others, like the Belgian financial cycle and the German business cycle, become less volatile. The changes in volatility for the EA aggregates are not statistically significant for most countries. This finding reflects the dampening effect of the heterogeneous developments at the country level. 
Table 2.3 Descriptive statistics - cycles

\begin{tabular}{|c|c|c|c|c|c|c|c|c|c|}
\hline$F C_{i t}$ & & BE & FI & FR & GE & IR & IT & NE & SP \\
\hline \multirow{4}{*}{$\begin{array}{c}\text { 1975Q1- } \\
1998 Q 4\end{array}$} & mean & 0.01 & -0.01 & 0.00 & -0.00 & -0.01 & 0.00 & 0.00 & -0.00 \\
\hline & $\max$ & 0.16 & 0.18 & 0.10 & 0.04 & 0.13 & 0.17 & 0.19 & 0.13 \\
\hline & $\min$ & -0.14 & -0.12 & -0.09 & -0.04 & -0.16 & -0.14 & -0.09 & -0.19 \\
\hline & std & 0.08 & 0.09 & 0.05 & 0.03 & 0.08 & 0.08 & 0.09 & 0.09 \\
\hline \multirow{5}{*}{$\begin{array}{l}\text { 1999Q1- } \\
\text { 2017Q3 }\end{array}$} & mean & 0.01 & 0.00 & 0.00 & 0.00 & 0.03 & 0.00 & 0.01 & 0.02 \\
\hline & $\max$ & 0.03 & 0.08 & 0.06 & 0.05 & 0.18 & 0.12 & 0.08 & 0.24 \\
\hline & $\min$ & -0.05 & -0.10 & -0.08 & -0.04 & -0.14 & -0.14 & -0.09 & -0.17 \\
\hline & std & 0.03 & 0.06 & 0.04 & 0.04 & 0.10 & 0.08 & 0.06 & 0.14 \\
\hline & F-test & 10.61 & 2.73 & 1.47 & $\mathbf{0 . 5 7}$ & 0.63 & 1.15 & 2.18 & 0.38 \\
\hline \multirow[t]{2}{*}{$B C_{i t}$} & & BE & FI & FR & GE & IR & IT & NE & SP \\
\hline & mean & 0.00 & -0.01 & -0.00 & 0.00 & -0.01 & -0.00 & -0.00 & -0.00 \\
\hline \multirow{3}{*}{$\begin{array}{c}\text { 1975Q1- } \\
\text { 1998Q4 }\end{array}$} & $\max$ & 0.03 & 0.08 & 0.03 & 0.03 & 0.07 & 0.04 & 0.05 & 0.04 \\
\hline & $\min$ & -0.02 & -0.12 & -0.03 & -0.04 & -0.09 & -0.04 & -0.03 & -0.06 \\
\hline & std & 0.02 & 0.06 & 0.02 & 0.02 & 0.05 & 0.02 & 0.03 & 0.03 \\
\hline \multirow{5}{*}{$\begin{array}{l}\text { 1999Q1- } \\
\text { 2017Q3 }\end{array}$} & mean & 0.00 & 0.01 & 0.00 & -0.00 & 0.00 & 0.00 & 0.00 & 0.00 \\
\hline & $\max$ & 0.02 & 0.07 & 0.02 & 0.01 & 0.11 & 0.04 & 0.04 & 0.07 \\
\hline & $\min$ & -0.02 & -0.05 & -0.02 & -0.01 & -0.19 & -0.04 & -0.05 & -0.08 \\
\hline & std & 0.01 & 0.04 & 0.02 & 0.01 & 0.11 & 0.03 & 0.03 & 0.05 \\
\hline & F-test & 1.47 & 2.00 & 1.28 & 10.71 & 0.23 & 0.62 & 0.82 & 0.41 \\
\hline \multirow[t]{2}{*}{$F C_{E A t}$} & & BE & FI & FR & GE & IR & IT & NE & SP \\
\hline & mean & -0.00 & 0.00 & -0.00 & 0.00 & 0.00 & -0.00 & 0.00 & 0.00 \\
\hline \multirow{3}{*}{$\begin{array}{c}\text { 1975Q1- } \\
1998 Q 4\end{array}$} & $\max$ & 0.06 & 0.06 & 0.05 & 0.10 & 0.06 & 0.05 & 0.07 & 0.06 \\
\hline & $\min$ & -0.07 & -0.07 & -0.06 & -0.10 & -0.07 & -0.05 & -0.07 & -0.06 \\
\hline & std & 0.04 & 0.04 & 0.04 & 0.06 & 0.04 & 0.03 & 0.04 & 0.04 \\
\hline \multirow{5}{*}{$\begin{array}{l}\text { 1999Q1- } \\
\text { 2017Q3 }\end{array}$} & mean & 0.00 & 0.00 & 0.01 & 0.01 & 0.00 & 0.01 & 0.00 & 0.00 \\
\hline & $\max$ & 0.06 & 0.06 & 0.06 & 0.10 & 0.06 & 0.05 & 0.06 & 0.04 \\
\hline & $\min$ & -0.06 & -0.06 & -0.06 & -0.09 & -0.06 & -0.05 & -0.06 & -0.04 \\
\hline & std & 0.04 & 0.04 & 0.04 & 0.06 & 0.04 & 0.04 & 0.04 & 0.03 \\
\hline & F-test & 0.89 & 0.95 & 0.83 & 0.87 & 1.01 & 0.86 & 0.95 & 1.63 \\
\hline \multirow[t]{2}{*}{$B C_{E A t}$} & & BE & FI & FR & GE & IR & IT & NE & SP \\
\hline & mean & -0.00 & -0.00 & -0.00 & -0.00 & -0.00 & -0.00 & -0.00 & -0.00 \\
\hline \multirow{3}{*}{$\begin{array}{c}\text { 1975Q1- } \\
\text { 1998Q4 }\end{array}$} & $\max$ & 0.03 & 0.03 & 0.03 & 0.03 & 0.03 & 0.03 & 0.03 & 0.03 \\
\hline & $\min$ & -0.03 & -0.03 & -0.03 & -0.04 & -0.03 & -0.03 & -0.03 & -0.03 \\
\hline & std & 0.02 & 0.02 & 0.02 & 0.02 & 0.02 & 0.02 & 0.02 & 0.02 \\
\hline \multirow{5}{*}{$\begin{array}{l}\text { 1999Q1- } \\
2017 Q 3\end{array}$} & mean & 0.00 & 0.00 & 0.00 & 0.00 & 0.00 & 0.00 & 0.00 & 0.00 \\
\hline & $\max$ & 0.03 & 0.03 & 0.03 & 0.04 & 0.03 & 0.02 & 0.03 & 0.02 \\
\hline & $\min$ & -0.03 & -0.03 & -0.04 & -0.04 & -0.03 & -0.03 & -0.03 & -0.03 \\
\hline & & 0.02 & 0.02 & 0.02 & 0.03 & 0.02 & 0.02 & 0.02 & 0.02 \\
\hline & F-test & 0.85 & 0.92 & 0.80 & 0.59 & 0.94 & 1.05 & 0.89 & 1.15 \\
\hline
\end{tabular}

I perform the F-test to see if the standard deviations of the cycles have changed over the periods. I test the null hypothesis of equal variances in the two periods, $H_{0}: \sigma_{p r e-E M U}^{2}=\sigma_{E M U}^{2}$ against the alternative $H_{A}: \sigma_{p r e-E M U}^{2} \neq \sigma_{E M U}^{2}$. Under the null hypothesis, the F-statistic is distributed $F(95,74) . F>1$ if $s t d_{\text {pre-EMU }}>s t d_{E M U}$ and $F<1$ if $s t d_{p r e-E M U}<s t d_{E M U}$. For a significance level of $\alpha=0.05$, I accept $H_{0}$ if $0.64 \leq F \leq 1.56$. Bold print indicates statistical significance. 
I am also interested to see how the amplitudes of the domestic cycles compare to the amplitudes of the EA aggregates and how the amplitudes of domestic financial and business cycles are related. The results of the respective F-tests for both sample periods are presented in Table 2.4. I find that the amplitudes of domestic and EA cycles generally differ significantly in both periods and that domestic cycles are more volatile than EA cycles. An increase in the test statistic indicates an increase in the relative dispersion of cycles. The results show that the domestic financial cycles of most countries have become relatively less volatile compared with their corresponding EA aggregate in the euro period. This finding does not hold for Ireland and, in particular, Spain. To the contrary, domestic business cycles are relatively more volatile in the euro period. The increase in dispersion is particularly large in Ireland. Domestic financial cycles are relatively less volatile compared with their business cycle counterparts in the euro period.

Table $2.4 \quad$ F-test results for standard deviations of various cycles

\begin{tabular}{|lcccccccc|}
\hline $\boldsymbol{F C}_{\boldsymbol{i}, \boldsymbol{t}}$ vs. $\boldsymbol{F} \boldsymbol{C}_{\boldsymbol{E A 7 ,} \boldsymbol{t}}$ & $\mathrm{BE}$ & $\mathrm{FI}$ & $\mathrm{FR}$ & $\mathrm{GE}$ & $\mathrm{IR}$ & $\mathrm{IT}$ & $\mathrm{NE}$ & $\mathrm{SP}$ \\
$1975 \mathrm{Q} 1-1998 \mathrm{Q} 4$ & $\mathbf{4 . 6 6}$ & $\mathbf{5 . 7 2}$ & $\mathbf{1 . 7 9}$ & $\mathbf{4 . 9 9}$ & $\mathbf{4 . 0 4}$ & $\mathbf{6 . 5 3}$ & $\mathbf{4 . 6 8}$ & $\mathbf{6 . 2 0}$ \\
$1999 \mathrm{Q} 1-2017 \mathrm{Q} 3$ & $\mathbf{2 . 5 6}$ & $\mathbf{1 . 9 8}$ & 1.01 & $\mathbf{3 . 2 4}$ & $\mathbf{6 . 4 7}$ & $\mathbf{4 . 8 9}$ & $\mathbf{2 . 0 4}$ & $\mathbf{2 6 . 2 5}$ \\
\hline $\boldsymbol{B C}_{\boldsymbol{i}, \boldsymbol{t}}$ vs. $\boldsymbol{B C}_{\boldsymbol{E} A 7, \boldsymbol{t}}$ & $\mathrm{BE}$ & $\mathrm{FI}$ & $\mathrm{FR}$ & $\mathrm{GE}$ & $\mathrm{IR}$ & $\mathrm{IT}$ & $\mathrm{NE}$ & $\mathrm{SP}$ \\
$1975 \mathrm{Q} 1-1998 \mathrm{Q} 4$ & 1.31 & $\mathbf{8 . 9 2}$ & 1.01 & 1.06 & $\mathbf{8 . 2 4}$ & 1.39 & $\mathbf{2 . 0 5}$ & $\mathbf{3 . 0 4}$ \\
$1999 \mathrm{Q} 1-2017 \mathrm{Q} 3$ & $\mathbf{2 . 2 6}$ & $\mathbf{4 . 1 0}$ & $\mathbf{1 . 5 8}$ & $\mathbf{1 7 . 1 9}$ & $\mathbf{3 4 . 0 6}$ & $\mathbf{2 . 3 6}$ & $\mathbf{2 . 2 5}$ & $\mathbf{8 . 5 0}$ \\
\hline $\boldsymbol{F} \boldsymbol{C}_{\boldsymbol{i}, \boldsymbol{t}}$ vs. $\boldsymbol{B} \boldsymbol{C}_{\boldsymbol{i}, \boldsymbol{t}}$ & $\mathrm{BE}$ & $\mathrm{FI}$ & $\mathrm{FR}$ & $\mathrm{GE}$ & $\mathrm{IR}$ & $\mathrm{IT}$ & $\mathrm{NE}$ & $\mathrm{SP}$ \\
$1975 \mathrm{Q} 1-1998 \mathrm{Q} 4$ & $\mathbf{2 6 . 5 1}$ & $\mathbf{2 . 8 2}$ & $\mathbf{7 . 1 4}$ & 1.48 & $\mathbf{2 . 2 8}$ & $\mathbf{1 4 . 6 2}$ & $\mathbf{1 0 . 7 4}$ & $\mathbf{8 . 0 4}$ \\
$1999 \mathrm{Q} 1-2017 \mathrm{Q} 3$ & $\mathbf{3 . 6 7}$ & $\mathbf{2 . 0 6}$ & $\mathbf{6 . 2 0}$ & $\mathbf{2 7 . 9 7}$ & 1.21 & $\mathbf{7 . 8 2}$ & $\mathbf{4 . 0 2}$ & $\mathbf{8 . 5 8}$ \\
\hline
\end{tabular}

The F-statistic is distributed $F(95,95)$ in the pre-euro period and $F(74,74)$ in the euro period. The corresponding critical value is $(p \leq 0.05)$ for both is roughly 1.5 . Bold print indicates statistical significance. Italics indicate that the standard deviation of the domestic cycle is smaller than the standard deviation of the EA cycle. For the domestic financial and business cycles, italics indicate that the standard deviation of the domestic financial cycle is smaller than the standard deviation of the domestic business cycle.

In a last step, I investigate if the standard deviation of the cycles varies significantly across countries. I apply the Levene and the Brown-Forsythe tests to test for the cross-section equality of cycle variances $\left(H_{0}\right)$ against the alternative that at least one country has a different variance. The test results are given in Table 2.5. I reject the null hypothesis for all cycles and time periods. 
Table 2.5 Cross-section variance equality test

\begin{tabular}{|lcc|}
\hline & 1975Q1-1998Q4 & 1999Q1-2017Q3 \\
\hline Degrees of freedom: & $(7,760)$ & $(7,592)$ \\
\hline $\boldsymbol{F} \boldsymbol{C}_{\boldsymbol{i}, \boldsymbol{t}}$ & & \\
Levene & $15.76^{* * *}$ & $61.58^{* * *}$ \\
Brown-Forsythe & $10.64^{* * *}$ & $49.04^{* * *}$ \\
\hline $\boldsymbol{B C}_{\boldsymbol{i}, \boldsymbol{t}}$ & & \\
Levene & $62.49^{* * *}$ & $130.75^{* * *}$ \\
Brown-Forsythe & $53.97^{* * *}$ & $71.11^{* * *}$ \\
${ }^{* * *}$ indicates significance at the 1\% level. &
\end{tabular}

\subsubsection{Correlation analysis}

In this section, I assess the correlation between the cycles. The degree of cross-country comovement between cycles has important implications for policy makers. On the one hand, comovement is a necessary condition for conducting an optimal monetary policy in a monetary union. If the country-specific cycles are in different phases and monetary policy is based on average economic activity, common policy making cannot be optimal but might turn out to be disadvantageous for at least some economies. On the other hand, a high degree of correlation of booms and busts in financial cycles as well as recoveries and recessions in business cycles can amplify the cycles. This has implications for policy intensity. Further, a close relationship between financial and business cycles would confirm the common finding that developments in credit and housing markets could be key in driving macro-financial linkages (Claessens and Kose, 2018). Hence, I compute three different correlations: the correlation between domestic and EA7 financial cycles, the correlation between domestic and EA7 business cycles and the correlation between domestic financial and business cycles. The results for the two sub-periods are presented in Table 2.6. ${ }^{13}$

Focusing on financial cycles, I find that correlations between the domestic cycle and the EA7 cycle are typically positive and significant, suggesting a fair amount of co-movement on the financial side both in the pre-euro period and the euro period. The exception is Germany, for which I observe a significantly negative correlation with the EA7 cycle. This result is in line with the findings of Franks et al. (2018) who observe that Germany's financial cycle became increasingly disconnected from the others throughout the euro period. Germany's flat financial cycle reflects credit and house price dynamics quite distinct from those of most other EA

\footnotetext{
${ }^{13}$ Please refer to Table 2.11 in Appendix II for the correlations between the domestic FC and BC with the corresponding $\mathrm{EA} \mathrm{BC}$ and $\mathrm{FC}$, respectively.
} 
countries. On the business cycle side, all correlations between the domestic and EA7 cycle are positive and significant as well, with the exception of Finland in the pre-euro period. The business cycle correlations tend to be higher than those for the financial cycles across countries and periods, suggesting strong economic - real - integration in Europe. The lowest correlation between the domestic and EA7 business cycles is found in Germany, reflecting the relative independence of Germany due to its size and economic strength. Finally, I turn to the correlation between the business cycle and financial cycle within each country. Again, most correlations are significantly positive with the exception of Finland in the euro period and Italy in the preeuro period. Overall, the evidence points to strong macro-finance linkages at the national level.

Table 2.6 Contemporaneous correlations and z-test results

\begin{tabular}{|ccccccccc|}
\hline $\boldsymbol{F} \boldsymbol{C}_{\boldsymbol{i}, \boldsymbol{t}}$ and $\boldsymbol{F} \boldsymbol{C}_{\boldsymbol{E A 7}, \boldsymbol{t}}$ & $\mathbf{B E}$ & $\mathbf{F I}$ & $\mathbf{F R}$ & $\mathbf{G E}$ & $\mathbf{I R}$ & $\mathbf{I T}$ & $\mathbf{N E}$ & $\mathbf{S P}$ \\
$\rho_{1}$ & $0.57^{* * *}$ & $0.44^{* * *}$ & $0.85^{* * *}$ & $-0.25^{* *}$ & $0.23^{* *}$ & $0.65^{* * *}$ & $0.31^{* * *}$ & $0.76^{* * *}$ \\
$\rho_{2}$ & $0.57^{* * *}$ & $0.53^{* * *}$ & $0.83^{* * *}$ & $-0.42^{* * *}$ & $0.81^{* * *}$ & $0.63^{* * *}$ & $0.47^{* * *}$ & $0.97^{* * *}$ \\
$z$ & 0.04 & -0.68 & 0.43 & 1.27 & $\mathbf{- 5 . 5 7}$ & 0.13 & -1.25 & $\mathbf{- 7 . 2 6}$ \\
\hline $\boldsymbol{B C}_{\boldsymbol{i}, \boldsymbol{t}}$ and $\boldsymbol{B} \boldsymbol{C}_{\boldsymbol{E A 7 , t}}$ & $\mathbf{B E}$ & $\mathbf{F I}$ & $\mathbf{F R}$ & $\mathbf{G E}$ & $\mathbf{I R}$ & $\mathbf{I T}$ & $\mathbf{N E}$ & $\mathbf{S P}$ \\
$\rho_{1}$ & $0.99^{* * *}$ & 0.17 & $0.92^{* * *}$ & $0.46^{* * *}$ & $0.55^{* * *}$ & $0.78^{* * *}$ & $0.78^{* * *}$ & $0.75^{* * *}$ \\
$\rho_{2}$ & $0.94^{* * *}$ & $0.96^{* * *}$ & $0.97^{* * *}$ & $0.43^{* * *}$ & $0.76^{* * *}$ & $0.94^{* * *}$ & $0.89^{* * *}$ & $0.94^{* * *}$ \\
$z$ & $\mathbf{6 . 4 9}$ & & $\mathbf{- 3 . 2 5}$ & 0.19 & $\mathbf{- 2 . 3 6}$ & $\mathbf{- 4 . 0 7}$ & $\mathbf{- 2 . 4 3}$ & $\mathbf{- 4 . 9 4}$ \\
\hline $\boldsymbol{F} \boldsymbol{C}_{\boldsymbol{i}, \boldsymbol{t}}$ and $\boldsymbol{B} \boldsymbol{C}_{\boldsymbol{i}, \boldsymbol{t}}$ & $\mathbf{B E}$ & $\mathbf{F I}$ & $\mathbf{F R}$ & $\mathbf{G E}$ & $\mathbf{I R}$ & $\mathbf{I T}$ & $\mathbf{N E}$ & $\mathbf{S P}$ \\
$\rho_{1}$ & $0.72^{* * *}$ & $0.32^{* * *}$ & $0.56^{* * *}$ & $0.19^{*}$ & $0.71^{* * *}$ & 0.04 & $0.89^{* * *}$ & $0.88^{* * *}$ \\
$\rho_{2}$ & $0.72^{* * *}$ & 0.05 & $0.37^{* * *}$ & $0.80^{* * *}$ & $0.55^{* * *}$ & $0.40^{* * *}$ & $0.92^{* * *}$ & $0.78^{* * *}$ \\
$z$ & 0.00 & & 1.60 & & 1.71 & & -1.03 & $\mathbf{2 . 0 3}$ \\
\hline
\end{tabular}

Pre-euro period $\left(\rho_{1}\right), 1975 \mathrm{Q} 1-1998 \mathrm{Q} 4, n_{1}=96$ observations; euro period $\left(\rho_{2}\right), 1999 \mathrm{Q} 1-2017 \mathrm{Q}$, $n_{2}=75$ observations. $\left.{ }^{* * *}\right|^{* *} /{ }^{*}$ indicate significance at the $1 \% / 5 \% / 10 \%$ level. Bold print indicates statistical significance of the z-scores for $\alpha=0.05$. z-scores are computed when both correlation coefficients are statistically significant at the $5 \%$ level.

Next, I am interested to see if the introduction of the single currency significantly changed the synchronisation of cycles. I compute the $z$-test statistic and test the hypothesis $\left(H_{0}\right)$ that the correlation coefficients in the two periods are equal (Table 2.6). A negative value of $z$ indicates an increase in correlation and the difference is significant if the test measure is larger than |1.96| ( $\alpha=0.05$ ) (Gächter et al., 2012). The impact of the single currency on the synchronisation of cycles differs across countries. The euro significantly promotes synchronisation of the domestic financial cycles with their corresponding EA aggregates in Ireland and Spain. There is no significant euro-effect on this relationship in the other countries. Business cycle synchronisation significantly increases in all countries except Belgium - which shows a small but significant detachment of its cycle from the EA aggregate - and Germany. The increase in correlation between the Finnish business cycle and its EA7 counterpart is particularly 
noteworthy: whereas its business cycle is disconnected in the pre-euro period, the single currency promotes synchronisation with other EA economies. Overall, the results indicate that real and financial markets across EA countries are closely related and that the synchronising effect of the euro was stronger in real than in the financial markets.

At the national level, the euro's impact on the degree of co-movement between business and financial cycles varies across countries. I observe a high degree of synchronisation in Belgium, Ireland, the Netherlands and Spain both before and after the euro's introduction. Higher synchronisation of the Finnish business cycle at the European level in the euro period seems to come at the expense of (significantly) detached domestic cycles. Conversely, German domestic cycles show a significantly higher degree of co-movement under the single currency. The significant increase in the co-movement of Italian national cycles goes along with a higher degree of synchronisation of the Italian business cycle at the European level. Despite the significant reduction in synchronisation between the Spanish domestic cycles, their correlation remains one of the highest among EA countries in the euro period.

Overall, the results in this section suggest that there is co-movement of cycles both at the national and EA level. The introduction of the euro had a synchronising effect on business cycles in most EA countries. Its impact on financial cycle synchronisation is less evident. Further, the euro impact on the synchronisation of national cycles is heterogeneous.

\subsubsection{Dispersion of cycles over time}

While the analysis of standard deviations shows that the amplitudes of domestic cycles differ significantly across countries and compared to the amplitudes of EA aggregates, correlation analysis suggests that cross-country co-movement of national financial and business cycles is generally high. However, if the differences in cycle amplitudes persist between countries, the intensity in common policy making might be too strong for some and too moderate for other countries (Belke et al., 2016). In this section, I compute the cross-sectional standard deviation, $\sigma_{t}$, to investigate the cross-country dispersion of domestic business and financial cycles over time. The corresponding graphs for business and financial cycles are presented in Figure 2.2. The shaded areas in the figure give the CEPR recessions for the EA. I also indicate the approximate dates of four financial crises which are relevant for the EA.

I do not find a clear trend over the sample period towards cross-country convergence in amplitudes for either financial or business cycles. This finding reflects the heterogeneous developments at the national level (Table 2.3). Differences in amplitude fluctuate over time and appear to be larger at the extremes - i.e. peak or trough - of the country-specific cycles. 
Furthermore, the graph reveals a systematic relationship between financial crises and the dispersion of the financial cycles: the dispersion is largest just before the onset of a financial crisis and financial cycles converge as the crisis develops. This result is in line with the findings by Stremmel (2015). I do not identify a similar relationship between business cycle dispersion and CEPR recessions. For instance, while business cycle dispersion is a minimum around $2008 / 2009$, it reaches a maximum in $2012 / 2013$. This finding exemplifies the asymmetry in the amplitudes of business cycle fluctuations and the resulting challenges to economic policy makers.

Figure 2.2 Cross-country standard deviation of domestic business and financial cycles

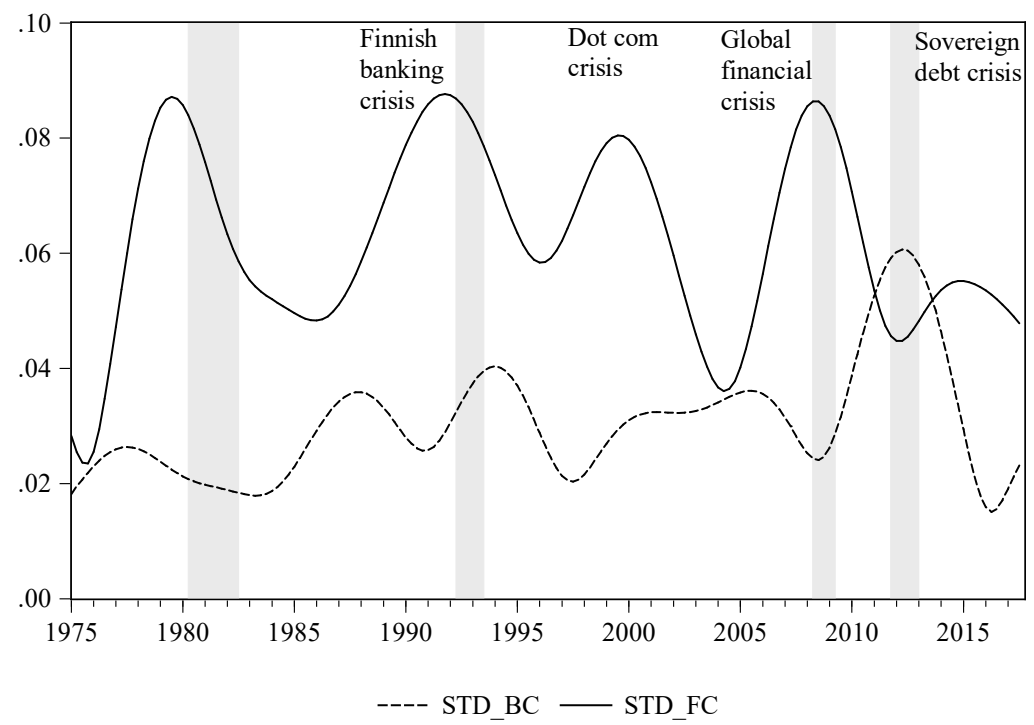

The shaded areas give the CEPR based recession indicator for the euro area business cycle. The shading follows the trough method used by FRED to compute NBER recessions indicators for the US. It shows a recession from the quarter following the peak through the quarter of the trough, i.e. the peak is not included in the recession shading, but the trough is.

Sources: OECD, BIS, IMF-IFS, CEPR; own computations.

\subsection{Panel estimation}

The literature review of sections 2.2.2 and 2.2.3 provides empirical evidence of the synchronisation of financial and business cycles as well as of strong macro-financial linkages. 
In particular, financial cycles are found to play an important role in shaping business cycle recessions and recoveries, and cycles in the real economy can introduce cyclicality in credit markets. In section 2.4 I show that the degree of co-movement between financial and business cycles within and across EA countries is high. But the bivariate analysis does not take account of concurrent developments in the other markets. Yet, significant spillover effects between countries and markets can be expected in the EA.

Now, I turn to the main focus of this chapter and use a panel approach to investigate the dynamics of domestic business cycles and financial cycles, respectively. In particular, I ask if and to what extent changes in domestic financial and business cycles are affected by each other and their EA counterparts. Secondly, I analyse if these relationships have changed with the single currency.

I use the domestic and EA specific financial and business cycles in a panel framework to minimise the impact of possible artefactual oscillations resulting from moving average filtering. In this setting, the regression coefficients represent a summary statistic of the individual countries' results and existing cross-country heterogeneities are diluted. Further, as the cycles are highly persistent, i.e. a major part of the fluctuations in a cycle can be explained by own past values, I choose to use the dependent variable in first differences. With this definition, I explain those fluctuations in the domestic business and financial cycles which are not explained by own past values. Strictly speaking, a causal interpretation of the results is not possible. However, the results do allow to assess whether (lagged) EA business and financial cycle conditions add value in predicting short-term changes in the domestic cycles in excess of the informational value of domestic conditions. In particular, I am interested in the sign of the estimated relationships, the euro effect and the explanatory power of the regression.

\subsubsection{Domestic business cycles}

First, I focus on the explanation of domestic business cycles dynamics. I start with a simple benchmark equation (2.3) which I gradually extend to combinations of domestic and EA business and financial cycles as explanatory variables into the estimated equation. The results are presented in Table 2.7.

The benchmark specification relates the change in the domestic business cycle to its own lagged value in levels as well as lagged values of the domestic financial cycle. Thus, this specification examines possible spillovers from the domestic financial to the real markets. In addition, I include a euro dummy variable which interacts with the lagged domestic cycles. The dummy is 
equal to zero for the pre-euro period 1975Q1-1998Q4 and it is equal to one in the euro period 1999Q1-2017Q3. The estimated equation is given by

$$
\Delta B C_{i, t}=\alpha_{0}+\alpha_{1} B C_{i, t-1}+\alpha_{2} B C_{i, t-1} D_{t-1}^{E M U}+\alpha_{3} F C_{i, t-1}+\alpha_{4} F C_{i, t-1} D_{t-1}^{E M U}+\alpha_{5} D_{t-1}^{E M U}+\varepsilon_{t}{ }^{14}
$$

where $B C_{i, t-1}$ is a $8 \times 1$ vector of domestic business cycles at time $\mathrm{t}-1, \Delta B C_{i, t}$ is the corresponding vector of changes in period t, $F C_{i, t-1}$ is a $8 \times 1$ vector of domestic financial cycles at time t-1 and $D_{t-1}^{E M U}$ is the euro dummy variable. ${ }^{15} \mathrm{I}$ do not control for country-fixed effects as the F-test rejects their joint significance. $\alpha_{1}\left(\alpha_{3}\right)$ gives the impact of the lagged domestic business (financial) cycle level on the current period change in the domestic business cycle in the pre-euro period. The corresponding coefficient in the euro period is given by $\alpha_{1}+$ $\alpha_{2}\left(\alpha_{3}+\alpha_{4}\right)$.

The results in column I of Table 2.7 show that the state of the domestic financial cycle has a significant and negative impact in the pre-euro period and that this negative impact intensified with the introduction of the euro. The result suggests that a strong financial market, i.e. high levels of domestic credit and house prices tend to dampen domestic economic activity. This result contradicts the general empirical finding and demand-side argument that credit and housing markets are of a procyclical nature. ${ }^{16}$ The lagged domestic business cycle has a significantly positive coefficient, indicating real growth persistence. Further, the coefficient is of approximately equal size - but opposite sign - as the domestic financial cycle. It suggests that the net effect - and, hence, the relative positions - of the business cycle and financial cycle explains the future change in the business cycle. More specifically, if the financial cycle level exceeds the business cycle level, the business cycle tends to contract, while if the business cycle level exceeds the financial cycle level, the business cycle expansion continues. Overall, the lagged domestic cycles explain about $41 \%$ of the change in the domestic business cycle.

\footnotetext{
${ }^{14}$ My explanatory variables are jointly determined with the dependent variable at $t$. To solve the issue of endogeneity, I include all explanatory variables with a lag.

${ }^{15}$ Given the high persistence of the series, the difference in the estimation results for explanatory variables dated at $t$ and $t-1$ is marginal.

${ }^{16}$ In line with my result, Mian et al. (2017) show that a positive shock to household debt leads to a decline in GDP in the medium term. Borio et al. (2015) investigate the supply-side transmission of credit to the real economy and show that credit booms undermine productivity growth due to labour reallocations towards lower productivity growth sectors.
} 
Table 2.7 Panel estimation (business cycle)

\begin{tabular}{|c|c|c|c|c|}
\hline$\Delta B C_{i, t}$ & I & II & III & IV \\
\hline Constant & $\begin{array}{c}\mathbf{0 . 0 0 0} \\
(0.000)\end{array}$ & $\begin{array}{c}\mathbf{0 . 0 0 0} \\
(0.000)\end{array}$ & $\begin{array}{c}\mathbf{0 . 0 0 0} \\
(0.000)\end{array}$ & $\begin{array}{c}\mathbf{0 . 0 0 0} \\
(0.000)\end{array}$ \\
\hline$B C_{i, t-1}$ & $\begin{array}{c}\mathbf{0 . 0 3 5}^{\text {**** }}(0.004)\end{array}$ & $\begin{array}{c}\mathbf{0 . 0 3 4}^{\text {****}} \\
(0.005)\end{array}$ & $\begin{array}{c}\mathbf{0 . 0 3 8}^{\text {**** }}(0.004) \\
(0.0)\end{array}$ & $\begin{array}{c}\mathbf{0 . 0 2 4}^{* * * *} \\
(0.004)\end{array}$ \\
\hline$B C_{i, t-1} \times D_{t-1}^{E M U}$ & $\begin{array}{c}\mathbf{- 0 . 0 0 3} \\
(0.007) \\
\end{array}$ & $\begin{array}{c}\mathbf{- 0 . 0 0 1} \\
(0.008) \\
\end{array}$ & $\begin{array}{c}\mathbf{- 0 . 0 0 5} \\
(0.006) \\
\end{array}$ & $\begin{array}{c}\mathbf{0 . 0 0 2} \\
(0.007) \\
\end{array}$ \\
\hline$F C_{i, t-1}$ & $\begin{array}{c}\mathbf{- 0 . 0 3 3}^{\text {***k* }} \\
(0.002)\end{array}$ & $\begin{array}{c}\mathbf{- 0 . 0 3 3}^{\text {****k }} \\
(0.001)\end{array}$ & $\begin{array}{c}\mathbf{- 0 . 0 2 8}^{* * * *} \\
(0.001)\end{array}$ & $\begin{array}{c}\mathbf{- 0 . 0 2 9}^{* * * * *} \\
(0.001)\end{array}$ \\
\hline$F C_{i, t-1} \times D_{t-1}^{E M U}$ & $\begin{array}{c}\mathbf{- 0 . 0 1 2}^{* * * *} \\
(0.004)\end{array}$ & $\begin{array}{c}\mathbf{- 0 . 0 1 1}^{* * * *} \\
(0.003)\end{array}$ & $\begin{array}{c}\mathbf{- 0 . 0 1 3}^{\text {**** }} \\
(0.003)\end{array}$ & $\begin{array}{c}-\mathbf{- 0 . 0 1 0}^{* * * *} \\
(0.003)\end{array}$ \\
\hline$B C_{E A 7, t-1}$ & & $\begin{array}{c}\mathbf{0 . 0 0 3} \\
(0.009)\end{array}$ & & $\begin{array}{c}\mathbf{0 . 0 8 2}^{* * * *} \\
(0.010)\end{array}$ \\
\hline$B C_{E A 7, t-1} \times D_{t-1}^{E M U}$ & & $\begin{array}{c}\mathbf{- 0 . 0 1 1} \\
(0.013)\end{array}$ & & $\begin{array}{c}\mathbf{- 0 . 0 4 6}^{* * * * *} \\
(0.014)\end{array}$ \\
\hline$F C_{E A 7, t-1}$ & & & $\begin{array}{c}\mathbf{- 0 . 0 2 7}^{* * * *} \\
(0.003)\end{array}$ & $\begin{array}{c}\mathbf{- 0 . 0 5 0}^{* * * *} \\
(0.002)\end{array}$ \\
\hline$F C_{E A 7, t-1} \times D_{t-1}^{E M U}$ & & & $\begin{array}{c}\mathbf{0 . 0 0 6} \\
(0.004)\end{array}$ & $\begin{array}{c}\mathbf{0 . 0 1 9}^{* * * *} \\
(0.004)\end{array}$ \\
\hline$D_{t-1}^{E M U}$ & $\begin{array}{c}\mathbf{0 . 0 0 0} \\
(0.000) \\
\end{array}$ & $\begin{array}{c}\mathbf{0 . 0 0 0} \\
(0.000) \\
\end{array}$ & $\begin{array}{c}\mathbf{0 . 0 0 0} \\
(0.000) \\
\end{array}$ & $\begin{array}{c}\mathbf{0 . 0 0 0} \\
(0.000) \\
\end{array}$ \\
\hline$R^{2}$ & 0.414 & 0.414 & 0.467 & 0.505 \\
\hline$\overline{R^{2}}$ & 0.411 & 0.411 & 0.464 & 0.501 \\
\hline Log likelihood & 5956.13 & 5956.73 & 6020.95 & 6070.68 \\
\hline \multicolumn{5}{|c|}{ Log likelihood ratio (LR) test } \\
\hline Restricted model & & I & I & III \\
\hline $\begin{array}{c}\text { Test statistic } \\
\text { Df } \\
\text { p-value }\end{array}$ & & $\begin{array}{c}1.2 \\
2 \\
0.549\end{array}$ & $\begin{array}{c}129.64 \\
2 \\
0.000\end{array}$ & $\begin{array}{c}99.46 \\
2 \\
0.000\end{array}$ \\
\hline
\end{tabular}

White cross-section standard errors in parentheses.

${ }^{* * *}$ indicates significance at the $1 \%$ level.

The extended specifications in columns II and III include, respectively, the EA business cycle and the EA financial cycle as additional explanatory variables. I hypothesise a positive effect of the EA business cycle since favourable economic conditions in the EA will boost domestic economic activity via trade and the transmission of technological advances across borders. However, I find that the EA business cycle does not add additional explanatory power to the regression. The result suggests that domestic business cycle dynamics are independent of the state of the EA real economy if I control for domestic economic and financial conditions. The LR-test - relative to the specification I - on the exclusion of the EA business cycle variables cannot be rejected at any reasonable level of significance. In contrast, EA financial conditions (specification III) significantly drive down the domestic business cycle. The effect is insensitive 
to the introduction of the euro. The EA financial cycle tends to intensify the negative impact of the domestic financial cycle: the state of the financial system - both at home and abroad dampens the domestic business cycle. The EA financial cycle variables increase the explanatory power of the regression by about 5 percent and their exclusion - compared to specification Iis strongly rejected.

The specification in column IV estimates the joint impact of domestic and EA7 real and financial conditions on changes in the domestic business cycle. Now, the levels of both - the domestic and EA business cycles - are found to explain domestic business cycle dynamics significantly and positively. However, the common currency significantly reduced the effect of the EA business cycle, suggesting that real EA markets are less important for changes in the domestic business cycle under the common currency. Conversely, domestic and EA7 financial cycles relate significantly and negatively to domestic business cycle dynamics. The introduction of the euro increased the negative impact of the domestic financial cycle, while it reduced the negative effect of the EA financial cycle. This finding suggests that while domestic macro-financial linkages increased, the importance of cross-country macro-financial linkages decreased with the common currency. Overall, the explanatory power of the statistically preferred specification IV is about $50 \%$. The marginal contribution of the EA aggregates is almost 10 percent, showing a significant impact of EA conditions on domestic business cycles. Across specifications, the size, sign and significance of coefficients is quite stable. The significance of the EA business cycle level depends on the inclusion of its financial cycle counterpart. Typically, the business cycle effects are positive while the financial cycle effects are negative. Given their roughly similar size, it suggests that it is their net effect that plays a role in explaining the change in the domestic business cycle. A more in-depth investigation of this issue is left for future research.

\subsubsection{Domestic financial cycles}

In this section, I intend to explain fluctuations in domestic financial cycle dynamics closely following the specifications in section 2.5.1. Equation (2.4) is the benchmark specification. It regresses the change in the domestic financial cycle on (the lagged values of) the domestic financial cycle level, the domestic business cycle level and the corresponding interaction effects with the euro dummy:

$$
\Delta F C_{i, t}=\beta_{0}+\beta_{1} F C_{i, t-1}+\beta_{2} F C_{i, t-1} D_{t-1}^{E M U}+\beta_{3} B C_{i, t-1}+\beta_{4} B C_{i, t-1} D_{t-1}^{E M U}++\beta_{5} D_{t-1}^{E M U}+v_{t}
$$


Table 2.8 Panel estimation (financial cycle)

\begin{tabular}{|c|c|c|c|c|}
\hline$\Delta F C_{i, t}$ & $\mathbf{V}$ & VI & VII & VIII \\
\hline Constant & $\begin{array}{c}\mathbf{0 . 0 0 0} \\
(0.000)\end{array}$ & $\begin{array}{c}\mathbf{0 . 0 0 0} \\
(0.000)\end{array}$ & $\begin{array}{c}\mathbf{0 . 0 0 0} \\
(0.000)\end{array}$ & $\begin{array}{c}\mathbf{0 . 0 0 0} \\
(0.000)\end{array}$ \\
\hline$F C_{i, t-1}$ & $\begin{array}{c}-\mathbf{- 0 . 0 3 6}^{* * *} \\
(0.004)\end{array}$ & $\begin{array}{c}-\mathbf{- . 0 3 5}^{* * *} \\
(0.003)\end{array}$ & $\begin{array}{c}\mathbf{- 0 . 0 2 9}^{* * *} \\
(0.003)\end{array}$ & $\begin{array}{c}\mathbf{- 0 . 0 3 0}^{* * *} \\
(0.003)\end{array}$ \\
\hline$F C_{i, t-1} \times D_{t-1}^{E M U}$ & $\begin{array}{l}\mathbf{- 0 . 0 0 8}^{*} \\
(0.005)\end{array}$ & $\begin{array}{l}\mathbf{- 0 . 0 1 1}^{* *} \\
(0.005)\end{array}$ & $\begin{array}{l}\mathbf{- 0 . 0 1 3}^{* * * *} \\
(0.005)\end{array}$ & $\begin{array}{l}\mathbf{- 0 . 0 0 9}^{* * *} \\
(0.005)\end{array}$ \\
\hline$B C_{i, t-1}$ & $\begin{array}{l}\mathbf{0 . 1 6 5} 5^{* * *} \\
(0.005)\end{array}$ & $\begin{array}{c}\mathbf{0 . 1 6 9} \\
(0.005) \\
\end{array}$ & $\begin{array}{c}\mathbf{0 . 1 7 0}^{* * *} \\
(0.004)\end{array}$ & $\begin{array}{c}\mathbf{0 . 1 5 6} \\
(0.004)\end{array}$ \\
\hline$B C_{i, t-1} \times D_{t-1}^{E M U}$ & $\begin{array}{l}-\mathbf{0 . 0 4 7} \\
(0.007)\end{array}$ & $\begin{array}{c}\mathbf{- 0 . 0 6 0}^{* * * *} \\
(0.008)\end{array}$ & $\begin{array}{l}-\mathbf{- 0 . 0 5 1} \\
(0.007)\end{array}$ & $\begin{array}{l}\mathbf{- 0 . 0 5 7}^{* \ldots * *} \\
(0.007)\end{array}$ \\
\hline$B C_{E A 7, t-1}$ & & $\begin{array}{l}\mathbf{- 0 . 0 1 9} \\
(0.018)\end{array}$ & & $\begin{array}{l}\mathbf{0 . 0 7 9}^{* * * *} \\
(0.021)\end{array}$ \\
\hline$B C_{E A 7, t-1} \times D_{t-1}^{E M U}$ & & $\begin{array}{l}\mathbf{0 . 0 5 8}^{* * *} \\
(0.022)\end{array}$ & & $\begin{array}{c}\mathbf{0 . 0 1 5} \\
(0.022) \\
\end{array}$ \\
\hline$F C_{E A 7, t-1}$ & & & $\begin{array}{l}\mathbf{- 0 . 0 4 0}^{* * *} \\
(0.005)\end{array}$ & $\begin{array}{c}\mathbf{- 0 . 0 6 2}^{* * * *} \\
(0.006)\end{array}$ \\
\hline$F C_{E A 7, t-1} \times D_{t-1}^{E M U}$ & & & $\begin{array}{l}\mathbf{0 . 0 2 7}^{* * *} \\
(0.006)\end{array}$ & $\begin{array}{l}\mathbf{0 . 0 2 3}^{* * * *} \\
(0.006)\end{array}$ \\
\hline$D_{t-1}^{E M U}$ & $\begin{array}{c}\mathbf{0 . 0 0 0} \\
(0.000) \\
\end{array}$ & $\begin{array}{c}\mathbf{0 . 0 0 0} \\
(0.000)\end{array}$ & $\begin{array}{c}\mathbf{0 . 0 0 0} \\
(0.000)\end{array}$ & $\begin{array}{c}\mathbf{0 . 0 0 0} \\
(0.000) \\
\end{array}$ \\
\hline$R^{2}$ & 0.418 & 0.422 & 0.442 & 0.461 \\
\hline$\overline{R^{2}}$ & 0.416 & 0.419 & 0.439 & 0.458 \\
\hline Log likelihood & 5097.86 & 5102.38 & 5126.47 & 5149.99 \\
\hline \multicolumn{5}{|c|}{ Log likelihood ratio test } \\
\hline Restricted model & & $\mathbf{V}$ & $\mathbf{V}$ & VII \\
\hline $\begin{array}{c}\text { Test statistic } \\
\text { Df } \\
\text { p-value }\end{array}$ & & $\begin{array}{c}9.04 \\
2 \\
0.011 \\
\end{array}$ & $\begin{array}{c}57.22 \\
2 \\
0.000\end{array}$ & $\begin{array}{c}47.04 \\
2 \\
0.000 \\
\end{array}$ \\
\hline
\end{tabular}

White cross-section standard errors in parentheses.

$\left.{ }^{* * *}\right|^{* *} / /^{*}$ indicate significance at the $1 \% / 5 \% / 10 \%$ level.

The results are presented Table 2.8. The benchmark specification in column V investigates possible spillovers from the domestic real to the domestic financial markets. The state of the domestic business cycle is found to significantly drive up the financial cycle, but this impact is reduced in the euro period. In an upturn, better growth prospects improve borrower creditworthiness and collateral values which leads lenders to respond with an increased supply of credit. In a downturn, the process is reversed (Dell'Ariccia et al., 2015). The state of the domestic financial cycle has a significantly negative impact on future changes in the financial cycle. As for the business cycle analysis in section 2.5.1, the lagged levels of the domestic business cycle and the domestic financial cycle have opposite effects. However, now the business cycle coefficient significantly exceeds the financial cycle coefficient. This indicates 
that the impact of the domestic real economy on financial cycle dynamics is larger than the impact of domestic financial conditions. Moreover, in contrast with the business cycle dynamics, the own effect now is negative and the other effect positive. While the domestic business cycle is driven by growth persistence, a higher financial cycle increases the chances of observing a financial cycle downturn in the future. The explanatory power of specification $\mathrm{V}$ is almost $42 \%$.

In specifications VI and VII, I in turn include the state of the EA business cycle and the state of the EA financial cycle into the regression. Based on the LR-test, both specifications are preferred to specification $\mathrm{V}$, indicating that both the EA business cycle conditions and the EA financial cycle conditions on their own have explanatory power for the domestic financial cycle. Especially for the EA business cycle, the effect is small and due to the euro period only.

Specification VIII estimates the joint impact of domestic and EA7 real and financial conditions on domestic financial cycle dynamics. All four variables have a significant effect on the domestic financial cycle. It is the preferred specification, as shown by the LR-test. The explanatory power of 46 percent, as compared to about 42 percent for specification $\mathrm{V}$, shows that EA variables contribute significantly to the explanation of the domestic financial cycle dynamics. However, the EA contribution for the domestic financial cycle is only half as large as it is for the domestic business cycle. While the impact of the financial cycles is significantly negative in the pre-euro period, it is significantly positive for the business cycles. The euro significantly changes the relationships for most variables: It significantly reduces the positive impact of the domestic business cycle and the negative impact of the EA financial cycle, while it significantly increases the impact of the domestic financial cycle. As was the case for the business cycle, the business cycle and financial cycle effects have opposite signs, indicating it is their joint effect that is important.

Overall, I find close macro-financial linkages for both the domestic business cycle and the domestic financial cycle. While individual EA economies are not insulated from economic developments in the rest of the EA, the impact of these external developments on the domestic cycles seems to have decreased with the common currency. Past experience suggests that macro-financial risks such as excessive lending in some EA countries are most likely spread across EA countries and, hence, affect both domestic real and financial markets.

My results also have implications for the conduct of common monetary policy. In particular, the European Central Bank faces two challenges. First, the intensity of its common policy must meet the needs of a (heterogenous) group of EA economies. This is particularly important when 
the shocks which the countries are facing are asymmetric or the countries' business cycles have different amplitudes. Second, there are multiple channels of seemingly opposing impact through which monetary policy is transmitted into the domestic economy. Accommodative monetary policy to boost the economy when growth is slowing is intended to have a positive impact on the domestic business cycle via investment in productive capacity. Further, domestic demand should rise in response to lower interest rates which results in increased lending. As the impact of financial and business cycles on the domestic business cycle differ in sign, the overall impact of the policy depends on the relative state of both the real and financial cycles. Further, as the financial cycles - both domestic and EA7 - tend to be countercyclical in my analysis, the overall impact of monetary policy is expected to be reduced via macro-financial linkages. An optimal policy response needs to take the various channels into account.

\subsection{Conclusions}

In this chapter, I investigate macro-financial linkages for eight EA countries over the period 1975-2017. I contribute to the literature by shifting the focus from country-level analysis to the interaction between individual EA countries and their respective EA environment. In a panel framework, I study how individual EA countries' financial and business cycles are affected by domestic and EA financial and macroeconomic conditions before and after the introduction of the single currency. I find that macro-financial linkages are strong within and across EA countries.

First, I construct business cycles and financial cycles for eight individual EA countries using the CF-frequency-band filtering technique. Subsequently, I compute corresponding countryspecific EA cycles as a proxy for the most relevant external environment. The preliminary descriptive analysis of the cycles shows that financial and business cycles across EA countries are closely related. Also, the synchronising effect of the euro was stronger in real than in financial markets. The degree of co-movement between business and financial cycles is heterogeneous at the country level. Cycle volatility differs across countries and it significantly and heterogeneously changes over time. Domestic cycles tend to be more volatile than EA cycles. Relative volatility of domestic financial cycles compared to their EA counterparts decreases and relative volatility of domestic business cycles compared to their EA counterparts increase in the euro period. Financial cycles are more volatile than business cycles but have become comparatively less volatile in the euro period. I do not identify a clear trend towards 
cross-country convergence in amplitudes between business and financial cycles and find that financial cycle dispersion is largest just before the onset of a financial crisis. Cycles converge as the crisis develops.

My panel estimations reveal that there is a fair amount of explanatory power in domestic and EA7 business and financial cycles. Together, they explain about $50 \%$ in domestic business and financial cycle dynamics. External (EA7) conditions contribute about 10 percent to the explanation of the domestic business cycle and about 5 percent to the explanation of the domestic financial cycle. I find all coefficients to be highly statistically significant before and after the introduction of the single currency, indicating the importance of spillovers between countries and markets. While the state of the domestic and EA7 business cycles tends to drive up the domestic business and financial cycles, the state of the domestic and EA7 financial cycles tends to drive down the domestic business and financial cycles. Typically, corresponding business cycle and financial cycle effects have opposite signs, often of similar size. This suggests that the relative business cycle condition and financial cycle condition play a role in the dynamics. This observation is left for further research. 


\section{References}

Abbate, A., 2016. Essays on Macro Financial Linkages. Doctoral dissertation, European University Institute, Florence.

Ahmed, J., Chaudhry, S.M., Straetmans, S., 2018. Business and Financial Cycles in the Eurozone: Synchronization or Decoupling. The Manchester School 86 (3), 358-389.

Aikman, D., Haldane, A.G., Nelson, B.D., 2015. Curbing the Credit Cycle. The Economic Journal 125 (June), 1072-1109.

Alcidi, C., 2017. Fiscal policy stabilisation and the financial cycle in the euro area. European economy Discussion Paper 052. European Commission, Luxembourg.

Alcidi, C., Dolls, M., Fuest, C., Krolage, C., Neumeier, F., 2017. The Nature of Shocks in the Eurozone and Their Absorption Channels. EconPol Policy Report 3.

Antonakakis, N., Breitenlechner, M., Scharler, J., 2015. Business cycle and financial cycle spillovers in the G7 countries. The Quarterly Review of Economics and Finance 58, 154162.

Belke, A., Domnick, C., Gros, D., 2016. Business cycle synchronization in the EMU: Core vs. periphery. ROME Discussion Paper Series 16-08.

BIS, 2014. 84th Annual Report.

Borio, C., 2014. The financial cycle and macroeconomics: What have we learnt? Journal of Banking \& Finance 45, 182-198.

Borio, C., Drehmann, M., Xia, D., 2018. The financial cycle and recession risk. BIS Quarterly Review (December), 59-71.

Borio, C., Upper, C., Zampolli, F., Kharroubi, E., 2015. Labour reallocation and productivity dynamics: financial causes, real consequences. BIS Working Papers 534.

Cagliarini, A., Price, F., 2017. Exploring the Link between the Macroeconomic and Financial Cycles, in: Monetary policy and financial stability in a world of low interest rates: Proceedings of a Conference Held in Sydney on 16-17 March 2017, pp. 7-50.

Claessens, S., Kose, M.A., 2018. Frontiers of macrofinancial linkages. BIS papers 95.

Claessens, S., Kose, M.A., Terrones, M.E., 2011. Financial Cycles: What? How? When? International Monetary Fund. IMF Working Paper WP/11/76.

Claessens, S., Kose, M.A., Terrones, M.E., 2012. How do business and financial cycles interact? Journal of International Economics (87), 178-190.

Comin, D., Gertler, M., 2006. Medium-Term Business Cycles. The American Economic Review 96 (3), 523-551.

Dell'Ariccia, G., Igan, D., Laeven, L., Tong, H., 2015. Policies for Macrofinancial Stability: How to Deal with Credit Booms? Economic Policy, 62nd Panel Meeting. Banque Centrale du Luxembourg.

Drehmann, M., Borio, C., Tsatsaronis, K., 2012. Characterising the financial cycle: don't lose sight of the medium term! BIS Working Papers 380.

Duran, H.E., Ferreira-Lopes, A., 2016. Determinants of co-movement and of lead and lag behavior of business cycles in the Eurozone. International Review of Applied Economics 31 (2), 255-282. 
Égert, B., Sutherland, D., 2012. The Nature of Financial and Real Business Cycles: The Great Moderation and Banking Sector Pro-Cyclicality. OECD Economics Department Working Papers 938.

Franks, J., Barkbu, B., Blavy, R., Oman, W., Schoelermann, H., 2018. Economic Convergence in the Euro Area: Coming Together or Drifting Apart? IMF Working Paper WP/18/10.

Furceri, D., Karras, G., 2008. Business-cycle synchronization in the EMU. Applied Economics 40 (12), 1491-1501.

Gächter, M., Riedl, A., Ritzberger-Grünwald, D., 2012. Business Cycle Synchronization in the Euro Area and the Impact of the Financial Crisis. Monetary Policy \& The Economy Q2/12, $33-60$.

Gächter, M., Riedl, A., Ritzberger-Grünwald, D., 2013. Business cycle convergence or decoupling? Economic adjustment in CESEE during the crisis. BOFIT Discussion Papers 3. Bank of Finland.

Galati, G., Hindrayanto, I., Koopman, S.J., Vlekke, M., 2016. Measuring financial cycles in a model-based analysis: Empirical evidence for the United States and the euro area. Economics Letters (145), 83-87.

Gayer, C., 2007. Synchronisation of business cycles in the euro area. European Economy Economic Papers 287.

Gogas, P., 2013. Business cycle synchronisation in the European Union: The effect of the common currency. Journal of Business Cycle Measurement and Analysis 2013/1, 1-14.

Gonçalves, C.E.S., Rodrigues, M., Soares, T., 2009. Correlation of business cycles in the euro zone. Economics Letters 102 (1), 56-58.

Gouveia, S., Correia, L., 2008. Business cycle synchronisation in the Euro area: The case of small countries. International Economics and Economic Policy 5 (1-2), 103-121.

Granville, B., Hussain, S., 2017. Eurozone cycles: An analysis of phase synchronization. International Journal of Finance and Economics 22 (2), 83-114.

Grigoraş, V., Stanciu, I.E., 2016. New evidence on the (de)synchronisation of business cycles: Reshaping the European business cycle. International Economics 147, $27-52$.

Ha, J., Kose, M.A., Otrok, C., Prasad, E.S., 2020. Global macro-financial cycles and spillovers. NBER Working Paper Series 26798.

Harding, D., Pagan, A., 2002. Dissecting the cycle: a methodological investigation. Journal of Monetary Economics 49 (2), 365-381.

Harding, D., Pagan, A., 2005. A Suggested Framework for Classifying the Modes of Cycle Research. Journal of Applied Econometrics 20 (2), 151-159.

Harding, D., Pagan, A., 2006. Synchronization of cycles. Journal of Econometrics 132 (1), 5979.

Helbling, T., Huidrom, R., Kose, M.A., Otrok, C., 2011. Do credit shocks matter? A global perspective. European Economic Review 55 (3), 340-353.

Hiebert, P., Klaus, B., Peltonen, T., Schüler, Y.S., Welz, P., 2014. Capturing the financial cycle in euro area countries, in: European Central Bank (Ed.), Financial Stability Review, November, pp. 109-117. 
Massmann, M., Mitchell, J., 2005. Reconsidering the Evidence: Are Euro Area Business Cycles Converging? Journal of Business Cycle Measurement and Analysis 2004 (3), 275-307.

Merler, S., 2015. Squaring the cycle: Financial cycles, capital flows and macroprudential policy in the Euro area. Bruegel Working Paper 2015/14.

Mian, A., Sufi, A., Verner, E., 2017. Household Debt and Business Cycles Worldwide. The Quarterly Journal of Economics 132 (4), 1755-1817.

OECD, 2016. Irish GDP up by $26.3 \%$ in 2015? OECD. https://www-oecdorg.proxy.library.uu.nl/sdd/na/Irish-GDP-up-in-2015-OECD.pdf (accessed 29 January 2020).

Rünstler, G., Vlekke, M., 2016. Business, housing and credit cycles. European Central Bank. Working Paper Series 1915.

Schüler, Y.S., Hiebert, P.P., Peltonen, T.A., 2017. Coherent Financial cycles for G-7 countries: Why extending credit can be an asset. ESRB Working Paper Series 43.

Slutzky, E., 1937. The Summation of Random Causes as the Source of Cyclic Processes. Econometrica 5 (2), 105-146.

Stremmel, H., 2015. Capturing the Financial Cycle in Europe. European Central Bank. Working Paper Series 1811.

Tsatsaronis, K., 2005. Investigating the relationship between the financial and real economy, in: Monetary and Economic Department (Ed.), Investigating the relationship between the financial and real economy. BIS Papers 22, pp. 1-4.

Weyerstrass, K., van Aarle, B., Kappler, M., Seymen, A., 2011. Business Cycle Synchronisation with(in) the Euro Area: In Search of a 'Euro Effect'. Open Econ Rev 22 (3), 427-446. 


\section{Appendix I.}

Table 2.9 Data sources

\begin{tabular}{|l|l|l|}
\hline Variable & Source & Description \\
\hline Real GDP & OECD & $\begin{array}{l}\text { National currency, volume estimates, } \\
\text { OECD reference year (2010), seasonally } \\
\text { adjusted, annual levels }\end{array}$ \\
\hline Credit & BIS & $\begin{array}{l}\text { Credit to the private non-financial sector } \\
\text { from all sectors at market value, billions of } \\
\text { euros, adjusted for breaks }\end{array}$ \\
\hline Credit/GDP ratio & BIS & $\begin{array}{l}\text { Credit to the private non-financial sector } \\
\text { from all sectors at market value, } \\
\text { percentage of GDP, adjusted for breaks }\end{array}$ \\
\hline House prices & OECD & Real house price index, 2010=100 \\
\hline $\begin{array}{l}\text { Consumer price } \\
\text { index }\end{array}$ & $\begin{array}{l}\text { OECD } \\
\text { IMF-IFS (for } \\
\text { Ireland) }\end{array}$ & $2010=100$ \\
$2010=100$
\end{tabular}




\section{Appendix II.}

Table 2.10 Lagged correlations

\begin{tabular}{|lc|}
\hline & Lag (-) / lead (+) \\
BE & -2 \\
FI & -13 \\
FR & -6 \\
GE & -11 \\
IR & -9 \\
IT & -10 \\
NE & -4 \\
SP & -5 \\
\hline
\end{tabular}

Sample period:1975Q1-2017Q3

Table 2.11 Contemporaneous correlations and z-test results

\begin{tabular}{|c|c|c|c|c|c|c|c|c|}
\hline $\boldsymbol{F} \boldsymbol{C}_{\boldsymbol{i}, \boldsymbol{t}}$ and $\boldsymbol{B} \boldsymbol{C}_{\boldsymbol{E A 7 , t}}$ & $\mathbf{B E}$ & $\mathbf{F I}$ & $\mathbf{F R}$ & $\mathbf{G E}$ & $\mathbf{I R}$ & $\mathbf{I T}$ & $\mathbf{N E}$ & $\mathbf{S P}$ \\
$\rho_{1}$ & $0.74^{* * *}$ & 0.16 & $0.59^{* * *}$ & 0.14 & $0.50^{* * *}$ & $0.44^{* * *}$ & $0.80^{* * *}$ & $0.61^{* * *}$ \\
$\rho_{2}$ & $0.69^{* * *}$ & -0.19 & $0.33^{* * *}$ & $0.46^{* * *}$ & $0.95^{* * *}$ & 0.10 & $0.86^{* * *}$ & $0.56^{* * *}$ \\
$z$ & 0.64 & & $\mathbf{2 . 1 3}$ & & $\mathbf{- 8 . 2 6}$ & & -1.24 & 0.46 \\
\hline $\boldsymbol{B} \boldsymbol{C}_{\boldsymbol{i}, \boldsymbol{t}}$ and $\boldsymbol{F} \boldsymbol{C}_{\boldsymbol{E A 7 , t}}$ & $\mathbf{B E}$ & $\mathbf{F I}$ & $\mathbf{F R}$ & $\mathbf{G E}$ & $\mathbf{I R}$ & $\mathbf{I T}$ & $\mathbf{N E}$ & $\mathbf{S P}$ \\
$\rho_{1}$ & $0.69^{* * *}$ & -0.12 & $0.74^{* * *}$ & $0.68^{* * *}$ & 0.07 & $0.73^{* * *}$ & $0.27^{* * *}$ & $0.63^{* * *}$ \\
$\rho_{2}$ & $0.82^{* * *}$ & $0.83^{* * *}$ & $0.78^{* * *}$ & $-0.39^{* * *}$ & 0.11 & $0.95^{* * *}$ & $0.35^{* * *}$ & $0.82^{* * *}$ \\
$z$ & $\mathbf{- 1 . 9 2}$ & & -0.55 & $\mathbf{7 . 9 2}$ & & $\mathbf{- 5 . 6 8}$ & -0.51 & $\mathbf{- 2 . 7 3}$ \\
\hline
\end{tabular}

Pre-euro period $\left(\rho_{1}\right)$ : 1975Q1-1998Q4, $n_{1}=96$ observations; euro period $\left(\rho_{2}\right)$ : 1999Q1-2017Q3, $n_{2}=$ 75 observations. ${ }^{* * *}$ indicates significance at the $1 \%$ level. Bold print indicates statistical significance of the z-scores for $\alpha=0.05$. z-scores are computed when both correlation coefficients are statistically significant at the $5 \%$ level. 


\section{Appendix III.}

The literature review in the main text makes clear that economic cycles are the outcome of a multitude of ex ante decisions and choices and that, therefore, special care should be taken in cross-study comparisons. In this appendix, I compare the financial cycles of the chapter with two other sets of financial cycles. These are, on the one hand, financial cycles computed and published by the Bank of International Settlements (BIS). ${ }^{17}$ On the other hand, I modify my initial assumptions and compute composite financial cycles based on the annual growth rates (rather than log levels) of my financial series. I am interested in two questions. First, how do the log level financial cycles compare to the other cycle definitions at the country-level? Second, do the various cycle measures yield similar results in co-movement analysis?

The first comparison is graphical. I plot the three financial cycles for each country and a simple EA8 average (Figure 2.3). I identify several regularities. First, the amplitude of the BIS cycle exceeds the amplitude of the other two cycles by a factor of ten or more. Since I do not know how the BIS cycles were computed nor which variables were used in the computation, I can only speculate about these differences. Growth cycles have the smallest amplitude in all countries. Second, despite the differences in amplitude, the periodicity and the timing of peaks and troughs are remarkably similar between my level cycles and the BIS for all countries. Third, level and growth cycles appear to be more heterogeneous. Peaks and troughs are shifted across time and therefore lead to different conclusions about the timing of events. Fourth, growth cycles appear to be more frequent than both level and BIS cycles. Fifth, the EA8 financial cycles are less volatile than most individual countries' financial cycles. This graphical analysis already shows that the cycles exhibit differences in amplitude and timing depending on the ex ante decisions made in their computations.

I now turn to a more formal analysis of the cycles and start with an analysis of their frequency. The results in Table 2.12 confirm earlier observations that growth cycles are generally more frequent than level and BIS cycles. The table shows the number of peaks and troughs per series in all countries over the sample period. I compute these peaks and troughs using the BryBoschan dating algorithm and assume a minimum phase duration of two quarters and a minimum cycle length of five quarters. Overall, I identify between two and five peaks and/or troughs per country (and therefore between one and four complete cycles). For most countries, growth cycles are indeed more frequent than level and BIS cycles.

\footnotetext{
${ }^{17}$ I do not have information about the underlying financial series and the computational methods.
} 
Figure 2.3 Financial cycles
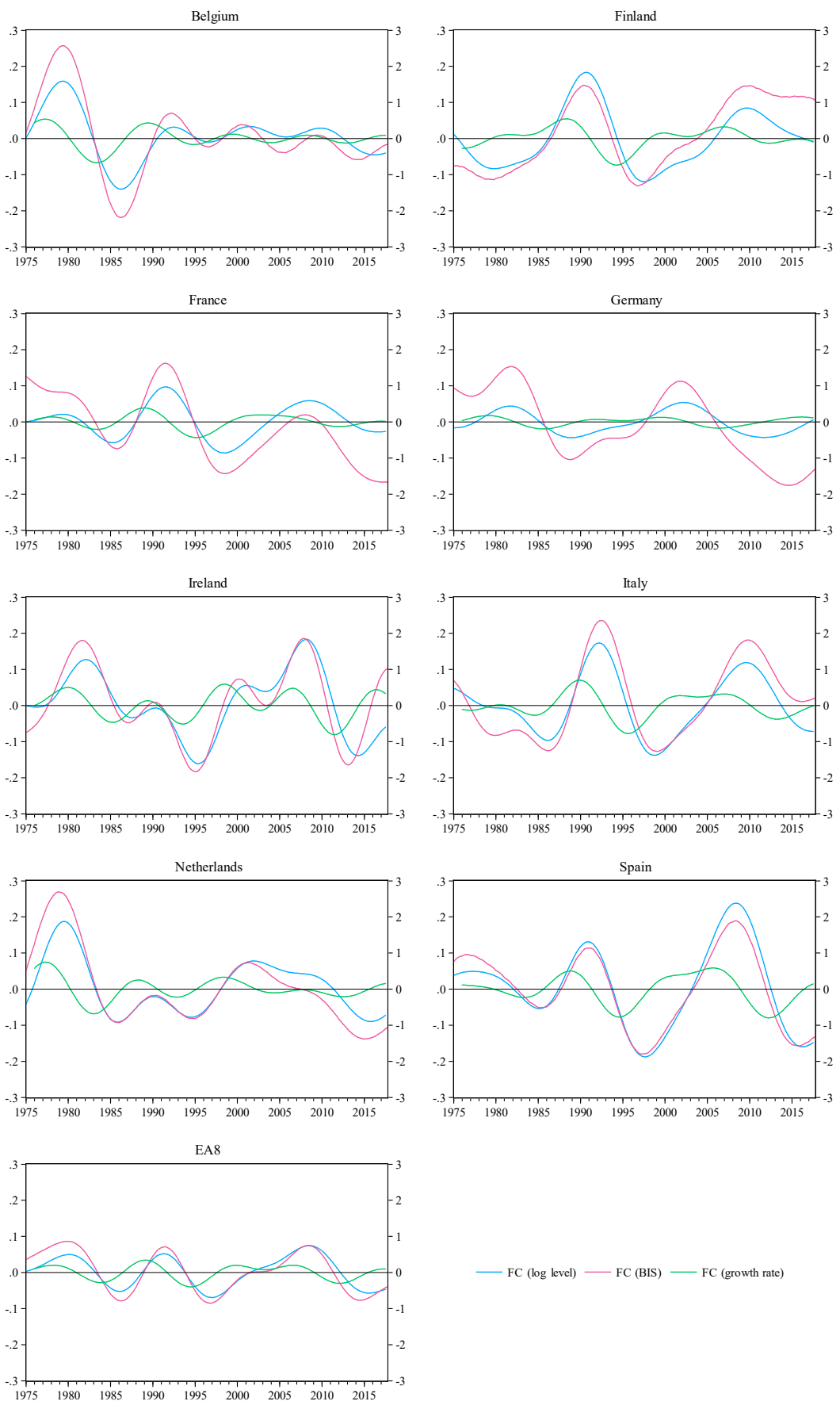

$-\mathrm{FC}(\log$ level) $\longrightarrow \mathrm{FC}(\mathrm{BIS})-\mathrm{FC}$ (growth rate)

The log level and growth rate financial cycles are measured on the left axis, the BIS financial cycle is measured on the right axis. 
Table 2.12 Number of peaks and troughs in cycles

\begin{tabular}{|c|c|c|c|c|}
\hline & & $\begin{array}{c}\text { BIS cycle } \\
(1975 Q 1-2017 Q 4)\end{array}$ & $\begin{array}{c}\text { Level cycle } \\
(1975 Q 1-2017 Q 3)\end{array}$ & $\begin{array}{c}\text { Growth cycle } \\
(1976 Q 1-2017 Q 3)\end{array}$ \\
\hline \multirow{2}{*}{ BE } & $\mathrm{P}$ & 4 & 4 & 4 \\
\hline & $\mathrm{T}$ & 4 & 4 & 4 \\
\hline \multirow{2}{*}{ FI } & $\mathrm{P}$ & 2 & 2 & 5 \\
\hline & $\mathrm{T}$ & 2 & 2 & 4 \\
\hline \multirow{2}{*}{ FR } & $\mathrm{P}$ & 2 & 3 & 4 \\
\hline & $\mathrm{T}$ & 2 & 3 & 3 \\
\hline \multirow{2}{*}{ GE } & $\mathrm{P}$ & 3 & 2 & 4 \\
\hline & $\mathrm{T}$ & 4 & 2 & 3 \\
\hline \multirow{2}{*}{ IR } & $\mathrm{P}$ & 4 & 4 & 5 \\
\hline & $\mathrm{T}$ & 4 & 5 & 4 \\
\hline \multirow{2}{*}{ IT } & $\mathrm{P}$ & 3 & 2 & 4 \\
\hline & $\mathrm{T}$ & 4 & 2 & 5 \\
\hline \multirow{2}{*}{ NE } & $\mathrm{P}$ & 3 & 3 & 4 \\
\hline & $\mathrm{T}$ & 3 & 3 & 4 \\
\hline \multirow{2}{*}{ SP } & $\mathrm{P}$ & 3 & 3 & 2 \\
\hline & $\mathrm{T}$ & 3 & 3 & 3 \\
\hline \multirow{2}{*}{ EA8 } & $\mathrm{P}$ & 3 & 3 & 4 \\
\hline & $\mathrm{T}$ & 3 & 3 & 4 \\
\hline
\end{tabular}

$\mathrm{P}$ is the number of identified peaks and $\mathrm{T}$ is the number of identified troughs per cycle.

The graphical analysis further suggests varying degrees of synchronisation between series. The level cycles appear to be highly synchronised with the BIS cycles, but the relationship between level/BIS cycles and growth cycles appears to be weaker. To confirm this observation, I compute the correlations and concordance statistics between the BIS and level financial cycles and between level and growth financial cycles. The statistics are presented in Table 2.13. The table shows that correlations between level and BIS cycles are generally high and exceed 0.85 for most countries. Further, the concordance statistics indicate that level and BIS cycles are in the same cycle phase more than $85 \%$ of the time for all countries. Despite the observed differences in amplitude, the two series show a high degree of co-movement. Unsurprisingly, the correlations between level and growth cycles are generally much lower, but still positive. The concordance statistic is below 0.6 for most countries, suggesting a low degree of comovement between level and growth cycles.

In the light of these similarities and differences, it is interesting to find out if the various cycle definitions nevertheless yield comparable cross-country results. The graphical analysis showed that the amplitude of the BIS cycle exceeds the amplitudes of both - the level and growth cycle - by a multiple. I take the scale of the cycle measures as given and try to establish if the crosscountry differences in financial cycle amplitude compare across cycle measures. 


\section{Table 2.13 Correlation and concordance statistics}

\begin{tabular}{|c|c|c|c|c|}
\hline & \multicolumn{2}{|c|}{ Level and BIS cycles ${ }^{1}$} & \multicolumn{2}{|c|}{ Level and growth cycles ${ }^{2}$} \\
\hline & Correlation & Concordance & Correlation & Concordance \\
\hline BE & $0.97^{* * *}$ & 0.90 & $0.27^{* * *}$ & 0.55 \\
\hline FI & $0.84^{* * *}$ & 0.85 & $0.16^{* *}$ & 0.50 \\
\hline FR & $0.76^{* * *}$ & 0.85 & $0.23^{* * *}$ & 0.53 \\
\hline GE & $0.84^{* * *}$ & 0.85 & $0.14^{*}$ & 0.55 \\
\hline IR & $0.89^{* * *}$ & 0.89 & $0.19^{* *}$ & 0.62 \\
\hline IT & $0.92^{* * *}$ & 0.89 & $0.22^{* * *}$ & 0.54 \\
\hline NE & $0.92^{* * *}$ & 0.94 & $0.26^{* * *}$ & 0.54 \\
\hline SP & $0.98^{* * *}$ & 0.96 & $0.24^{* * *}$ & 0.63 \\
\hline EA8 & $0.95^{* * *}$ & 0.95 & $0.27^{* * *}$ & 0.59 \\
\hline
\end{tabular}

I compute the standard deviation for each country and cycle measure. The results are presented in Table 2.14. Since the standard deviation is a scale-dependent statistic, a direct cross-country comparison of numbers is not possible. To circumvent this complication, I rank the countries from lowest to highest amplitude for each cycle measure. The ranks are given in parentheses. This ranking is broadly similar for level and growth cycles (which are based on the same underlying data) and suggests that the financial cycle has the smallest amplitude in Germany and the largest amplitude in Spain. According to the BIS cycle, financial cycle amplitude is smallest in France and largest in Italy. Therefore, the choice of the cycle measure can have a direct impact on the relative financial cycle amplitudes.

\section{Table 2.14 Standard deviation}

\begin{tabular}{|lccc|}
\hline EA8 & BIS cycle $^{\mathbf{1}}$ & Level cycle $^{\mathbf{1}}$ & Growth cycle $^{\mathbf{2}}$ \\
BE & $0.55(1)$ & $0.04(2)$ & $0.02(3)$ \\
FI & $1.03(6)$ & $0.07(4)$ & $0.03(4)$ \\
FR & $0.96(3)$ & $0.08(6)$ & $0.03(5)$ \\
GE & $0.93(2)$ & $0.05(3)$ & $0.02(2)$ \\
IR & $0.99(4)$ & $0.03(1)$ & $0.01(1)$ \\
IT & $1.00(5)$ & $0.09(8)$ & $0.04(8)$ \\
NE & $1.06(9)$ & $0.08(7)$ & $0.03(7)$ \\
SP & $1.05(8)$ & $0.08(5)$ & $0.03(6)$ \\
\hline
\end{tabular}

${ }^{1}$ 1975Q1-2017Q3; ${ }^{2}$ 1976Q1-2017Q3

I now turn to investigating the cross-country synchronisation of financial cycles. For this analysis I compute the simple average of a country's bilateral correlations with its EA counterparts as well as the correlations and concordance of individual countries' cycles with 
the EA8 average. Table 2.15 shows the average bilateral correlations over the sample period. The financial cycles of all countries are on average positively correlated with the financial cycles in the other EA countries. Average bilateral correlations tend to be lowest for the BIS cycle and highest for the growth cycle. For both level and growth cycles, the relationship is weakest for Germany. For the BIS cycle, the relationship is weakest for Finland. France and Spain show the highest average bilateral synchronisation across measures.

\section{Table 2.15 Average bilateral correlations}

\begin{tabular}{|lccc|}
\hline & BIS cycle $^{\mathbf{1}}$ & Level cycle $^{\mathbf{1}}$ & Growth cycle $^{\mathbf{2}}$ \\
BE & 0.38 & 0.39 & 0.49 \\
FI & $\mathbf{0 . 0 2}$ & 0.20 & 0.38 \\
FR & 0.44 & 0.47 & 0.58 \\
GE & 0.22 & $\mathbf{0 . 0 4}$ & $\mathbf{0 . 1 2}$ \\
IR & 0.30 & 0.40 & 0.43 \\
IT & 0.19 & 0.42 & 0.48 \\
NE & 0.37 & 0.39 & 0.43 \\
SP & 0.47 & 0.52 & 0.54 \\
\hline
\end{tabular}

1975Q1-2017Q3; ${ }^{2}$ 1976Q1-2017Q3

The respective correlations and concordance statistics with the EA8 cycle are summarised in Table 2.16. I find the correlations to be positive and significant for all countries except Finland and Germany. The level and growth cycles of Germany are least synchronised with the EA8 average, the correlations are highest in France and Spain. For the BIS cycle, Finland displays lowest synchronicity with EA8, Spain the highest. I obtain similar results from the concordance analysis. Individual countries' cycles spend most of the time in the same phase as the EA8 average. The concordance is lowest for the BIS cycle of Finland and the German level and growth cycles. 
Table 2.16 Correlations and concordance with the EA8 cycle

\begin{tabular}{|c|c|c|c|c|c|c|}
\hline & \multicolumn{2}{|c|}{ BIS cycle $^{1}$} & \multicolumn{2}{|c|}{ Level cycle $^{1}$} & \multicolumn{2}{|c|}{ Growth cycle ${ }^{2}$} \\
\hline & Correlation & Concordance & Correlation & Concordance & Correlation & Concordance \\
\hline BE & $0.70^{* * * *}$ & 0.81 & $0.59^{* * *}$ & 0.80 & $0.69^{* * *}$ & 0.86 \\
\hline FI & 0.03 & 0.52 & $0.38^{* * *}$ & 0.64 & $0.64^{* * *}$ & 0.80 \\
\hline FR & $0.80^{* * *}$ & 0.74 & $0.80^{* * *}$ & 0.90 & $0.89^{* * *}$ & 0.80 \\
\hline GE & $0.40^{* * *}$ & 0.58 & 0.01 & 0.52 & 0.06 & 0.62 \\
\hline IR & $0.55^{* * *}$ & 0.75 & $0.71^{* * *}$ & 0.73 & $0.67^{* * *}$ & 0.82 \\
\hline IT & $0.34^{* * *}$ & 0.67 & $0.71^{* * *}$ & 0.74 & $0.76^{* * *}$ & 0.75 \\
\hline NE & $0.68^{* * *}$ & 0.72 & $0.62^{* * *}$ & 0.74 & $0.60^{* * *}$ & 0.78 \\
\hline SP & $0.86^{* * *}$ & 0.83 & $0.91^{* * *}$ & 0.88 & $0.89^{* * *}$ & 0.80 \\
\hline
\end{tabular}

These results show that the major difference between the various cycle measures are the frequency of the cycles and their amplitudes. The cross-country co-movement analysis produces fairly similar results between the various cycle measures.

I stated earlier that economic cycles are the outcome of a multitude of ex ante decisions and choices. The observed differences between the three analysed cycles are in line with earlier findings. As research results and policy suggestions strongly depend on the aforementioned choices, a careful definition of underlying data and approaches is necessary to put research results into perspective (Égert and Sutherland, 2012; Harding and Pagan, 2005). ${ }^{18}$

\footnotetext{
${ }^{18}$ See also section 2.2.1.
} 


\section{Chapter 3}

\section{Growth at Risk and Financial Cycles in Euro Area Countries}

\subsection{Introduction}

The 2010 euro crisis can be seen as the unavoidable correction of the unsustainable accumulation of several large and long-lasting divergences between euro area (EA) countries (Hessel, 2019). Its impact on economic fluctuations put to the test the mere existence of the European Economic and Monetary Union (EMU). More generally, asymmetries in currency unions pose substantial challenges to economic policy makers. The question of whether EMU constitutes an Optimum Currency Area (OCA) has been on the research agenda for a long time. In practice, research on EMU often focused on the symmetry of shocks (Bayoumi and Eichengreen, 2017; Campos and Macchiarelli, 2016; Coco and Silvestrini, 2017) and the synchronisation of short-term fluctuations, especially business cycle fluctuations with a frequency up to 8 years (Hessel, 2019). However, the literature does not unambiguously answer the question of increasing economic convergence between EA countries. Instead, the answer depends on a multitude of issues, in particular the definition of the underlying time series, the approach to measure fluctuations and the time period under consideration. Most studies report increasing synchronisation after the introduction of the euro (Alcidi et al., 2017; Franks et al., 2018; Chapter 2 of this thesis), but a reduction thereof in the aftermath of the financial crisis (Alcidi et al., 2017; Belke et al., 2016).

The severity of the recent financial crisis has renewed research interest in the linkages between financial markets and the real economy. ${ }^{1}$ Studies like Borio (2012) and Drehmann et al. (2012), for instance, emphasise the role of financial factors in amplifying and prolonging

\footnotetext{
${ }^{1}$ See Claessens and Kose (2018) for a literature review of macro-financial linkages.
} 
economic fluctuations via movements in asset prices, credit and private debt and house prices. Further, my results in Chapter 2 document the importance of macro-financial linkages in EA countries. OCA studies do not generally focus on the existence of macro-financial linkages. The reasons can be understood from a historical perspective. The theory of OCA was developed in the middle of the $20^{\text {th }}$ century in a North American context when banks were more strictly regulated and financial markets were less internationalised than subsequently. The theory was incomplete and misleading in important respects when applied to the circumstances of Europe at the turn of the 21 st century. In particular, the role of cross-border financial flows as a de-stabilising mechanism within a currency union did not receive the attention it deserved (Eichengreen, 2014; Eichengreen, 2018). Alcidi (2017), Granville and Hussain (2017) and WGEM (2018) take first steps to overcome this deficiency. These papers examine the co-movement of business and financial cycles in the EA. I examine macrofinancial linkages in the EA in Chapter 2 in this thesis.

In recent years, a new branch of literature developed linking a measure of financial conditions to the probability distribution of future GDP growth (Adrian et al., 2019; IMF, 2017). Whereas in the past much of economic forecasting concentrated on point estimates for the conditional mean, this recent literature shows an increasing interest in the full distribution of GDP growth and the associated downside risk to growth. One of the main messages of this literature is that the distribution of GDP growth is not stable over time and that higher moments of the distribution are correlated with financial indicators. Further, the correlation between financial conditions and economic activity is found to be stronger in bad times.

The aim of this chapter is to link the concepts of growth at risk (GaR) and OCA for eight EA countries. $^{2}$ In particular, I estimate the impact of the financial cycle on the downside risk to growth and assess its degree of cross-country synchronisation. My empirical analysis closely follows Adrian et al. (2019). I estimate the full distribution of future (one year ahead) real GDP growth as a function of current economic conditions and the financial cycle using the quantile regression method (predicted distribution). I then fit a parametric form skewed tdistribution to smooth the empirical quantile function (conditional distribution). This optimisation process yields the moments - mean, variance, skewness and kurtosis - of the skewed t-distribution. Both predicted and conditional distributions are the basis for my crosscountry analysis. First, I analyse the predicted distributions. In particular, I investigate if the

\footnotetext{
${ }^{2}$ Belgium (BE), Finland (FI), France (FR), Germany (GE), Ireland (IR), Italy (IT), Netherlands (NE) and Spain (SP).
} 
financial cycle signals changes in downside tail risks across countries. Second, I examine the time series properties of the conditional distributions and their first two moments - mean and variance - to assess the degree of cross-country synchronisation between EA countries. Third, similar to Alessandri et al. (2019), I compute the time series of the one year ahead recession probability and compare it across countries.

My analysis adds to the literature along three dimensions. First, unlike other GaR studies (Adrian et al., 2018; Alessandri et al., 2019; IMF, 2017), I use the financial cycle as conditioning variable in the quantile regressions. ${ }^{3}$ The concept refers to the "self-reinforcing interactions between perceptions of value and risk, attitudes towards risk and financing constraints, which translate into booms followed by busts. These interactions can amplify economic fluctuations and possibly lead to serious financial distress and economic dislocations" (Borio, 2014). Research interest in (the definition and computation of) financial cycles and the relationship between financial cycles and the real economy was growing in recent years (see also Chapter 2). Studies like Borio and Drehmann (2009) and Schularick and Taylor (2012) for instance show that there is a tight link between financial crisis and recessions, and credit booms are found to weaken output in the medium run (Mian et al., 2017). The recent financial crisis was caused by a combination of credit bubbles and asset price bubbles, primarily in the real estate sector (Gros and Alcidi, 2010). I conjecture that a financial cycle that captures the movements in those markets can help predict downside risks in real GDP growth. Indeed, Borio et al. (2018) find that medium term fluctuations in credit and property prices capture well those periods that have proven more damaging for economic activity and could therefore be helpful for gauging recessions. Second, my analysis focuses uniquely on individual EA countries and cross-EA comparison. I am not aware of any study doing GaR cross-country analysis with this geographic focus. Third, I use the results from $\mathrm{GaR}$ analysis to assess the degree of economic synchronisation between EA countries in the spirit of OCA theory. It is an attempt to introduce a financial component into OCA analysis. While I estimate the quantile regressions for the period 1975Q1-2017Q3, my analysis focuses on the euro period. In particular, I am interested in a comparison between the pre-crisis period (1999Q1-2007Q4) and the crisis period (2008Q1-2017Q3). There are two general

\footnotetext{
${ }^{3} \mathrm{GaR}$ studies generally use a Financial Conditions Index (FCI) as conditioning variable. These indexes summarise the immediate impact of the central bank's policy instruments on financial prices. This, in turn, can be related to future output and inflation through the usual channels of the transmission mechanism. Financial prices reflect wealth, which enters into key consumption and investment relationships and they incorporate market expectations of future price and output developments (Mayes and Virén, 2001).
} 
observations. First, unlike Adrian et al. (2019), I find that the financial cycle includes information about both downside and upside risks to future economic growth. Second, in line with the findings in Adrian et al. (2019), the time series movements in conditional mean (conditional variance) are negatively (positively) related to the fluctuations in the financial cycle.

Based on a more thorough analysis of the conditional moments and recession probabilities, I identify two groups of countries: the core group (Belgium, France, Germany, Netherlands) and the periphery group (Finland, Ireland, Italy, Spain). ${ }^{4}$ Booming financial cycles in the early euro period translated into continuously declining conditional means, increasing conditional variances and rising recession probabilities, primarily in the periphery. This suggests that the financial crisis loomed for a long time in periphery countries without being reflected in actual economic performance. I do not identify a similar trend in the core countries, possibly as a result of differences in growth persistence between core and periphery countries as well as the lack of financial cycle synchronisation between the two groups of countries. I find recession probabilities in periphery countries to be on average much lower in the pre-crisis period compared with the crisis period, while they are relatively constant over time in the core countries. The maxima of the forward-looking recession probabilities pick up the actual recessions in the sample and these maxima generally turn out to be higher in periphery countries. In the aftermath of the crisis, the trend in conditional mean growth and recession probabilities reverses in the periphery countries. Both correlations and dispersion of conditional means and recession probabilities between all countries are higher in the crisis period than in the pre-crisis period. Germany's predicted economic development is disconnected from that in the rest of the EA in the crisis period. Hence, the results give no straightforward indication of economic convergence between countries.

The remainder of the chapter is structured as follows. The related literature is summarised in Section 3.2. Section 3.3 describes the empirical methodology. Section 3.4 presents the data and stylised facts. The empirical results are discussed in Section 3.5. Section 3.6 concludes.

\footnotetext{
${ }^{4}$ The empirical results show that France cannot be assigned unconditionally to either of the two groups. Following the convention in the literature (see for instance Alcidi et al. (2017) or Belke et al. (2016)), I assign France to the group of core countries.
} 


\subsection{Related Literature}

In this section, I review the related literature on optimum currency areas and growth at risk. I first summarise the literature on the synchronisation of economic fluctuations in the EA. I then present the results from the $\mathrm{GaR}$ literature.

\subsubsection{Optimum currency areas}

An abundant literature investigates economic convergence between EA countries in the spirit of OCA theory. This literature review focusses on the synchronisation (co-movement and dispersion) of EA business cycle fluctuations which presents the most popular approach to verify OCA criteria in the EA. ${ }^{5}$ The studies generally cover and compare either the pre- and post-euro periods to investigate the endogenous forces of monetary union (Alcidi et al., 2017; Gogas, 2013; Gonçalves et al., 2009;) or the pre- and post-crisis periods (Alcidi et al., 2017; Belke et al., 2016; Grigoraş and Stanciu, 2016; Weyerstrass et al., 2011).

I first review those studies which examine the degree of co-movement between EA economies. For pre-/post-euro comparisons, Alcidi et al. (2017) find that the introduction of the euro increased the synchronisation of core and periphery countries with the EA-12 cycle, Gonçalves et al. (2009) detect a rise in cross-country correlations after 1999, and Gogas (2013) finds higher correlations between individual countries and the G3 aggregate - consisting of France, Germany, and Italy - in the period after 1999. Weyerstrass et al. (2011) investigate output gaps and real GDP growth and find increasing correlations between individual countries and the EA-12 aggregate in the euro period. Furceri and Karras (2008) compare various de-trending methods and find rising synchronisation of cyclical output between individual member states and EA-wide cyclical output. The concordance analysis by Franks et al. (2018) also shows an increase in synchronisation after 1999. Chapter 2 in this thesis reports that both business and financial cycles are closely related between EA countries and that the synchronising effect of the euro is stronger in real than in financial markets.

However, the positive impact of the euro's introduction on co-movement is not confirmed by all studies. Ahmed et al. (2018) observe a reduction in co-movement for business cycles computed from industrial production data. The moving window analysis by Weyerstrass et al. (2011) does not confirm increased business cycle synchronisation in the euro period. Granville

\footnotetext{
${ }^{5}$ The most common measures of co-movement are the correlation coefficient and the concordance statistic. The standard deviation is a common measure of dispersion.
} 
and Hussain (2017) present conflicting results. They show an increase in the average concordance between growth cycles over the considered time period, but a decrease in the average concordance between classical cycles starting in the pre-euro period. Hence, deviations from the trend became more synchronised relative to the trends. Hessel (2019) studies the size and symmetry (measured as synchronicity and similarity) of short- and medium-term fluctuations in business cycles. They find that medium-term fluctuations have become larger and less symmetric over time compared with short-term fluctuations. This result differs across countries: while medium- and short-term fluctuations are of approximately the same size in Belgium, France and Germany, medium-term fluctuations exceed short-term fluctuations in countries with macroeconomic imbalances, like Greece, Ireland, Portugal and Spain. Further, medium-term fluctuations in the EA are less symmetric than short term fluctuations: while the synchronicity of medium-term fluctuations is comparable to the synchronicity of short-term fluctuations, differences in the amplitudes of medium-term fluctuations are substantially less similar than short-term fluctuations.

For pre-/post-crisis developments in co-movement, Alcidi et al. (2017) find that the degree of symmetry between national output cycles in the peripheral countries and the EA-12 cycle was dampened in the aftermath of the financial and economic crisis. Likewise, Belke et al. (2016) show that co-movement patterns have changed after the eruption of the financial crisis. Whereas core countries were growing stronger together as a group since the financial crisis, peripheral countries were less aligned among themselves and relative to the core. Gächter et al. (2012) also find that EA business cycles have de-synchronised since the most recent financial crisis, and Duran and Ferreira-Lopes (2017) show that the mean correlation increased until 2008 and fell thereafter. Van Beers et al. (2014) find a strong convergence effect in the euro period until the onset of the financial crisis. They conclude that synchronisation among EA countries decreased since the start of the crisis but is still larger than before the euro's introduction. To the contrary, the concordance analysis by Franks et al. (2018) indicates a sharp rise in synchronisation in the post-2008 period. De Grauwe and Ji (2016) separate longterm growth and the short-term variation (business cycle) using the HP filter. The results show a decline in long term growth of GDP in all countries (except Germany) and great variability in the temporary component of GDP. The cyclical movements are highly correlated between countries. The intensity of the boom-bust dynamics is found to be asymmetric, i.e. business cycle fluctuations are more volatile in peripheral countries. This asymmetry increased in boom years until the crash and then declined dramatically. 
I now turn to studies which investigate the dispersion of business cycles. Franks et al. (2018) show that while business cycles became more synchronised over time, the size of the fluctuations diverged. Gächter et al. (2012) identify a rise in the standard deviation of bilateral correlation coefficients since early 2007 and this rise was largely driven by smaller countries. Duran and Ferreira-Lopes (2017) find increasing GDP dispersion after 2008. Belke et al. (2016) also show that the standard deviation of national business cycles increased after the outbreak of the crisis in both core and peripheral countries. Alcidi et al. (2017) show that booms and recessions between the group of core and peripheral countries compared to the EA-12 average were of similar magnitude, but they find a notable degree of heterogeneity within both groups of countries. My own finding in Chapter 2 suggests that there was no clear trend before and after the euro period towards cross-country convergence in amplitudes of either business or financial cycles.

To sum, the empirical evidence for synchronisation between EA business cycles is mixed and the results depend on the set up of the research in terms of countries under investigation, the underlying data and the employed methods. There are signs that the euro promoted synchronisation of business cycles across EA countries and that the financial crisis reversed this trend. Differences in amplitudes between cycles have at best not increased.

\subsubsection{Growth at risk}

The concept of Growth at Risk $(\mathrm{GaR})$ which summarises the expected maximum economic downturn over a target horizon at a given confidence level was introduced by Wang and Yao (2001). The authors construct a panel set on GaR for 84 countries over the period 1980-1998 based on the empirical distribution of growth rates and investigate the relationship between downside risks and long-term average growth in a cross-country analysis. Perceived levels of downside growth risk are found to be negatively associated with long-term growth.

$\mathrm{GaR}$ has become an increasingly popular topic in economic research in recent years. The empirical implementation consists of a two-step procedure involving quantile regression estimation and smoothing using the skewed t-distribution to model the full distribution of future real GDP growth as a function of current economic and financial conditions. Typically, financial conditions are approximated by a financial conditions index (FCI). The studies generally find that movements in the FCI are powerful signals of changes in downside tail risk, but that they are less informative about the baseline growth outlook and the strength of economic booms (Adrian et al., 2019; IMF, 2017). Adrian et al. (2019) find that the probability distribution of real GDP growth evolves over time and that deteriorating financial conditions 
are associated with a decline in the conditional mean and an increase in the conditional volatility of real GDP growth. Further, most of the explanatory power of future GDP vulnerability arises from the information content of financial conditions while economic conditions are uninformative for predicting tail outcomes. IMF (2017) investigates 21 advanced $^{6}$ and emerging market economies over the near and medium term (one quarter, four quarters, 12 quarters). The results reveal heterogeneity in the information content of financial conditions for growth risks across forecasting horizons and countries. Asset prices are most informative about risks to growth in the short term, while credit aggregates provide information over the longer time horizon. Changes in a country's financial conditions shift the distribution of future GDP growth in both advanced and emerging market economies. Alessandri et al. (2019) study the relationship between financial conditions and economic activity in Italy. The analysis investigates a broad set of financial indicators. The paper evaluates the performance of the baseline models against two benchmark models - namely a model with intercept and an AR(1) model. When compared to the intercept benchmark model, the baseline models show strong evidence of time variation in tail risk affecting the left tail but not the right tail of the distribution. Controlling for the autoregressive term of the target results in smaller gains confined to only a small number of financial indicators. Unlike in Adrian et al. (2019), this suggests that many fluctuations in 'tail risk' in the data are explained by the dynamics of the economic activity indicators. In a forecasting exercise, the paper further analyses the performance of the FCI in the estimation of growth risk. The average recession probability is found to be high reflecting the weakness of the Italian economy over the sample period. Adrian et al. (2018) investigate the term structure of GaR over a projection horizon of 1 to 12 quarters using panel quantile regression. The results indicate that the impact of financial conditions on the GaR term structure depends on the initial conditions (FCI and credit market), the forecasting horizon and the set of countries under consideration. GaR conditional on high FCI and a credit boom is found to be higher in the near term but lower in the medium term relative to GaR conditional on average FCI. Median or upper tail are less responsive to financial conditions than the lower tail.

This review suggests that the predictive power of financial conditions depends on the definition of the financial conditions indicator, the forecasting horizon and the country under

\footnotetext{
${ }^{6}$ From my sample, the analysis includes France, Germany, Italy and Spain.
} 
consideration. In general, FCI are found to be powerful signals of changes in downside tail risk and their changes shift the distribution of GDP.

\subsection{Methodology}

My empirical methodology closely follows Adrian et al. (2019). In this section, I briefly outline their approach, but I refer to their paper for a more detailed exposition. I estimate a set of 19 quantile regressions for each country in the sample to characterise the conditional relationship between future real GDP growth and current financial and economic conditions as

$$
y_{t+h}=x_{t} \beta_{\tau}+\varepsilon_{t}
$$

I denote by $y_{t+h}$ the annualised average growth rate of real GDP between $t$ and $t+h$, computed as $y_{t+h}=\sum_{i=1}^{h} \frac{y_{t+i}}{h}$, where $y_{t+i}$ is the annualised quarterly growth rate at $t+i$ and $h$ is the forecasting horizon. In this chapter, I investigate the one-year ahead predicted distribution $(h=4), x_{t}$ is a vector containing the conditioning variables, namely current quarter real GDP growth and the financial cycle, and a constant. $\beta_{\tau}$ is a vector of quantile regression coefficients for $\tau \epsilon\{0.05,0.1, \ldots, 0.95\}$. I choose the regression slope $\beta_{\tau}$ to minimise the quantile weighted absolute value of errors

$$
\hat{\beta}_{\tau}=\underset{\beta_{\tau} \in \mathbb{R}^{k}}{\operatorname{argmin}} \sum_{t=1}^{T-h}\left(\tau \cdot \mathbf{1}_{\left(y_{t+h} \geq x_{t} \beta\right)}\left|y_{t+h}-x_{t} \beta_{\tau}\right|+(1-\tau) \cdot \mathbf{1}_{\left(y_{t+h}<x_{t} \beta\right)}\left|y_{t+h}-x_{t} \beta_{\tau}\right|\right)
$$

where $\mathbf{1}_{(\cdot)}$ denotes the indicator function. The quantile regression gives an approximate estimate of the conditional quantile function, which is an inverse cumulative distribution function, $h$ quarters ahead

$$
\hat{Q}_{y_{t+h} \mid x_{t}}\left(\tau \mid x_{t}\right)=x_{t} \hat{\beta}_{\tau}
$$

These estimates of the quantile function are found to be noisy in practice and recovering the corresponding probability density function requires its smoothing. I achieve this by fitting a parametric form skewed t-distribution. For each quarter, I chose the four parameters 
$\left\{\mu_{t}, \sigma_{t}, \alpha_{t}, v_{t}\right\}$ of the skewed t- distribution $f(y ; \mu, \sigma, \alpha, v)^{7}$, i.e. location $\left(\mu_{t}\right)$, scale $\left(\sigma_{t}\right)$, shape $\left(\alpha_{t}\right)$ and fatness $\left(v_{t}\right)$ to minimise the squared distance between the estimated quantile function $\hat{Q}_{y_{t+h} \mid x_{t}}(\tau)$ and the quantile function of the skewed t-distribution $F^{-1}(\tau ; \mu, \sigma, \alpha, v)$ to match the $5,25,75$ and 95 percent quantiles:

$$
\left\{\hat{\mu}_{t+h}, \hat{\sigma}_{t+h}, \hat{\alpha}_{t+h}, \hat{v}_{t+h}\right\}=\underset{\mu, \sigma, \alpha, v}{\operatorname{argmin}} \sum_{\tau}\left(\hat{Q}_{y_{t+h} \mid x_{t}}\left(\tau \mid x_{t}\right)-F^{-1}(\tau ; \mu, \sigma, \alpha, v)\right)^{2}
$$

where $\hat{\mu}_{t+h} \in \mathbb{R}, \hat{\sigma}_{t+h} \in \mathbb{R}^{+}, \hat{\alpha}_{t+h} \in \mathbb{R}$, and $\hat{v}_{t+h} \in \mathbb{Z}^{+}$. This can be viewed as an exactly identified nonlinear cross-sectional regression of the predicted quantiles on the quantiles of the skewed t-distribution.

In my empirical analysis I am further interested in computing the probability that a country will fall into a recession over the forecasting horizon, along the lines of Alessandri et al. (2019). My approach thus differs from Adrian et al. (2019) and Wang and Yao (2001), for instance. These studies look at the expected maximum economic downturn ('shortfall') over the forecasting horizon for a chosen target probability. I proceed as follows. First, I evaluate the estimated probability density function (PDF) each period over a constant interval $\left[1.2 \min _{t \leq T}\left(y_{t}\right), 1.2 \max _{t \leq T}\left(y_{t}\right)\right]$ at equally spaced observations $\delta$, defined as $\delta=$ $1.2\left[\max _{t \leq T}\left(y_{t}\right)-\min _{t \leq T}\left(y_{t}\right)\right] / 1000$. Second, based on this evaluation of the PDF, I approximate the cumulative density function (CDF) in a discrete way. Let $\kappa$ be the number of $y_{k}$ for which $y_{k} \leq 0$. Then in each period, the recession probability is given as

$$
\operatorname{Prob}\left(y_{k} \leq 0\right)=F\left(y_{k}\right)=\kappa \cdot \delta \cdot \sum_{k=1}^{\kappa} f\left(y_{k}\right)
$$

These computations yield the time series of recession probabilities for each country.

\subsection{Data and stylised facts}

The analysis covers eight EA countries: Belgium (BE), Finland (FI), France (FR), Germany (GE), Ireland (IR), Italy (IT), Netherlands (NE) and Spain (SP) over the period 1975Q12017Q3. I use the data from Chapter 2 in this chapter. For each country, the dataset includes

${ }^{7} f(y ; \mu, \sigma, \alpha, v)=\frac{2}{\sigma} t\left(\frac{y-\mu}{\sigma} ; v\right) T\left(\alpha \frac{y-\mu}{\sigma} \sqrt{\frac{v+1}{v+\left(\frac{y-\mu}{\sigma}\right)^{2}}} ; v+1\right)$, where $t(\cdot)$ denotes the PDF and $T(\cdot)$ denotes the CDF of the Student t-distribution. 
two variables, the annualised quarter-by-quarter growth rate of real GDP and the domestic financial cycle. ${ }^{8}$

Table 3.1 Descriptive statistics

\begin{tabular}{|lcccccccc|}
\hline $\boldsymbol{y}_{\boldsymbol{t}+\boldsymbol{h}}$ & $\mathbf{B E}$ & $\mathbf{F I}$ & $\mathbf{F R}$ & $\mathbf{G E}$ & $\mathbf{I R}$ & $\mathbf{I T}$ & $\mathbf{N E}$ & SP \\
mean & 1.65 & 1.56 & 1.40 & 1.43 & 4.26 & 0.44 & 1.63 & 1.90 \\
$\max$ & 6.18 & 13.29 & 4.95 & 8.11 & 27.23 & 6.12 & 6.91 & 6.33 \\
$\min$ & -8.46 & -28.17 & -6.70 & -18.36 & -15.69 & -11.16 & -12.87 & -6.45 \\
std & 2.21 & 5.02 & 1.92 & 3.37 & 8.17 & 2.87 & 2.81 & 2.76 \\
\hline $\boldsymbol{F} \boldsymbol{C}_{\boldsymbol{t}}$ & $\mathbf{B E}$ & $\mathbf{F I}$ & $\mathbf{F R}$ & $\mathbf{G E}$ & $\mathbf{I R}$ & $\mathbf{I T}$ & $\mathbf{N E}$ & $\mathbf{S P}$ \\
mean & 0.01 & 0.00 & 0.00 & 0.00 & 0.03 & 0.00 & 0.01 & 0.02 \\
$\max$ & 0.03 & 0.08 & 0.06 & 0.05 & 0.18 & 0.12 & 0.08 & 0.24 \\
$\min$ & -0.04 & -0.10 & -0.08 & -0.04 & -0.14 & -0.14 & -0.09 & -0.17 \\
std & 0.03 & 0.06 & 0.04 & 0.03 & 0.10 & 0.08 & 0.06 & 0.14 \\
\hline
\end{tabular}

Sample period: 1999Q1-2017Q3. Observations: 75

The descriptive statistics of the data are summarised in Table 3.1. Although I estimate the quantile regressions over the entire sample period, the focus of my analysis in this chapter is on the euro period. The table therefore gives the descriptive statistics for the euro period only. ${ }^{9}$ It shows that although the mean growth rates of real GDP are broadly similar across countries, there are two extreme exceptions. At the one extreme, Ireland's ${ }^{10}$ mean growth rate is about 2.5 times larger than in the average EA country. Growth in Ireland was primarily driven by a large number of multinational companies which have generated the lion's share of growth. (OECD, 2008; OECD, 2015a). At the other extreme, Italy's mean growth rate is only about one third of the average EA countries' growth rates, reflecting the comparative weakness of the Italian economy. Deep-seated structural problems led to stagnant productivity and worsening cost competitiveness (OECD, 2015b). The specialisation in traditional low-skill products further contributed to declining international competitiveness and a difficulty to cope with the shock of globalisation (OECD, 2007). Correspondingly, GDP growth is most volatile in Ireland over the sample period. Finland experienced the largest one-time contraction in real GDP growth: its minimum growth rate was more than four times as large in absolute terms as

\footnotetext{
${ }^{8}$ I apply the frequency-based Christiano-Fitzgerald (CF) filter to compute composite medium-term (32-120 quarters) financial cycles using credit, credit to GDP and real house price data. Nominal credit data are deflated by the CPI.

${ }^{9}$ Descriptive statistics for the period 1975Q2-2017Q3 are presented in Table 3.6 in Appendix I.

${ }^{10}$ The original series of Ireland displayed an outlier in 2015 when real GDP growth jumped to almost $79 \%$ in one quarter. Attracted by low corporation tax rates, a number of large multinational corporations relocated their economic activities, and more specifically their underlying intellectual property, to Ireland (OECD (2016). I corrected for this outlier by linear interpolation.
} 
the minimum growth rate in crisis country Spain, which shows the smallest minimum growth rate in absolute terms. Declining exports are the main reason for the major drop in Finnish output (OECD, 2010). ${ }^{11}$ By construction, the financial cycles fluctuate around zero. The Irish and Spanish financial cycles are most volatile.

The graphs for annualised quarterly real growth and the financial cycle are presented in Figure 3.1. Real GDP growth is measured on the left axis and the financial cycle is measured on the right axis. The graphs cover the entire sample period, but I am most interested in the euro period starting in 1999. Financial cycles in Finland, France, Ireland, Italy and Spain have increased since the start of the monetary union and their contraction started with the onset of the 2008/09 economic downturn. To the contrary, the financial cycles in Belgium, Germany and the Netherlands contracted after the euro's introduction and were therefore out of sync with the former countries in the early years of EMU. Financial cycles appear more synchronised in the crisis period, with the exception of Germany. ${ }^{12}$ All countries experience a more or less serious dip in economic growth around the time of the 2008 financial crisis. While I detect severe short contractions in Finland and Germany, I observe extended economic contractions in Italy and Spain.

\footnotetext{
${ }^{11}$ Between 2008 and 2009, trade volumes dropped by almost 30\%. Besides a high degree of openness, this reflects the structure and destination of exports. Two-fifth of exports are from ICT industries with high income elasticities and one-tenth of exports were destined to Russia, which was severely affected by the crisis. Further, a strong euro in the period prior to the downturn further contributed to the decline in export volume given the large share of Finland's trade outside of the EA (OECD (2010).

${ }^{12}$ Footnote 14 explains the German peculiarities.
} 
Figure 3.1 Real GDP growth rates and financial cycles
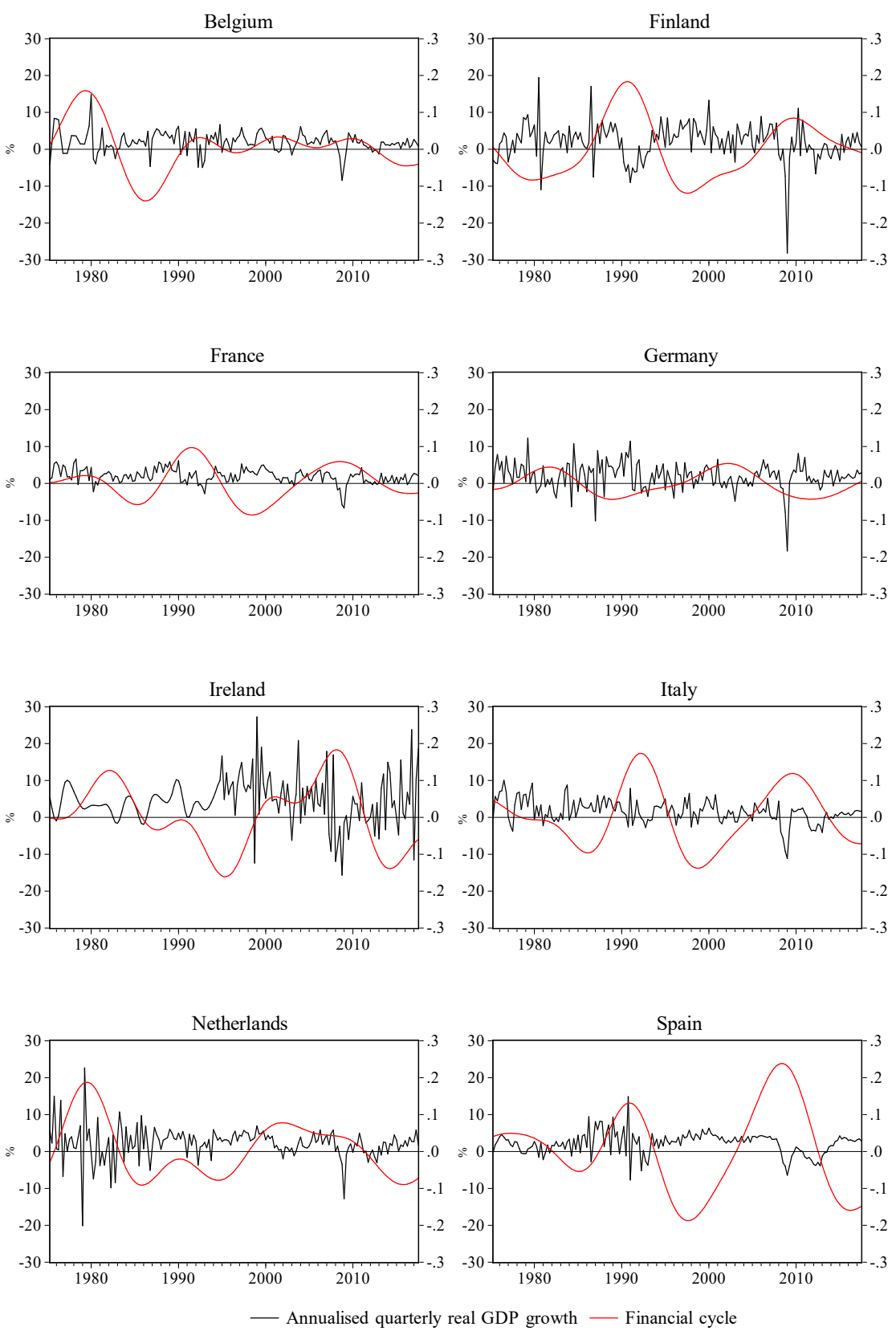

The figure shows the time series of the annualised quarterly growth rates of real GDP and the financial cycles. Growth rates of real GDP are measured on the left axis, the financial cycles are measured on the right axis. 


\subsection{Empirical results}

In this section, I present the results of my estimations. The first part discusses the findings from quantile estimation. ${ }^{13}$ The second part presents the smoothed predicted growth distributions. I perform a cross-country comparison of the distribution parameters conditional means and variances - and recession probabilities in the spirit of OCA theory.

\subsubsection{Quantile regression results}

In Figure 3.2 I display the one-year ahead predicted distributions of real GDP growth from equation (3.3). These are based on the quantile regression results with current real GDP growth and the financial cycle as conditioning variables (equation (3.1)). The figure shows the realised four-quarter ahead real GDP growth together with its conditional median for all eight countries in the sample. The shaded areas indicate the predicted distribution between the 5 percent quantile (lower limit) and the 95 percent quantile (upper limit). The figure also displays the financial cycle. Clearly, the predicted distributions are not constant over time: fluctuations in the limits of the shaded area indicate that either the upper or the lower tail of the distribution, or in some countries both, are time varying. These fluctuations are heterogeneous across countries and appear to be countercyclical to the fluctuations in the financial cycle if they appear.

Depending on the country under consideration, the financial cycle can carry information about both downside and upside risks to future economic growth and the fluctuations in the median can be quite large. This finding is in contrast to Adrian et al. (2019) who show that the dependence of future real GDP on current financial conditions is stronger for the lower quantiles of the distribution than for the upper quantiles. Also, IMF (2017) finds that movements in the global FCI are powerful signals of changes in downside tail risks to global GDP and claim that the baseline growth outlook and the strength of booms are considerably less responsive to changes in the FCI.

I identify three groups of countries. In the first group (FI, FR, IR), the financial cycle affects both the lower and upper quantiles of the predicted distribution. Figure 3.2 suggests that the predicted downside risk to growth is highest (in absolute terms) in the immediate aftermath of a financial cycle peak and that the predicted upper tail growth simultaneously declines as

${ }^{13}$ The coefficients of the quantile regression are an intermediate step in the computation of the conditional distribution. I refer to Appendix II for their presentation and discussion. 
Figure 3.2 Predicted distributions
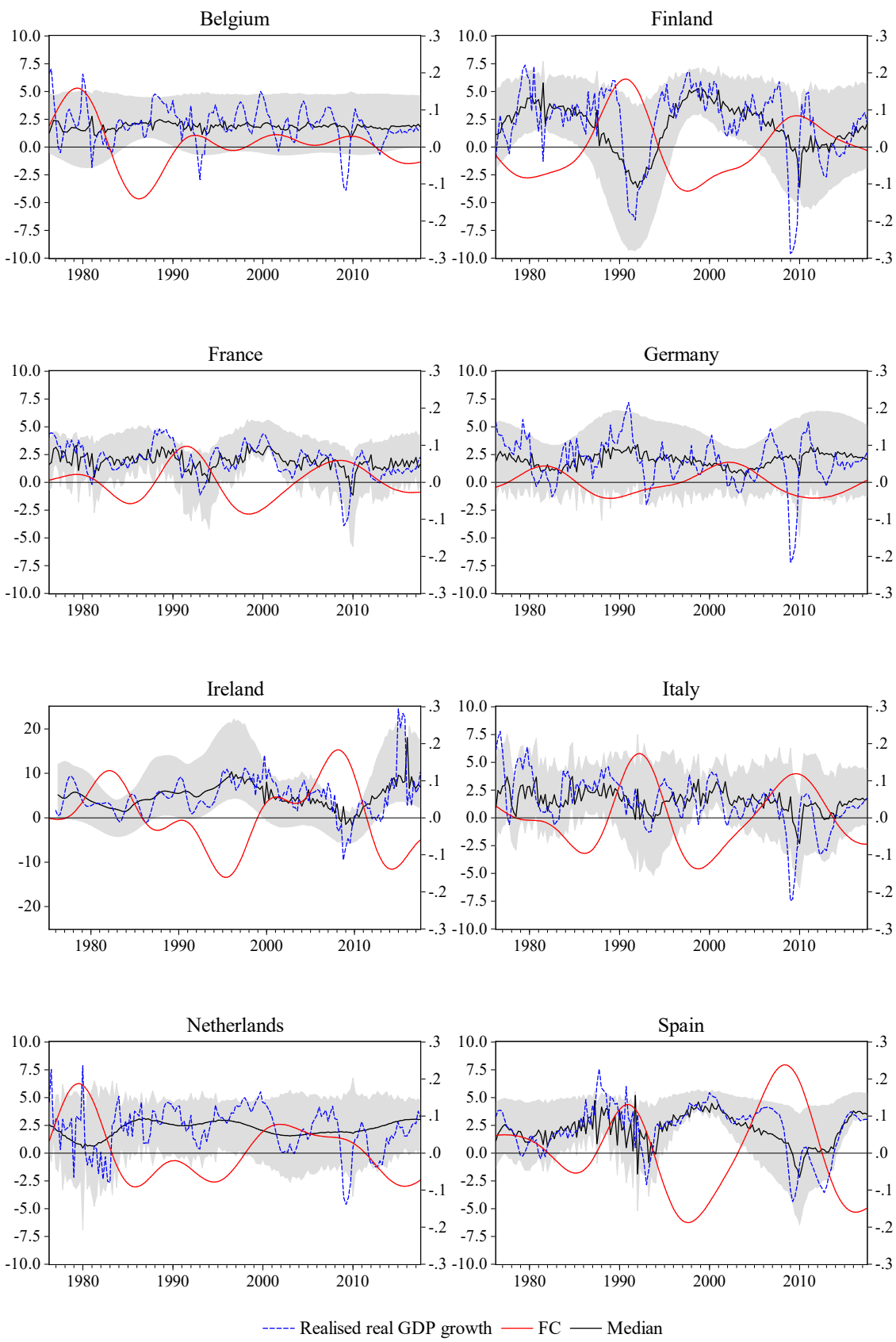

The figure shows the time series evolution of the predicted distribution of fourquarters-ahead real GDP growth $(t+4)$ evaluated at $t$, measured on the left axis. The shaded area gives the predicted distribution between the $5 \%$ and the $95 \%$ quantiles. Financial cycles are measured on the right axis. 
Figure 3.3 Distribution of real GDP growth over time

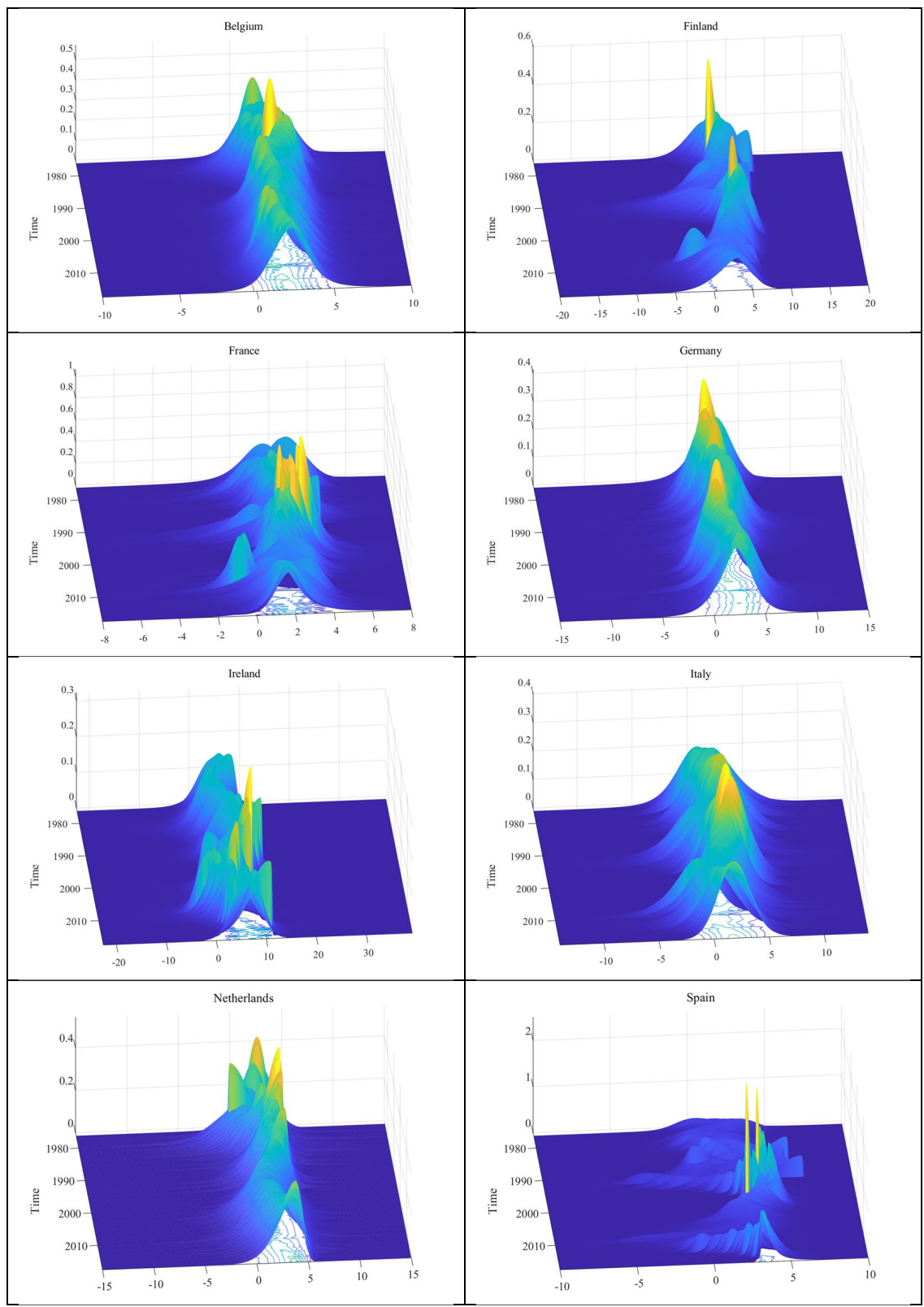

The figure shows the one-year-ahead conditional distribution of real GDP growth, based on quantile regressions with current real GDP growth and financial cycle as conditioning variables. 
the entire distribution shifts downwards. In the second group (BE, IT, NE, SP), only the lower quantiles seem to be affected. This suggests that an increase in the financial cycle signals increasing downside risk to future GDP growth while upper tail growth appears to be largely unaffected. In the third group (GE), the financial cycle carries information about the upside risk of future GDP growth, while the lower quantiles of the distribution are relatively unaffected by financial cycle fluctuations. The results therefore indicate asymmetries in predicted growth distributions across EA countries which I am going to examine in the next section.

\subsubsection{Conditional GDP distribution}

For the main analysis of the chapter, I smooth the estimated quantile distribution every quarter as described in equation (3.4) using the skewed t-distribution. This optimisation procedure yields the time series of the conditional mean, variance, skewness and kurtosis, which are used to recover the conditional distributions of real GDP growth over time (Figure 3.3). The densities confirm that the conditional GDP distributions are time varying (Adrian et al., 2019) and heterogeneous across countries. The distributions appear to be more stable over time in Belgium, Germany and the Netherlands than in the rest of the EA. I am interested in investigating more thoroughly these distributions across countries and use the first two estimated moments - conditional mean and variance - from equation (3.4) for cross-country comparison. Thus, it is possible to gain further insights into similarities and differences in growth prospects and uncertainty between EA countries. In addition to analysing conditional mean and variance, I compute the probability that a country will encounter a recession and compare this probability across countries (equation (3.5)). In my analysis, I focus on the euro period, 1999Q1-2017Q3 and compare the two sub-periods 1999Q1-2007Q4 (pre-crisis period) and 2008Q1-2017Q3 (crisis-period).

\subsubsection{Conditional Mean}

I start with a graphical analysis and plot the time series for the conditional means of GDP growth for all eight countries over the period 1999Q1-2017Q3 (Figure 3.4). The panel on the left shows the core countries (BE, FR, GE, NE) and the panel on the right shows the periphery countries (FI, IR, IT, SP). The graphs indicate that, in general, core countries' conditional means tend to be relatively stable over time until the onset of the financial crisis. Only France shows a moderate decline in its conditional mean growth in the early euro period. In contrast, periphery countries' conditional means steadily decline after the euro's introduction. During 
the financial crisis, the conditional means drop more or less seriously in all countries and over various quarters. While they turn negative in the periphery countries and France, the reduction is comparatively small in Belgium, Germany and the Netherlands. Mean growth prospects increase in the aftermath of the financial crisis to approximate pre-crisis levels in the core countries. In the periphery countries, this increase is very pronounced in Ireland. Italy and Spain, to the contrary, experience an extended period of low conditional mean growth until the end of the sovereign debt crisis around 2014. Overall, these findings suggest that signs of the crisis are visible in the peripheral countries since the start of the euro as decreasing conditional mean growth. To the contrary, there is no indication of an imminent crisis in the core countries.

Figure 3.4 Conditional mean
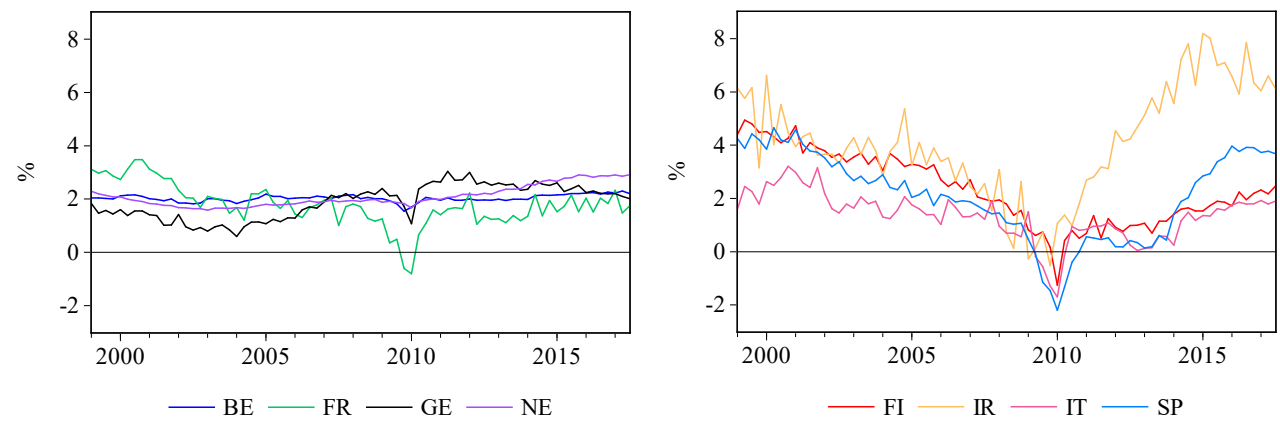

I continue with a more formal analysis of the conditional means. Table 3.2 presents the descriptive statistics of the series. Conditional mean growth is on average two times higher in Ireland over the sample period than in the other EA countries. This result is in line with the findings of Table 3.1. At the same time, its variance is largest among the eight EA countries, followed by Spain. In Belgium, the conditional mean is most stable over the sample period. Mean growth is predicted to be negative in the four periphery group countries and France during the financial crisis.

Table 3.2 Descriptive statistics - conditional mean

\begin{tabular}{|lcccccccc|}
\hline & BE & FI & FR & GE & IR & IT & NE & SP \\
mean & 2.03 & 2.33 & 1.79 & 1.88 & 4.09 & 1.35 & 2.09 & 2.09 \\
$\max$ & 2.30 & 4.94 & 3.48 & 3.03 & 8.19 & 3.20 & 2.91 & 4.65 \\
$\min$ & 1.54 & -1.26 & -0.81 & 0.60 & -0.52 & -1.70 & 1.59 & -2.20 \\
std & 0.13 & 1.35 & 0.78 & 0.64 & 2.06 & 0.91 & 0.40 & 1.63 \\
\hline
\end{tabular}

Sample period: 1999Q1-2017Q3. Observations: 75 
When I compare this result with the upper part of Table 3.1, I see that the estimated conditional mean is higher, and the related standard deviation is lower. While the results in Table 3.1 assume a symmetric distribution, the distributions in Table 3.2 are constructed to allow for skewness. If the distributions are negatively skewed, the means tend to be higher on average. In section 3.2.1, I summarise the literature on OCAs and on economic convergence in the EA. Numerous papers investigate economic convergence in terms of the correlation of short-term and medium-term economic fluctuations and the dispersion of business cycles. Following the empirical approaches in this literature, I investigate cross-country convergence in terms of correlation and dispersion of the estimated conditional mean growth outlook.

\section{Table 3.3 Cross-country correlations of conditional mean}

\begin{tabular}{|lccccccc|}
\hline 1999Q1-2007Q4 & BE & FI & FR & GE & IR & IT & NE \\
FI & -0.12 & & & & & & \\
FR & 0.22 & $0.78^{* * *}$ & & & & & \\
GE & $0.59^{* * *}$ & -0.29 & 0.11 & & & & \\
IR & 0.08 & $0.74^{* * *}$ & $0.60^{* * *}$ & -0.13 & & & \\
IT & 0.19 & $0.63^{* * *}$ & $0.78^{* * *}$ & 0.04 & $0.47^{* * *}$ & & \\
NE & $0.55^{* * *}$ & 0.29 & $0.49^{* * *}$ & $0.71^{* * *}$ & $0.37^{* *}$ & 0.22 & \\
SP & -0.12 & $0.90^{* * *}$ & $0.85^{* * *}$ & -0.14 & $0.64^{* * *}$ & $0.72^{* * *}$ & $0.34^{* *}$ \\
\hline 2008Q1-2017Q3 & $\mathbf{B E}$ & FI & FR & GE & IR & IT & NE \\
FI & $0.87^{* * *}$ & & & & & & \\
FR & $0.81^{* * *}$ & $0.76^{* * *}$ & & & & & \\
GE & 0.23 & 0.18 & $0.57^{* * *}$ & & & & \\
IR & $0.69^{* * *}$ & $0.62^{* * *}$ & $0.60^{* * *}$ & 0.23 & & & \\
IT & $0.92^{* * *}$ & $0.83^{* * *}$ & $0.85^{* * *}$ & $0.37^{* * *}$ & $0.60^{* * *}$ & & \\
NE & $0.80^{* * *}$ & $0.76^{* * *}$ & $0.61^{* * *}$ & 0.10 & $0.90^{* * *}$ & $0.74^{* * *}$ & \\
SP & $0.91^{* * *}$ & $0.89^{* * *}$ & $0.71^{* * *}$ & 0.05 & $0.75^{* * *}$ & $0.87^{* * *}$ & $0.91^{* * *}$ \\
\hline$\left.\left.* * *\right|^{* *}\right|^{*}$ indicate significance at the $1 \% / 5 \% / 10 \%$ level. & & & \\
\hline
\end{tabular}

Table 3.3 shows the cross-country correlations for the pre-crisis and for the crisis period. I report that, overall, correlations are higher in the crisis period suggesting greater co-movement in the countries' growth outlooks during economic contractions. Yet, the size and signs of the correlations indicate asymmetries between individual EA countries in each period. I find that the correlations within the two groups - core and periphery - are higher than the correlations between the two groups in the pre-crisis period. An exception is France, which is more highly correlated with periphery group countries than with the other core countries. In the crisis period, conditional mean growth is generally highly correlated between all countries, with the 
exception of Germany. ${ }^{14}$ Hence, my earlier division of the countries into core and periphery is no longer valid in the crisis period.

While the correlation coefficient measures the strength of the relationship (co-movement) between two time series, it does not give information about their similarity in size. Large differences in the sizes of the conditional means pose challenges to economic policy makers. I compute the cross-country standard deviation of the conditional mean growth rates to see if their sizes converge over time (Figure 3.5). The main message of the figure is that there is no clear continuous trend towards convergence or divergence of conditional mean growth over the sample period. Instead, I identify periods of convergence and divergence. Until the crisis, I find strong signals of convergence - which might possibly be wrong signals based on imbalances in other dimensions. During the crisis and its aftermath, dispersion starts increasing again and returns to pre-euro levels. This is in line with the findings in Belke et al. (2016) and Duran and Ferreira-Lopes (2017), for instance, who report increasing dispersion in GDP after the outbreak of the crisis.

\section{Figure 3.5 Cross-country standard deviation of conditional mean growth}

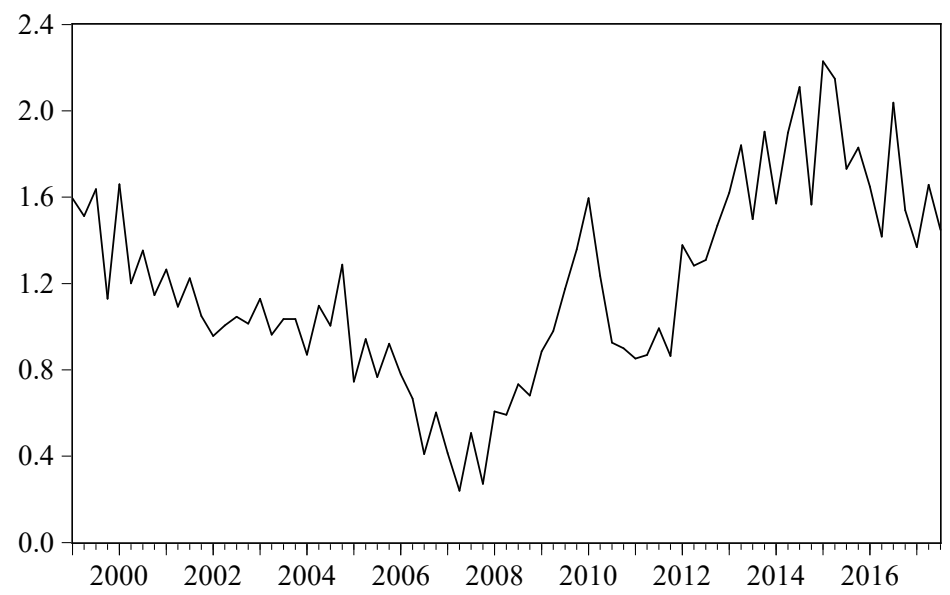

Figure 3.5 therefore indicates big differences in the growth outlook of EA countries around the financial crisis. In combination with the results in Table 3.2 and Table 3.3, this suggests

\footnotetext{
${ }^{14}$ A number of studies identify asynchronous behaviour of the German financial cycle with respect to other EA countries (Alcidi, 2017; Monteiro and Vašiček, 2018; WGEM, 2018 and WGEM, 2018). In particular, the German financial cycle does not exhibit an extensive upswing before the financial crisis. In the course of reunification, Germany experienced a boom in property markets as well as a strong credit expansion. The correction of this boom was still ongoing in the years preceding the financial crisis (Jannsen and Quast, 2018). The findings in this paper might be related to this observation.
} 
that although the conditional means of countries tend to move up and down together, some countries (i.e. Italy) display permanently lower mean growth rates than others (i.e. Ireland). The implications of these findings are twofold. First, if some countries are more heavily affected by economic crises than others, the intensity of the monetary policy reaction as a crisis response does not satisfy the needs of all countries in the monetary union. Second, countries with a persistently lower growth outlook will find it increasingly difficult to abide by the criteria of the Stability and Growth Pact (SGP) for sound public finances in the long run.

\subsubsection{Conditional variance}

The conditional variance of the distribution provides information about the uncertainty related to future growth. I plot the time series of the conditional variance for all countries over the period 1999Q1-2017Q3 (Figure 3.6) to investigate if and how this uncertainty has changed since the introduction of the euro and how it compares across countries. At the one extreme, the distribution variance is lowest in absolute level and relatively constant over time in the core countries Belgium and France, suggesting that predicted growth uncertainty does not drastically increase during economic contractions in those countries. This finding is in line with the results of Figure 3.2, but it masks a fundamental difference between the two distributions. The quantiles of the Belgian growth distribution are relatively constant over time suggesting that the likelihood of both - higher and lower growth outcomes - does not significantly change over time. Conversely, the French distribution tends to fluctuate with its mean. As a result, higher growth outcomes become less likely and lower growth outcomes become more likely when conditional means are lower. At the other extreme, the variance continuously increases in the early years of EMU and peaks around the financial crisis in the periphery countries. Hence, in addition to lower expected mean growth these countries are confronted with increasing growth uncertainty. With hindsight it can be ascertained that the development of both - conditional mean and variance - in the aftermath of the euro's introduction portended an emerging crisis in these countries. The distribution variance does not indicate an imminent crisis in the core countries. Adrian et al. (2019) show that mean and variance of the predicted distribution are negatively correlated, i.e. lower mean growth is commonly associated with higher variances and, hence, greater risk to growth. I present the scatter plots between mean and variance for all countries in Figure 3.10 in Appendix III. The figure confirms this negative relationship for most countries in the sample. As economic 
conditions worsen, growth uncertainty also increases. Again, Germany constitutes an exception to this regularity.

Figure 3.6 Conditional variance
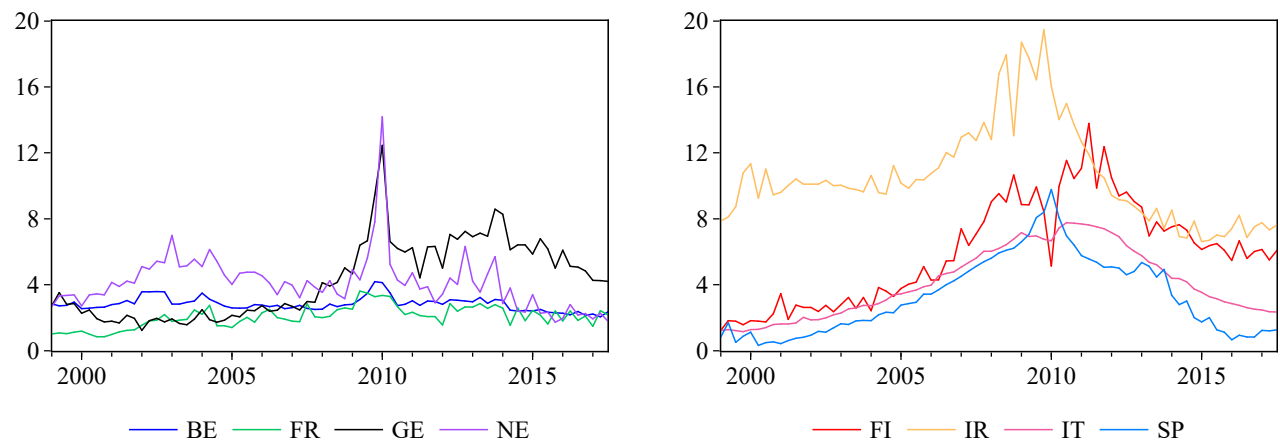

\subsubsection{Recession probabilities}

In this section, I take a closer look at what the conditional distributions can tell about the probability that countries will experience an economic recession. I compute the probability that quantifies the chances of observing a net contraction in economic activity over the fourquarter forecasting horizon, at any point in time, as specified in equation (3.5). A similar exercise was conducted by Alessandri et al. (2019) for Italy. I first compare these forwardlooking recession probabilities across countries and then turn to their cross-country synchronisation.

For visual inspection and comparison of the time series properties, I plot in Figure 3.7 the estimated forward-looking recession probabilities together with an indicator of observed economic performance, namely the realised four-quarter ahead real GDP growth, which I already used as reference in Figure 3.2. The figure shows that both the forward-looking recession probabilities and real GDP growth evolve heterogeneously in core and periphery countries. In the core countries, recession probabilities remain fairly constant over the sample period. In particular, the minor changes in the recession probabilities do not indicate a financial crisis of the observed dimension. The significant rise in forward-looking recession probabilities in France around the financial crisis is, therefore, exceptional between core countries. To the contrary, the likelihood of a recession is continuously increasing in periphery countries starting from low levels in roughly 2003. The maxima of the forward-looking recession probabilities approximately pick up the timing of the actual recessions in 
Figure 3.7 Recession probabilities and economic growth
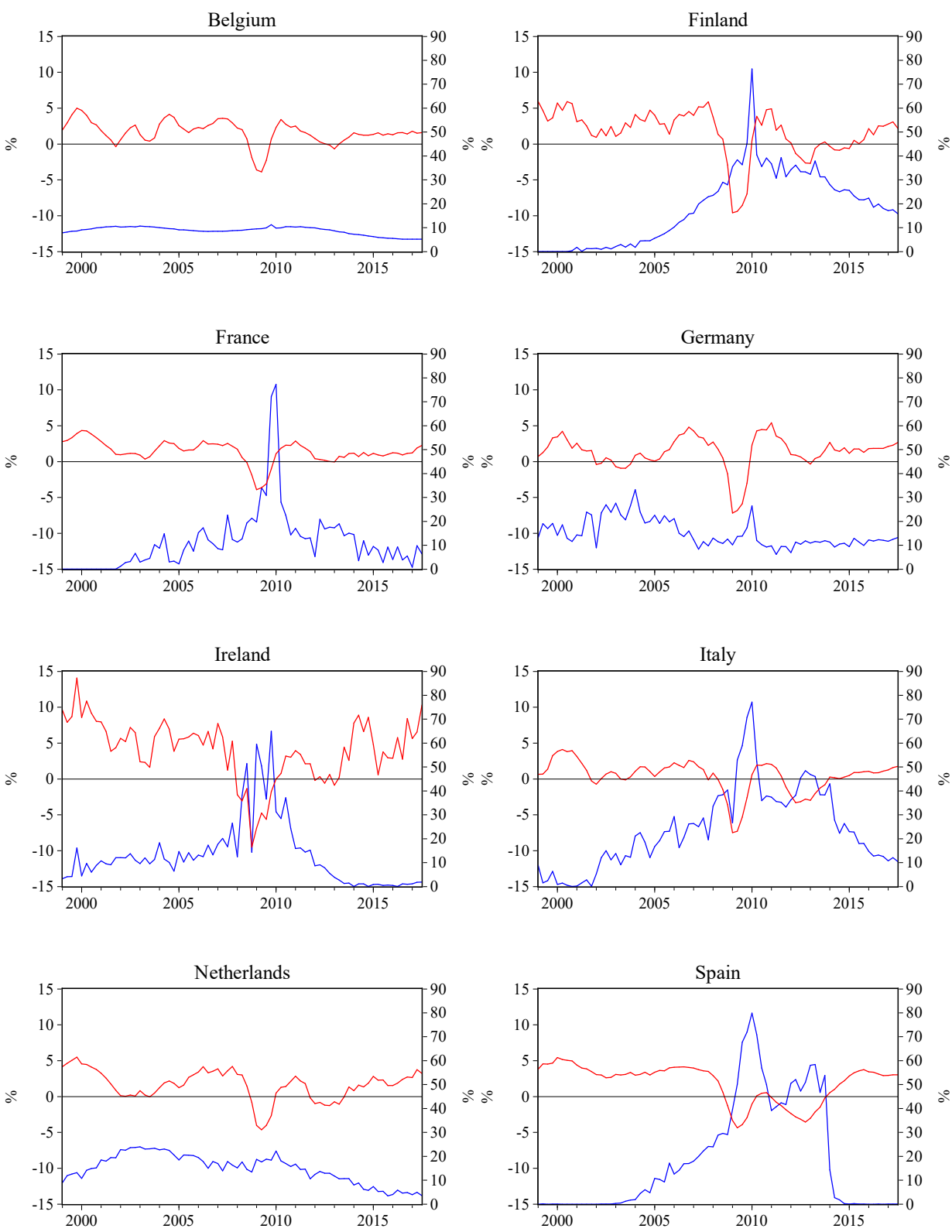

— Recession probability —_ Annulised average growth

Recession probabilities are measured on the right axis, annualised average growth is measured on the left axis. 
the periphery countries as well as in France. The European debt crisis which followed the financial crisis shows up with once again increasing forward-looking recession probabilities between 2012-2014 in Italy and Spain, indicating a double-dip recession in these countries. In the crisis aftermath, recession probabilities decline in all (periphery) countries, most rapidly in France and Spain. Comparison of the estimated forward-looking recession probabilities with the actual economic performance underlines the differences between core and periphery countries. Figure 3.7 shows that core countries experience mixed growth performance prior to the financial crisis while the corresponding estimated recession probabilities do not provide advanced signalling of an imminent recession in these countries. Conversely, all periphery countries with the exception of Italy exhibit continuously positive growth rates in the precrisis period, while forward-looking recession probabilities are continuously rising. This increase in recession probabilities indicates growing underlying economic problems in periphery countries which are not reflected in their actual economic performance prior to the financial crisis. The reason for this result can be found in the observed growth persistence, primarily in periphery countries. The quantile regressions results (Appendix II) suggest persistence in economic growth in France, Ireland, Italy and Spain. To the contrary, the financial cycle is related negatively to future predicted growth in most countries. This suggests that the increasing financial cycle in peripheral countries prior to the financial crisis induces rising recession probabilities in the pre-crisis period, when actual real growth is still positive, indicating economic contractions in the future. Thus, the information content in the financial cycle appears to predict economic downturns in the periphery countries.

I now turn to a more formal analysis. Table 3.4 presents the descriptive statistics for the two time series. In this table, I split the sample again in pre-crisis and crisis periods. The upper part of the table gives the statistics for the realised four-quarter ahead real GDP growth. I also compute the corresponding realised recession percentages, which I define as the percentage of the number of times that economic growth was smaller or equal to zero over the sub-sample period. The lower part of the table presents the statistics for the forward-looking recession probabilities. Mean realised growth rates are on average higher in the periphery than in the core countries in the pre-crisis period. The corresponding standard deviations roughly compare across core and periphery countries. Furthermore, the minimum values confirm that periphery countries - with the exception of Italy - do not go through periods of economic contraction in the pre-crisis period. In contrast, realised recession percentages show that the core countries Belgium, Germany and the Netherlands faced economic contractions between 
$2.8 \%(\mathrm{BE}, \mathrm{NE})$ and $16.7 \%(\mathrm{GE})$ of the times in the pre-crisis period. The continuous increase in forward-looking recession probabilities of periphery countries in the pre-crisis period (Figure 3.7) is reflected in lower minima and higher standard deviations compared with the core countries. The latter generally display positive, relatively constant and, hence, less volatile recession probabilities. Unsurprisingly, I find mean growth rates to be lower and standard deviations to be higher in the crisis period in all countries. Periphery countries are generally hit more severely by the crisis and spent more time in a recession than core countries. Also, forward-looking recession probabilities are on average, but also in absolute values, higher in most periphery countries than in core countries during this period.

Table 3.4 Descriptive statistics and realised recession percentages

\begin{tabular}{|c|c|c|c|c|c|c|c|c|c|}
\hline $\begin{array}{l}\text { Realised } \\
\text { rates }\end{array}$ & ur-quarter growth & $\mathbf{B E}$ & FI & FR & GE & IR & IT & NE & SP \\
\hline & mean & 2.44 & 3.52 & 2.23 & 1.64 & 6.33 & 1.48 & 2.53 & 3.78 \\
\hline & $\max$ & 4.99 & 5.94 & 4.33 & 4.81 & 14.07 & 4.10 & 5.51 & 5.44 \\
\hline 1999Q1- & $\min$ & -0.38 & 0.93 & 0.35 & -0.94 & 1.24 & -0.73 & -0.05 & 2.63 \\
\hline 2007Q4 & std & 1.29 & 1.49 & 1.01 & 1.62 & 2.58 & 1.27 & 1.67 & 0.72 \\
\hline & $\begin{array}{l}\text { Realised recession } \\
\text { percentage }^{*}\end{array}$ & $2.8 \%$ & $0 \%$ & $0 \%$ & $16.7 \%$ & $0 \%$ & $13.9 \%$ & $2.8 \%$ & $0 \%$ \\
\hline & mean & 0.91 & -0.10 & 0.65 & 1.12 & 1.96 & -0.61 & 0.80 & 0.21 \\
\hline & $\max$ & 3.43 & 4.91 & 2.86 & 5.42 & 10.31 & 2.13 & 3.76 & 3.74 \\
\hline 2008Q1- & $\min$ & -3.89 & -9.59 & -3.92 & -7.18 & -9.50 & -7.48 & -4.62 & -4.36 \\
\hline 2017Q3 & std & 1.56 & 3.52 & 1.53 & 2.76 & 4.45 & 2.45 & 2.11 & 2.57 \\
\hline & $\begin{array}{l}\text { Realised recession } \\
\text { percentage* }\end{array}$ & $15.4 \%$ & $41 \%$ & $17.9 \%$ & $15.4 \%$ & $0.8 \%$ & $41 \%$ & $33.3 \%$ & $46.2 \%$ \\
\hline $\begin{array}{l}\text { Forward } \\
\text { probabili }\end{array}$ & $\begin{array}{l}\text { oking recession } \\
\text { es }\end{array}$ & BE & FI & FR & GE & IR & IT & NE & SP \\
\hline & mean & 0.09 & 0.05 & 0.06 & 0.19 & 0.12 & 0.13 & 0.19 & 0.06 \\
\hline 1999Q1- & $\max$ & 0.11 & 0.23 & 0.23 & 0.33 & 0.27 & 0.29 & 0.24 & 0.24 \\
\hline 2007Q4 & $\min$ & 0.08 & 0.00 & 0.00 & 0.08 & 0.03 & 0.00 & 0.09 & 0.00 \\
\hline & std & 0.01 & 0.07 & 0.06 & 0.06 & 0.05 & 0.09 & 0.04 & 0.08 \\
\hline & mean & 0.08 & 0.30 & 0.17 & 0.12 & 0.14 & 0.34 & 0.11 & 0.31 \\
\hline 2008Q1- & $\max$ & 0.11 & 0.76 & 0.77 & 0.26 & 0.65 & 0.77 & 0.22 & 0.80 \\
\hline 2017Q3 & $\min$ & 0.05 & 0.16 & 0.01 & 0.06 & 0.00 & 0.10 & 0.03 & 0.00 \\
\hline & std & 0.02 & 0.11 & 0.16 & 0.03 & 0.18 & 0.16 & 0.05 & 0.26 \\
\hline
\end{tabular}

${ }^{*}$ Based on the number of times that realised four-quarter growth rates were smaller or equal to zero over the sample period.

Recession probabilities in periphery countries rise and peak as compared to the pre-crisis period, while they remain virtually constant over the two periods in the core countries. As I observe seemingly different developments in core and periphery countries, I investigate the implications of these findings on the cross-country synchronisation of recession probabilities. 
I compute bilateral correlation coefficients and the cross-country standard deviation to analyse, respectively, the bilateral degree of co-movement in the two sub-periods (Table 3.5) and the dispersion of recession probabilities over time (Figure 3.8). In the pre-crisis period, forward-looking recession probabilities are highly correlated within the group of periphery countries and to a lesser degree within the group of core countries. France, as an exception, tends to be more highly synchronised with periphery countries in the pre-crisis period. Correlations between countries belonging to different groups are either negative or insignificant. Hence, recession probabilities tend to be synchronised in the early years of EMU within groups of countries, but not between them, confirming that the two groups of countries behaved differently in the run up to the crisis. Conversely, I observe overall higher correlations in the crisis period suggesting a higher degree of co-movement of recession probabilities within the two groups, but also between them. Germany is the only exception. Its recession probabilities are unrelated to the rest of the EA in the crisis period.

\section{Table 3.5 Correlation of recession probabilities}

\begin{tabular}{|lccccccc|}
\hline 1999Q1-2007Q4 & BE & FI & FR & GE & IR & IT & NE \\
FI & $-0.51^{* * *}$ & & & & & & \\
FR & $-0.33^{*}$ & $0.77^{* * *}$ & & & & & \\
GE & $0.50^{* * *}$ & $-0.43^{* *}$ & -0.03 & & & & \\
IR & -0.10 & $0.72^{* * *}$ & $0.56^{* * *}$ & -0.09 & & & \\
IT & $-0.37^{* * *}$ & $0.76^{* * *}$ & $0.82^{* * *}$ & 0.07 & $0.61^{* * *}$ & & \\
NE & $0.71^{* * *}$ & -0.07 & 0.24 & $0.61^{* * *}$ & 0.20 & 0.30 & \\
SP & $-0.59^{* * *}$ & $0.97^{* * *}$ & $0.75^{* * *}$ & $-0.40^{* *}$ & $0.67^{* * *}$ & $0.79^{* * *}$ & -0.10 \\
\hline 2008Q1-2017Q3 & $\mathbf{B E}$ & FI & FR & GE & IR & IT & NE \\
FI & $0.72^{* * *}$ & & & & & & \\
FR & $0.57^{* * *}$ & $0.84^{* * *}$ & & & & & \\
GE & 0.02 & $0.54^{* * *}$ & $0.75^{* * *}$ & & & & \\
IR & $0.67^{* * *}$ & $0.52^{* * *}$ & $0.66^{* * *}$ & 0.27 & & & \\
IT & $0.79^{* * *}$ & $0.86^{* * *}$ & $0.83^{* * *}$ & $0.47^{* * *}$ & $0.57^{* * *}$ & & \\
NE & $0.92^{* * *}$ & $0.79^{* * *}$ & $0.69^{* * *}$ & 0.27 & $0.79^{* * *}$ & $0.83^{* * *}$ & \\
SP & $0.87^{* * *}$ & $0.82^{* * *}$ & $0.70^{* * *}$ & 0.27 & $0.57^{* * *}$ & $0.88^{* * *}$ & $0.86^{* * *}$ \\
\hline$\left.* * * * *\right|^{*}$ indicate significance at the $1 \% / 5 \% / 10 \%$ level. & & & \\
\end{tabular}

Despite this increase in co-movement over time, the standard deviation reflects the rise in recession probabilities in peripheral countries as compared to the core countries. Figure 3.8 reveals that the dispersion of forward-looking recession probabilities across countries develops unfavourably around the time of the financial crisis. In the early euro period, the standard deviation is relatively constant and indicates some degree of convergence shortly before the financial crisis, possibly at the time when rising recession probabilities in periphery 
countries reach approximately the level of the core countries. Dispersion drastically increases during the financial crisis, hence reflecting the differences in the predicted recession probabilities around the financial crisis between core and periphery countries. Dispersion rises again during the European sovereign debt crisis but almost returns to pre-crisis levels at the end of the period.

Figure 3.8 Standard deviation of recession probabilities

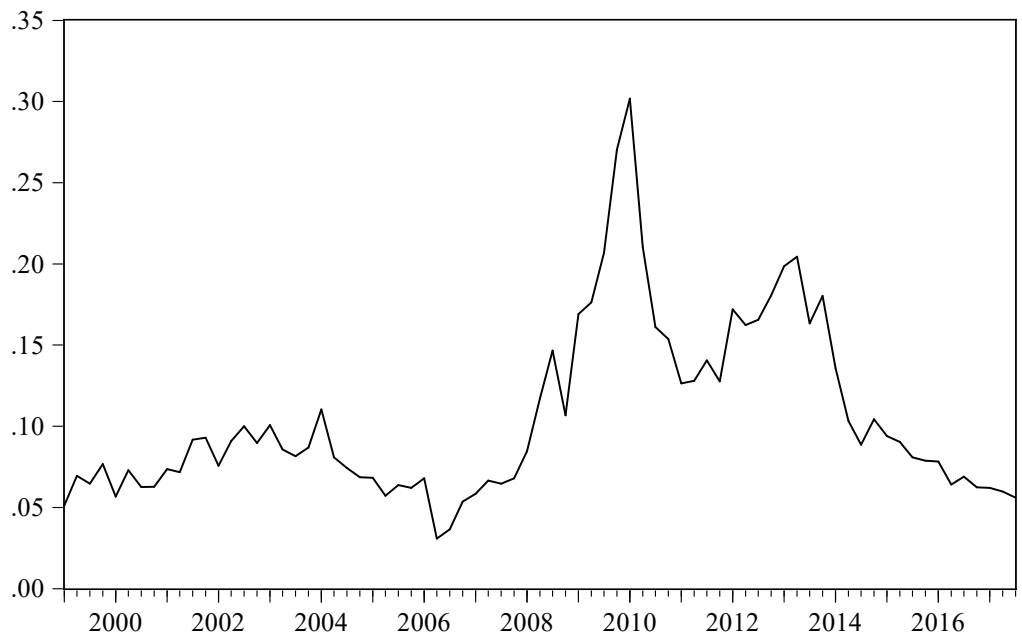

Overall, the empirical results suggest that countries tend to differ in both expected mean growth and forward-looking recession probabilities. Asymmetries arise both from differences in size (dispersion) and from a lack of co-movement. Common monetary policy cannot cope with this type of asymmetries as the intensity of the monetary policy reaction does not satisfy the needs of all countries in the monetary union. Other mechanisms are needed to cope with asymmetric developments and compensate for the loss of independent monetary policy and exchange rates. As both labour mobility and wage and price adjustments - suggested by the original OCA theory as compensation for the loss of independent monetary policy - are low in the EA, other mechanisms may need to be put in place to cushion asymmetric economic developments.

The literature on risk insurance (often defined in terms of consumption smoothing) presents several channels for absorbing asymmetric output shocks in a currency union: domestic fiscal policy (public saving), private sector risk sharing and public policies at the supranational level. Consumption smoothing in the EA is found to be generally low and to differ across periods. Depending on the study, between $16 \%$ and $60 \%$ of output fluctuations are smoothed (Alcidi 
and Thirion, 2017; Milano, 2017; Cimadomo et al., 2020). While Cimadomo et al. (2020) find that smoothing in the EA increased after the euro's introduction, Furceri and Zdzienicka (2015) show that smoothing decreased. Further, consumption smoothing is found to be higher in core than in periphery countries (Alcidi and Thirion, 2017).

Alcidi and Thirion (2017) also show that, on average, roughly $20 \%$ of asymmetric output shocks are smoothed via the domestic fiscal policy channel, and that the intensity of this channel varies over time. My findings suggest that the homogeneous rules of the SGP which are to ensure sound fiscal systems of the EA members, constrain the domestic fiscal policy channel heterogeneously across countries, particularly in crisis periods. The lack of fiscal space associated with weak fiscal positions of some countries limit the ability of automatic stabilisers to provide insurance against shocks (Furceri and Zdzienicka, 2015) or might even lead to a collapse of fiscal policy-smoothing (Kalemli-Ozcan et al., 2014).

Private sector risk sharing can take place via credit (intertemporal) or capital (cross-country) markets. Cimadomo et al. (2020) find that credit market integration (bank lending) does not have any effect on consumption risk sharing in the EA, but that cross-border holdings of (corporate and sovereign) debt are a powerful channel in insulating households against country-specific shocks ( $20 \%$ of shock absorption through portfolio debt). Cross border holdings of equity are found to be less effective in the EA. On the one hand, higher integration of credit (banking union) and capital (capital market union) markets should bring about more risk sharing, on the other hand, integration might also amplify idiosyncratic shocks as shocks are transmitted through the international financial system and credit markets freeze up during downturns (Furceri and Zdzienicka, 2015). Further, market-based insurance might turn out to be suboptimal in the EA as private agents do not internalise the macroeconomic stabilisation effects of portfolio choices.

If private risk sharing and domestic fiscal policy cannot stabilise the economy against (asymmetric) shocks, the lack of appropriate risk-sharing mechanisms at the EA level can contribute to the severity of economic downturns in the eurozone (periphery) and put at risk the mere existence or the EA. Hence, some form of fiscal insurance at the supranational level will most likely be necessary to safeguard the stability of the EA and increase overall welfare. At the moment, the EA still lacks this type of mechanisms to smooth the impact of regionspecific shocks (Bordignon and Baglioni, 2018). In the past, special purpose vehicles, such as 
the EFSF, EFSM and $\mathrm{EMS}^{15}$ have provided financial assistance to EA crisis countries ex post and largely compensated the reduced role of national governments (Milano, 2017). Most recently, the European Commission has presented a proposal to amend the Multiannual Financial Framework (MFF) of the EU budget for the 2021-2027 period, integrating a recovery plan as a response to deal with the immediate, medium and long-term impact of the Covid-19 pandemic on national economies and the single market. This plan gives the Commission the ability to raise funds amounting to $€ 750 \mathrm{bn}$ from the financial markets backed by the Union as a whole to be repaid between 2028 and 2058. The revenues will be allocated to the EU budget under the existing programmes to manage asymmetric economic impacts in member states and presents a first attempt of risk sharing at the EU supranational level.

\subsection{Conclusions}

In this chapter, I estimate quantile regressions and compute the conditional distribution of real GDP growth for eight EA countries over the period 1975Q1-2017Q3. I use the financial cycle instead of the FCI as conditioning variable in the quantile regressions and further contribute to the literature by combining the concepts of growth at risk and optimum currency areas.

I estimate the predicted distributions and find that financial cycles include information about both downside and upside risks to future economic growth. My analysis of the conditional distribution covers the euro period 1999Q1-2017Q3 and compares two sub-periods: the precrisis and crisis periods. I investigate the time series properties of the conditional mean and variance and their cross-country synchronisation and dispersion. From the conditional densities, I compute forward-looking recession probabilities which I compare across countries.

I find that the financial cycle can carry information about both downside and upside risks to future economic growth. This effect is heterogeneous across countries. Further, I identify two groups of countries, the core and periphery groups. Booming financial cycles in the periphery in the early euro period translate into continuously declining conditional means, increasing conditional variances and rising recession probabilities. These developments can be interpreted as early signs of an imminent economic crisis. I do not find similar trends for the core countries in the pre-crisis period. In the crisis period, synchronisation between countries

${ }^{15}$ EFSF: European Financial Stability Facility; EFSM: European Financial Stabilisation Mechanism; EMS: European Stability Mechanism. 
increases with the exception of Germany. I do not identify convergence in terms of dispersion of conditional means and recession probabilities. Conditional mean growth rates converge in the early years of EMU, but their dispersion starts rising again with the onset of the financial crisis. Likewise, the dispersion of recession probabilities sharply increases with onset of the crisis, reflecting higher recession probabilities in times of economic stress in the peripheral countries. 


\section{References}

Adrian, T., Boyarchenko, N., Giannone, D., 2019. Vulnerable Growth. American Economic Review 109 (4), 1263-1289.

Adrian, T., Grinberg, F., Liang, N., Malik, S., 2018. The Term Structure of Growth-at-Risk. IMF Working Papers WP/18/180.

Ahmed, J., Chaudhry, S.M., Straetmans, S., 2018. Business and Financial Cycles in the Eurozone: Synchronization or Decoupling. The Manchester School 86 (3), 358-389.

Alcidi, C., 2017. Fiscal policy stabilisation and the financial cycle in the euro area. European economy Discussion Paper 052.

Alcidi, C., Dolls, M., Fuest, C., Krolage, C., Neumeier, F., 2017. The Nature of Shocks in the Eurozone and Their Absorption Channels. EconPol Policy Report 03.

Alcidi, C., Thirion, G., 2017. Fiscal Risk Sharing and Resilience to Shocks: Lessons for the euro area from the US. CEPS Working Document 2017/07.

Alessandri, P., Del Vecchio, L., Miglietta, A., 2019. Financial conditions and growth at risk in Italy. Temi di discussione 1242. Banca d'Italia.

Bayoumi, T., Eichengreen, B., 2017. Aftershocks of monetary unification: Hysteresis with a financial twist. NBER Working Paper Series 23205.

Belke, A., Domnick, C., Gros, D., 2016. Business Cycle Synchronization in the EMU: Core vs. Periphery. ROME Discussion Paper Series 16-08.

Bordignon, M., Baglioni, A.S., 2018. The Future of Fiscal Policy in the Euro Area. ifo DICE Report 16 (2), 32-37.

Borio, C., 2012. The financial cycle and macroeconomics: What have we learnt? BIS Working Papers 395.

Borio, C., 2014. The financial cycle and macroeconomics: What have we learnt? Journal of Banking and Finance 45, 182-198.

Borio, C., Drehmann, M., 2009. Assessing the risk of banking crises - revisited. BIS Quarterly Review March.

Borio, C., Drehmann, M., Xia, D., 2018. The financial cycle and recession risk. BIS Quarterly Review December.

Campos, N.F., Macchiarelli, C., 2016. Core and Periphery in the European Monetary Union: Bayoumi and Eichengreen 25 years later. Economics Letters 147, 127-130.

Cimadomo, J., Ciminelli, G., Furtuna, O., Giuliodori, M., 2020. Private and public risk sharing in the euro area. European Economic Review 121.

Claessens, S., Kose, M.A., 2018. Frontiers of macrofinancial linkages. BIS papers 95.

Coco, A., Silvestrini, A., 2017. The nature and propagation of shocks in the euro area: a comparative SVAR analysis. International Journal of Computational Economics and Econometrics 7 (1/2), 95-114.

De Grauwe, P., Ji, Y., 2016. Flexibility versus stability. A difficult trade-off in the Eurozone. CEPR Discussion Paper Series DP11372.

Drehmann, M., Borio, C., Tsatsaronis, K., 2012. Characterising the financial cycle: don't lose sight of the medium term! BIS Working Papers 380. 
Duran, H.E., Ferreira-Lopes, A., 2017. Determinants of co-movement and of lead and lag behavior of business cycles in the Eurozone. International Review of Applied Economics 31 (2), 255-282.

Eichengreen, B., 2014. The Eurozone Crisis: The Theory of Optimum Currency Areas Bites Back. Notenstein Academy White Paper Series 3.

Eichengreen, B., 2018. Optimum Currency Areas Past and Future. Oxford Encyclopedia of Economics and Finance (June).

Franks, J., Barkbu, B., Blavy, R., Oman, W., Schoelermann, H., 2018. Economic Convergence in the Euro Area: Coming Together or Drifting Apart? IMF Working Papers WP/18/10.

Furceri, D., Karras, G., 2008. Business-cycle synchronization in the EMU. Applied Economics 40 (12), 1491-1501.

Furceri, D., Zdzienicka, A., 2015. The Euro Area Crisis: Need for a Supranational Fiscal Risk Sharing Mechanism? Open Econ Rev 26 (4), 683-710.

Gächter, M., Riedl, A., Ritzberger-Grünwald, D., 2012. Business Cycle Synchronization in the Euro Area and the Impact of the Financial Crisis. Monetary Policy and The Economy Q2/12.

Gogas, P., 2013. Business cycle synchronisation in the European Union: The effect of the common currency. Journal of Business Cycle Measurement and Analysis 2013/1, 1-14.

Gonçalves, C.E.S., Rodrigues, M., Soares, T., 2009. Correlation of business cycles in the euro zone. Economics Letters 102 (1), 56-58.

Granville, B., Hussain, S., 2017. Eurozone cycles: An analysis of phase synchronization. International Journal of Finance and Economics 22 (2), 83-114.

Grigoraş, V., Stanciu, I.E., 2016. New evidence on the (de)synchronisation of business cycles: Reshaping the European business cycle. International Economics 147, $27-52$.

Gros, D., Alcidi, C., 2010. The Impact of the Crisis on the Real Economy. CEPS Policy Brief No. 201.

Hessel, J., 2019. Medium-term Asymmetric Fluctuations and EMU as an Optimum Currency Area. DNB Working Paper 644.

IMF, 2017. Financial Conditions and Growth at Risk, in: International Monetary Fund (Ed.), Global Financial Stability Report: Is growth at risk?, Chapter 3, pp. 91-118.

Jannsen, N., Quast, J., 2018. Der Finanzzyklus in Deutschland. IfW-Box 2018-15.

Kalemli-Ozcan, S., Luttini, E., Sørensen, B., 2014. Debt Crises and Risk-Sharing: The Role of Markets versus Sovereigns. The Scandinavian Journal of Economics 116 (1), 253-276.

Koenker, R., Bassett, Jr., G., 1982. Robust Tests for Heteroscedasticity Based on Regression Quantiles. Econometrica 50 (1), 43-61.

Mayes, D.G., Virén, M.E.E., 2001. Financial conditions indexes. Bank of Finland discussion papers 17 , Helsinki.

Mian, A., Sufi, A., Verner, E., 2017. Household Debt and Business Cycles Worldwide. The Quarterly Journal of Economics 132 (4), 1755-1817.

Milano, V., 2017. Risk sharing in the eurozone: the role of European institutions. CeLEG Working Paper Series 01/17. 
Monteiro, D., Vašíček, B., 2018. Financial cycle in euro area. Quarterly Report on the Euro Area 17 (2), 17-30.

OECD, 2007. OECD Economic Surveys: Italy. OECD Publishing 12.

OECD, 2008. OECD Economic Surveys: Ireland. OECD Publishing 5.

OECD, 2010. OECD Economic Surveys: Finland. OECD Publishing 4.

OECD, 2015a. OECD Economic Surveys: Ireland. OECD Publishing.

OECD, 2015b. OECD Economic Surveys: Italy. OECD Publishing.

OECD, 2016. Irish GDP up by $26.3 \%$ in 2015? OECD. https://www-oecdorg.proxy.library.uu.nl/sdd/na/Irish-GDP-up-in-2015-OECD.pdf (accessed 29 January 2020).

Schularick, M., Taylor, A.M., 2012. Credit Booms Gone Bust: Monetary Policy, Leverage Cycles, and Financial Crises, 1870-2008. American Economic Review 102 (2), 10291061.

Van Beers, N.J., Bijlsma, M., Zwart, G., 2014. Cross-country insurance mechanisms in currency unions: an empirical assessment. Bruegel Working Paper 2014/04.

Wang, Y., Yao, Y., 2001. Measuring Economic Downside Risk and Severity: Growth at Risk. Policy Research Working Paper 2674. The World Bank.

Weyerstrass, K., van Aarle, B., Kappler, M., Seymen, A., 2011. Business Cycle Synchronisation with(in) the Euro Area: in Search of a 'Euro Effect'. Open Econ Rev 22 (3), 427-446.

WGEM, 2018. Real and financial cycles in EU countries - Stylised facts and modelling implications. ECB Occasional Paper Series 205. 
Appendix I.

Table 3.6 Descriptive statistics

\begin{tabular}{|lcccccccc|}
\hline $\boldsymbol{y}_{\boldsymbol{t}+\boldsymbol{h}}$ & $\mathbf{B E}$ & $\mathbf{F I}$ & $\mathbf{F R}$ & $\mathbf{G E}$ & $\mathbf{I R}$ & IT & NE & SP \\
mean & 1.94 & 2.06 & 1.92 & 1.91 & 4.43 & 1.52 & 2.18 & 2.19 \\
$\max$ & 14.77 & 19.47 & 6.60 & 12.23 & 27.23 & 10.04 & 22.65 & 14.85 \\
min & -8.46 & -28.17 & -6.70 & -18.36 & -15.69 & -11.16 & -20.12 & -7.76 \\
std & 2.75 & 4.93 & 1.96 & 3.67 & 6.25 & 3.11 & 4.28 & 2.99 \\
\hline $\boldsymbol{F} \boldsymbol{C}_{\boldsymbol{t}}$ & $\mathbf{B E}$ & $\mathbf{F I}$ & $\mathbf{F R}$ & $\mathbf{G E}$ & $\mathbf{I R}$ & $\mathbf{I T}$ & $\mathbf{N E}$ & $\mathbf{S P}$ \\
mean & 0.01 & 0.00 & 0.00 & 0.00 & 0.01 & 0.00 & 0.01 & 0.01 \\
$\max$ & 0.16 & 0.18 & 0.10 & 0.05 & 0.18 & 0.17 & 0.19 & 0.24 \\
min & -0.14 & -0.12 & -0.09 & -0.04 & -0.16 & -0.14 & -0.09 & -0.19 \\
std & 0.07 & 0.08 & 0.05 & 0.03 & 0.09 & 0.08 & 0.08 & 0.11 \\
\hline
\end{tabular}

Sample period: 1975Q2-2017Q3. Observations: 170

Table 3.7 Correlation of conditional means

\begin{tabular}{|lccccccc|}
\hline 1999Q1-2017Q3 & BE & FI & FR & GE & IR & IT & NE \\
FI & 0.18 & & & & & & \\
FR & $0.43^{* * *}$ & $0.81^{* * *}$ & & & & & \\
GE & $0.28^{* *}$ & $-0.70^{* * *}$ & $-0.28^{* *}$ & & & & \\
IR & $0.57^{* * *}$ & $0.26^{* *}$ & $0.42^{* * *}$ & $0.13^{*}$ & & & \\
IT & $0.51^{* * *}$ & $0.83^{* * *}$ & $0.87^{* * *}$ & $-0.39^{* * *}$ & $0.40^{* * *}$ & & \\
NE & $0.63^{* * *}$ & $-0.28^{* *}$ & 0.01 & $0.64^{* * *}$ & $0.69^{* * *}$ & 0.00 & \\
SP & $0.51^{* * *}$ & $0.83^{* * *}$ & $0.81^{* * *}$ & $-0.43^{* * *}$ & $0.58^{* * *}$ & $0.88^{* * *}$ & $0.21^{*}$ \\
\hline$\left.\left.{ }^{* * * *}\right|^{* *}\right|^{*}$ indicate significance at the $1 \% / 5 \% / 10 \%$ level. & & & & \\
\hline
\end{tabular}




\section{Appendix II.}

This appendix summarises the quantile regression results for equation (3.1) in the main text.

$$
y_{t+h}=x_{t} \beta_{\tau}+\varepsilon_{t}
$$

I estimate the regression for 19 quantiles between the extreme 5\% and $95 \%$ tail outcomes. The quantile coefficient estimates and their 95\% confidence bounds are plotted in Figure 3.9 for all countries. For comparison, I also plot the OLS estimates of the regression. The corresponding 95\% confidence intervals are computed from HAC adjusted standard errors. The figures show that shifts in the distribution of future real GDP growth are mostly captured by the intercept which shows a strong upward trend across quantiles and thus takes out part of the quantile variation in the coefficients on current real GDP growth and the financial cycle. The explanatory content of current real GDP growth on its predicted value varies across countries. While in Belgium, Finland, Germany and Netherlands current real GDP growth does not explain future growth, its impact is positive in the crisis countries (FR, IR, IT, SP). Alessandri et al. (2019) also find that fluctuations in tail risks are explained by the dynamics of the economic activity indicators. To the contrary, the financial cycle is a significant predictor of future growth in most countries. The conditional quantile estimates for the financial cycle are negative and statistically significant across the distribution for most countries. A positive financial cycle dampens future growth and this impact appears to be larger at lower quantiles. However, the confidence intervals of the quantile regression coefficients are overlapping with the OLS estimates, suggesting that there is only limited quantile information in the financial cycle. The slope equality test developed by Koenker and Bassett, Jr. (1982) tests for the equality of the slope coefficients across quantiles. I perform this test to detect possible significant variation in the quantile slope coefficients of the financial cycle. The null hypothesis of the test is $H_{0}: \beta_{\tau_{-} h i g h}^{F C}-\beta_{\tau_{-} l o w}^{F C}=0$ for the individual quantiles, where $\beta_{\tau_{-} h i g h}^{F C}$ is the coefficient on the financial cycle at the higher quantile and $\beta_{\tau_{-} l o w}^{F C}$ is the coefficient on the financial cycle at the lower quantile. Table 3.8 presents the test results. I compare the slope coefficient for the median against the coefficients estimated at the $5 \%$ and $95 \%$ quantile (upper part of the table) and for the median against those estimated at the $10 \%$ and $90 \%$ quantiles (lower part of the table). The table gives the corresponding restricted values and the Wald test summary statistics. The coefficients in both the lower and upper tail differ significantly from the median coefficients and the Wald test statistics are significant for the majority of countries at conventional test levels. Hence, the impact of the 
financial cycle significantly differs across quantiles in most countries and it is largest at the lower tail of the distribution (Figure 3.9). In Germany and Ireland, the tail coefficients do not significantly differ from the median. This suggests that the financial cycle cannot predict downside or upside tail risks in these countries.

Table $3.8 \quad$ Slope equality test

\begin{tabular}{|lccccccccc|}
\hline & Quantiles & BE & FI & FR & GE & IR & IT & NE & SP \\
Restricted & $0.05,0.5$ & $-6.86^{*}$ & -18.80 & $-17.05^{* * *}$ & 20.54 & -9.50 & $-11.47^{* *}$ & -4.10 & $-9.59^{* * *}$ \\
value & $0.5,0.95$ & -4.00 & $-15.43^{* * *}$ & 8.76 & $19.17^{*}$ & -1.17 & -9.62 & $-11.04^{*}$ & $-4.17^{*}$ \\
Wald Test & & 4.21 & $16.62^{* * *}$ & $21.57^{* * *}$ & $4.99^{*}$ & 2.41 & $9.71^{* *}$ & $4.91^{*}$ & $42.31^{* * *}$ \\
\hline Restricted & $0.1,0.5$ & $-9.55^{* * *}$ & $-9.54^{* * *}$ & $-11.31^{* * *}$ & 4.16 & -5.38 & $-10.03^{* *}$ & $-7.76^{*}$ & $-7.83^{* * *}$ \\
value & $0.5,0.9$ & 0.84 & $-16.09^{* * *}$ & 2.96 & 4.74 & 2.11 & -1.49 & -5.66 & $-4.02^{* *}$ \\
Wald Test & & $11.45^{* * *}$ & $35.14^{* * *}$ & $8.71^{* *}$ & 0.86 & 1.11 & $7.35^{* *}$ & $6.58^{* *}$ & $25.85^{* * *}$ \\
\hline
\end{tabular}

The Wald test statistic is distributed $\chi^{2}$ with 2 degrees of freedom.

$\left.{ }^{* * * *}\right|^{* *} / /^{*}$ indicate significance at the $1 \% / 5 \% / 10 \%$ level. 
Figure 3.9 Quantile process coefficients

(1975Q1-2017Q3)

Belgium

Constant

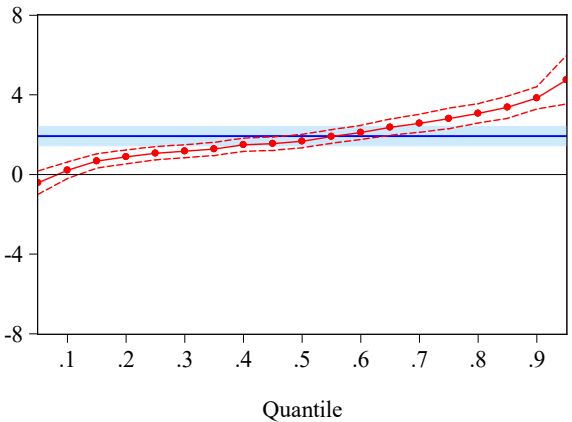

Financial cycle

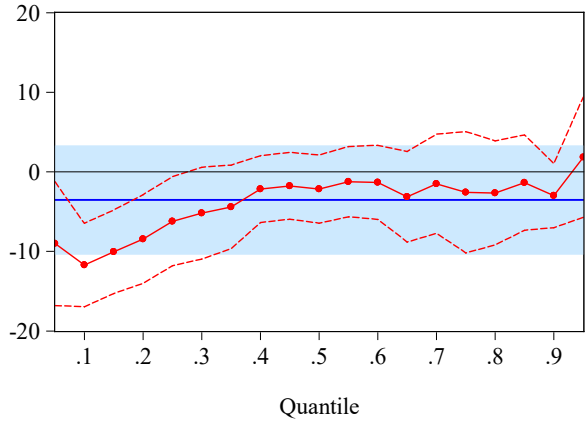

Real GDP growth

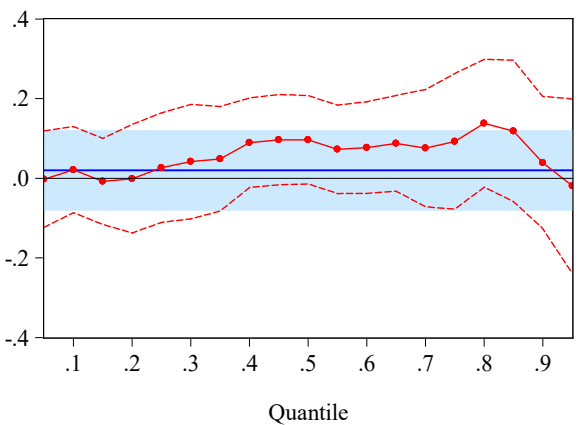

Finland

Constant

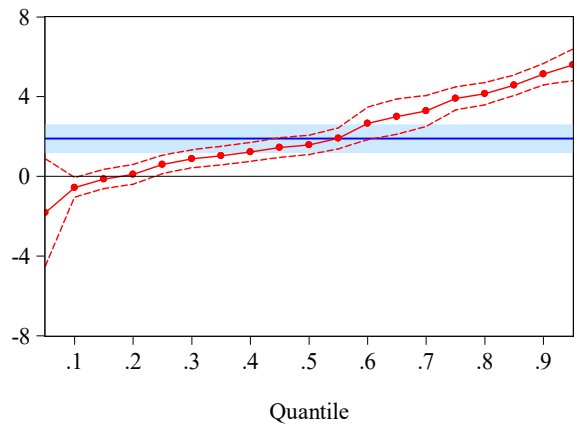

Financial cycle



Real GDP growth

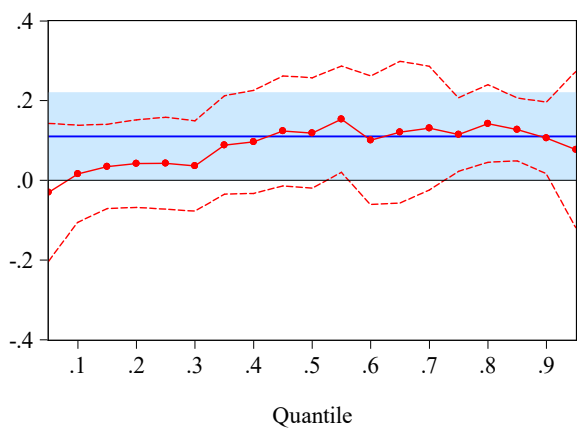

The red dotted lines give the quantile regression coefficients, and the red dashed lines indicate the corresponding $95 \%$ confidence intervals. The blue solid lines give the OLS coefficients and the blue shaded areas indicate the corresponding $95 \%$ confidence intervals. 
France

Constant

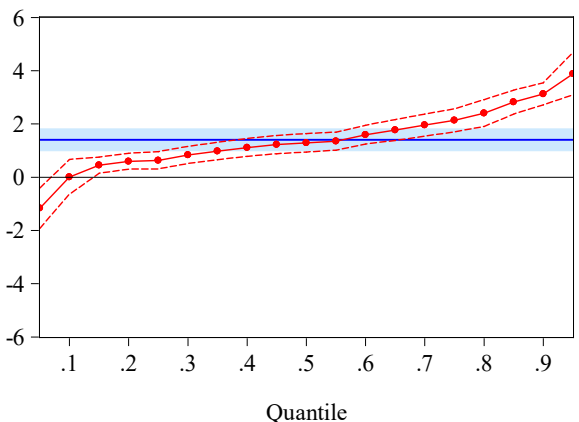

Financial cycle

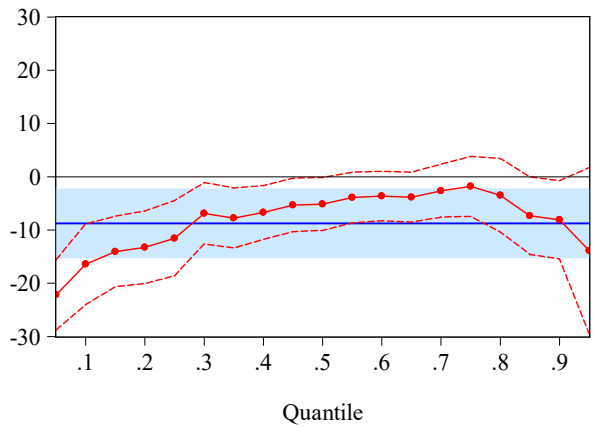

Real GDP growth

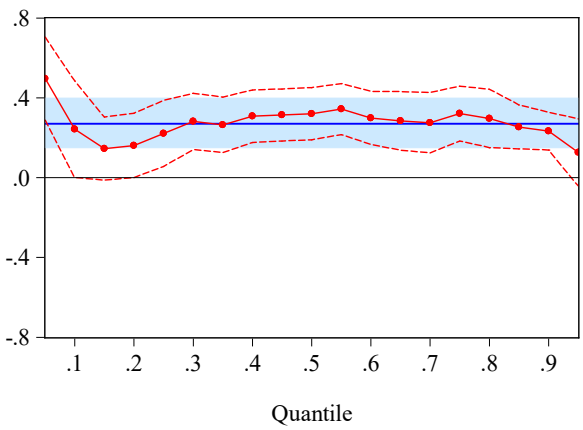

Germany

Constant

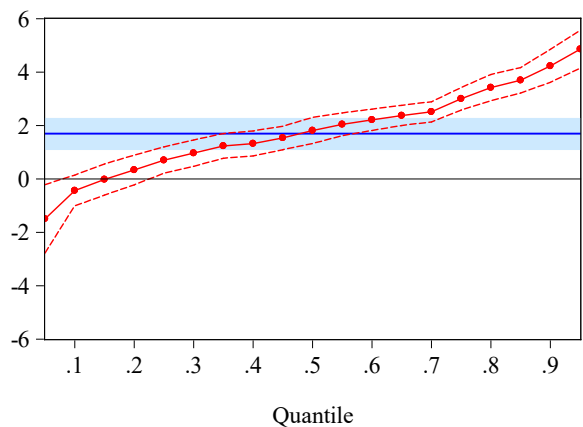

Financial cycle

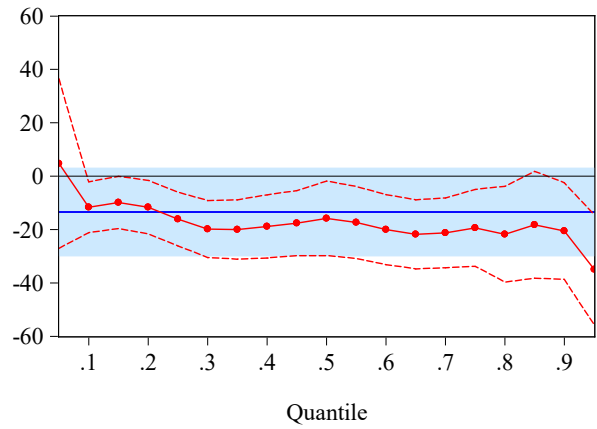

Real GDP growth

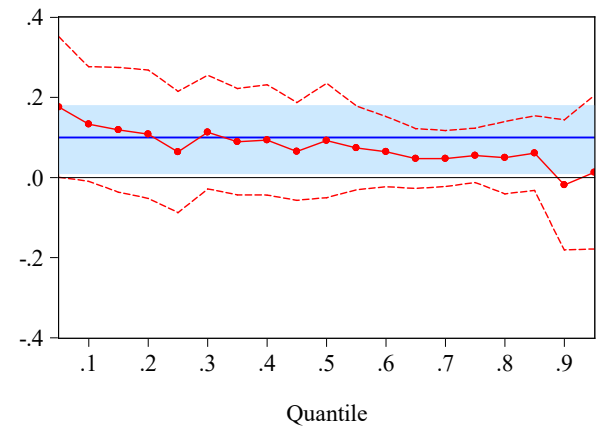


Ireland

Constant

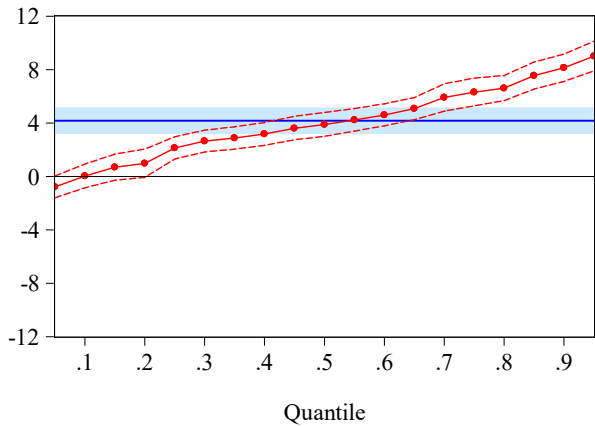

Financial cycle

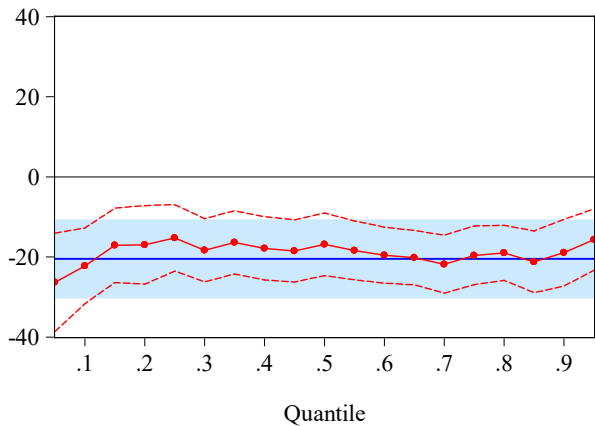

Real GDP growth

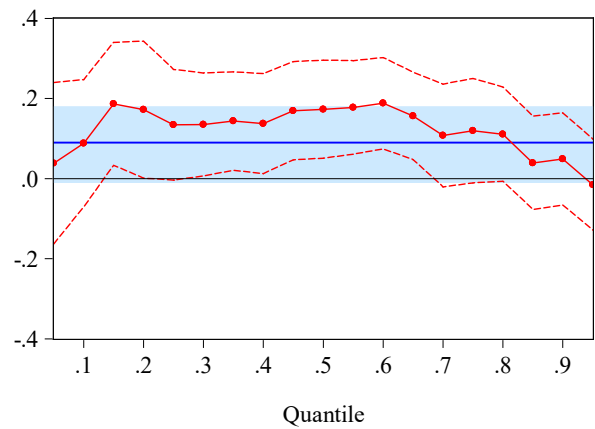

Italy

Constant

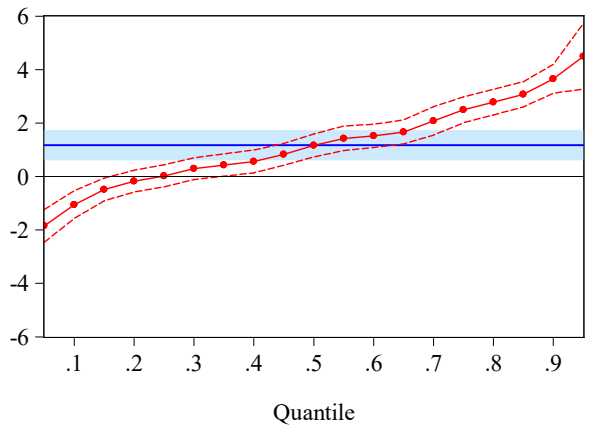

Financial cycle

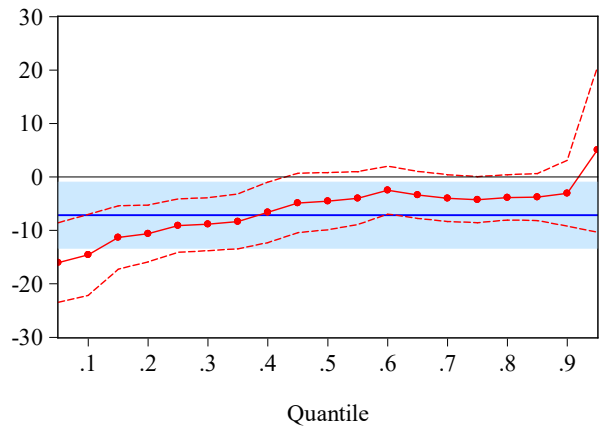

Real GDP growth

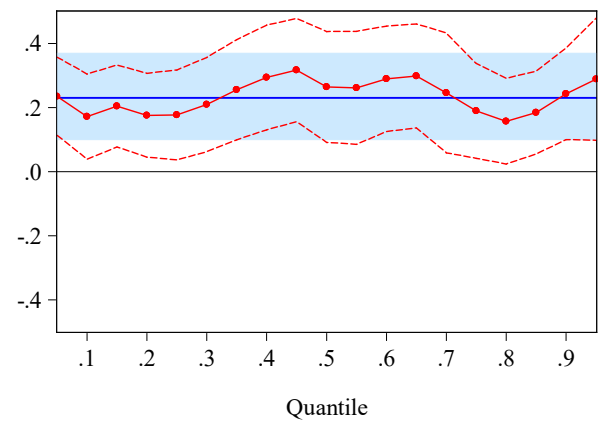


Netherlands

Constant



Financial cycle

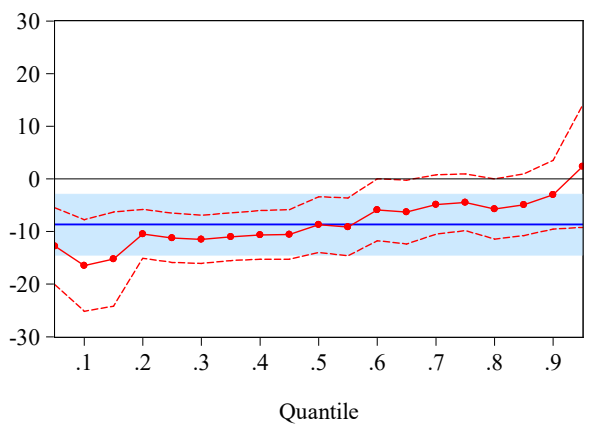

Real GDP growth

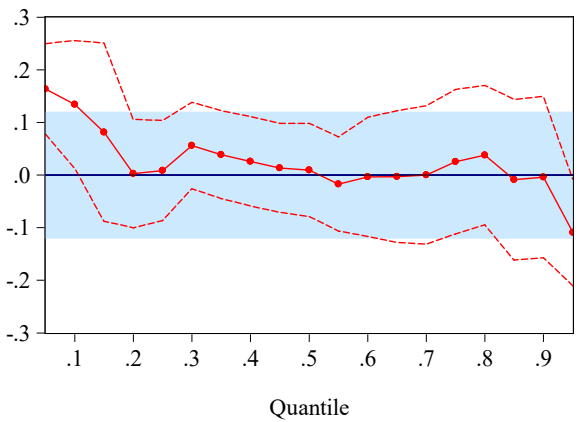

Spain

Constant

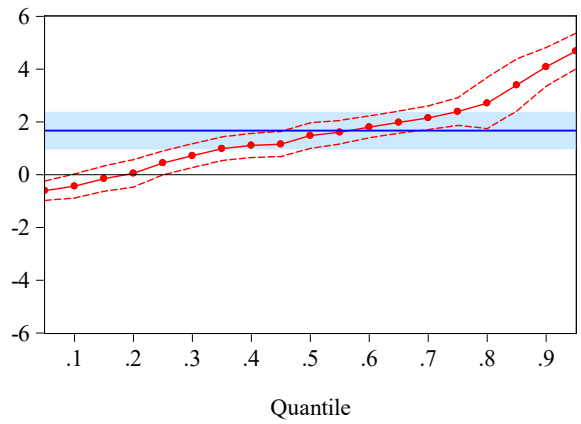

Financial cycle

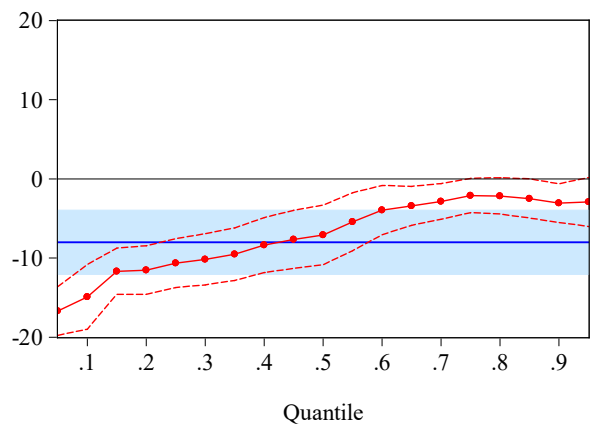

Real GDP growth






\section{Appendix III.}

Figure 3.10 Conditional mean and variance (1999Q1-2017Q3)
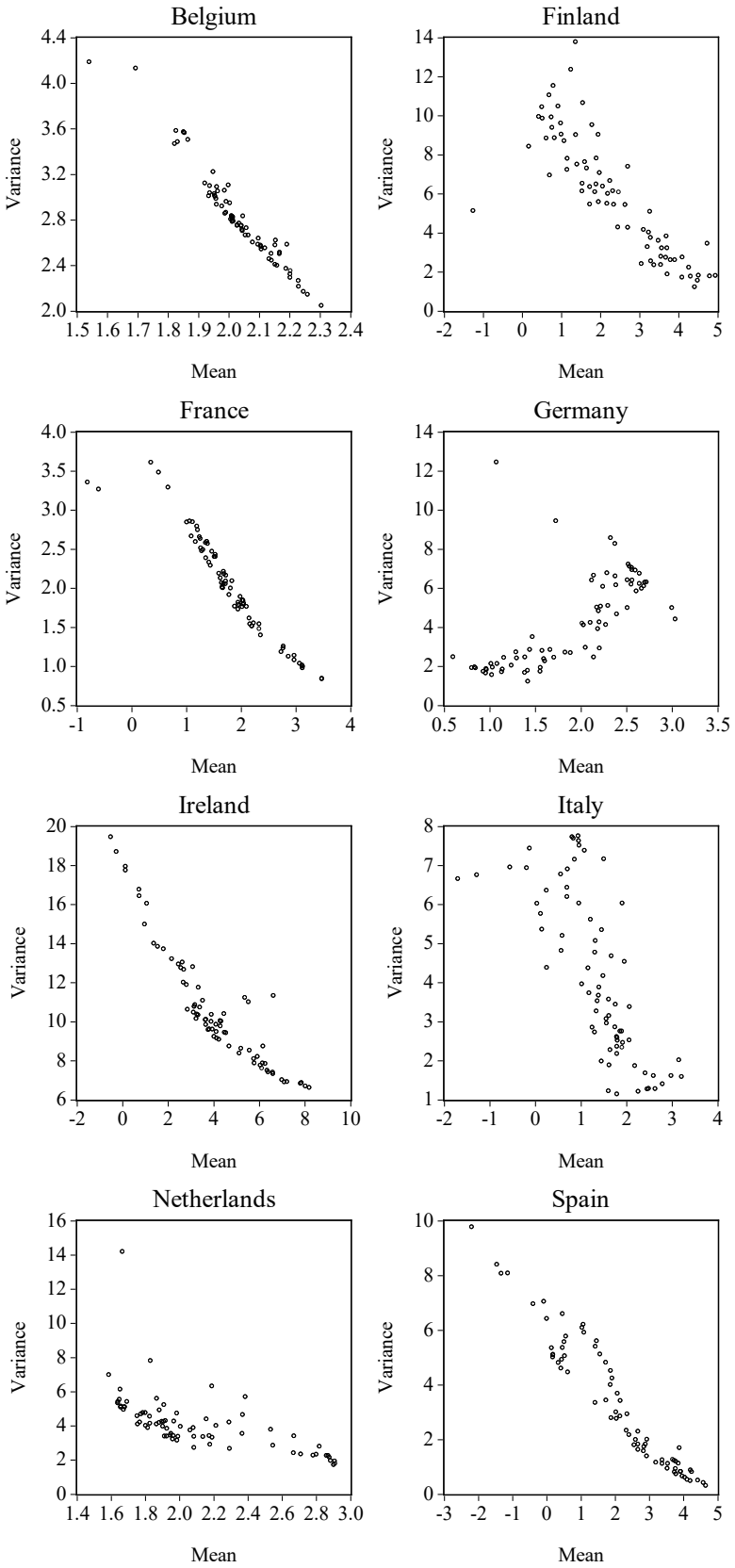



\section{Chapter 4}

\section{Trade Imbalances in the Euro Area: A GVAR Analysis}

\subsection{Introduction}

Over the past decades, international trade integration has progressed and geographical patterns of trade have changed dramatically with the acceleration of globalisation (Cesa-Bianchi et al., 2012). Besides the emergence of new global players, such as China, and the re-integration of the Central and Eastern-European countries into the global economy, trade between euro area (EA) member states has increased as a result of European economic integration and the introduction of the euro as the common European currency. In addition to the overall increase in trade volumes, external imbalances of EA member states widened considerably between 1999 and 2008 (Croci Angelini and Farina, 2012; Holinski et al., 2012). An increasing divergence between two groups of countries could be observed. The "external surplus group" includes countries that ran external current account surpluses over a period of five years ending in 2007 (Austria, Finland, Germany and the Netherlands), and the "external deficit group" includes countries with external current account deficits over the same time period (France, Ireland, Italy, Portugal and Spain).

While, initially, diverging external positions of EA countries were not considered the problem but a consequence of economic integration after the introduction of the euro, the analysis of global imbalances has gained increasing importance as their presence proved detrimental in the past years. A number of recent empirical studies attempt to shed light on the driving forces of external imbalances (Arghyrou and Chortareas, 2008; Belke and Dreger, 2011; Chen et al., 2012; Croci Angelini and Farina, 2012; Holinski et al., 2012; Zemanek et al., 2010). Current account $(\mathrm{CA})$ or trade balance (TB) data can be used to empirically approximate external 
imbalances. The overall development of current accounts and trade balances are strongly linked in many countries (Ahearne et al., 2008; Nieminen, 2015; Schmitz and Von Hagen, 2011). The advantage of using trade as opposed to CA data is the availability of bilateral trade data. Aggregate trade imbalances of EA countries increased and widened from the late 1980s until the 2008 financial crisis comparable to CA developments. Their geographical pattern is similar, with Southern countries like Spain and Portugal running trade deficits and Northern countries like Germany, the Netherlands and Finland running trade surpluses. ${ }^{1}$ In addition to the aggregate trade imbalances that have emerged and widened between EA members, some EA countries exhibit a divergence between intra-EA and extra-EA trade balances. Here, the intraEA trade balance is defined as external balance of an EA country with respect to the aggregate of its EA trading partners, while the extra-EA trade balance is defined as the external balance of an EA country with respect to all trading partners outside the EA (Schmitz and Von Hagen, 2011).

The EA and its individual economies are tightly embedded into the global economy, and the transmission of economic shocks is affected by close domestic and international trade relations. My empirical approach intends to take account of these complex international transmission channels in explaining trade balance movements across EA countries. I apply the global vector auto-regression (GVAR) approach to a subset of nine EA countries and their nine most important international trading partners. My research closely follows Bettendorf (2012) for the choice of variables included into the estimations but extends his work in three ways. First, I model individual EA countries instead of treating the EA as a single region to take account of country-specific differences and allow for heterogeneity across countries. Second, the most important modification, my model specification treats EA countries differently from non-EA countries. Following the research of Bayoumi et al. (2011), Nieminen (2015), Nieminen and Junttila (2015) and Schmitz and Von Hagen (2011) I argue that additional insights into the development of external balances and their determinants can be gained from differentiating between countries' intra-EA and extra-EA trade balances. ${ }^{2}$ I distinguish between the intra-EA and extra-EA trade balance and real effective exchange rate (REER) for the EA countries, and I use a single overall trade balance and REER for non-EA countries. To my knowledge this specification is a novelty in the GVAR literature. Third, all of the imposed shocks are regionspecific shocks to either domestic (EA) or foreign (non-EA) variables. I analyse four different

\footnotetext{
${ }^{1}$ Ireland is the exception, combining trade balance surpluses with CA deficits. This is due to the extreme influence of its income account.

${ }^{2}$ Unfortunately, bilateral CA data are unavailable.
} 
shocks, which are related to the major global economic developments in recent years: 1) a positive region-specific shock to EA real GDP, 2) a positive region-specific shock to real GDP in all non-EA countries, 3) a positive shock to the extra-EA REER (mimicking a euro appreciation) and 4) a negative region-specific shock to EA interest rates. As a result of my model specification, I can investigate the impact of those shocks on intra-EA and extra-EA trade balance and REER in terms of sign and intensity for a single country, and I can compare the impact of shocks in terms of sign, intensity and dispersion across countries. In addition, I will be able to answer the following questions: What is the importance of the various shocks in explaining external imbalances? Are imbalances primarily an issue of intra-EA trade or of extra-EA trade or both?

My analysis shows that symmetric shocks - both domestic and foreign - are transmitted heterogeneously into the various EA countries and that their impact is not related to the initial state of the trade balance. Sometimes, intra-EA and extra-EA trade balances are found to move in opposite directions in response to the same shock. Real GDP shocks are the most important drivers of EA trade balances, and their impact is more heterogeneous on intra-EA than on extraEA trade balances. The impact of exchange rate movements on trade balances is small. Monetary policy is not suitable to narrow the gap in EA trade balances.

The remainder of the chapter is organised as follows. Section 4.2 reviews the relevant empirical literature on EA imbalances, EA competitiveness and GVAR modelling. Section 4.3 derives the theoretical foundations of the GVAR model and describes how the model will be implemented empirically. Section 4.4 presents the data. Section 4.5 discusses the empirical model specification and stability. Section 4.6 analyses the dynamic properties of my model by means of generalised impulse response analysis. Section 4.7 concludes.

\subsection{Literature review and data analysis}

This section reviews the empirical evidence for the development of EA external imbalances and the competitive performance of EA countries. In addition, the section summarises results from GVAR applications to the EA.

\subsubsection{External imbalances of euro area member states}

Research on EA external imbalances shows that while the aggregate EA external balance has remained relatively close to zero, the external balances of individual EA member states have 
exhibited increasing and persistent imbalances since the introduction of the single currency (Ahearne et al., 2008; Arghyrou and Chortareas, 2008; Barnes et al., 2010; ECB, 2012a; Holinski et al., 2012). I distinguish between the "external surplus group" of countries exhibiting CA surpluses over a period of five years ending in 2007 (Austria, Finland, Germany and the Netherlands) and the "external deficit group" of countries showing external CA deficits over the same time period (France, Ireland, Italy, Portugal and Spain). Except for France, these groups correspond to the generally recognised "core" and "periphery" of the EA (Cesaroni and De Santis, 2014; Croci Angelini and Farina, 2012). In addition to the different - positive and negative - overall external imbalances that have emerged for individual EA countries, the external imbalances with respect to all other members of the monetary union (intra-EA trade balance) have developed differently from the external balances with respect to all non-member states (extra-EA trade balance) for some EA countries.

The development of EA imbalances has received increasing attention in the years following the 2008 financial turmoil. In the empirical literature, external imbalances are approximated either by $\mathrm{CA}$ or trade balance data. Among the two the CA is the broader measure of external imbalances and includes, besides the trade balance, net factor income and net transfers. Empirical research focuses primarily on the development of individual EA countries' CAs (Arghyrou and Chortareas, 2008; Barnes et al., 2010; Belke and Dreger, 2011; Brissimis et al., 2011; Cesaroni and De Santis, 2014; Croci Angelini and Farina, 2012; Diaz Sanchez and Varoudakis, 2013; Podstawski, 2016; Staehr and Vermeulen, 2016). Studies explaining diverging trade balances include Communale and Hessel (2014), Dées (2013), Holinski and Vermeulen (2009) and Zemanek et al. (2010). Additional insights can be gained from differentiating between countries' intra-EA and extra-EA trade balances, but this distinction is only occasionally made (Ahearne et al., 2008; Berger and Nitsch, 2010; Nieminen, 2015; Schmitz and Von Hagen, 2011). The existing research typically uses trade data for this purpose, as bilateral CA data are unavailable. Bilateral data on exports and imports of goods is easily accessible in the IMF's Directions of Trade Statistics and allows for the separate analysis of EA countries' intra-EA and extra-EA trade balances. Another advantage of using trade data in empirical research is that they allow a more direct analysis of the impact of competitiveness shocks. Schmitz and Von Hagen (2011) find that the dispersion of individual countries' intraEA trade balances is persistently larger than that of the extra-EA trade balances. Berger and Nitsch (2010) show that trade imbalances between EA countries widened considerably with the 
advent of the Economic and Monetary Union (EMU) and that these imbalances have become more persistent over time.

The legitimacy of using either measure - CA or trade balance - as a proxy for external imbalances in empirical studies is examined by Ahearne et al. (2008), Nieminen (2015) and Schmitz and Von Hagen (2011). The studies investigate the co-movements of trade balance and CA data for EA countries and find the correlations between the CA and the trade balance series to be above 0.75 for most countries. Ireland presents a notable exception: the country combines trade balance surpluses with CA deficits. This is due to the extreme influence of its income account. Generally, recent developments in the net foreign asset positions of EA countries and the increase in income flows can be expected to widen the gap between the CA and the trade balance in the future. In particular, as a result of faster financial innovation and the creation of the euro, cross-border asset flows and cross-border asset and liability positions have increased (Lane and Milesi-Ferretti, 2008). ${ }^{3}$

The literature suggests a large set of theoretically plausible explanatory variables to explain the diverging and persistent external balances of EA countries. These include measures of competitiveness (Arghyrou and Chortareas, 2008; Belke and Dreger, 2011; Berger and Nitsch, 2010; Croci Angelini and Farina, 2012; Diaz Sanchez and Varoudakis, 2013; Staehr and Vermeulen, 2016), domestic and foreign GDP (Arghyrou and Chortareas, 2008; Chen et al., 2012), per capita GDP (Brissimis et al., 2011; Schmitz and Von Hagen, 2011), business or financial cycle measures (Berger and Nitsch, 2010; Communale and Hessel, 2014), fiscal indicators (Berger and Nitsch, 2010; Brissimis et al., 2011), the oil price (Nieminen, 2015; Schmitz and Von Hagen, 2011), structural indicators such as employment and product market regulation (Berger and Nitsch, 2010; Nieminen, 2015) and demographic factors (Jaumotte and Sodsriwiboon, 2010; Nieminen, 2015). In the remainder of this section, I focus on three of these channels which are related to the empirical analysis: (i) domestic demand, (ii) foreign demand and (iii) external competitiveness.

With respect to the first factor, the launch of the euro, the implementation of the common monetary policy and the resulting disappearance of the currency risk premium on public debt led to a fall in peripheral countries' nominal interest rates to the level of core countries' rates. At the same time, persistently higher inflation in the peripheral countries caused the real interest

\footnotetext{
${ }^{3}$ I use trade balance data as a proxy for external balances in the empirical GVAR analysis. I have computed the correlations between trade balance and corresponding CA data for the countries included in my analysis. The results show that the trade balance continues to be a good proxy for the CA over the estimation period.
} 
rates between core and periphery to diverge. Further, the financial integration of European capital markets increased the availability of cross-border loanable funds and thus boosted the demand for credit and imports. The resulting rise in domestic demand is often found to be responsible for the deterioration of deficit countries' CAs (Arghyrou and Chortareas, 2008; Croci Angelini and Farina, 2012; Diaz Sanchez and Varoudakis, 2013; Podstawski, 2016). Berger and Nitsch (2010) find that EA members growing faster than their trading partners suffer on average a deterioration of their bilateral trade balances. Communale and Hessel's (2014) findings suggest that domestic demand fluctuations at the frequency of the financial cycle ${ }^{4}$ are more important drivers of changes in trade balances in the EA than differences in price competitiveness.

Second, extra-EA demand conditions changed in the course of globalisation. Central and Eastern European as well as East Asian countries gained importance in world trade. Differences in export specialisation across EA countries contributed to diverging CA imbalances. Zemanek et al. (2010) stress the importance of non-price competition (sectoral and geographical specialisation of the export sector, production and technology structure, the quality of goods) and the heterogeneity of exported goods in international trade. Chen et al. (2012) examine how the export and import performance of EA countries are related to intra-EA factors and to external trade shocks. They find that declines in export competitiveness and trade shocks originating outside the EA have a large impact on the external imbalances of deficit countries. In particular, the rise of China generated strong demand for machinery and equipment goods exported by Germany and resulted in the displacement of exports from EA debtors from foreign markets by Chinese competitors.

Third, the loss in external competitiveness reflected in the appreciation of (periphery countries') REERs might have led to diverging external balances between EA countries. A number of studies show that the impact of REER movements on external balances of EA countries is heterogeneous (Brissimis et al., 2011; Communale and Hessel, 2014; Staehr and Vermeulen, 2016). In particular, Communale and Hessel (2014) find that the REER improved the trade balance in Germany and worsened the trade balance in peripheral countries, mostly Spain and Ireland. Brissimis et al. (2011) find the impact of REER on Austrian CA balances to be negative and statistically significant, positive and statistically significant on Finnish and Irish CA balances ("favourable product mix" in exports) and insignificant in all other countries. Overall,

\footnotetext{
${ }^{4}$ The financial cycle is driven by credit and housing prices and displays a wider amplitude and longer duration than the normal business cycle. (see also Chapter 2)
} 
the empirical importance of competitiveness measures is not straightforward. Staehr and Vermeulen (2016) show that measures of competitiveness have little explanatory power for CA movements in general. In addition, their findings suggest heterogeneous responses of CAs to the various competitiveness measures and across countries.

This literature review indicates that empirical research identifies various channels which can help explain the diverging development in EA external balances. There is no consensus about the importance of the various channels, but changes in demand seem particularly important in explaining deficit countries' external deficits and are on average more important than changes in competitiveness in explaining diverging external balances.

\subsubsection{Competitiveness and the real effective exchange rate ${ }^{5}$}

I showed in the last sub-section that the divergence in external competitiveness of EA countries is frequently cited as one of the reasons for growing external imbalances in the EA. Competitiveness is often approximated by international price competitiveness as measured by exchange rate indicators, differently deflated (di Mauro and Forster, 2008). REERs are defined as nominal effective exchange rates (NEER) deflated by similarly weighted measures of relative prices or costs. The NEER of the euro is calculated as the geometric weighted average of a basket of bilateral nominal exchange rates. The weights ${ }^{6}$ reflect the importance of each partner country in total EA exports as well as competition in third markets:

$$
N E E R_{t}=\prod_{i=1}^{N}\left(e_{i t, \text { euro }}\right)^{w_{i}}
$$

where $N$ stands for the number of competitor countries, $e_{i t, \text { euro }}$ is an index of the average exchange rate of the currency of partner country $i$ vis-à-vis the euro in period $t$ (expressed in terms of foreign currency per euro, i.e. an increase in the index represents an appreciation of the euro), and $w_{i}$ is the trade weight assigned to the currency of trading partner $i$. Likewise, the REER of the euro is measured as the geometric weighted average of deflated bilateral nominal exchange rates

\footnotetext{
${ }^{5}$ I start the exposition in 1999Q1 to show how exchange rates have developed since the launch of the euro.

${ }^{6}$ The construction of effective exchange rates requires several choices with respect to the currencies to be included, the use of fixed (base year) or time varying (continuously updated) weights, and the weighting scheme. In practice, the double-weighting scheme is the most prominent weighting scheme among institutions like the BIS, OECD, IMF, World Bank, Eurostat and Bruegel. For a detailed discussion, please refer to Darvas (2012), Klau and Fung (2006) and Turner and Van 't dack (1993). Schmitz et al. (2012) present the methodology for calculating the effective exchange rates of the euro.
} 


$$
R E E R_{t}=\prod_{i=1}^{N}\left(\frac{d_{t, \text { euro }} e_{i t, \text { euro }}}{d_{i t}}\right)^{w_{i}}
$$

where $d_{t, e u r o}$ and $d_{i t}$ are, respectively, the deflators for the EA and partner country $i$.

Traditionally, a distinction is made between REERs defined in terms of relative prices (consumer price index (CPI), producer price index, GDP deflator) and those defined in terms of relative costs (unit labour cost in manufacturing, unit labour cost in the total economy). Relative export prices expressed in a common currency are another indicator for gauging price competitiveness. Chinn (2006); Lafrance et al. (1998), Schmitz et al. (2012) and Turner and Van 't dack (1993), for instance, review the advantages and drawbacks of the various deflators as measures of international competitiveness. The European Central Bank publishes the Harmonised Competitiveness Indicators (HCI) for individual EA member states which are conceptually equivalent to the REER of a currency, as they consider both intra- and extra-EA trade relations of the respective country. HCIs are calculated on the basis of weighted averages of bilateral exchange rates vis-à-vis the currencies of the trading partners of each EA country and are deflated by appropriate cost or price indicators. ${ }^{7}$

A number of empirical studies investigated developments in the competitive performance of the aggregate EA and of its constituent member states. Competitiveness of the aggregate EA is examined using the various cost and price deflators. At the country level, competitiveness is compared across and within countries (intra-EA versus extra-EA competitiveness). Ca'Zorzi and Schnatz (2007) and Schmitz et al. (2012) investigate the competitive performance of the aggregate EA. Their results point to a slight improvement in EA competitiveness since the introduction of the single currency with respect to the EA's main trading partners and they indicate that the choice of deflator is of minor importance for this result. Further, it is widely acknowledged that the aggregate EA developments do not reflect the competitive performance of individual EA member states. Persistent and steady divergence in competitiveness across EA countries was observed since the introduction of the euro (Croci Angelini and Farina, 2012; de Grauwe, 2007; Schmitz et al., 2012; WGEM, 2012). However, the high co-movement of different REER indicators at the EA level does not translate to the individual country level. Rather, the results depend on the underlying choice of competitiveness indicator (Schmitz et al., 2012; Schmitz and Von Hagen, 2011; WGEM, 2012). Also, Bayoumi et al. (2011) question the reliability of REER based indicators in assessing external competitiveness. To sum, the

\footnotetext{
${ }^{7}$ www.ecb.europa.eu
} 
choice of the deflator might determine the outcome of any economic analysis (Staehr and Vermeulen, 2016). Despite the apparent discrepancies across competitiveness indicators there is general agreement in the literature that Austria and Germany are the two EA countries having gained competitiveness since the introduction of the single currency, across indicators and with respect to all trading partners.

\subsubsection{Global VAR modelling}

The GVAR framework was introduced by Pesaran et al. (2004). Bussière et al.(2009) and Chudik and Pesaran (2016) contain an overview of subsequent developments of the GVAR. ${ }^{8}$ The GVAR model is composed of a large number of unit ${ }^{9}$-specific models. It was initially developed as a tool for credit risk analysis, but the approach was applied to a variety of questions. ${ }^{10}$ In the context of multi-country macroeconomic models, core domestic variables (such as real output, interest rate, exchange rate) are related to observed global variables, such as international energy prices, for instance, and to foreign specific variables. The foreign specific variables are constructed as weighted averages of foreign variables corresponding to the domestic variables in questions, typically using trade weights. In order to overcome the 'curse of dimensionality', country-specific error-correcting models (ECM) are separately estimated, conditional on the foreign variables that are treated as weakly exogenous. Countryspecific models are then solved simultaneously for all the endogenous variables in the global model (di Mauro et al., 2010). The approach is particularly suited to analyse the transmission of shocks from one market, country, or region to other markets and economies. It allows the modelling of long-run relations between domestic and foreign variables, and it can be used for ex-ante forecasting of global macro variables.

Applications with respect to the EA and global imbalances include the analysis of the international linkages of the EA (Dées et al., 2005; Koukouritakis et al., 2015) and crosscountry linkages within the EA (Sun et al., 2013), the modelling of sovereign bond spreads in the EA (Croci Angelini et al., 2015, 2015; Favero, 2013; Niehof, 2014), the identification of fiscal spillovers in the EA (Belke and Osowski, 2016) and regional financial spillovers across Europe (Galesi and Sgherri, 2013). Bussière et al. (2009) were the first to apply the GVAR methodology to the issue of international trade and global imbalances. Their study identifies

\footnotetext{
${ }^{8}$ In this paper, I use the GVAR Toolbox 2.0 Smith and Galesi (2014) for all my empirical computations.

${ }^{9}$ These units can be for instance countries, or regions, industries or sectors of a given economy.

${ }^{10}$ The GVAR handbook by di Mauro and Pesaran (2013) gives an overview of the various applications of the GVAR model in the literature, including international transmission and forecasting, finance applications and regional applications.
} 
the drivers of exports and imports at the individual country level. Shocks to US output are found to significantly affect international exports, and their impact is more important than the impact of shocks to the US REER. Holinski and Vermeulen (2009) test the link between asset prices, consumption and the trade balance and find the international wealth effect to be present in some but not all countries. Bettendorf (2012) investigates the international drivers of external imbalances and provides evidence of the relative unimportance of shocks to real GDP and of US exchange rate shocks in explaining trade balance movements of the aggregate EA. Oil price shocks are found to be important drivers of the trade balance. Bettendorf (2017) investigates the development of external balances and shows that a shock to US real GDP can have short run (Germany and Spain) as well as long run (France) effects on international trade balances of individual EA countries. Furthermore, shocks to real equity prices and the oil price are shown to significantly affect some but not all EA trade balances. Dées (2013) investigates the impact of heterogeneous developments in price-cost competitiveness between EA member states on their trade balances and finds evidence for the positive impact of favourable supply shocks on economic activity and external accounts.

\subsection{Constructing the GVAR model}

In this section, I derive the theoretical foundations of my empirical GVAR model and describe how the model will be empirically implemented.

\subsubsection{The GVAR methodology}

I assume that there are $N$ countries in the global economy, indexed by $i=1, \ldots, N$. For each country, the country specific variables are related to the global economy variables measured as country-specific weighted averages of foreign variables, plus deterministic variables (constant and time trend) and a global (weakly) exogenous variable (oil price). The GVAR methodology proceeds in two stages. In the first stage, a country-specific $\operatorname{VARX} X^{*}\left(p_{i}, q_{i}\right)$ model is estimated for each country $i$ in the sample.

$$
\boldsymbol{x}_{i t}=\boldsymbol{a}_{i 0}+\boldsymbol{a}_{i 1} t+\sum_{l=1}^{p_{i}} \boldsymbol{\Phi}_{i l} \boldsymbol{x}_{i, t-l}+\sum_{m=0}^{q_{i}} \boldsymbol{\Psi}_{i m} \boldsymbol{x}_{i, t-m}^{*}+\boldsymbol{u}_{i t}, \quad i=1, \ldots, N, t=1, \ldots, T
$$

$\boldsymbol{a}_{i 0}$ and $\boldsymbol{a}_{i 1}$ are $k_{i} x 1$ coefficient vectors of the deterministic intercept and time trend. $\boldsymbol{x}_{i t}$ is a

$k_{i} \times 1$ vector of endogenous country-specific variables with corresponding $k_{i} \times k_{i}$ matrices of lagged coefficients $\boldsymbol{\Phi}_{i l} \cdot \boldsymbol{x}_{i t}^{*}$ is a $k_{i}^{*} \times 1$ vector of exogenous trade-weighted foreign variables 
with corresponding $k_{i} \times k_{i}^{*}$ matrices of contemporaneous and lagged coefficients $\boldsymbol{\Psi}_{i m} \cdot \boldsymbol{u}_{i t}$ is a $k_{i} \times 1$ vector of zero mean, idiosyncratic country-specific shocks, assumed to be serially uncorrelated with time-invariant covariance matrix $\Sigma_{i i}$. Given the short time span over which the model is estimated and the number of variables included in the estimations, I allow at maximum for a $\operatorname{VARX}^{*}(2,1)$ specification. This maximum specification is standard in the GVAR literature (Bettendorf, 2012; Dées et al., 2005; Holinski and Vermeulen, 2009). The modelling approach is well-suited to deal with variables that are approximately integrated of order one. The $\operatorname{VARX}^{*}(2,1)$ can be written and estimated in a compact error-correction representation, $V E C M X^{*}$, as

$$
\Delta \boldsymbol{x}_{i t}=\boldsymbol{a}_{i 0}+\boldsymbol{a}_{i 1} t-\left(\boldsymbol{A}_{i}-\boldsymbol{B}_{i}-\boldsymbol{C}_{i}\right) \mathbf{z}_{i t-1}-\boldsymbol{\Phi}_{i 2} \Delta \boldsymbol{x}_{i t-1}+\boldsymbol{\Psi}_{i 0} \Delta \boldsymbol{x}_{i, t}^{*}+\boldsymbol{u}_{i t}, i=1, \ldots, N
$$

where $\boldsymbol{z}_{i t}=\left(\begin{array}{l}\boldsymbol{x}_{i t} \\ \boldsymbol{x}_{i t}^{*}\end{array}\right), \boldsymbol{A}_{i}=\left(\boldsymbol{I}_{k_{i}},-\boldsymbol{\Psi}_{i 0}\right), \boldsymbol{B}_{\boldsymbol{i}}=\left(\boldsymbol{\Phi}_{i 1}, \boldsymbol{\Psi}_{i 1}\right)$ and $\boldsymbol{C}_{i}=\left(\boldsymbol{\Phi}_{i 2}, \mathbf{0}_{k_{i}^{*}}\right) . \boldsymbol{A}_{i}, \boldsymbol{B}_{i}$ and $\boldsymbol{C}_{i}$ are matrices of dimension $k_{i} \times\left(k_{i}+k_{i}^{*}\right)$. Let

$$
\boldsymbol{\Pi}_{i}=\left(\boldsymbol{A}_{i}-\boldsymbol{B}_{i}-\boldsymbol{C}_{i}\right)
$$

The rank $\left(\tau_{i}\right)$ of $\boldsymbol{\Pi}_{i}$ determines the number of long-run relationships between domestic and country-specific foreign variables $\boldsymbol{x}_{i t}$ and $\boldsymbol{x}_{i, t}^{*}$. Therefore, I have

$$
\left(\boldsymbol{A}_{i}-\boldsymbol{B}_{i}-\boldsymbol{C}_{i}\right)=\boldsymbol{\alpha}_{i} \boldsymbol{\beta}_{i}^{\prime}
$$

where $\boldsymbol{\alpha}_{i}$ is the $k_{i} \times \tau_{i}$ loading matrix of full column rank and $\boldsymbol{\beta}_{i}$ is the $\left(k_{i}+k_{i}^{*}\right) \times \tau_{i}$ matrix of cointegrating vectors, also of full column rank. Pesaran et al. (2000) show that in the case where $\boldsymbol{\Pi}_{i}$ is rank deficient and the linear trend coefficients $\boldsymbol{a}_{i 1}$ are unrestricted, the linear trend in the error-correction model transforms into a quadratic trend in $\boldsymbol{x}_{i t}$. In order to retain the same deterministic trend properties for the elements of $\boldsymbol{x}_{i t}$ under different rank restrictions on $\boldsymbol{\Pi}_{i}$, the trend coefficients need to be restricted so that

$$
\boldsymbol{a}_{i 1}=\left(\boldsymbol{A}_{i}-\boldsymbol{B}_{i}-\boldsymbol{C}_{i}\right) \boldsymbol{\gamma}_{i}
$$

where $\gamma_{i}$ is a $\left(k_{i}+k_{i}^{*}\right) \times 1$ vector of fixed constants. Equation (4.4) can then be written as

$$
\Delta \boldsymbol{x}_{i t}=\boldsymbol{c}_{i 0}-\boldsymbol{\Pi}_{i}\left(\boldsymbol{z}_{i t-1}-\boldsymbol{\gamma}_{i}(t-1)\right)-\boldsymbol{\Phi}_{i 2} \Delta \boldsymbol{x}_{i t-1}+\boldsymbol{\Psi}_{i 0} \Delta \boldsymbol{x}_{i, t}^{*}+\boldsymbol{u}_{i t}
$$

where $\boldsymbol{c}_{i 0}=\boldsymbol{a}_{i 0}+\boldsymbol{\Pi}_{i} \boldsymbol{\gamma}_{i}$. This specification includes the trend into the ECM specification and imposes $k_{i}-\tau_{i}$ restrictions on the trend coefficients (Pesaran et al., 2004). 
The contemporaneous dependence of the domestic variables $\boldsymbol{x}_{i t}$ on foreign variables $\boldsymbol{x}_{i t}^{*}$ requires simultaneous solving of the country-specific models for all of the domestic variables $\boldsymbol{x}_{i}$. In the second step of the GVAR methodology, all of the country-specific variables are collected in the $k \times 1$ global vector $\boldsymbol{x}_{t}=\left(\boldsymbol{x}_{1 t}^{\prime}, \ldots, \boldsymbol{x}_{N t}^{\prime}\right)^{\prime}$, where $k=\sum_{i=1}^{N} k_{i}$ is the total number of endogenous variables in the global model. The country-specific variables can all be written in terms of $\boldsymbol{x}_{t}$,

$$
\boldsymbol{z}_{i t}=\boldsymbol{W}_{i} \boldsymbol{x}_{t}, i=1, \ldots, N
$$

where the $\boldsymbol{W}_{i}$ are $\left(k_{i}+k_{i}^{*}\right) \times k$ country-specific matrices of fixed (known) constants defined in terms of the country-specific trade weights used in the construction of foreign variables. $\boldsymbol{W}_{i}$ can be viewed as the 'link' matrix that allows the country-specific models to be written in terms of the global variable vector $\boldsymbol{x}_{t}$.

Rewrite (4.4) as

$$
\boldsymbol{A}_{i} \Delta \boldsymbol{z}_{i t}=\boldsymbol{a}_{i 0}+\boldsymbol{a}_{i 1} t-\left(\boldsymbol{A}_{i}-\boldsymbol{B}_{i}-\boldsymbol{C}_{i}\right) \boldsymbol{z}_{i t-1}-\boldsymbol{\Phi}_{i 2} \Delta \boldsymbol{x}_{i t-1}+\boldsymbol{u}_{i t}
$$

Stacking these equations yields

$$
\boldsymbol{F} \Delta \boldsymbol{x}_{t}=\boldsymbol{a}_{0}+\boldsymbol{a}_{1} t-(\boldsymbol{F}-\boldsymbol{G}-\boldsymbol{H}) \boldsymbol{x}_{t-1}-\boldsymbol{\Phi}_{2} \Delta \boldsymbol{x}_{t-1}+\boldsymbol{u}_{t}
$$

where

$$
\begin{gathered}
\boldsymbol{a}_{0}=\left(\begin{array}{c}
\boldsymbol{a}_{10} \\
\vdots \\
\boldsymbol{a}_{N 0}
\end{array}\right), \boldsymbol{a}_{1}=\left(\begin{array}{c}
\boldsymbol{a}_{11} \\
\vdots \\
\boldsymbol{a}_{N 1}
\end{array}\right), \boldsymbol{\Phi}_{2}=\left(\begin{array}{c}
\boldsymbol{\Phi}_{12} \\
\vdots \\
\boldsymbol{\Phi}_{N 2}
\end{array}\right), \boldsymbol{u}_{t}=\left(\begin{array}{c}
\boldsymbol{u}_{1 t} \\
\vdots \\
\boldsymbol{u}_{N t}
\end{array}\right), \\
\boldsymbol{F}=\left(\begin{array}{c}
\boldsymbol{A}_{1} \boldsymbol{W}_{1} \\
\vdots \\
\boldsymbol{A}_{N} \boldsymbol{W}_{N}
\end{array}\right), \boldsymbol{G}=\left(\begin{array}{c}
\boldsymbol{B}_{1} \boldsymbol{W}_{1} \\
\vdots \\
\boldsymbol{B}_{N} \boldsymbol{W}_{N}
\end{array}\right), \boldsymbol{H}=\left(\begin{array}{c}
\boldsymbol{C}_{1} \boldsymbol{W}_{1} \\
\vdots \\
\boldsymbol{C}_{N} \boldsymbol{W}_{N}
\end{array}\right)
\end{gathered}
$$

$\boldsymbol{F}$ is a $k \times k$-dimensional, generally full-rank, nonsingular matrix. The GVAR model in all variables can hence be written as

$$
\Delta \boldsymbol{x}_{t}=\boldsymbol{F}^{-1} \boldsymbol{a}_{0}+\boldsymbol{F}^{-1} \boldsymbol{a}_{1} t-\boldsymbol{F}^{-1}(\boldsymbol{F}-\boldsymbol{G}-\boldsymbol{H}) \boldsymbol{x}_{t-1}-\boldsymbol{F}^{-1} \boldsymbol{\Phi}_{2} \Delta \boldsymbol{x}_{t-1}+\boldsymbol{F}^{-1} \boldsymbol{u}_{t} .
$$

The GVAR allows for interactions among the different economies through three separate but interrelated channels: (1) contemporaneous dependence of the domestic variables $\boldsymbol{x}_{i t}$ on $\boldsymbol{x}_{i, t}^{*}$ and on its lagged values, (2) dependence of the country-specific variables on common global exogenous variables (e.g. oil price), (3) nonzero contemporaneous dependence of shocks in country $i$ on the shocks in country $j$, as the shocks are allowed to be weakly correlated in $\Sigma_{i j}$. 


\subsubsection{Model specification}

The focus of my empirical analysis is on nine initial EA members: Austria (AT), Finland (FI), France (FR), Germany (GE), Ireland (IR), Italy (IT), the Netherlands (NE), Portugal (PT) and Spain (SP). ${ }^{11}$ They are modelled separately within the GVAR modelling framework to account for inter-linkages among the EA countries as well as between individual EA countries and the global economic system. In addition to country-specific models for these nine initial EA member states, I include country-specific models for nine of their most important trading partners: China (CHN), Denmark (DK), Japan (JP), Norway (NO), Poland (PL), Sweden (SWE), Switzerland (SWI), the UK and the US.

\section{Table 4.1 Geographic coverage of the GVAR model}

\begin{tabular}{|lll|}
\hline Euro area & Rest of the world & \\
Austria & EU countries & World \\
Finland & Denmark & US \\
France & Poland & China \\
Germany & Sweden & Japan \\
Ireland & UK & \\
Italy & & \\
Netherlands & Rest of Western Europe & \\
Portugal & Norway & \\
Spain & Switzerland & \\
\hline
\end{tabular}

The geographic coverage of my GVAR model is less complete than in other applications. Compared with other GVAR studies, my analysis leaves out India, Russia, Latin American and South East Asian countries, Saudi Arabia and also the OECD countries Australia, Canada, Mexico and New Zealand. I focus on the most important trading partners of EA countries on average. To this end, I identified the top-20 trading partners for each of the 9 EA countries. India is not among the top-20 trading partners for any of the nine EA countries. To the contrary, Russia has gained importance as a trading partner for all 9 EA countries in recent years, in particular Finland. However, the country is not included in the analysis due to the lack of reliable data. Among the top-20 trading partners, I observe a strong regional dependence among EA countries. For example, the Russian Federation and Estonia are important trading partners

\footnotetext{
${ }^{11}$ I have chosen to leave out both Belgium and Luxembourg from the analysis because of gaps in the trade data series. The IMF Direction of Trade statistics (DOTS) database treats the Economic Union of Belgium and Luxembourg as single trading partner until 1996Q4. For 1997 and 1998, there is (in many cases) a reporting gap for both Belgium and Luxembourg. For instance, no data on bilateral exports from Germany to either Belgium or Luxembourg are available for the years 1997 and 1998.
} 
for Finland, while Portugal and Spain have important trade relations with African and Latin American countries. In 1999 (2012), the countries included in the analysis account for 70\% $84 \%(57 \%-76 \%)$ of total trade of the individual EA countries. Table 4.1 gives an overview of the countries included in the analysis of this chapter.

The choice of variables for the GVAR models depends on the empirical application under study. I seek to identify how shocks to domestic or foreign GDP, to external competitiveness or domestic monetary policy shocks are transmitted to intra-EA and extra-EA trade balances and REERs, and to what extent those shocks are disruptive. I therefore include both intra- and extraEA trade balances into the country-specific models of EA countries. The same distinction applies for the REER of EA countries. The intra- and extra-EA distinction for trade balances and REER does not apply for the country-specific models of the ROW countries. This modelling specification exploits the flexibility of the GVAR approach to allow for different sets of variables in the individual country models (Assenmacher, 2013). It results in the following specification. For the EA countries, the vector of country-specific endogenous variables equals

$$
\boldsymbol{x}_{i t}=\left(t b_{i t}^{e a}, t b_{i t}^{\text {row }}, q_{i t}^{e a}, q_{i t}^{\text {row }}, y_{i t}, r_{i t}\right) \text {, with } k_{i}=6 \text {, and } i \in E A
$$

Likewise, the vector of endogenous country-specific variables for ROW countries is given by

$$
\boldsymbol{x}_{i t}=\left(t b_{i t}^{w}, q_{i t}^{w}, y_{i t}, r_{i t}\right), \text { with } k_{i}=4, \text { and } i \in R O W
$$

and for the US by

$$
\boldsymbol{x}_{i t}=\left(t b_{i t}^{w}, q_{i t}^{w}, y_{i t}, r_{i t}, p o i l\right), \text { with } k_{i}=5
$$

where $t b_{i t}^{e a}$ is the intra-EA trade balance of EA country i, $t b_{i t}^{\text {row }}$ is the extra-EA trade balance of EA country $i, t b_{i t}^{w}$ is the trade balance of ROW country $i$ with respect to all other countries in the model. All trade balances are defined as the log of the respective exports over imports. Likewise, $q_{i t}^{e a}$ is the REER of EA country $i$ with respect to the EA countries, $q_{i t}^{\text {row }}$ is the REER of EA country $i$ with respect to non-EA countries, and $q_{i t}^{w}$ is the REER of ROW country $i$ with respect to all other countries. All REERs are computed using the CPI and are expressed in logs. $y_{i t}$ is the $\log$ of the domestic real GDP index. The domestic short-term real interest rate $r_{i t}$ is the $\log$ of an annualised nominal short-term interest rate deflated by the consumer price index and adjusted for quarterly frequency. An overview of the variables' definitions, sources and manipulations are presented in Table 4.2. ${ }^{12}$ The oil price poil is the log of the oil price index

\footnotetext{
${ }^{12}$ The descriptive statistics are presented in Table 4.10 in Appendix II.
} 
and is included in the computations to account for possible common factors influencing the external balances. Since the GVAR model is a closed system, all variables need to be determined endogenously. I follow the general practice in GVAR modelling and include the oil price as endogenous variable into the US country-specific model (Dées et al., 2005; Holinski and Vermeulen, 2009). My model specification and the definition of the variables is close to Bettendorf (2012). The major difference is the distinction of intra-EA and extra-EA trade balance and REER for EA countries in this chapter.

In addition, the country-specific foreign real GDP and the country-specific foreign real interest rate are included into the system as exogenous variables and provide the link between the individual country models. Foreign variables are computed as trade-weighted averages of the corresponding domestic variables of all countries: $y_{i t}^{*}=\sum_{j=1}^{N} \omega_{i j} y_{j t}$ and $r_{i t}^{*}=\sum_{j=1}^{N} \omega_{i j} r_{j t}$, where $\omega_{i j}$ are a set of trade weights such that $\omega_{i i}=0$ and $\sum_{j=1}^{N} \omega_{i j}=1$. The vector of countryspecific foreign variables $\boldsymbol{x}_{i t}^{*}$ is, hence, a $k_{i}^{*} \times 1$ vector of weighted averages, where $k_{i}^{*}=3$, $\forall i \backslash U S$, i.e. $\boldsymbol{x}_{i t}^{*}=\left(y_{i t}^{*}, r_{i t}^{*}\right.$, poil $)$. Likewise, the vector of country-specific foreign variables in the US model is a $k_{i}^{*} \times 1$ vector of weighted averages, where $k_{i}^{*}=2$, i.e. $\boldsymbol{x}_{i t}^{*}=\left(y_{i t}^{*}, r_{i t}^{*}\right)$. The country-specific trade weights $\omega_{i j}$ for $i, j=1, \ldots, N$ are the sum of bilateral exports and imports between country $i$ and $j$ relative to the sum of total bilateral exports and imports of country $i$. I employ time-invariant trade weights, which I obtain as averages over the years 2009-2011. Fixed trade weights are the preferred option in open economy macroeconomic modelling (Bettendorf, 2012; Bussière et al., 2009; Holinski and Vermeulen, 2009). ${ }^{13}$ Other weighting schemes such as GDP or financial weights can also be used. The GVAR analysis can accommodate different weighting schemes for the various variables. Chudik and Pesaran (2009) show that weights are of secondary importance if the small open economy conditions are satisfied. Holinski and Vermeulen (2009) compute country-specific foreign variables using fixed and time-varying weights and find that the series are highly correlated. The $18 \times 18$ trade share matrix that is used in constructing the country-specific foreign variables is presented in Table 4.3.

\footnotetext{
${ }^{13}$ Cesa-Bianchi et al. (2012) use time-varying trade weights, motivated by changes in geographical trade patterns over time. A disadvantage is that temporary changes in trade relations might be overestimated. It also can lead to a change in the number of co-integrating relationships compared to the fixed weights analysis.
} 


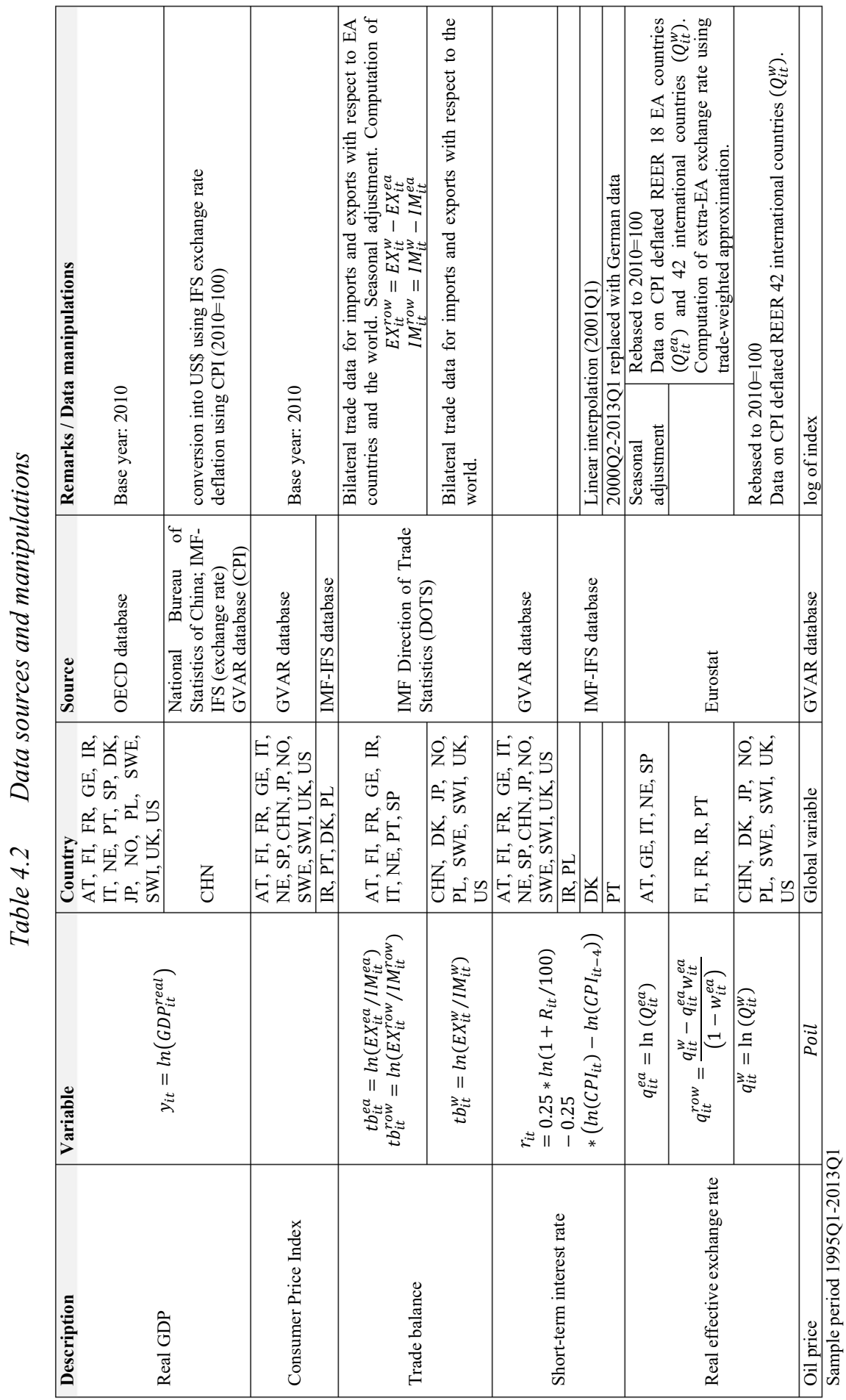




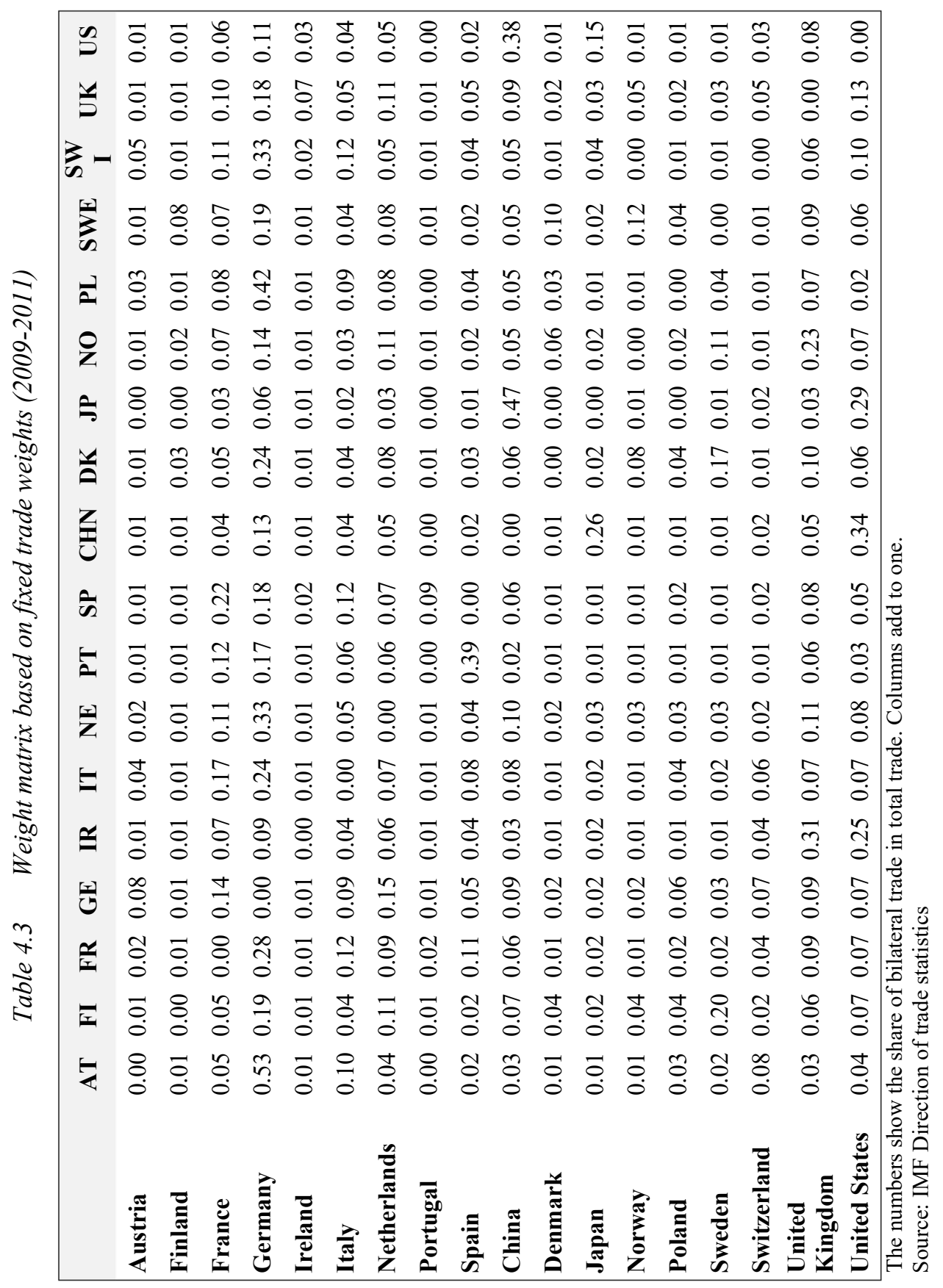


Figure 4.1 Intra-EA and extra-EA trade balances
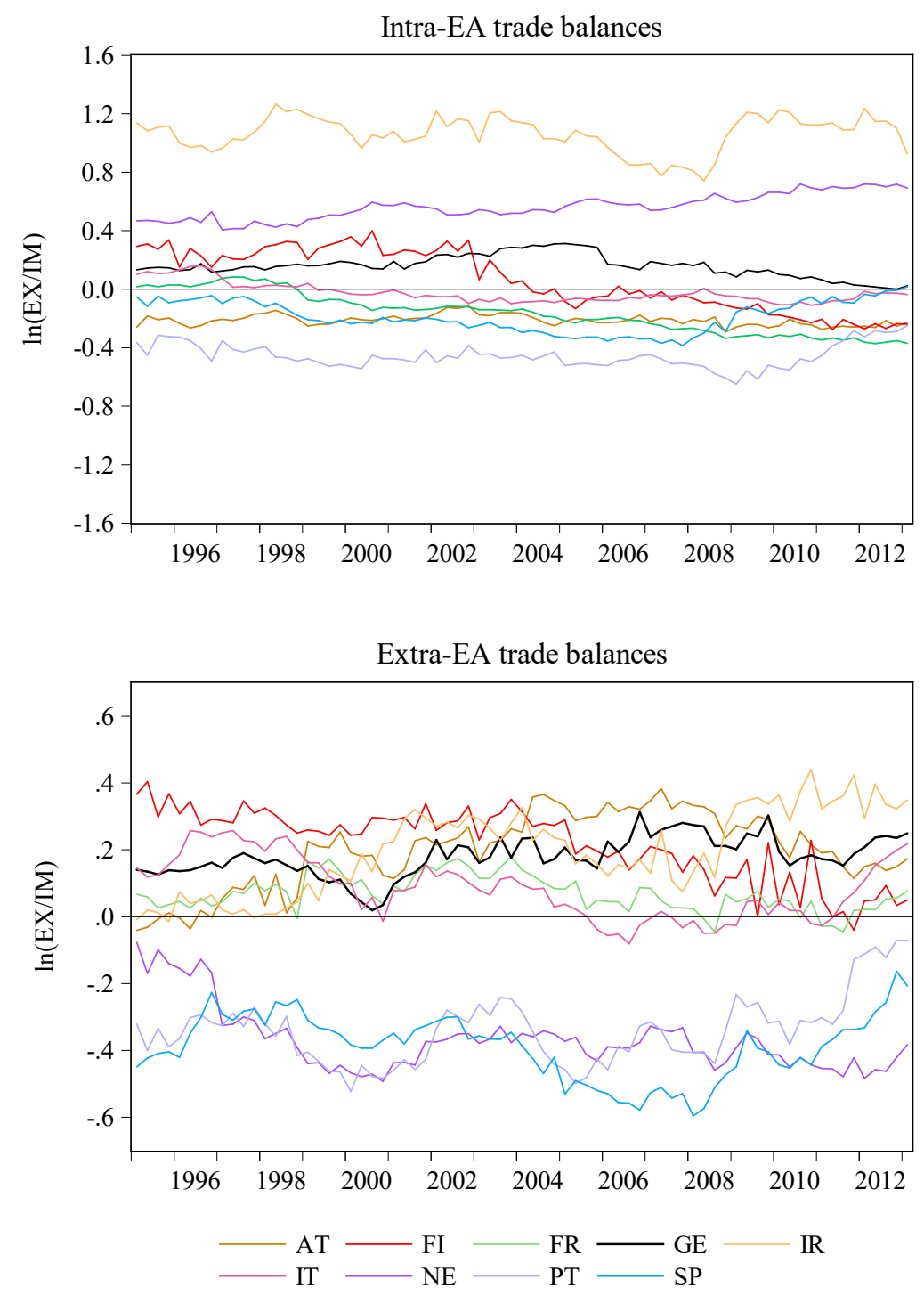

\subsection{Data}

In this section, I present my empirical data. I use data from different sources for the period 1995Q1-2013Q1. Although I am interested in investigating trade balance developments of individual EA countries in the euro period, I have extended my sample period to include preeuro data in order to increase the total number of observations. Nominal exchange rates between 
EA countries have displayed a certain degree of stability in the aftermath of the 1992/93 ERM ${ }^{14}$ crisis and in the run up to the introduction of the single currency.

The literature overview in section 4.2 provides evidence that the average EA trade position and competitiveness relative to the rest of the world mask significant heterogeneities among individual EA countries. In addition to cross-country differences, the intra-EA and extra-EA trade performance of individual EA countries might diverge. Figure 4.1 displays the development of intra-EA and extra-EA trade balances. Persistent cross-country heterogeneities are directly apparent. Whereas Germany and Ireland unambiguously display intra-EA and extra-EA trade balance surpluses over time, the trade balances of Portugal and Spain exhibit deficits since 1995. Austria, France and Italy show differences in intra-EA and extra-EA trade performance: whereas their intra-EA trade balances are in deficit, their extra-EA trade balances are in surplus most of the time. The Finnish trade balances are in surplus until 2004 when the country becomes a net importer within the EA. In both Ireland and the Netherlands, the size of the intra-EA trade balance by far exceeds the extra-EA trade balance. I note that the recent global crisis does not show up as an obvious break in the data series. ${ }^{15}$ The negative trend in the Finnish and French intra-EA trade balance continues unabated after the crisis. Also, consolidation of the German intra-EA trade balance continues in the aftermath of the crisis. To the contrary, the crisis leads to a trend reversal in the development of the Irish, Portuguese and Spanish trade balances; the countries see both their intra-EA and extra-EA trade balances improve since 2008.

The definition of the REER in equation (4.2) in section 4.2.2 also applies to individual countries with the deflators adjusted accordingly. I disaggregate the resulting country-specific definition of the REER into intra-EA and extra-EA REER. Broadly speaking, REER movements of individual EA members represent a weighted average of intra-EA and extra-EA exchange rates and can be approximated by

$$
R E E R_{z t}=\prod_{\substack{i=1 \\ i \in E A \backslash z}}\left(\frac{d_{z t}}{d_{i t}}\right)^{w_{i}} \times \prod_{\substack{j=1 \\ j \in R O W}}^{N-M}\left(\frac{d_{z t} e_{j t, e u r o}}{d_{j t}}\right)^{w_{j}}, z \in E A
$$

$w_{i}$ and $w_{j}$ are not the same across EA countries $z$. Since the NEER between EA countries is fixed since the start of EMU, fluctuations in $R E E R_{z t}$ are due to 1) changes in price competitiveness of country $z$ with respect to other EA member states, 2) changes in price

\footnotetext{
${ }^{14}$ European Exchange Rate Mechanism

${ }^{15}$ The crisis had a dampening effect on global trade. Both intra-EA and extra-EA imports and exports significantly decreased. The graphs suggest that the magnitude of the decreases were of similar size.
} 
competitiveness of country $z$ with respect to international trading partners that do not belong to the EA, 3) the bilateral exchange rates between the euro and international trading partners $j$. The REER of individual EA countries with respect to EA countries and the REER of individual EA countries with respect to the rest of the world including all other EA members can be extracted from the Eurostat database. To the contrary, empirical data on extra-EA REER is not readily available. There is no straightforward way to extract REER movements for non- EA trading partners because of the double weighting scheme used by international institutions in the computation of the REER. I have extracted the REER of individual EA countries with respect to extra-EA trading partners using an approximation. Specifically, I assume that the REER of EA countries with respect to the rest of the world is a trade-weighted average of bilateral exchange rates between country $i$ and its trading partners $j$

$$
q_{i}^{W}=\sum_{j \in W} \alpha_{i j}^{W} q_{i}^{j}
$$

where $\alpha_{i j}^{W}=\frac{E X_{i}^{j}+I M_{i}^{j}}{\sum_{j \in W}\left(E X_{i}^{j}+I M_{i}^{j}\right)}$ is the trade share of country $i$ with country $j$ in country $i$ 's total trade, $q_{i}^{j}=\left(\frac{P_{i}}{E_{j i} P_{j}}\right)$ is the bilateral exchange rate of country $i$ with respect to country $j .{ }^{16}$

It follows that

$$
q_{i}^{W}=\sum_{j \in E A} \alpha_{i j}^{W} q_{i}^{j}+\sum_{j \in R O W} \alpha_{i j}^{W} q_{i}^{j}
$$

I show in Appendix I that the extra-EA exchange rate of country $i$ is given by

$$
q_{i}^{R O W}=\frac{q_{i}^{W}-q_{i}^{E A} w_{i}^{E A}}{\left(1-w_{i}^{E A}\right)}
$$

$w_{i}^{E A}$ and $w_{i}^{R O W}$ are the share of EA and ROW trade in total trade of country $i$, respectively.

\footnotetext{
${ }^{16}$ The REER is defined such that a rise means a loss of competitiveness (real appreciation).
} 
Figure 4.2 Intra-EA and extra-EA real effective exchange rates $(2010 Q 1=100)$


I observe that intra-EA REERs are less volatile than the extra-EA exchange rates (Figure 4.2), because most of the variation in CPI based REER is typically accounted for by movements in the nominal exchange rate, yielding a strong correlation between the NEER and the REER (Schmitz et al., 2012). While the intra-EA REER of Austria, Finland, France and Germany depreciates after 1999, the other countries' intra-EA competitive position deteriorates. A similar picture emerges for extra-EA REER. All countries more or less share the up and down swings 
in the extra-EA REER, due to the dominating effect of the nominal exchange rate changes. However, the size of the swings differs. As a result, the extra-EA competitive position of Austria, Finland and Germany improves in 2013 compared with 1995, while the competitive position of Ireland, Portugal and Spain deteriorates between these two dates. Hence, overall, the data analysis shows heterogeneous developments in both - trade balances and real exchange rates - across the nine EA countries.

\subsection{Model specification and stability}

In this section, I perform a number of preliminary tests for GVAR model specification and stability.

\subsubsection{Unit root tests}

The reduced-rank regression techniques discussed in section 4.3.1 are based on the assumption that the underlying endogenous and exogenous variables in the country-specific models are approximately integrated of order unity (Pesaran et al., 2004). I perform the unit root test for domestic, foreign and the global variables to determine the integration properties of these variables. The unit root test results are based on weighted symmetric (WS) estimations of ADF type regressions (Pesaran et al., 2004) that possess superior power performance compared to standard ADF tests (Park and Fuller, 1995). Table 4.4 and Table 4.5 report unit root t-statistics for the levels, first and second differences of the domestic, foreign and global variables. The statistics are based on univariate AR(p) specifications in the level of the variables where the lag length is determined by the AIC criterion and $p \leq 4$. For the EA countries, all variables are I(1). In the group of the ROW countries the REER of Norway is borderline I(0)/I(1). The interest rates of Norway and Switzerland and the UK trade balance are found to be stationary. All country specific foreign variables are found to be $I(1)$ and the oil price is borderline $I(0) / I(1)$. Based on this evidence, I treat all variables as approximately I(1) in the remainder of my analysis. 


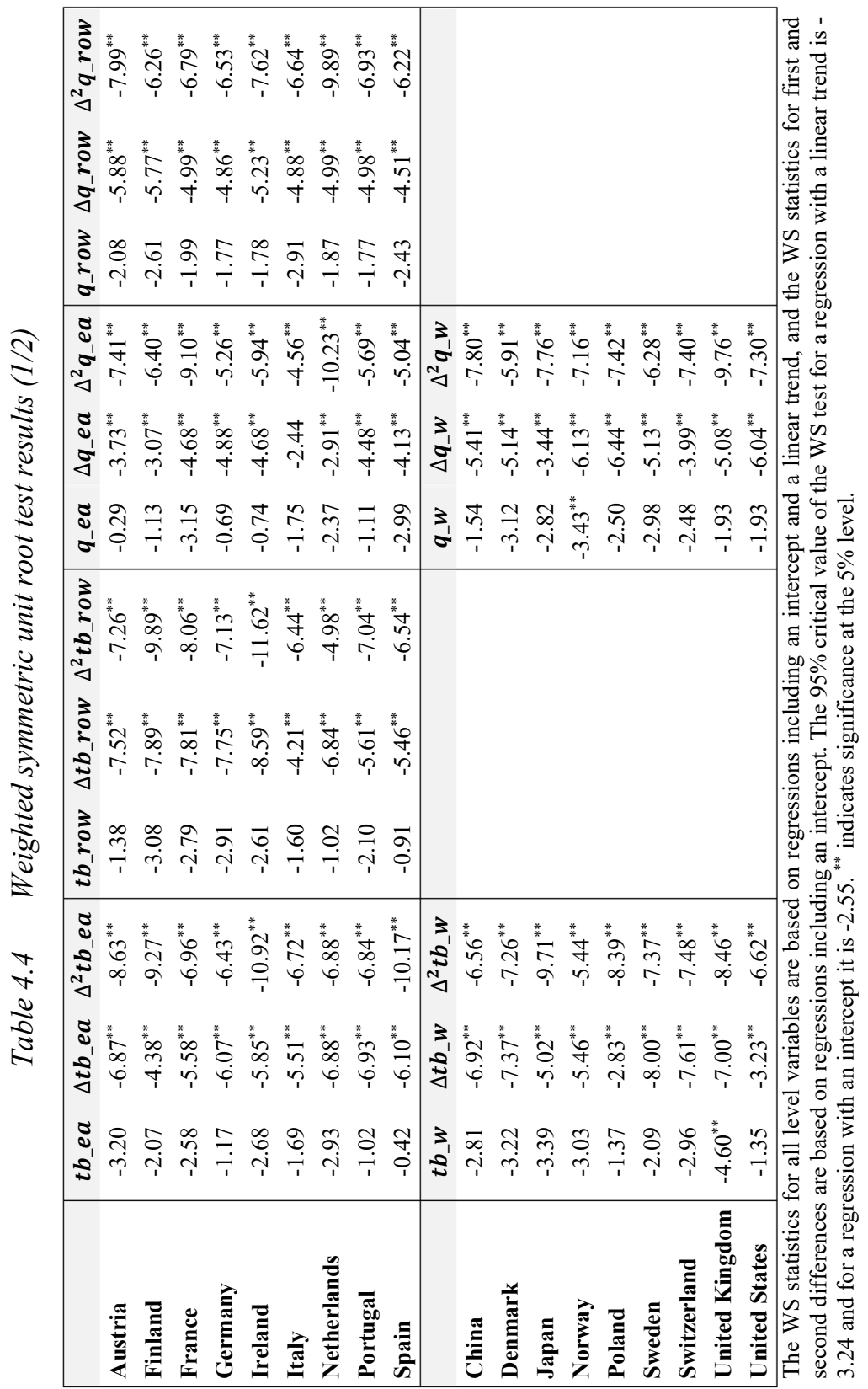




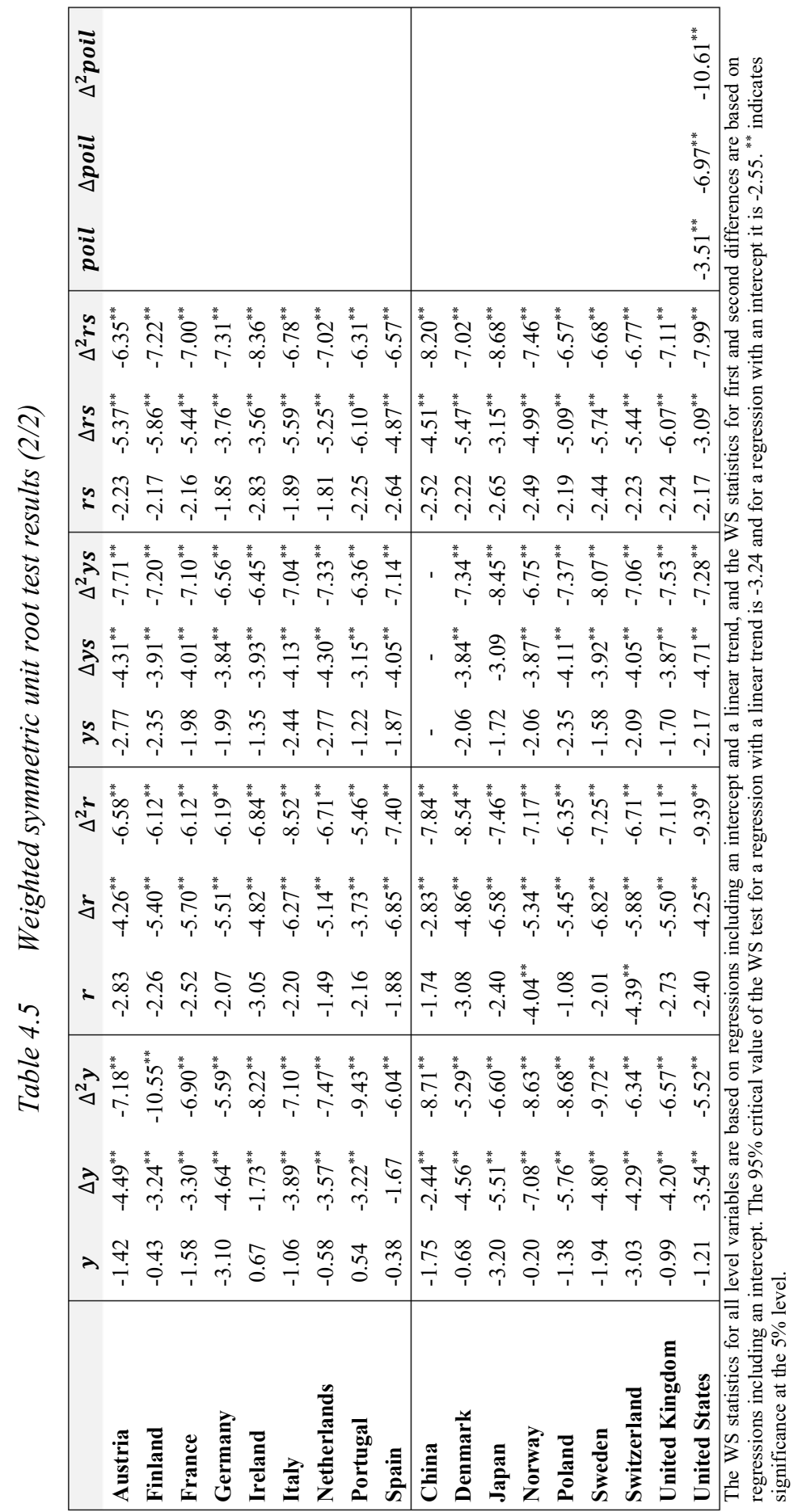


Table 4.6 Lag specification and number of co-integrating relations

\begin{tabular}{lccc|}
\hline Austria & $\mathbf{p}$ & $\mathbf{q}$ & $\begin{array}{c}\text { Co-integrating } \\
\text { relations }\end{array}$ \\
Finland & $2^{*}$ & 1 & 2 \\
France & 2 & 1 & 2 \\
Germany & $2^{*}$ & 1 & 3 \\
Ireland & $2^{*}$ & 1 & 1 \\
Italy & $2^{*}$ & 1 & 2 \\
Netherlands & 2 & 1 & 3 \\
Portugal & 2 & 1 & $3^{\circ}$ \\
Spain & $2^{*}$ & 1 & 1 \\
China & 2 & 1 & $1^{\circ}$ \\
Denmark & 2 & 1 & 3 \\
Japan & 2 & 1 & 0 \\
Norway & 1 & 1 & 2 \\
Poland & 1 & 1 & 1 \\
Sweden & 2 & 1 & 1 \\
Switzerland & 2 & 1 & 2 \\
United & 1 & 1 & 0 \\
Kingdom & 2 & 1 & 2 \\
United States & $2^{*}$ & 1 & 2 \\
*indicates the change in the number of lags. ${ }^{\circ}$ denotes a change in the co- \\
integrating relationships in order to maintain model stability.
\end{tabular}

\subsubsection{Dynamic specification and co-integration}

The order of the dynamic specification of the individual country $\operatorname{VARX^{*}}\left(p_{i}, q_{i}\right)$ model with $p_{i} \leq 2$ and $q_{i}=1$ is determined according to the Akaike information criterion (AIC). The results are reported in Table 4.6. I chose to set the number of lags for domestic variables of EA countries uniformly equal to $2^{17}$.

I next compute the rank of the co-integrating space for each country using Johansen's trace statistics as set out in Pesaran, Shin and Smith (2000) for models with weakly exogenous regressors. The test is known to be more robust to departures from normal errors than the maximum eigenvalue test (Cheung and Lai, 1993). I include an unrestricted constant and a restricted trend coefficient in each of the individual countries' $\mathrm{ECMs}^{18}$. The number of cointegrating relationships, which can be interpreted as long-run relations, either among the domestic variables and/or domestic and foreign variables, varies between 0 (Denmark and

\footnotetext{
${ }^{17}$ The reason for this choice is the high t-statistics for the contemporaneous effect of foreign variables on their domestic counterparts, which disappear under the present model specification.

${ }^{18}$ This specification corresponds to Case IV in Pesaran et al. (2000).
} 
Switzerland) and 3. Figure 4.3 presents the bootstrap means of the persistence profiles which show the speed at which the long-run relations converge to their equilibrium states in response to system wide shocks. All persistence profiles are converging towards zero, suggesting that all considered vectors are co-integrating vectors.

Figure 4.3 Persistence profiles

(Effect of system-wide shocks to the co-integrating relations of the GVAR model)

(bootstrapped median)

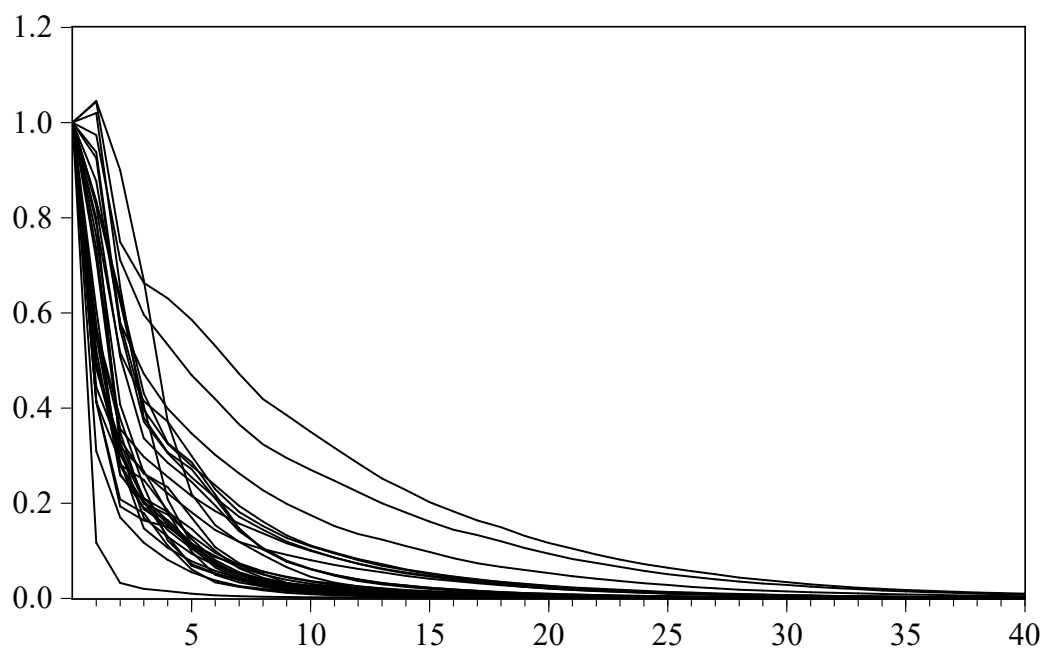

Quarters after the shock

\subsubsection{Weak exogeneity}

One of the key assumptions underlying the estimation approach is the weak exogeneity of the country-specific foreign variables (Pesaran et al., 2004). Following Granger and Lin (1995) and Johansen (1992), the weak exogeneity assumption in the context of cointegrating models implies no long run feedback from $x_{i t}$ to $x_{i t}^{*}$, without necessarily ruling out lagged short run feedback between the two sets of variables. The assumption implies that the error correction terms of the individual country VECMX ${ }^{*}$ models do not enter in the marginal model of $x_{i t}^{*}$ and it represents the statistical formalisation of the standard assumption in the small open economy literature that most economies are too small relative to the size of the world economy to have an impact on the latter (Holinski and Vermeulen, 2009).

A formal test of this assumption is conducted along the lines described in Harbo et al. (1998) and Johansen (1992). This involves a test of the joint significance of the estimated error 
correction terms in auxiliary equations for the country-specific foreign variables $x_{i t}^{*}$. For each $s^{\text {th }}$ element of $x_{i t}^{*}$ the following regression is carried out

$$
\Delta x_{i t, s}^{*}=a_{i s}+\sum_{j=1}^{\tau_{i}} \delta_{i j, s} E \hat{C} M_{i j, t-1}+\sum_{l=1}^{p_{i}^{*}} \phi_{i l, s}^{\prime} \Delta x_{i, t-l}+\sum_{m=1}^{q_{i}^{*}} \psi_{i m, s}^{\prime} \Delta x_{i, t-m}^{*}+\eta_{i t, s}
$$

where $E \hat{C} M_{i j, t-1}, j=1, \ldots, \tau_{i}$ are the estimated error correction terms corresponding to the $\tau_{i}$ cointegrating relations found in the $i^{\text {th }}$ country model, and $p_{i}^{*}$ and $q_{i}^{*}$ are the orders of the lagged changes for the domestic and foreign variables, respectively. ${ }^{19}$ The test for weak exogeneity is an F- test of the joint null hypothesis that $\delta_{i j, l}=0, j=1, \ldots, \tau_{i}$ in the above regression.

\section{Table 4.7 Weak exogeneity test}

\begin{tabular}{|lcccc|}
\hline Austria & F-test & ys & rs & poil \\
Finland & $\mathrm{F}(2,59)$ & 0.35 & 0.01 & 0.73 \\
France & $\mathrm{F}(2,59)$ & 0.25 & $3.17^{* *}$ & 0.22 \\
Germany & $\mathrm{F}(3,58)$ & 1.57 & 0.93 & 0.38 \\
Ireland & $\mathrm{F}(1,60)$ & 0.68 & 0.90 & 1.74 \\
Italy & $\mathrm{F}(2,59)$ & 0.12 & 1.80 & 0.02 \\
Netherlands & $\mathrm{F}(3,58)$ & 1.75 & 0.56 & 1.82 \\
Portugal & $\mathrm{F}(3,58)$ & 0.86 & 0.85 & 0.23 \\
Spain & $\mathrm{F}(1,60)$ & 0.47 & 0.47 & 3.10 \\
China & $\mathrm{F}(1,60)$ & 0.26 & 0.16 & 3.28 \\
Denmark & $\mathrm{F}(3,60)$ & $3.42^{* *}$ & 0.31 & 1.38 \\
Japan & $\mathrm{F}(0,63)$ & - & - & - \\
Norway & $\mathrm{F}(2,61)$ & 1.81 & 2.22 & 0.37 \\
Poland & $\mathrm{F}(1,62)$ & 0.76 & 0.16 & 0.04 \\
Sweden & $\mathrm{F}(1,62)$ & 0.10 & 0.17 & 0.05 \\
Switzerland & $\mathrm{F}(2,61)$ & 1.57 & 0.28 & 1.88 \\
United & $\mathrm{F}(0,63)$ & - & - & - \\
Kingdom & $\mathrm{F}(2,61)$ & 0.68 & 0.06 & 0.04 \\
United States & $\mathrm{F}(2,61)$ & 0.10 & 2.63 & - \\
\hline ** indicates statistical & significance at the 5\% level. & \\
\hline
\end{tabular}

The results of the test are presented in Table 4.7. The weak exogeneity assumption is satisfied for all country-specific foreign variables, except for the foreign real GDP in the Chinese model and the short-term interest rate in the Finnish model. Given the increasing global importance of the Chinese economy, it is a sensible assumption that foreign real GDP is not weakly exogenous in the Chinese model. I therefore leave out from the estimations the foreign real GDP in the

\footnotetext{
${ }^{19}$ Both are set equal to 1 in our analysis.
} 
Chinese model. ${ }^{20}$ To the contrary it is very unlikely that the world real interest rate is endogenous in Finland. It is suitable to assume that this result is biased by the small size of the sample. I do not provide statistics for Denmark and Switzerland, because the number of cointegrating relationships in these models is equal to zero. As a result, the test for weak exogeneity could not be performed. However, these economies are too small to play a major role in the world economy. It is therefore reasonable to assume exogeneity of their foreign variables (Bettendorf, 2012).

\subsubsection{Serial correlation}

Given the relatively large number of endogenous and exogenous variables involved in the estimations, the comparatively short time period (as compared to other GVAR studies) and the resulting limited number of lags included into the country-specific $V A R X^{*}$ models, I test the adequacy of the country-specific models in dealing with the complex dynamic interrelationships of the world economy.

Table 4.8 Serial correlation of country-specific VECMX* residuals

\begin{tabular}{|c|c|c|c|c|c|c|c|c|c|c|}
\hline & & $t b_{-} e a$ & tb_row & $t b_{-} w$ & $q_{-} e a$ & q_row & $q_{-} w$ & $y$ & $r$ & poil \\
\hline Austria & $\mathrm{F}(4,55)$ & 1.14 & 1.30 & & 1.47 & 0.55 & & 1.01 & 1.12 & \\
\hline Finland & $F(4,55)$ & $2.65^{* *}$ & 2.23 & & 2.22 & 2.28 & & $3.34^{* *}$ & $2.64^{* *}$ & \\
\hline France & $F(4,54)$ & 2.51 & 0.18 & & $3.45^{* *}$ & 0.70 & & 0.31 & 1.89 & \\
\hline Germany & $\mathrm{F}(4,56)$ & 0.75 & 0.57 & & 1.93 & 0.21 & & 2.13 & $5.56^{* *}$ & \\
\hline Ireland & $F(4,55)$ & 1.90 & $2.94^{* *}$ & & $3.44^{* *}$ & 1.86 & & 1.64 & $4.92^{* *}$ & \\
\hline Italy & $F(4,54)$ & 1.19 & 0.76 & & 1.61 & 0.53 & & 0.42 & 2.43 & \\
\hline Netherlands & $\mathrm{F}(4,54)$ & 1.29 & 1.03 & & 1.33 & 0.30 & & 1.33 & $3.03^{* *}$ & \\
\hline Portugal & $F(4,56)$ & 1.43 & 0.16 & & $3.16^{* *}$ & 0.87 & & 0.22 & $2.91^{* *}$ & \\
\hline Spain & $\mathrm{F}(4,56)$ & 0.38 & 0.72 & & 1.83 & 2.31 & & $4.16^{* *}$ & $3.35^{* *}$ & \\
\hline China & $F(4,57)$ & & & 0.33 & & & 0.94 & $2.97^{* *}$ & 2.52 & \\
\hline Denmark & $F(4,59)$ & & & $3.11^{* *}$ & & & 0.36 & 0.30 & 0.93 & \\
\hline Japan & $\mathrm{F}(4,61)$ & & & 0.87 & & & 2.38 & 0.70 & $4.37^{* *}$ & \\
\hline Norway & $F(4,62)$ & & & 2.37 & & & 0.42 & 1.22 & 2.21 & \\
\hline Poland & $\mathrm{F}(4,58)$ & & & 0.34 & & & 0.95 & 0.48 & 0.55 & \\
\hline Sweden & $F(4,57)$ & & & 1.37 & & & 0.24 & 1.34 & 2.49 & \\
\hline Switzerland & $\mathrm{F}(4,63)$ & & & 1.27 & & & 0.83 & 1.13 & 1.08 & \\
\hline United Kingdom & $\mathrm{F}(4,57)$ & & & 0.33 & & & 0.70 & 1.14 & $2.63^{* *}$ & \\
\hline United States & $F(4,57)$ & & & $2.69^{* *}$ & & & 1.66 & 0.98 & $3.98^{* *}$ & 2.01 \\
\hline
\end{tabular}

Table 4.8 provides F-statistics for tests of serial correlation of order 4 in the residuals of the ECM for all of the 91 endogenous variables in the GVAR models. 72 out of the 91 regressions

\footnotetext{
${ }^{20}$ As a result, the lag order for domestic variables increases from 1 to 2 in the Chinese model.
} 
pass the residual serial correlation test at the $95 \%$ level. Serial correlation is primarily found in the interest rate regressions, a variable with known persistence. The results of this test are in line with earlier studies (Pesaran et al., 2004).

\subsubsection{Structural Stability}

Structural stability of parameter coefficients and error variances is an important issue in macroeconomic modelling in general and in GVAR modelling in particular. The recent global slump is only the latest example of structural breaks which generally lead to significant changes in a time series' history and, as a consequence, to heteroscedasticity in error variances. Dées et al. (2005) point out that the inclusion of foreign variables in the country-individual models within the GVAR reduces the structural problem and thus accommodates the so-called "cobreaking”, as described in Hendry and Mizon (1998). The GVAR should therefore be more robust to the possibility of structural breaks than reduced-form single-equation models.

\section{Table 4.9 Stability tests}

\begin{tabular}{|c|c|c|c|c|c|c|c|c|c|c|}
\hline \multirow[t]{2}{*}{ Test } & \multicolumn{9}{|c|}{ Domestic variables } & \multirow[t]{2}{*}{ Total } \\
\hline & $t b_{-} e a$ & $t b \_r o w$ & q_ea & q_row & $y$ & $\boldsymbol{r}$ & $t b_{-} w$ & $q_{-} w$ & poil & \\
\hline $\mathbf{P K}_{\text {sup }}$ & $\begin{array}{c}2 \\
(22.2)\end{array}$ & - & $\begin{array}{c}1 \\
(11.1)\end{array}$ & - & $\begin{array}{c}3 \\
(16.7)\end{array}$ & - & - & - & - & $\begin{array}{c}6 \\
(6.6)\end{array}$ \\
\hline $\mathbf{P K} K_{\mathrm{msq}}$ & $\begin{array}{c}2 \\
(22.2)\end{array}$ & - & $\begin{array}{c}1 \\
(11.1)\end{array}$ & - & $\begin{array}{c}3 \\
(16.7)\end{array}$ & - & - & - & - & $\begin{array}{c}6 \\
(6.6)\end{array}$ \\
\hline $\begin{array}{l}\text { Robust } \\
\text { Nyblom }\end{array}$ & - & - & $\begin{array}{c}1 \\
(11.1)\end{array}$ & - & $\begin{array}{c}1 \\
(5.6)\end{array}$ & - & $\begin{array}{c}1 \\
(11.1)\end{array}$ & $\begin{array}{c}1 \\
(11.1)\end{array}$ & - & $\begin{array}{c}4 \\
(4.4)\end{array}$ \\
\hline $\begin{array}{l}\text { Robust } \\
\text { QLR }\end{array}$ & - & - & - & - & - & $\begin{array}{c}1 \\
(5.6)\end{array}$ & - & $\begin{array}{c}1 \\
(11.1)\end{array}$ & - & $\begin{array}{c}2 \\
(2.2)\end{array}$ \\
\hline $\begin{array}{l}\text { Robust } \\
\text { MW }\end{array}$ & - & - & - & - & $\begin{array}{c}2 \\
(11.1) \\
\end{array}$ & $\begin{array}{c}1 \\
(5.6) \\
\end{array}$ & - & $\begin{array}{c}2 \\
(22.2) \\
\end{array}$ & - & $\begin{array}{c}5 \\
(5.5) \\
\end{array}$ \\
\hline $\begin{array}{l}\text { Robust } \\
\text { APW }\end{array}$ & - & - & - & - & $\begin{array}{c}1 \\
(5.6) \\
\end{array}$ & - & - & $\begin{array}{c}2 \\
(22.2) \\
\end{array}$ & - & $\begin{array}{c}3 \\
(3.3) \\
\end{array}$ \\
\hline
\end{tabular}

The table shows the number (percentage) of rejections of the null of parameter stability per variable across country-specific models at the $5 \%$ level. The critical values of the tests are computed by bootstrap under the null of parameter stability.

There is no consensus on how to test for the stability of model parameters. I follow Dées et al. (2005) by performing a number of stability tests based on the residuals of the individual equations of the country-specific models. I test for the time-varying stability of the model parameters using the maximal OLS cumulative sum statistic (CUSUM) by Ploberger and Krämer (1992) (PKsup) as well as its mean square variant ( $\mathrm{PK}_{\mathrm{msq}}$ ). I consider a test for parameter constancy by Nyblom (1989) which accounts for a non-stationary alternative parameter 
evolution in the form of a martingale process (Robust Nyblom). I identify structural changes by computing the Wald form of the likelihood ratio statistic by Quandt (1960) (Robust QLR). Furthermore, I compute the mean Wald statistic as described in Andrews and Ploberger (1994) and Hansen (1992) (Robust MW) as well as the Wald statistic by Andrews and Ploberger (1994) which is based on the exponential average (Robust APW). I present the heteroscedasticityrobust versions for all tests except Ploberger and Krämer (1992). ${ }^{21}$

Table 4.9 reports the absolute number and the corresponding percentage of rejections of parameter stability for each endogenous variable across country-specific models at the $5 \%$ level. The last column shows the total number and percentage of rejections by each test. The tests do not always reject stability for the same variables. Whereas the $\mathrm{PK}_{\text {sup }}$ and $\mathrm{PK}_{\mathrm{msq}}$ tests primarily reject stability of real GDP, the results for the other tests are less specific. All tests indicate rejection rates well below 10\%. Most of the structural parameters in the model seem to be relatively stable. I follow Dées et al. (2005) and account for heteroscedasticity by using bootstrapped values and confidence intervals for the interpretation of the generalised impulse response functions in the main GVAR analysis in the next section.

\subsection{Generalised impulse response analysis}

I use my model to investigate the dynamic response of the system to shocks in a given variable. The analysis is based on generalised impulse response functions (GIRF) as proposed by Koop et al. (1996) for non-linear systems and advanced by Pesaran and Shin (1998) for vector errorcorrecting systems. The advantage of GIRFs over orthogonalised impulse response functions (OIRF) is twofold: First, GIRFs do not require the imposition of identification restrictions on the error terms. Second, they are invariant to the ordering of the endogenous variables in the global vector $\boldsymbol{x}_{t}$. In order to fully understand the dynamics at work and to uncover heterogeneities between the nine EA countries, I investigate and compare the time profiles and dynamic responses of real GDP, intra-EA and extra-EA trade balances and intra-EA and extra-

\footnotetext{
${ }^{21}$ The percentage of rejections of parameter stability increases substantially when the unadjusted versions of the tests are used. The result indicates that breaks in error variances are more important than changes in parameter coefficients.
} 
EA REERs for the aggregated EA and across individual EA countries. ${ }^{22}$ Unlike most other GVAR applications, I choose to impose region-specific instead of country-specific shocks, i.e. all countries in a region (either EA or ROW) are simultaneously hit by a shock of equal size. ${ }^{23}$ I consider four shocks. First, I simulate a positive shock to EA - and hence domestic - real GDP. The second shock is a positive shock to real GDP in all non-EA countries, and hence it is exogenous to EA countries. Third, I simulate a positive shock to the extra-EA exchange rate. This shock is to mimic a nominal appreciation of the euro and represents a common loss in international competitiveness. Fourth, I consider a negative shock to the EA real interest rate to investigate the impact of expansionary monetary policy on EA trade balances. For each shock, I present graphs showing their impact on five variables of interest, namely the intra-EA and extra-EA trade balances, the intra-EA and extra-EA REER and real GDP. ${ }^{24}$ The corresponding figures show the bootstrapped median impulse response (2000 replications) for each variable and across all EA countries and, for comparative purposes, the aggregate EA for 40 quarters following the initial shock.

\subsubsection{Positive shock to EA real GDP}

I simulate a one standard-error positive shock to EA real GDP. The results are presented in Figure 4.4. Like most other GVAR applications, I restrain from labelling this shock as either demand or supply shock, since I do not impose any identification restrictions. ${ }^{25}$

The change in EA activity has a significant and positive contemporaneous effect on EA real output as well as on real output in individual EA countries, and the impact is persistent in the long run. The average EA real GDP increases by $0.4 \%$ on impact and by $0.6 \%$ in the long run. Regional aggregation masks statistically significant heterogeneities across countries related to the intensity of individual EA countries' GDP responses. On impact, the German GDP is about six times as responsive as the Spanish GDP. And whereas Austria, France and Italy see their

\footnotetext{
${ }^{22}$ With the GVAR Toolbox it is possible to construct geographical regions by grouping together individual countries in those regions using PPP-GDP weights. The approach enables the simulation of a shock that originates in a geographical region rather than in a specific country (a demand shock originating in the EA, rather than in a single EA country, for instance). It furthermore allows for the aggregation of country-specific into regional results. The outcome is a "synthetic measure" of impulse responses.

${ }^{23}$ The region-specific shocks are PPP-GDP weighted averages of country-specific standard deviations and, hence, of equal size in all countries.

${ }^{24}$ I include six graphs for the EA real interest rate shock.

${ }^{25}$ Some authors, like Dées (2013) for instance, model supply-side shocks more explicitly as gains to cost and price competitiveness or as productivity gains.
} 
respective real GDPs increase by around $0.5 \%$ in the long run, Finland and Germany are most affected by the expansion, with a long run increase in GDP of roughly $0.9 \%$.

Theoretically, a positive domestic GDP shock is expected to deteriorate the trade balance of the affected country, as higher income increases the domestic demand for imports but leaves the foreign demand for exports unchanged. In particular, International Real Business Cycle (IRBC) models suggest that the trade balance is countercyclical (Bettendorf, 2017). For EA countries' trade balances, the impact of this shock will most likely be less straightforward. The above line of reasoning can only be applied to extra-EA trade balances and it suggests that extra-EA trade balances should deteriorate in response to the common positive EA GDP shock. Conversely, changes in the intra-EA trade balances result from adjustments in both - imports and exports as all EA countries are exposed to the same shock. By definition, the changes in intra-EA trade balances have to be offsetting across EA countries, and thus inevitably give rise to improving intra-EA trade balances in some and deteriorating intra-EA trade balances in other EA countries. The overall impact on a country's external balances - both intra-EA and extra-EA depends on a multitude of factors, summarised by the demand elasticities of imports and exports. For instance, trade diversion, in response to the shock, away from extra-EA to intraEA imports can lead to improving extra-EA trade balances in a country.

In my analysis, the average extra-EA trade balance permanently deteriorates in response to the shock by approximately $0.25 \%$. The positive real GDP shock has the expected deteriorating effect on most individual EA countries' extra-EA trade balances, but both - the size of the impact and its significance - vary across countries. ${ }^{26}$ Whereas the extra-EA trade balances of France, Germany and Italy - three extra-EA trade balance surplus countries - respond significantly positive only on impact, the short run impact on the extra-EA trade balances is significantly negative in Ireland and in the three deficit countries Netherlands, Portugal and Spain. The extra-EA trade balances of most countries are not significantly affected in the long run. The long-run impact is significant and negative in Ireland $(0.4 \%)$, Portugal $(0.8 \%)$ and Spain $(0.8 \%)$. This trade balance deterioration further adds to the existing deficits in the latter two countries, hence further widening the gap with the extra-EA trade balances of other EA countries.

My results furthermore point to shifts in trade patterns between EA countries. As expected, the impact on intra-EA trade balances is more heterogeneous in sign and magnitude across EA

\footnotetext{
${ }^{26}$ Impulse response functions with associated $90 \%$ confidence bounds can be obtained by the author upon request.
} 
Figure 4.4 Response to 1 s.e. positive shock to EA real GDP
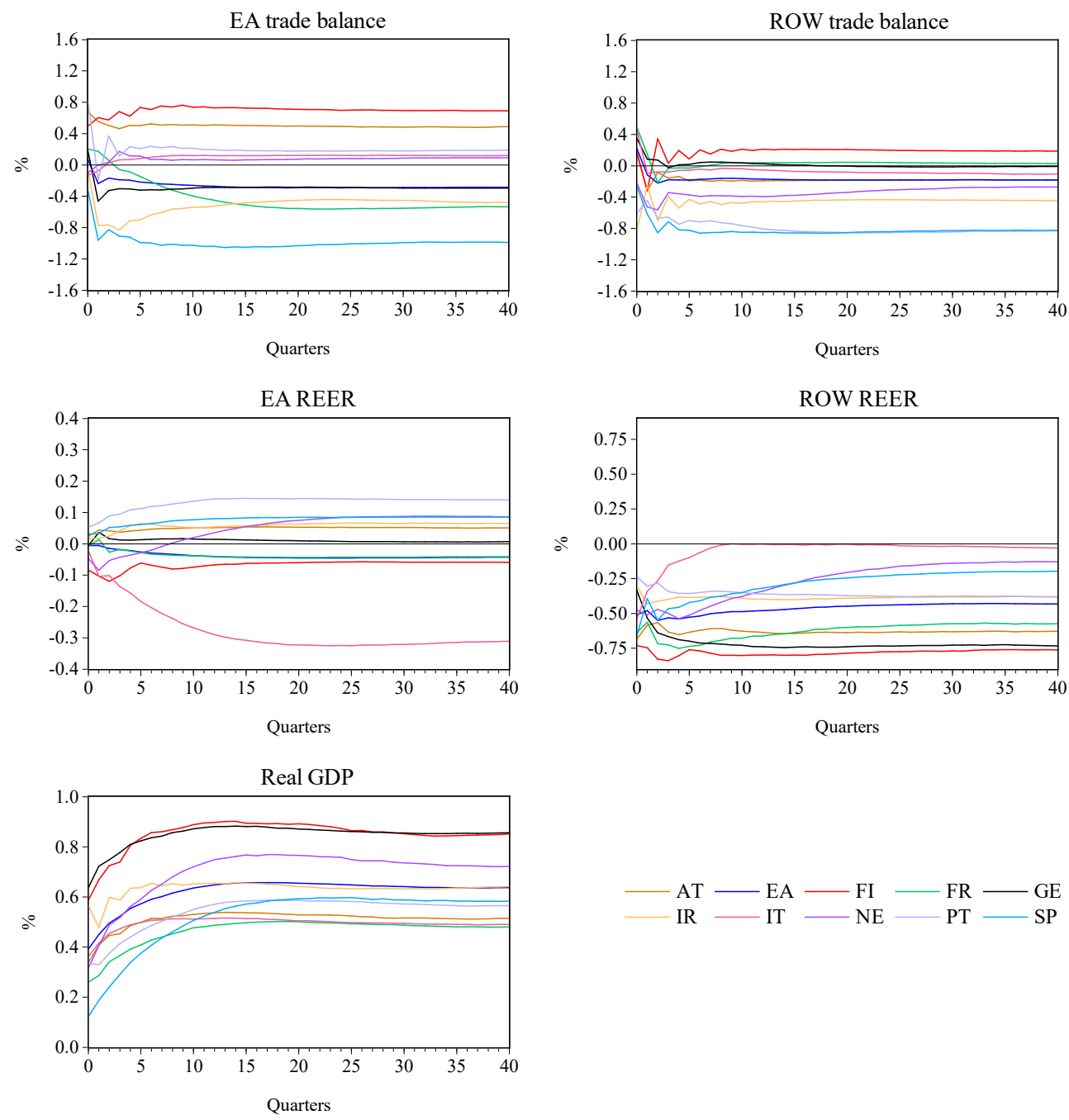

countries than the impact on extra-EA trade balances. Except for Italy and the Netherlands, the results show significant short-run responses of the intra-EA trade balances, with positive effects in some countries (Austria, Finland, France, Portugal) and negative effects in others (Germany, Ireland, Spain). The sign of the shock responses is therefore not related to the initial state of the intra-EA trade balance. The long-run impact of the shock is positive and statistically significant in Austria and Finland, with the intra-EA trade balances improving by roughly $0.5 \%$ and $0.7 \%$, respectively, and negative in France and Spain. The Spanish trade balance is estimated to deteriorate by about $1 \%$ in the long run. This deterioration further adds to the country's intraEA deficit and again increases the gap with its EA trading partners. The double-deficit country 
Spain is the only country which sees both its trade balances significantly deteriorate in the long run; EA GDP shocks seem to be important drivers of the Spanish trade balances.

The EA GDP shock also affects both intra-EA and extra-EA competitiveness. It translates into an immediate significant depreciation of the extra-EA exchange rates in all countries of between $0.2 \%$ (Portugal) and $0.7 \%$ (Finland). The depreciation is significant in the long run in Austria, Finland and Germany - three countries which have gained competitiveness over time, and marginally so in Ireland. It is also reflected in the average EA exchange rate which depreciates by about $0.5 \%$ on impact, and this depreciation is persistent in the long run. The result of a depreciating exchange rate appears peculiar in combination with deteriorating trade balances. While the trade balance responses are more in line with the theoretically expected results in response to a domestic demand shock, real currency depreciation - as a result of falling domestic prices - is intuitively more likely to be expected in response to a domestic supply shock.

Movements in intra-EA REER need to be offsetting across EA countries, hence, unless intraEA competitiveness remains unaffected, some countries will experience gains and others will experience losses in competitiveness. The intra-EA REER depreciates in Finland, Italy and the Netherlands for about 4 quarters after the shock; Austria, Germany, Portugal and Spain are losing internal competitiveness in the short run. The gain in long-run internal competitiveness is most important in Italy: the Italian intra-EA REER significantly depreciates by about $0.3 \%$. This result is counter to the empirical observation that the Italian intra-EA exchange rate heavily appreciated in particular during the late 1990s (Figure 4.2). To the contrary, the deficit countries Portugal and Spain experience a long-run loss in intra-EA competitiveness, in line with empirical observations.

The results in this section hence indicate as well cross-country heterogeneities as asymmetries between intra-EA and extra-EA trade balance and REER movements, respectively. Specifically, a domestic GDP shock contributes to the widening of external imbalances across EA countries. In some countries, the shock leads to a divergence of country-specific intra-EA and extra-EA trade balances. Hence, investigating separately intra-EA and extra-EA increases the understanding of EA trade balance and REER movements.

\subsubsection{Positive ROW real GDP shock}

In the course of globalisation and of increasing importance of emerging markets in world trade, extra-EA trade grew at a faster rate than intra-EA trade between 2000 and 2010 (ECB, 2012b). As a result, differences in sectoral and geographical specialisation of EA exports (Zemanek et al., 2010) can be expected to result in heterogeneous responses of EA external balances. An 
increase in demand for machinery and investment products, for instance, would most likely improve the extra-EA trade balances of the countries exporting those products, leaving the extra-EA trade balances of all other countries unchanged. In addition, the change in international demand for some countries' products might affect intra-EA trade if production depends on imports from other EA countries.

Figure 4.5 Response to 1 s.e. positive shock to $R O W$ real GDP
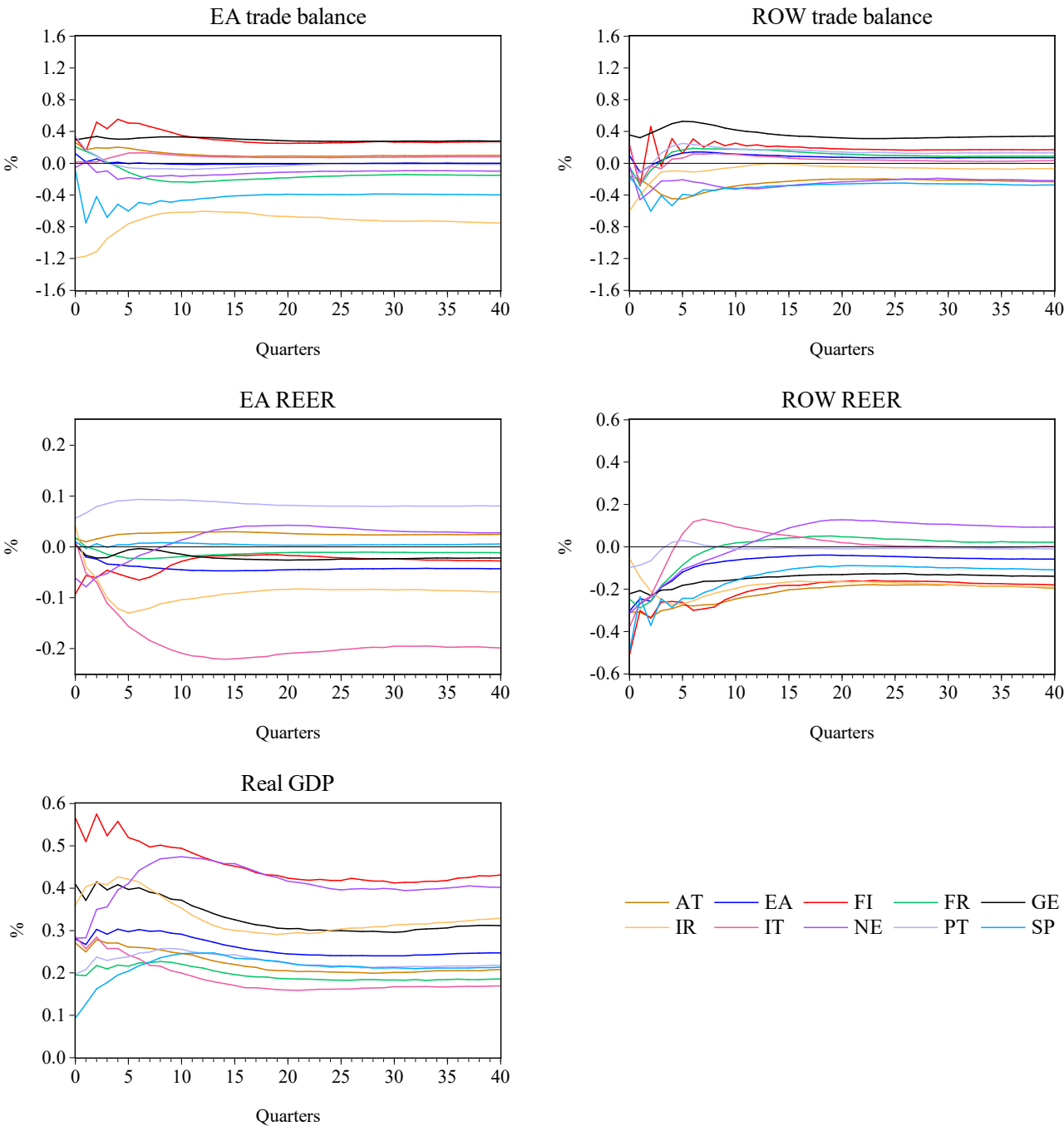

I simulate the symmetric increase in extra-EA GDP by a one standard error positive shock to all non-EA countries' real GDP (Figure 4.5). Whereas the domestic GDP shock permanently affects the level of GDP across EA countries, the increase in ROW GDP leads to a temporary 
rather than a permanent significant rise in real GDP in all EA countries for about 6-8 quarters. The Finnish GDP is most responsive in the short run and temporarily increases by $0.6 \%$. The Spanish GDP is least responsive in the short run $(0.1 \%)$. These short run responses are quantitatively similar to an EA GDP shock. The long run impact of the shock is at best marginally significant for EA countries. The increase in foreign GDP can also be expected to increase the international demand for EA exports and thus improve EA countries' extra-EA trade balances.

I find that extra-EA trade balances are only temporarily affected by the foreign GDP shock and that the shock responses are heterogeneous across countries. The German extra-EA trade balance outperforms the responses of all other countries and improves by roughly $0.5 \%$ for about eight quarters. The Irish extra-EA trade balance significantly deteriorates on impact by about $0.6 \%$; the Dutch and Spanish extra-EA trade balances deteriorate by $0.4 \%$ for about three and five quarters, respectively. Deteriorating trade balances in response to increasing foreign GDP are not theoretically expected but might empirically result from differences in export specialisation across EA countries in a globalising world. However, the argument of trade diversion as possible explanation for this result is certainly difficult to justify for the Netherlands as transit country.

The changes in external GDP lead to significant adjustments in intra-EA trade balances in both the short and the long run. The improvement in the German intra-EA trade balance of about $0.5 \%$ is marginally significant in both the short and the long run. The French intra-EA trade balance is positively affected in the short run and displays a marginal deterioration of about $0.1 \%$ in the long run. Both the Irish and the Spanish intra-EA trade balances are negatively affected in the short run. The Irish intra-EA trade balance deteriorates by $1.2 \%$ on impact. The temporary improvement of the Portuguese intra-EA trade balance of about $0.3 \%$ is found to be marginally significant. The result indicates that the initial state of the trade balance - surplus or deficit - does not determine the sign of the trade balance response to a foreign GDP shock. Further, just as for the EA GDP shock, intra-EA trade balances are more heterogeneously affected than extra-EA trade balances.

The change in foreign real GDP temporarily affects extra-EA and intra-EA competitiveness. The extra-EA competitiveness of all EA countries instantaneously improves in response to the common external GDP shock and this currency depreciation is significant but short-lived in most EA countries. Competitiveness improves most in Finland and Spain (0.5\%). Further, in the short run, the Finnish, the Italian and the Dutch intra-EA exchange rates depreciate with 
respect to EA trading partners. The significant depreciation of about $0.2 \%$ lasts longest in Italy, for about 12 quarters. To the contrary, the intra-EA competitiveness of Portugal is negatively affected. The Portuguese intra-EA REER appreciates by $0.1 \%$ for about 10 quarters. A foreign GDP shock is therefore found to be non-uniformly transmitted into EA countries, just as a domestic GDP shock, but its impact is only temporary.

\subsubsection{Positive ROW REER shock}

The next experiment investigates how changes in the external competitiveness of the euro affect the competitiveness and trade balances of EA countries. I simulate the impact of a euro appreciation and impose a one-unit standard error positive shock to the ROW REER. The results are displayed in Figure 4.6. The shock leads to a significant appreciation of the euro of about $1.2 \%$ on impact and a permanent significant increase in its value of about $1 \%$. The impact of the shock on individual countries' ROW REERs varies considerably. The German exchange rate is the most responsive. Its value appreciates by almost $1.4 \%$ on impact and reaches its longrun equilibrium of $1.4 \%$ after 8 quarters. France $(1.3 \%)$ and Italy $(1.2 \%)$ experience a comparable long-run impact. The magnitude of this appreciation for France and Germany compares to the results obtained by Holinski and Vermeulen (2009) for country-specific depreciations. The impact of a euro appreciation on the Dutch external exchange rate is lowest among all EA countries. After an initial appreciation of about $0.7 \%$, it depreciates and the permanent increase in its value of about $0.2 \%$ is at best marginally significant. These results indicate that fluctuations in the euro exchange rate lead to permanent changes in the relative external competitive positions of the various EA countries. The changes in the external value of the euro cause mostly insignificant shifts in intra-EA competitiveness across countries, except for Finland, France and the Netherlands. The Dutch and the Finnish intra-EA REER depreciates by about $0.2 \%$ and $0.1 \%$ respectively, in the long run, the French intra-EA REER marginally appreciates. The loss in external competitiveness has a mostly contractionary impact on real GDP across countries but lacks statistical significance in most cases.

A loss in international competitiveness is theoretically expected to result in a temporary improvement in the trade balance which results from the sluggish adjustment of import and export quantities in response to the underlying price changes. Depending on the relative price elasticities of imports and exports, a long-run deterioration in the trade balance can be expected (J-curve effect). The impact of a euro appreciation on the aggregate EA trade balance is found to be small and insignificant, suggesting that exchange rate movements of the euro leave the aggregate EA external balance unaffected. The extra-EA trade balances of Ireland, the 
Netherlands and Spain improve by between $0.3 \%$ and $0.5 \%$ on impact, but there are no significant short-run and long-run responses. To the contrary, the German trade balance significantly improves by $0.2 \%$ on impact and roughly $0.6 \%$ in the long run. This latter result suggests that other factors such as non-price competition or a favourable mix of export products are important in determining Germany's extra-EA trade balances. The intra-EA trade balances of France and Germany significantly improve on impact. Apart from this, the euro appreciation causes only insignificant shifts in the individual countries' intra-EA trade balances.

\section{Figure 4.6 Response to 1 s.e. positive shock to ROW REER}
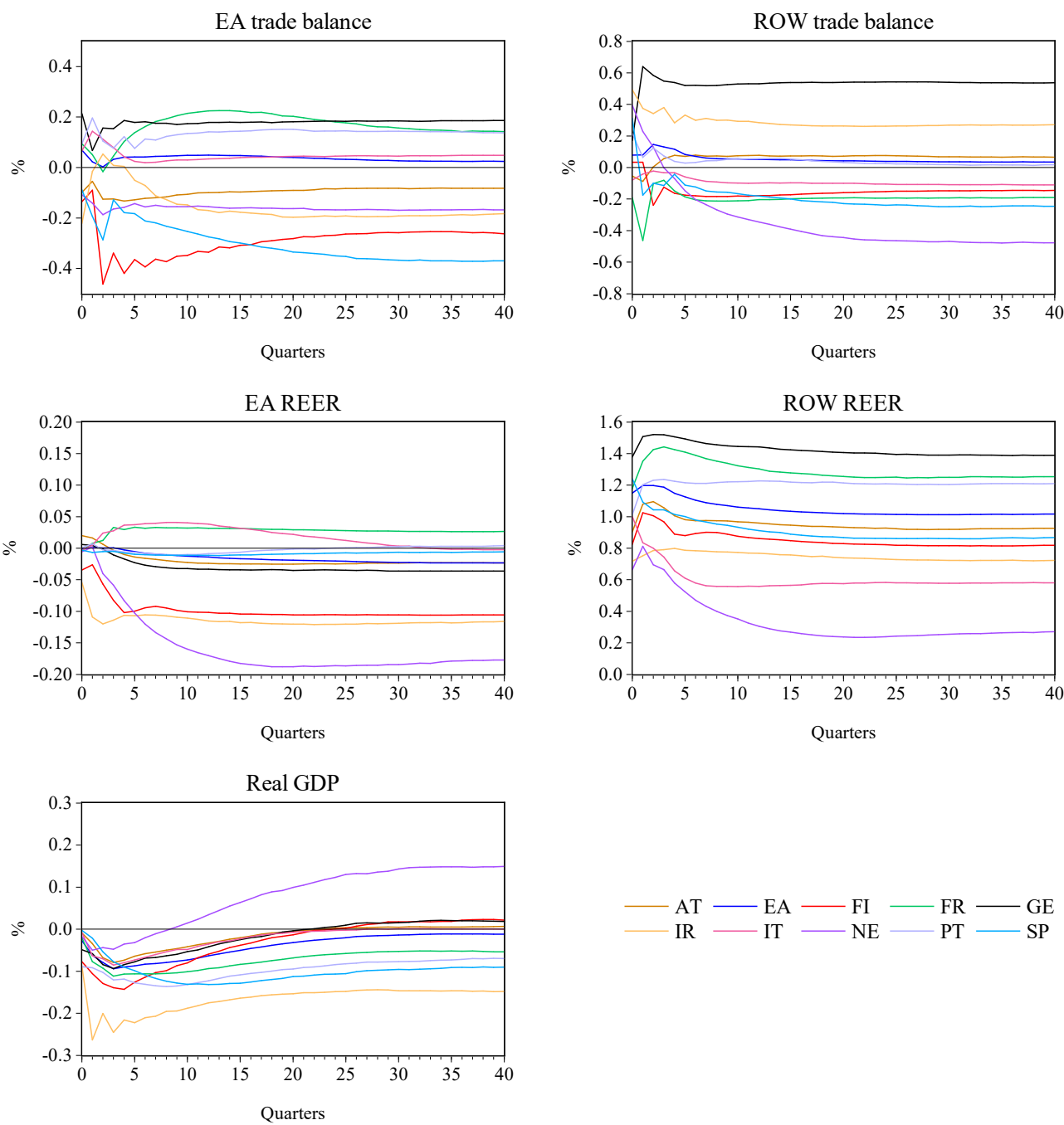
Insignificance of the results presented here might be due to the choice of the CPI as exchange rate deflator. Bayoumi et al. (2011), for instance, find only an insignificant relationship between the CPI as measure of competitiveness and intra-EA and extra-EA exports of EA countries. Hence, the use of other exchange rate deflators might change the outcome of the analysis. However, Staehr and Vermeulen (2016) have investigated the effect of various competitiveness measures on the CA balances of EA countries. In line with other empirical studies (Communale and Hessel, 2014; Diaz Sanchez and Varoudakis, 2013) the authors find little explanatory power of competitiveness measures for the CA balance. My result for the extra-EA trade balance of Germany seems to be a rare exception.

\subsubsection{Negative shock to EA real interest rate}

The above results give evidence of the heterogeneous responses of EA countries to domestic and foreign region-specific shocks. The question is if a common monetary policy which is to satisfy the needs of all economies in the EA can dampen or offset these random shocks or if it is likely to cause additional heterogeneities.

I simulate the effects of EA expansionary monetary policy by imposing a negative one standard error shock to the EA real interest rate (Figure 4.7). The interest rate shock is transmitted rather quickly into the individual countries. Though small in size, the monetary policy shock has a permanent long-run effect on most countries' interest rates. The long-run impact is not significant in Ireland and the Netherlands. The impact on real GDP is positive, as expected, in all countries, and the short-run responses are statistically significant for most countries. Real GDP increases are most important in Finland and Ireland, the Dutch GDP is least responsive. The reduction in the interest rate leads to a depreciation of the euro exchange rate of about $0.4 \%$. The exchange rates of all countries except Ireland instantaneously depreciate between $0.2 \%$ and $0.4 \%$. The Austrian, Italian, Dutch and Portuguese exchange rate are significantly affected in both the short and in the long run. Depreciation of the Finnish, the French, the German and the Spanish exchanges rates is marginally significant in the short and the long run. Whereas the Irish exchange rate remains virtually unaffected by monetary policy, the Italian real exchange rate displays the most significant depreciation of roughly $0.7 \%$ in the long run. Monetary policy also affects intra-EA competitiveness, but significantly so only in the short run. Interestingly, the Irish real exchange rate with respect to its EA trading partners shows a significant permanent appreciation of about $0.2 \%$, possibly reflecting the relative irresponsiveness of the real interest rate to the shock. There are (marginally) significant shortrun dynamics in the intra-EA trade balances. The Austrian and the Finnish intra-EA trade 
Figure 4.7 Response to 1 s.e. negative shock to EA real interest rate
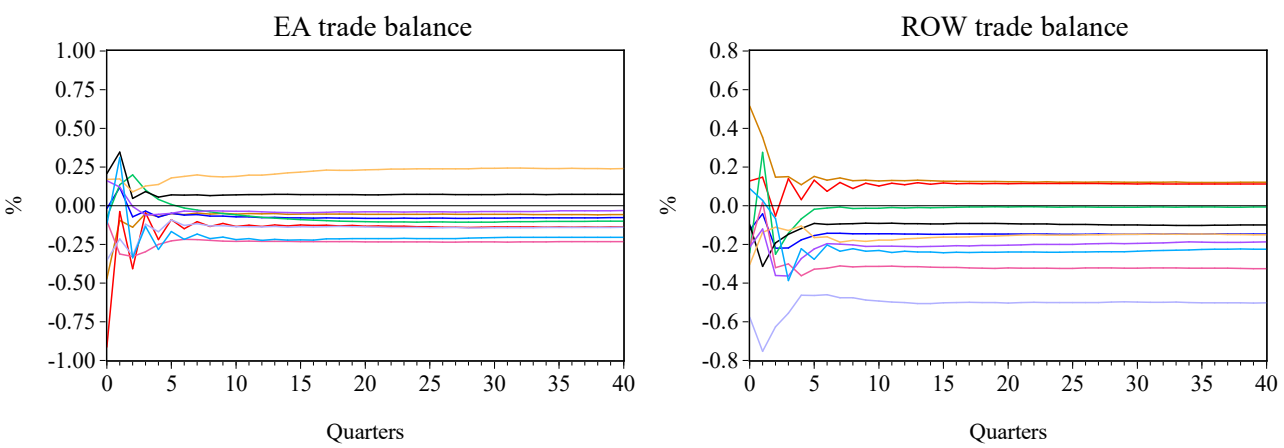

EA REER
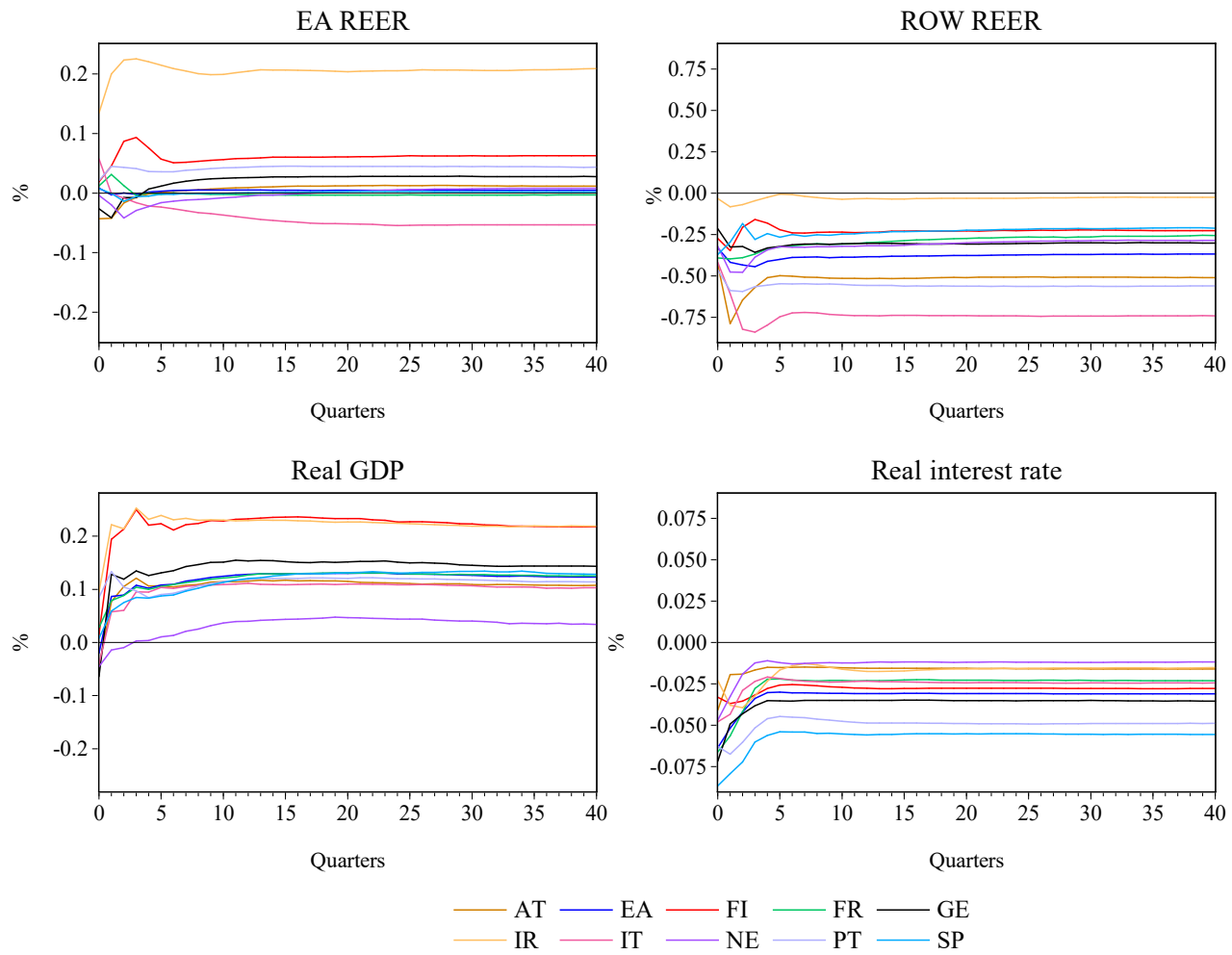

balances deteriorate on impact and in the short run; the Italian deterioration is significant in the short run. The short-run response of the French and German intra-EA trade balances is positive. The Irish intra-EA trade balance shows the most important but insignificant improvement in its intra-EA trade balance. With respect to the extra-EA trade balances, I see an improvement in the Austrian extra-EA trade balance on impact; the Dutch and the Portuguese extra-EA trade balances respond negatively: the former in the short run, the latter both on impact and in the short run. 
Overall, the results show that EA monetary policy significantly affects both exchange rates and trade balances of EA countries. Specifically, the effect is permanent on both internal and external competitiveness but only temporary on trade balances. Since the responses are not homogeneous, monetary policy might at least temporarily turn out to increase rather than remedy external imbalances, but less so than other common (random) shocks. However, monetary policy cannot be a successful tool to offset the gap in trade balance positions across countries.

Looking at the cumulative evidence across the four different shocks, my analysis shows that symmetric shocks - both foreign and domestic - are transmitted non-uniformly into the various EA countries. I do not identify a clear pattern of the responses dependent on the initial state of the trade balance, i.e. following the surplus-deficit dichotomy. Real GDP shocks are found to be the most important drivers of EA trade balances. However, their overall impact might be less disruptive than suggested by the graphs since the majority of the responses lack statistical significance, particularly in the long run. Whereas EA GDP shocks tend to significantly affect external balances and competitiveness in both the short and the long run, the responses to a foreign GDP shock are of transitory nature. Both domestic and foreign GDP shocks are heterogeneously transmitted into the various countries and therefore contribute to the widening of external imbalances across countries. The transitory nature of their impact makes foreign GDP shocks less of a concern. Shocks to the ROW REER affect EA countries' competitiveness in the long run. The effect on intra-EA competitiveness is small, however. The impact on trade balances from exchange rate movements is small; only the German extra-EA trade balance is significantly affected in both the short and the long run. Monetary policy is quickly transmitted into EA countries, and has a small but significant impact on EA countries' interest rates in both the short and the long run. The shock has a positive transitory effect on GDP in most EA countries and permanently affects extra-EA competitiveness. Monetary policy is not suitable to narrow the gap in EA trade balances.

The relevance of these findings for economic policy - other than monetary - largely depends on the stance that one takes on CA imbalances. The literature is ambiguous on whether CA imbalances are problematic from a macroeconomic stability point of view. Obstfeld (2012), for instance, summarises the arguments. Some authors view CA imbalances as the result of either complete markets or generated by optimising household and firm decisions that support intertemporally efficient resource allocation. In this view, CA imbalances are potentially selfcorrecting and no reason for concern. In the light of the EA experiences, however, the above 
assumptions appear increasingly implausible. This does not suggest that CA imbalances are inherently harmful. They can be warranted by macroeconomic fundamentals as long as they do not pose threats either to the national or international economy. In neoclassical theory, for instance, diverging CAs are considered a natural consequence of a convergence process in currency unions. However, external imbalances can also signal elevated macroeconomic and financial stresses, considering the systematic relationship among CA deficits, domestic credit and financial crises. In a currency union, persistent imbalances in combination with the lack of the own exchange rate as adjustment mechanism can entail capital flight to safe countries in the currency union, putting at risk the sustainability of external debt, increasing the likelihood of a financial crisis and, in the end, having strong real effects if the real exchange rate needs to be adjusted through internal depreciation.

Hence, large and persistent unexplained deficits warrant careful policy makers scrutiny. For the European Union, the macroeconomic imbalance procedure (MIP) was put in place in 2011 as a response to the financial crisis to identify, prevent and address the emergence of potentially harmful macroeconomic imbalances, summarised by a total of 14 headline indicators. In case of excessive imbalances, countries are subjected to enhanced monitoring (excessive imbalance procedure, EIP) and potentially face sanctions. In terms of policy recommendations to reduce external imbalances, Jaumotte and Sodsriwiboon (2010) suggest four different approaches. First, fiscal consolidation if public saving is too low; second, structural policies to improve productivity growth in order to regain competitiveness; third, internal devaluation to reduce labour costs relative to trading partners; fourth, financial supervision to limit the growth of private credit. These suggestions primarily address deficit countries.

The analysis in this chapter indicates that reducing imbalances might not be a straightforward task. First, I show that country-specific intra-EA and extra-EA trade balances do not necessarily move in the same direction in response to a shock, suggesting that policy measures might possibly be transmitted non-uniformly into intra-EA and extra-EA trade balances. Second, if country-specific intra-EA and extra-EA imbalances are of different signs, policy makers might need to prioritise between the imbalances in their policy choices Third, intra-EA trade balances across EA countries need to be offsetting. This implies that one country's deficit has to be matched by a surplus of equal size by some other country sharing the same currency. The reduction of intra-EA deficits must hence inevitably be accompanied by an intra-EA surplus reduction of equal size in some other country. Fiscal policy coordination of both deficit and 
surplus countries at the EA level, consistent labour market reforms, financial supervision and structural policies might proof useful to reduce the imbalances.

\subsection{Conclusion}

In this chapter I seek to identify the drivers of EA countries' intra-EA and extra-EA trade imbalances. I apply the GVAR approach to a set of nine EA and nine non-EA countries over the period 1995-2013. My analysis contributes to the existing literature in three ways. First, despite the global dimension of the underlying model, the exclusive focus of my analysis is on EA economies. Second, I introduce a distinction between EA and non-EA countries by differentiating between intra-EA and extra-EA trade balances and between intra-EA and extraEA REER, for the EA countries. Third, I impose only region-specific instead of countryspecific shocks.

Unsurprisingly, my analysis detects a large amount of heterogeneity in the responses of trade balances and REER to common shocks across and within EA countries. Some of the shocks are found to have a permanently heterogeneous impact, but the pattern of the impact does not follow the surplus - deficit dichotomy. Shocks to real GDP are important drivers of intra-EA and extraEA trade balances and these shocks significantly affect the internal and external competitiveness of individual EA countries. The heterogeneity is more important for the domestic than for the international GDP shock. An appreciation of the euro leads to a permanent change in the external competitive position of the various EA countries but has no long-run effect on trade balances. This result is in line with a number of earlier studies which find little explanatory power of competitiveness measures for the CA balance. In the short run, my results confirm the J-curve effect of an appreciating currency on extra-EA trade balances. Interest rate shocks permanently affect the internal and external competitiveness of some countries, but their impact on trade balances is only temporary.

One needs to keep in mind that the above analysis refers to developments in trade balances in response to domestic and foreign shocks, and hence to relative movements in exports and imports. The analysis gives no information about absolute changes in exports and imports in response to those shocks. The separate treatment of exports and imports would give further insight into the trade patterns of EA economies, in particular in the light of increasing global trade flows. Further, channels other than those identified above could help to shed light on the development of external EA imbalances. In particular, with the start of the common currency, 
the elimination of exchange rate risk and the integration of financial markets, the availability of credit to deficit countries has increased. The explicit inclusion of credit series into the current framework and the analysis of shocks to domestic credit could help refine the results of the underlying model. The analysis of these channels is left for further research. 


\section{References}

Ahearne, A., Schmitz, B., Von Hagen, J., 2008. Current Account Imbalances in the Euro Area, in: Aslund, A., Dabrowski, M. (Eds.), Challenges of Globalization. Imbalances and Growth, 1st ed. The Peterson Institute for International Economics, pp. 41-57.

Andrews, D.W.K., Ploberger, W., 1994. Optimal tests when a nuisance parameter is present only under the alternative. Econometrica 62 (6), 1383-1414.

Arghyrou, M.G., Chortareas, G., 2008. Current Account Imbalances and Real Exchange Rates in the Euro Area. Review of International Economics 16 (4), 747-764.

Assenmacher, K., 2013. Forecasting the Swiss economy with a small GVAR model, in: di Mauro, F., Pesaran, M.H. (Eds.), The GVAR Handbook. Structure and Applications of a Macro Model of the Global Economy for Policy Analysis. Oxford University Press.

Barnes, S., Lawson, J., Radziwill, A., 2010. Current account imbalances in the euro area: A comparative perspective. Economics Department Working Paper 826. OECD.

Bayoumi, T., Harmsen, R., Turunen, J., 2011. Euro Area Export Performance and Competitiveness. IMF Working Paper WP/11/140.

Belke, A., Dreger, C., 2011. Current Account Imbalances in the Euro Area: Catching Up or Competitiveness? DIW Discussion Papers 1106.

Belke, A., Osowski, T., 2016. Measuring fiscal spillovers in EMU and beyond: A global VAR approach. ROME Discussion Paper Series 16-06.

Berger, H., Nitsch, V., 2010. The Euro's Effect on Trade Imbalances. IMF Working Paper $\mathrm{WP} / 10 / 226$.

Bettendorf, T., 2012. Investigating Global Imbalances: Empirical Evidence from a GVAR Approach. School of Economics Discussion Papers. University of Kent.

Bettendorf, T., 2017. Investigating Global Imbalances: Empirical evidence from a GVAR approach. Economic Modelling 64, 201-210.

Brissimis, S., Hondroyiannis, G., Papazoglou, C., Tsaveas, N., Vasardani, M., 2011. The determinants of current account imbalances in the Euro Area: a panel estimation approach. MPRA Paper 35362.

Bussière, M., Chudik, A., Sestieri, G., 2009. Modelling global trade flows. Results from a GVAR model. ECB Working Paper Series 1087.

Ca'Zorzi, M., Schnatz, B., 2007. Explaining and forecasting euro area exports. Which competitiveness indicator performs best? ECB Occasional Paper Series 833.

Cesa-Bianchi, A., Pesaran, M.H., Rebucci, A., Xu, T.T., 2012. China's Emergence in the World Economy and Business Cycles in Latin America. Bank of Canada Working Paper 32.

Cesaroni, T., De Santis, R., 2014. Current account "core-periphery dualism" in the EMU. Temi di Discussione 996. Banca d'Italia.

Chen, R., Milesi-Ferretti, G.M., Tressel, T., 2012. External Imbalances in the Euro Area. IMF Working Paper WP/12/236.

Cheung, Y.-W., Lai, K.S., 1993. Finite-sample sizes of Johansen's likelihood ratio tests for cointegration. Oxford Bulletin of Economics and Statistics 55 (3). 
Chinn, M.D., 2006. A Primer on Real Effective Exchange Rates: Determinants, Overvaluation, Trade Flows and Competitive Devaluation. Open Economies Review (17), 115-143.

Chudik, A., Pesaran, M.H., 2009. Infinite-dimensional VARs and factor models. ECB Working Paper Series 998.

Chudik, A., Pesaran, M.H., 2016. Theory and practice of GVAR modelling. Journal of Economic Surveys 30 (1), 165-197.

Communale, M., Hessel, J., 2014. Current account imbalances in the Euro area: Competitiveness or financial cycle? DNB Working Paper 443.

Croci Angelini, E., Farina, F., 2012. Current account imbalances and systemic risk within a monetary union. Journal of Economic Behavior and Organization 83 (3), 647-656.

Croci Angelini, E., Farina, F., Valentini, E., 2015. Contagion across Eurozone's sovereign spreads and the Core-Periphery divide. Discussion Paper Series AISSEC DP 2015-4.

Darvas, Z., 2012. Real effective exchange rates for 178 countries: a new database. Bruegel Working Paper 06.

de Grauwe, P., 2007. Economics of Monetary Union, 7th ed. Oxford University Press.

Dées, S., 2013. Competitiveness, external imbalances, and economic linkages in the euro area, in: di Mauro, F., Pesaran, M.H. (Eds.), The GVAR Handbook. Structure and Applications of a Macro Model of the Global Economy for Policy Analysis. Oxford University Press, pp. 231-243.

Dées, S., di Mauro, F., Pesaran, M.H., Smith, L.V., 2005. Exploring the international linkages of the euro area: A global VAR analysis. CESifo working papers 1425.

di Mauro, F., Forster, K., 2008. Globalisation and the competitiveness of the euro area. ECB Occasional Paper Series 97.

di Mauro, F., Forster, K., Lima, A., 2010. The global downturn and its impact on euro area exports and competitiveness. ECB Occasional Paper Series 119.

di Mauro, F., Pesaran, M.H. (Eds.), 2013. The GVAR Handbook. Structure and Applications of a Macro Model of the Global Economy for Policy Analysis. Oxford University Press.

Diaz Sanchez, J.L., Varoudakis, A., 2013. Growth and Competitiveness as Factors of Eurozone External Imbalances: Evidence and Policy Implications. Policy Research Working Paper 6732. The World Bank.

ECB, 2012a. Monthly bulletin. Monthly bulletin 02 .

ECB, 2012b. Monthly bulletin. Monthly bulletin 03 .

Favero, C.A., 2013. Modelling sovereign bond spreads in the euro area: a nonlinear global VAR model, in: di Mauro, F., Pesaran, M.H. (Eds.), The GVAR Handbook. Structure and Applications of a Macro Model of the Global Economy for Policy Analysis. Oxford University Press.

Galesi, A., Sgherri, S., 2013. Regional financial spillovers across Europe, in: di Mauro, F., Pesaran, M.H. (Eds.), The GVAR Handbook. Structure and Applications of a Macro Model of the Global Economy for Policy Analysis. Oxford University Press.

Granger, C.W.J., Lin, J.-L., 1995. Causality in the Long Run. Economic Theory 11, 530-536.

Hansen, B.E., 1992. Tests for Parameter Instability in Regressions with 1(1) Processes. Journal of Business and Economic Statistics 10 (3), 321-335. 
Harbo, I., Johansen, S., Nielsen, B., Rahbek, A., 1998. Asymptotic Inference on Cointegrating Rank in Partial Systems. Journal of Business \& Economic Statistics 16, 388-399.

Hendry, D.F., Mizon, G.E., 1998. Exogeneity, causality, and co-breaking in economic policy analysis of a small econometric model of money in the UK. Empirical Economics 23 (3), 267-294.

Holinski, N., Kool, C., Muysken, J., 2012. Persistent Macroeconomic Imbalances in the Euro Area: Causes and Consequences. Federal Reserve Bank of St. Louis Review 94 (1).

Holinski, N., Vermeulen, R., 2009. The International Wealth Effect: A Global Error-Correcting Analysis. Meteor RM/09/019. Maastricht University, Maastricht.

Jaumotte, F., Sodsriwiboon, P., 2010. Current Account Imbalances in the Southern Euro Area. IMF Working Paper WP/10/139.

Johansen, S., 1992. Cointegration in Partial Systems and the Efficiency of Single-Equation Analysis. Journal of Econometrics 52, 389-402.

Klau, M., Fung, S.S., 2006. The new BIS effective exchange rate indices. BIS Quarterly Review.

Koop, G., Pesaran, M.H., Potter, S., 1996. Impulse Response Analysis in Nonlinear Multivariate Models. Journal of Econometrics 74, 119-147.

Koukouritakis, M., Papadopoulos, A.P., Yannopoulos, A., 2015. Linkages between the Eurozone and the South-Eastern European countries: A global VAR analysis. Economic Modelling 48, 129-154.

Lafrance, R., Osakwe, P., St-Amant, P., 1998. Evaluating Alternative Measures of the Real Effective Exchange Rate. Bank of Canada Working Paper 98-20.

Lane, P.R., Milesi-Ferretti, G.M., 2008. The Drivers of Financial Globalization. IIIS Discussion Paper 238.

Niehof, B., 2014. Spillover effects in government bond spreads: Evidence from a GVAR model. Joint Discussion Paper Series in Economics 58-2014. University of Marburg.

Nieminen, M., 2015. Trade imbalances within the euro area and with respect to the rest of the world. Economic Modelling 48, 306-314.

Nieminen, M., Junttila, J.P., 2015. The euro's effect on trade balance dynamics. https://www.researchgate.net/publication/282217733.

Nyblom, J., 1989. Testing for the Constancy of Parameters over Time. Journal of the American Statistical Association 84 (405), 223-230.

Obstfeld, M., 2012. Does the current account still matter? NBER Working Paper Series 17877.

Park, H.J., Fuller, W.A., 1995. Alternative Estimators and Unit Root Tests for the Autoregression Process. Journal of Time Series Analysis 16, 415-429.

Pesaran, H.H., Shin, Y., 1998. Generalized impulse response analysis in linear multivariate models. Economic Theory 58 (1), 17-29.

Pesaran, M.H., Schuermann, T., Weiner, S.M., 2004. Modelling Regional Interdependencies Using a Global Error-Correcting Macroeconometric Model. Journal of Business and Economic Statistics 22 (2), 129-162.

Pesaran, M.H., Shin, Y., Smith, R.J., 2000. Structural analysis of vector error correction models with exogenous I(1) variables. Journal of Econometrics 97 (2), 293-343. 
Ploberger, W., Krämer, W., 1992. The Cusum test with OLS residuals. Econometrica 60 (2), 271-285.

Podstawski, M., 2016. What drives EMU current accounts? - A time varying structural VAR approach. https://papers.ssrn.com/sol3/papers.cfm?abstract_id=2778147.

Quandt, R.E., 1960. Tests of the Hypothesis that a Linear Regression System Obeys Two Separate Regimes. Journal of the American Statistical Association 55 (290), 324-330.

Schmitz, B., Von Hagen, J., 2011. Current account imbalances and financial integration in the euro area. Journal of International Money and Finance 30 (8), 1676-1695.

Schmitz, M., De Clercq, M., Fidora, M., Lauro, B., Pinheiro, C., 2012. Revisiting the effective exchange rates of the euro. ECB Occasional Paper Series 134.

Smith, L.V., Galesi, A., 2014. GVAR Toolbox 2.0.

Staehr, K., Vermeulen, R., 2016. How Competitiveness Shocks Affect Macroeconomic Performance Across Euro Area Countries. ECB Working Paper Series 1940.

Sun, Y., Heinz, F.F., Ho, G., 2013. Cross-Country Linkages in Europe: A Global VAR Analysis. IMF Working Paper 13/194.

Turner, P., Van 't dack, J., 1993. Measuring international price and cost competitiveness. BIS Economic Papers 39.

WGEM, 2012. Competitiveness and external imbalances within the euro area. ECB Occasional Paper Series 139.

Zemanek, H., Belke, A., Schnabl, G., 2010. Current account balances and structural adjustment in the euro area. Ruhr economic papers 176. 


\section{Appendix I.}

\section{Data sources}

\section{Real GDP}

Quarterly index data on real GDP for all countries except China for the period 1995Q1-2013Q1 were taken from the OECD database: GDP, US dollars, volume estimates, fixed PPPs, OECD reference year (2010), annual levels, seasonally adjusted. For China, quarterly nominal GDP data in national currency (1995Q1-2013) was taken from the National Bureau of Statistics of China. The series are converted into US\$ using the IFS exchange rate and deflated using the CPI index from the GVAR database.

\section{CPI}

Quarterly index data for Austria, China, Finland, France, Germany, Italy, Japan, the Netherlands, Norway, Spain, Sweden, Switzerland, United Kingdom and United States for the period 1995Q1-2013Q1 from the GVAR Database (1979Q1-2013Q1) are used. For Ireland, Denmark, Poland and Portugal, quarterly CPI index data for the period 1995Q1-2013Q1 was downloaded from the IMF-IFS database.

\section{Trade balance}

Bilateral trade data for all countries with respect to the EA and the world were obtained from the IMF Direction of Trade statistics (DOTS) at quarterly frequency and in US\$. All series are seasonally adjusted in EViews using the X-13 method of the US Census Bureau over the period 1993Q1-2014Q3.

Exports and imports at time $t$ of a EA member country $i$ with respect to the world, excluding the EA (Rest of the World, ROW), are computed as $E X_{i t}^{R O W}=E X_{i t}^{W}-E X_{i t}^{E A}$ and $I M_{i t}^{R O W}=$ $I M_{i t}^{W}-I M_{i t}^{E A}, i \in E A$, respectively.

The trade balances are constructed following Holinski and Vermeulen (2009) and Bettendorf (2012) as the log of exports over imports $t b_{i t}=\ln \left(E X_{i t} / I M_{i t}\right)$.

Seasonally adjusted imports series of Sweden show a drop in imports in 1999Q4 that is more pronounced than in the original, seasonally unadjusted, data. The same holds for the Swedish export series in 2005Q4. Further data outliers were detected in the Swiss import series in 1998Q4 and 2006Q4 and the Swiss export series in 2005Q1. In all cases, these outliers result 
in excessive movements in the trade balance. The various observations are therefore replaced using the linear interpolation method in EViews.

\section{Short-term interest rate}

Data for Austria, China, Finland, France, Germany, Italy, Japan, the Netherlands, Norway, Spain, Sweden, Switzerland, UK and US comes from the GVAR database.

Short-term interest rate series (money market rate) for Denmark, Ireland, Poland and Portugal were taken from the IMFs IFS database at quarterly frequency. Observation 2001Q1 is missing in the original series for Denmark and is computed using the linear interpolation function in EViews. The series for Portugal is available for the period 1995Q1-2000Q1. This series is completed with German data as described in the GVAR database documentation.

The real short-term quarterly interest rate for country $i$ is computed as

$$
r_{i t}=0.25 * \ln \left(1+\frac{R_{i t}}{100}\right)-0.25 *\left(P_{i t}-P_{i t-4}\right)
$$

where $R_{i t}$ is the annualised nominal short-term interest rate (in percent) and $P_{i t}$ is the CPI.

\section{Real effective exchange rate data}

CPI deflated REER data (Index, 2005=100) for all countries with respect to the EA (18 countries), and with respect to a broad group of 42 countries (IC 37, Russia, China, Brazil, South Korea, Hong Kong) were downloaded from the Eurostat database and rebased to $2010=100$.

The REERs of Austria, Germany, Italy, the Netherlands and Spain with respect to the EA-18 are seasonally adjusted using the method described above. Although the PACF does not show statistically significant serial correlation, visual inspection of the graphs detects a clear seasonal pattern.

The REER of a country with respect to ROW as defined above is not readily available. I use REER-18 and REER-42 (REER-37) to construct an approximation for REER-ROW. REER-42 (REER-37) of country $i$ is a (double-export) weighted average of the 42 bilateral REERs of country $i$. As an approximation, I assume the REER to be a trade-weighted average of bilateral exchange rates between country $i$ and its trading partners $j$

$$
q_{i}^{W}=\sum_{j \in W} \alpha_{i j}^{W} q_{i}^{j}
$$


where $\alpha_{i j}^{W}=\frac{E X_{i}^{j}+I M_{i}^{j}}{\sum_{j \in W}\left(E X_{i}^{j}+I M_{i}^{j}\right)}$ is the trade share of country $i$ with country $j$ in country $i$ 's total trade, $q_{i}^{j}=\left(\frac{P_{i}}{E_{j i} P_{j}}\right)$ is the bilateral exchange rate of country $i$ with respect to country $j .{ }^{27}$

It follows that

$$
\begin{gathered}
q_{i}^{W}=\sum_{j \in E A} \alpha_{i j}^{W} q_{i}^{j}+\sum_{j \in R O W} \alpha_{i j}^{W} q_{i}^{j} \\
q_{i}^{W}=\sum_{j \in E A} \frac{E X_{i}^{j}+I M_{i}^{j} \frac{\sum_{j \in E A}\left(E X_{i}^{j}+I M_{i}^{j}\right)}{\sum_{j \in E A}\left(E X_{i}^{j}+I M_{i}^{j}\right)} q_{i}^{j}}{+\sum_{j \in W}\left(E X_{i}^{j}+I M_{i}^{j}\right)} \frac{E X_{i}^{j}+I M_{i}^{j}}{\sum_{j \in R O W}\left(E X_{i}^{j}+I M_{i}^{j}\right)} \frac{\sum_{j \in R O W}\left(E X_{i}^{j}+I M_{i}^{j}\right)}{\sum_{j \in W}\left(E X_{i}^{j}+I M_{i}^{j}\right)} q_{i}^{j} \\
q_{i}^{W}=\sum_{j \in E A} \alpha_{i j}^{E A} \frac{\sum_{j \in E A}\left(E X_{i}^{j}+I M_{i}^{j}\right)}{\sum_{j \in W}\left(E X_{i}^{j}+I M_{i}^{j}\right)} q_{i}^{j}+\sum_{j \in R O W} \alpha_{i j}^{R O W} \frac{\sum_{j \in R O W}\left(E X_{i}^{j}+I M_{i}^{j}\right)}{\sum_{j \in W}\left(E X_{i}^{j}+I M_{i}^{j}\right)} q_{i}^{j} \\
q_{i}^{W}=q_{i t}^{E A} \frac{\sum_{j \in E A}\left(E X_{i}^{j}+I M_{i}^{j}\right)}{\sum_{j \in W}\left(E X_{i}^{j}+I M_{i}^{j}\right)}+q_{i}^{R O W} \frac{\sum_{j \in R O W}\left(E X_{i}^{j}+I M_{i}^{j}\right)}{\sum_{j \in W}\left(E X_{i}^{j}+I M_{i}^{j}\right)} \\
q_{i}^{W}=q_{i}^{E A} w_{i}^{E A}+q_{i}^{R O W} w_{i}^{R O W} \\
q_{i}^{W}=q_{i}^{E A} w_{i}^{E A}+q_{i}^{R O W}\left(1-w_{i}^{E A}\right)
\end{gathered}
$$

Hence

$$
q_{i}^{R O W}=\frac{q_{i}^{W}-q_{i}^{E A} w_{i}^{E A}}{\left(1-w_{i}^{E A}\right)}
$$

$w_{i}^{E A}$ and $w_{i}^{R O W}$ are the share of EA and ROW trade in total trade of country $i$, respectively.

The weights $w_{i}^{E A}$ are flexible and computed as 3-year moving averages from annual bilateral trade data. For instance, the observations 1995Q1-1995Q4 of $q_{i}^{E A}$ are weighted by the average EA trade share over the years 1994-1996. An exception is the observation 2013Q1 which is weighted using 2011-2013 data, since annual trade data for 2014 is not available.

\section{Oil Price index}

The oil price index as global variable comes from the GVAR database (1979Q1-2013Q1).

${ }^{27}$ The REER is defined such that a rise means a loss of competitiveness (real appreciation). 


\section{Variable Definition}

$$
\begin{array}{lrl}
t b_{i t}^{e a}=\ln \left(E X_{i t}^{e a} / I M_{i t}^{e a}\right) & t b_{i t}^{\text {row }}=\ln \left(E X_{i t}^{\text {row }} / I M_{i t}^{\text {row }}\right) & t b_{i}=\ln \left(E X_{i t} / I M_{i t}\right) \\
q_{i t}^{e a}=\ln \left(Q_{i t}^{e a}\right) & q_{i t}^{\text {row }}=\ln \left(Q_{i t}^{\text {row }}\right) & q_{i t}=\ln \left(Q_{i t}\right) \\
y_{i t}=\ln \left(G D P_{i t}^{\text {real }}\right) & \\
r_{i t}=0.25 * \ln \left(1+R_{i t} / 100\right)-0.25 *\left(\ln \left(C P I_{i t}\right)-\ln \left(C P I_{i t-4}\right)\right)
\end{array}
$$

$E X_{i t}^{e a}=$ exports of country $i \in E A$ to the EA $I M_{i t}^{e a}=$ imports of country $i \in E A$ from the EA $E X_{i t}^{\text {row }}=$ exports of country $i \in E A$ to the ROW $I M_{i t}^{\text {row }}=$ imports of country $i \in E A$ from the ROW $E X_{i t}=$ exports of country $i \in R O W$ to $\mathrm{W}(=E A+R O W)$ $I M_{i t}=$ imports of country $i \in R O W$ from $\mathrm{W}(=E A+R O W)$ $Q_{i t}^{e a}=$ the REER index of country $i \in E A$ with respect to EA countries $Q_{i t}^{\text {row }}=$ the REER index of country $i \in E A$ with respect to ROW countries $Q_{i t}=$ REER index of country $i \in R O W$ with respect to $\mathrm{W}$ $G D P_{i t}^{r e a l}=$ real GDP index of country $i$ during period $t$ $R_{i t}=$ nominal short-term interest rate per annum, in percent Poil $=$ Oil price 
Appendix II.

Table 4.10 Descriptive statistics

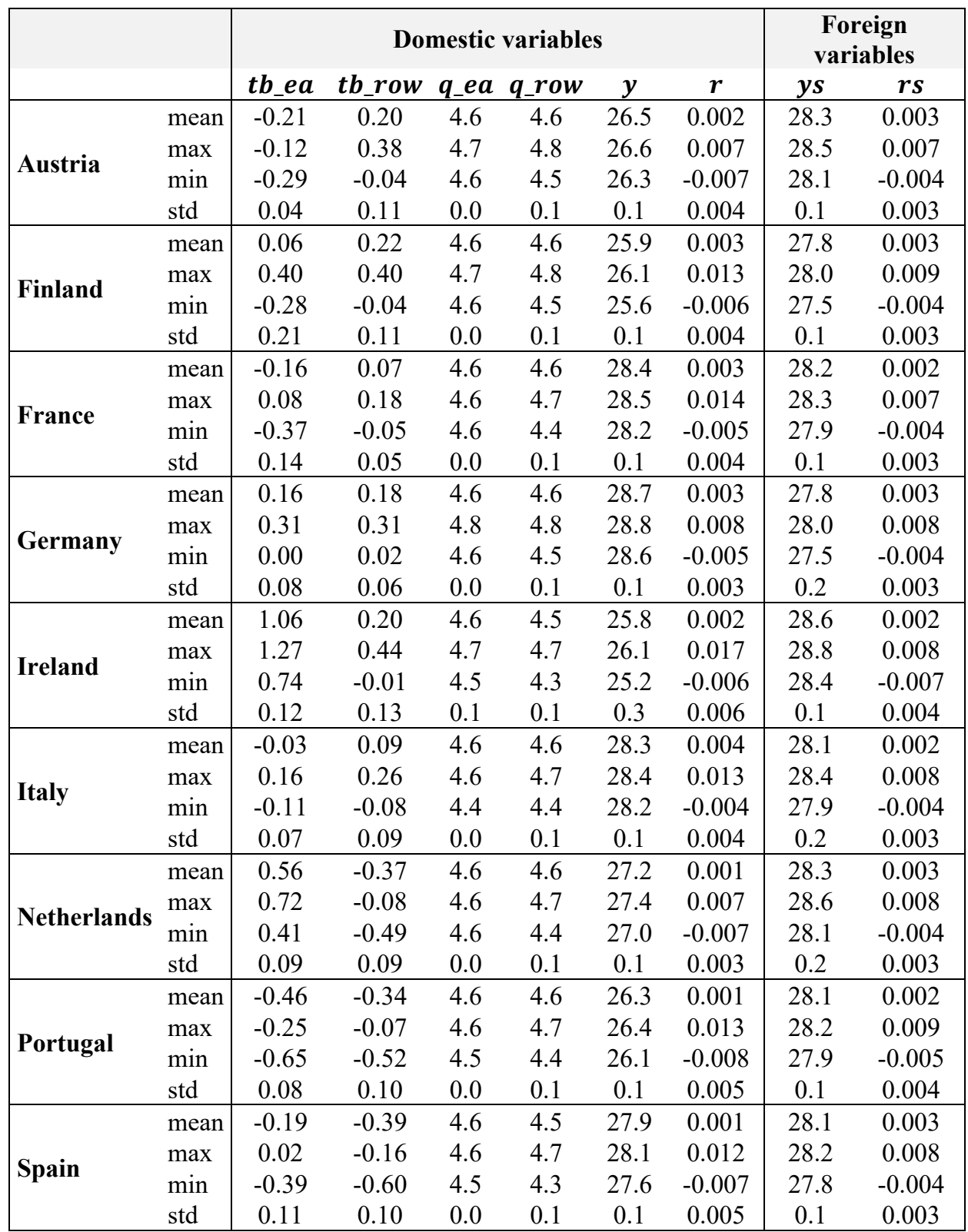

The table presents only the descriptive statistics for the 9 EA countries. The foreign variables present the weighted averages based on all countries in the model. 



\section{Chapter 5}

\section{Regional Growth and Convergence in Germany, 1995-2014}

\subsection{Introduction}

Ever since the German reunification in 1990, German authorities have put in tremendous efforts to transform the East-German industry into an internationally competitive economy and to equalise living conditions ${ }^{2}$ between the Eastern and the Western parts of the country. However, the substantive empirical literature on the - lack of - convergence in Germany provides mixed evidence. In this chapter, we investigate growth and convergence between the 16 German federal states over the period 1995-2014, using panel estimation. ${ }^{3}$ The empirical analysis consists of two parts. Empirical research using regional data sets typically offers more support for unconditional convergence than cross-country research. In a first step, we therefore hypothesise that all German federal states converge to the same steady state. In a second step, we relax this assumption and assume that all states converge to a different - state specific steady state by estimating a fixed effects model. This assumption is justified not only on the basis of persistent differences between the East and the West of the country, but more generally on possible differences between the North and the South and between city and area states.

\footnotetext{
${ }^{1}$ This chapter is co-authored by Clemens Kool and is intended to be published in the near future. We thank participants of the Euroframe 2017 conference (Berlin) and the seminar at Utrecht University for useful comments. We thank Ms. Antje Puhlmann (BAFA) for providing the data on structural funds and her explanatory comments. Any remaining errors are our own.

${ }^{2}$ Art. 72 Abs.2 GG (German constitution).

${ }^{3}$ The study is based on this level of geographic aggregation because the federal equalisation system works at the level of federal states.
} 
Our analysis contributes to the literature in three ways. First, the use of this relatively long and volatile period facilitates an analysis of the impact of the crisis on convergence. ${ }^{4}$ Second, we explicitly account for potential misspecification due to ongoing technology growth by including a trend term. Third, in contrast to the majority of earlier studies, we hypothesise that the effect of additional explanatory variables on growth depends on initial conditions using interaction effects. This leads to a non-linear specification and allows for the analysis of conditional marginal effects. As additional explanatory variables, we use within-country (net) migration, two different forms of fiscal equalisation, and a number of proxies for regional structural funding.

Overall, our empirical evidence provides support for slow unconditional convergence between East and West, once proper account is taken of the - significant - effects of the time trend and crisis dummy. However, the automatic convergence effect becomes insignificant when the additional explanatory variables are included in the analysis. Our empirical evidence supports the relevance of non-linear interaction effects. The marginal effect of explanatory variables strongly depends on initial income conditions. We find that net migration, investment subsidies to the East, and vertical fiscal equalisation contribute to convergence between East and West. We find no evidence of a convergence effect of horizontal fiscal equalisation. The crisis itself causes an extra convergence effect, driven by the negative impact of the crisis on real per capita GDP in the West rather than by a catch-up from the East.

Estimation of the fixed effects model supports the hypothesis of conditional convergence between German states. The speed of convergence increases compared to the unconditional convergence specification and, econometrically, the conditional convergence dominates unconditional convergence. The impact of all other explanatory variables is insignificant in the conditional specification, suggesting that conditional convergence is quasi automatic and that additional variables do not succeed in speeding up the convergence process.

The chapter is set up as follows. Section 5.2 summarises the literature on convergence in Germany in general and with respect to migration, the fiscal transfer system and structural funding in particular. Section 5.3 presents the data that we use in our empirical analysis. Section 5.4 specifies the empirical model and presents and discusses the results. Section 5.5 concludes.

\footnotetext{
${ }^{4}$ Throughout the paper, the term 'crisis' refers to the 2008 global financial crisis.
} 


\subsection{Literature review}

In this section, we summarise the literature on convergence in Germany. In section 5.2.1, we introduce the concept of $\beta$-convergence and discuss various empirical applications for Germany. We proceed with a summary of the empirical evidence for the impact of migration on regional growth and convergence in section 5.2.2. We focus on the German federal equalisation system and its impact in section 5.2.3 and on the effects of regional structural policy in section 5.2.4. So far, the empirical evidence for convergence in Germany is mixed. A number of studies provide support for unconditional $\beta$-convergence, but the results are often not robust to the inclusion of additional explanatory variables. Internal migration flows between East and West appear to have positive convergence effects. Studies on fiscal equalisation focus on the growth impact of various measures of horizontal and vertical redistribution. Generally, these do not report significant evidence in favour of the intended effects. The empirical evidence for structural funding is somewhat more promising in general.

\subsubsection{Concepts of convergence}

The growth-initial income equation which is generally applied empirically to test for $\beta$ convergence (Barro and Sala-i-Martin, 1992) is given by

$$
\ln \left(y_{i t} / y_{i t-T}\right) / T=c_{i t}-\left(1-e^{-\beta T}\right) / T \ln \left(y_{i t-T}\right)+u_{i t}
$$

where $\ln \left(y_{i t} / y_{i t-T}\right) / T$ is the average per capita income growth rate over horizon $T, \ln \left(y_{i t-T}\right)$ is the level of per capita income in the starting period, and the subscripts $t$ and $i$ denote time and country (region) respectively. $c_{i t}$ is a constant that includes the steady state level of per capita income and the steady state growth rate. The steady state level of income is determined by the savings rate, population growth, the rate of depreciation, technology and the share of capital.

Two types of $\beta$-convergence can be distinguished. Unconditional $\beta$-convergence assumes that the only difference across economies is their initial level of capital and hence that all economies converge to the same steady state level of per capita income. In terms of equation (5.1), it implies $c_{i t}=c_{t}, \forall i$ and the hypothesized sign of $\beta$ is positive. Empirical research using regional data sets typically offers more support for unconditional convergence than cross-country research, since different regions within a country are more likely to be similar with respect to 
technology and preferences than individual countries (Barro and Sala-i-Martin, 2004). ${ }^{5}$ Conditional convergence emphasises possible differences in the steady state between economies. In the case of conditional convergence, $c_{i t} \neq c_{j t}, \forall i, j$; appropriate explanatory variables need to be included into the empirical estimations to control for these differences (Islam, 2003; Sala-i-Martin, 1996). Empirical applications of equation (5.1) include both crosssection and panel analyses. For Germany, Berthold and Kullas (2009), Boltho et al. (2018) and Maseland (2014) use a cross-section approach, while Eggert et al. (2007) extend the analysis to panel estimation, for example.

Applications of equation (5.1) to Germany vary in the choice of convergence indicators and levels of regional data aggregation. The two most popular convergence indicators (Eltges, 2013) are GDP per capita (Boltho et al., 2018; Eggert et al., 2007; Scheufele and Ludwig, 2009) and GDP per effective unit of labour (Alecke et al., 2013; Berthold and Kullas, 2009; Kubis and Schneider, 2009). Maseland (2014) studies German districts, Alecke et al. (2013) and Eltges (2013) investigate German labour market regions, Eggert et al. (2007) look at NUTS2 and NUTS3 regions, Berthold and Kullas (2009), Boltho et al. (2018) and Scheufele and Ludwig (2009) study the German federal states. The empirical evidence for convergence between German regions is mixed. Berthold and Kullas (2009), Eggert et al. (2007), Scheufele and Ludwig (2009) and Maseland (2014) find unconditional convergence, but the results are not always robust to the inclusion of additional explanatory variables. In the presence of a dummy variable "East", Kubis and Schneider (2009) find the convergence of labour productivity to be higher between Eastern than between Western districts, and their result is robust to the inclusion of net migration. To the contrary, Boltho et al. (2018) do not find support of convergence between German states in the presence of the dummy.

\subsubsection{Migration}

According to neoclassical theory, the movement of people from lower to higher income regions should raise income per capita in the former while reducing that of the latter, due to diminishing returns to capital. In that case, migration contributes to per capita income convergence across regions (Shioji, 2001). Under this hypothesis, the estimated speed of convergence in equation (5.1) is expected to become smaller when migration is included as an explanatory variable (Barro and Sala-i-Martin, 2004).

\footnotetext{
${ }^{5}$ For applications of convergence between countries see, for example, Baumol (1986), Sala-i-Martin (1996) and Sousa and Pereira (2012). Examples of convergence between regions are Barro and Sala-iMartin (1991), Barro and Sala-i-Martin (1992) and Sala-i-Martin (1996)).
} 
The number of studies that empirically investigate the impact of internal migration on regional growth is rather limited. ${ }^{6}$ In an overview article, Etzo (2008b) shows that the empirical support for the positive impact of migration on convergence is generally rather weak. According to Shioji (2001) this may be due to the restrictive assumption of labour homogeneity. If heterogeneity of labour is allowed for, the impact of migration on convergence is ambiguous (Kubis and Schneider, 2009).

Migration flows from East to West have dominated German internal migration until recently. Kubis and Schneider (2009) document a positive correlation between growth and migration for more productive regions and a negative correlation between growth and migration for less productive regions in Germany. The reallocation of people from low-productivity regions to high productivity regions is found to be advantageous from a macroeconomic perspective. Scheufele and Ludwig (2009) argue that migratory flows have a significant impact on the growth rates of per capita incomes. IWH (2011) states that convergence in per capita incomes between East and West was the result of a decline in the East German population. Migratory flows between East and West seem therefore to have supported convergence in per capita incomes.

\subsubsection{Federal financial equalisation system (Länderfinanzausgleich)}

One of the key fiscal policy tools for promoting convergence and equalising living conditions between German regions is the federal fiscal equalisation system, which balances the fiscal revenues between states. The Eastern states joined the tax-sharing arrangement in 1995 after having received special fiscal transfers in the period 1990-1994.

Germany has three independent tiers of government: the federal government (Bund), state governments (Länder) and municipalities (Gemeinden) which are linked by a multitude of political and fiscal relationships. The sharing of tax revenues between the various levels of government lies at the core of those intergovernmental relations and takes account of personal and corporate income taxes as well as value-added taxes (VAT). The tax-sharing arrangement consists of four stages and includes (vertical) tax sharing between the federal government and the states (first stage), the horizontal distribution of taxes between states (second stage), the horizontal redistribution of taxes between states (third stage), and the provision of supplementary grants from the federal government to the states (fourth stage). There are two types of supplementary federal grants: (i) general supplementary grants which are meant to

\footnotetext{
${ }^{6}$ Internal migration involves the reallocation of people within the national borders. In contrast, international migration studies focus on the movement of people across different countries.
} 
further reduce the gap between the average financial capacity per inhabitant and the financial capacity of poor states after fiscal equalisation and (ii) special-need supplementary grants to compensate individual poor states for special burdens they have to bear.

Various empirical studies (Berthold et al., 2001; Berthold and Fricke, 2005; Berthold and Fricke, 2007) study the impact of horizontal and vertical fiscal redistribution on economic growth of the 16 German states over various periods after 1991 using a panel model. ${ }^{7}$ Horizontal and vertical fiscal redistribution are consistently found to have a highly significant but negative impact on growth. In a recent study Baskaran et al. (2017) investigate the effect of intergovernmental transfers on economic growth in West German states over the period 19752005 using a panel dataset. For the period under consideration, they find that transfer dependence was at best irrelevant and possibly even harmful for economic growth. Overall, there is no empirical support for a growth promoting or convergence effect of fiscal equalisation.

\subsubsection{Regional structural policy}

German structural funding (GRW-Förderung) is the main tool of the German federal and provincial governments for subsidising investments in plant and equipment as well as in local economic infrastructure in structurally disadvantaged regions to promote regional growth. EU structural and cohesion funds (in particular the European Regional Development Fund - ERDF) are used to co-finance GRW projects. Eggert et al. (2007) focus on EU structural funding using a panel for the 16 German states. Studies using district level data are Alecke and Untiedt (2007), Alecke et al. (2013), Eberle and Brenner (2016), Eckey and Kosfeld (2005), Koetter and Wedow (2013) and SVR (2004). The findings of these empirical studies are mixed.

EU structural funding is found to promote convergence between German states, but the overall impact on macroeconomic growth is negative (Eggert et al., 2007). Alecke and Untiedt (2007) and Alecke et al. (2013) find that total GRW funding has a significantly positive impact on the growth of per capita income and a positive impact on the convergence process between regions. On the other hand, Eckey and Kosfeld (2005) cannot identify a statistically significant direct (subsidy to the region) or indirect (subsidy to a neighbouring region) impact of GRW subsidies. A positive impact of corporate GRW funding on productivity growth is identified by SVR

\footnotetext{
${ }^{7}$ Horizontal redistribution refers to third stage intergovernmental redistribution and the redistributive element of VAT. Vertical redistribution includes GRW funding and supplementary federal funds, among others. GRW stands for Gemeinschaftsaufgabe "Verbesserung der regionalen Wirtschaftsstruktur“.
} 
(2004). Koetter and Wedow (2013), to the contrary, find a statistically significant growth impetus of corporate subsidies only when higher infrastructure investments are paired with regional business support, but the positive growth effect of corporate subsidies is crowded out by the negative influence of infrastructure subsidies. Further, the subsidies do not promote convergence between East and West. Similar results are presented by Eberle and Brenner (2016). It appears that both the empirical approach and the definition of the underlying funding series determine the outcome of the analysis.

\subsection{Data}

We use annual data for the 16 German federal states over the period 1991-2014, with the empirical analysis covering the period 1995-2014. The states in the West are BadenWürttemberg (BW), Bavaria (BY), Berlin (BE), Bremen (HB), Hamburg (HH), Hesse (HE), Lower Saxony (NI), Northrhine-Westphalia (NW), Rhineland Palatinate (RP), Saarland (SA), and Schleswig Holstein (SL). Those in the East are Mecklenburg Western Pomerania (MV), Brandenburg (BB), Saxony (SN), Saxony Anhalt (ST), and Thuringia (TH).

The data for nominal GDP is from the German regional accounts, while data on internal migration comes from the German statistical office. To deflate we use the overall German CPIindex, provided by the German statistical office. Population data comes from Eurostat. Data on fiscal equalisation comes from the German Ministry of Finance. Data on structural funds is provided by the Bundesamt für Wirtschaft und Ausfuhrkontrolle (BAFA). It refers to appropriated funds to industry and economic infrastructure that were actually paid out, assigned to the year in which the funds were granted. The data distinguishes between German (GRW) and European structural funding (ERDF).

The dependent variable in the empirical analysis is regional per capita growth of real GDP, while the main independent variable is the level of real per capita GDP. The well-known stylized facts that average per capita income in the West considerably exceeds that in the East, while per capita GDP growth was on average higher in the East, suggest some convergence of per capita income between the East and West.

For migration, we follow Etzo (2008a) and define the gross migration rates as $m_{i t}^{\text {out }}=\frac{E_{i t}}{\text { pop }_{i t-1}}$ and $m_{i t}^{i n}=\frac{I_{i t}}{p o p_{i t-1}}$ where $E_{i t}\left(I_{i t}\right)$ is the number of people who left (arrived in) state i during period $t$, pop $_{i t-1}$ is the population in state $\mathrm{i}$ at the beginning of year $t$. The net migration rate 
$m_{i t}$ is then defined as the difference of the two gross migration rates $m_{i t}=m_{i t}^{i n}-m_{i t}^{\text {out }}$. Migration from the East to the West has exceeded migration from the West to the East ever since reunification. The gap only closed in recent years. Except for Brandenburg, all EastGerman states experienced a permanent decline in population, due to continuous negative internal net migration. The migration-patterns for the West-German states are less clear-cut.

We use two proxy variables for fiscal equalisation (LFA) in our analysis: i) the amount of horizontal fiscal equalisation and ii) the amount of federal supplementary grants. In the analysis, we use $l f a_{i t}$ which is the real amount of fiscal equalisation paid or received in per capita terms in state $i$ and year $t$. To compute $l f a_{i t}$ we deflate the overall nominal amount using the German $\mathrm{CPI}\left(P_{t}\right)$ and scale by the state's population:

$$
\text { lf } a_{i t}=\frac{L F A_{i t}}{P_{t} p o p_{i t}}
$$

Typically, Eastern states are net recipients over the sample period. In the West, there are both contributors and recipients. Since 2010, horizontal fiscal redistribution is financed by only four Western states, viz. Bavaria, Baden-Württemberg, Hesse, and Hamburg, while Berlin and Bremen are the main recipients in per capita terms. The share of funds received by the Eastern states decreased from about 50\% in 1995 to roughly 35\% in the past few years.

The data on structural funds distinguishes between the sources of funds (GRW or ERDF) and the destination of funds (corporate or economic infrastructure projects) ${ }^{8}$. We follow Alecke et al. (2013) and compute the structural funds data in real per capita terms. For each state $i$ the series for structural funds in real per capita terms is computed as

$$
\text { funds }_{i t}=\frac{F U N D S_{i t}}{P_{t} \text { pop }_{i t}}, \forall i, t
$$

where $F U N D S_{i t}$ is used here as a general expression for the nominal amount of either corporate (corp) or infrastructure (infra) funding to state $i$ in period $t$. In the estimations, these series are either used as totals, or split up according to the funding source (GRW or ERDF). The large majority of structural funds - over 75 percent - went to the East over the sample period. Corporate structural funding exceeded funding to infrastructure in all periods. Budget resources available for structural funding decreased over time (Deutscher Bundestag, 2016).

\footnotetext{
${ }^{8}$ We use data on appropriated funds for which the proof of the use of resources was obtained, where the funding is assigned to the year in which the funds were granted. Over the long term this proof is received for about $87 \%$ of the appropriated funds, Bade and Alm (2010).
} 


\subsection{Empirical results}

This section discusses the empirical results. We first derive a benchmark specification for the relation between per capital income growth and the initial income level, including a time trend and a crisis dummy. Then, we add in turn variables for net migration, fiscal equalisation and structural funding. We derive a non-linear specification to take account of the conditionality of our additional explanatory variables and compute marginal effects to investigate the significance of their impact on growth and convergence. Based on these specifications, we first estimate an unconditional convergence model. We find that internal migration has a positive impact on growth in the East and thus contributes to the convergence between East and West. Horizontal tax equalisation appears ineffective in promoting growth and convergence. There is some evidence that federal supplementary grants contribute to convergence between grant receiving and non-receiving states. Structural funding appears to significantly promote convergence. We next relax the assumption of unconditional convergence and estimate a fixed effects model in both the cross-section and time dimension. We find support of the conditional convergence assumption between German states. The additional explanatory variables become insignificant.

\subsubsection{Model specification}

First, we expand equation (5.1) by assuming that the steady state level of income $y_{t}^{*}$ is growing over time at the rate of technological progress $x .{ }^{9}$ Then, it can be shown that

$$
\frac{\ln \left(y_{t} / y_{t-T}\right)}{T}=x+\frac{\left(1-e^{-\beta T}\right)}{T} x(t-T)+\frac{\left(1-e^{-\beta T}\right)}{T} \ln \left(y_{0}^{*}\right)-\frac{\left(1-e^{-\beta T}\right)}{T} \ln \left(y_{t-T}\right),
$$

so that the equation to be estimated becomes

$$
\ln \left(y_{t} / y_{t-T}\right) / T=\mu+\theta t+b\left[\ln \left(y_{t-T}\right)\right]+u_{t}
$$

with $\mu=x+\left(1-e^{-\beta T}\right) / T\left[\ln \left(y_{0}^{*}\right)\right], \theta=\left(1-e^{-\beta T}\right) / T x$ and $b=-\left(1-e^{-\beta T}\right) / T$.

In addition, we allow other potential determinants of growth differences between German states to enter the equation to avoid an omitted variable bias (Barro and Sala-i-Martin, 2004). In the majority of earlier studies, additional explanatory variables are simply added to the original equation, measuring the direct effect of these variables on economic growth. However, we also include indirect - interaction - effects, to allow the impact of our additional explanatory

\footnotetext{
${ }^{9}$ Here, we omit subscript $i$ for convenience.
} 
variables to depend on initial conditions, i.e. the relative prosperity of a region/state. When we take account of this conditionality a general non-linear specification results which has the following form:

$$
\ln \left(y_{t} / y_{t-T}\right) / T=c+b_{0} \ln \left(y_{t-T}\right)+b_{1} X \ln \left(y_{t-T}\right)+\gamma X+u_{t}
$$

where $X$ is any variable assumed to explain growth and convergence. The marginal effect of $X$ on the growth rate of $y$ is given by

$$
\frac{\partial \ln \left(y_{t} / y_{t-T}\right) / T}{\partial X}=b_{1} \ln \left(y_{t-T}\right)+\gamma
$$

$X$ is state-specific and may or may not be time-dependent. In our application, we choose $X$ to be a measure of net migration, fiscal equalisation and structural funding consecutively.

In the analysis, we divide the 1995-2014 sample period into four 5-year intervals (1995-2000, 2000-2005, 2005-2010, 2010-2014). It balances the desire for more observations with that of limiting the impact of cyclical disturbances (Eggert et al., 2007; Etzo, 2008a; Islam, 1995; Islam, 2003; Schmidt, 1997). We also introduce a time-dependent crisis dummy, dummy crisis $_{\text {, }}$ which is 1 for the period 2005-2010 and 0 in all other periods. In our standard specification, we include both the crisis dummy and its interaction with initial per capita income. It allows for the possibility that the crisis affected German states unevenly. This yields the following equation:

$$
\begin{aligned}
\ln \left(y_{t} / y_{t-T}\right) / T & =\mu+\theta t+b_{0} \ln \left(y_{t-T}\right)+b_{1} X \ln \left(y_{t-T}\right)+\gamma X+b_{2} d u m m y_{\text {crisis }} \ln \left(y_{t-T}\right) \\
& +\delta d u m m y_{\text {crisis }}+u_{t}
\end{aligned}
$$

\subsubsection{Estimation results - unconditional convergence}

We estimate equation (5.6) with panel estimation. In the benchmark specification, we include the trend term, the crisis dummy and the interaction term. Subsequently, we add each variable $X$ in turn. Table 5.1 contains the estimation results. ${ }^{10}$ The first column (I) shows the results for the benchmark specification. All coefficients are significant and have the expected sign. When we take account of trend growth due to technological progress and of the crisis, the convergence coefficient in the non-crisis periods equals -0.0075 . The crisis period has a strong significant effect on the convergence path, as witnessed by the significant interaction coefficient $b_{2}$, which

${ }^{10}$ We report ordinary standard errors. Given the relatively small number of observations, the computation of heteroskedasticity adjusted standard errors is infeasible. The presented inference needs hence to be treated with caution. The inclusion of more recent observations or the division of the period into shorter intervals (as for instance in Alecke and Untiedt, 2007) could resolve the issue. 
equals -0.0147 . Also, the dummy itself has a significant - positive - coefficient. These results confirm unconditional convergence between the German federal states but suggest that convergence towards the unique steady state is rather slow and implies a very long convergence path. The average speed of convergence to the (common) steady state is $0.76 \%$ per year, i.e. it will take about 91 years to reduce the differences in per capita incomes by half. Given that the average income gap between East and West is about 50\% (Figure 5.1), the income gap is closed by roughly $0.4 \%$ per year. In the crisis period, the speed of convergence was higher at $2.3 \%$ per year and the half-life was 29.4 years.

Figure 5.1 Growth effect of the crisis



The solid line gives the marginal effect of the crisis (2005-2010); the dashed lines indicate the 95\% confidence interval. The shaded areas indicate the ranges of significance.

We show the overall - marginal - effect of the crisis which is equal to $b_{2} \ln \left(y_{t-T}\right)+\delta$ in Figure 5.1 (solid line), across the observed range of initial incomes. The $95 \%$ confidence bands indicate for which income levels - shown by the shaded area - the crisis has a statistically significant effect on the growth rate of per capita GDP. To increase intuition, we insert the state acronyms at their initial (1995) per capita income (in logs) in the figure. For the lower income (East) states on the left, the crisis has no significant growth effect. However, the crisis did significantly reduce growth in the western states with the highest per capita income (shaded area on the right). In this way, the crisis promotes "convergence" between lower and higher income states, even in the absence of a catch-up by the East. Starting from the benchmark 


\begin{tabular}{|c|c|c|c|c|c|c|c|c|c|c|c|c|c|c|c|c|c|c|c|}
\hline 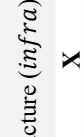 & 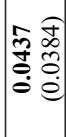 & 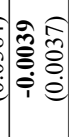 & $\mid \begin{array}{c}0 \\
* \\
0 \\
0 \\
0 \\
0 \\
0\end{array}$ & 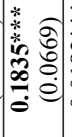 & 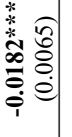 & & & & & & & & & & & 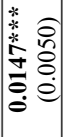 & 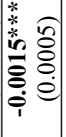 & & $\frac{0}{8}$ \\
\hline  & 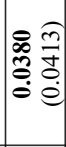 & $\hat{0}$ & 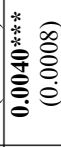 & $\mid$\begin{tabular}{ll}
$*$ & 0 \\
0 & 0 \\
0 & 0 \\
0 & 0 \\
0 & 0 \\
\hdashline & 0
\end{tabular} & 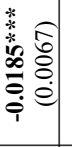 & & & & & & & & & 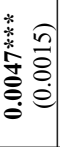 & 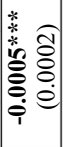 & & & & $\stackrel{8}{0}$ \\
\hline 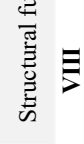 & 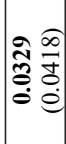 & 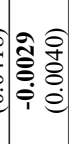 & 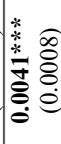 &  & $\begin{array}{ll}* & \\
* & \hat{0} \\
0 & 0 \\
0 & 0 \\
0 & 0 \\
\dot{\varphi} & \stackrel{9}{9}\end{array}$ & & & & & & & 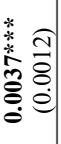 & 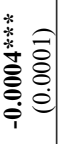 & & & & & & $\stackrel{8}{0}$ \\
\hline 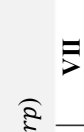 &  & 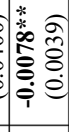 & 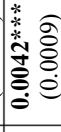 & 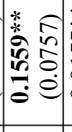 & 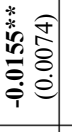 & & & & & & & & & & & $\begin{array}{ll}\infty & \widehat{0} \\
0 & 0 \\
0 & 0 \\
\dot{0} & 0 \\
\end{array}$ & 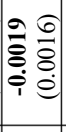 & & ڤి \\
\hline 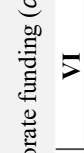 & 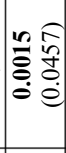 & $\hat{0}$ & 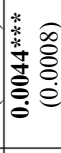 & 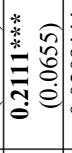 & 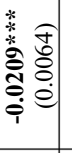 & & & & & & & & & 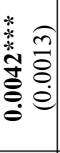 &  & & & 范 & : \\
\hline${ }^{5}$ & 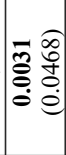 & 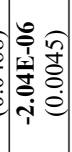 & 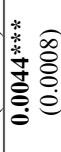 & 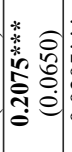 & 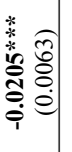 & & & & & 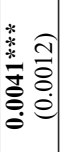 & 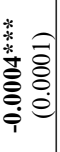 & & & & & & & $\tilde{n}$ & 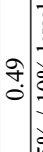 \\
\hline 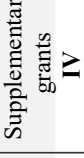 & 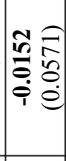 &  &  & 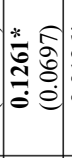 & 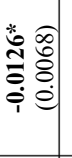 & & & 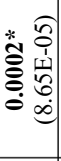 & 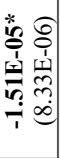 & & & & & & & & & ?. & ले \\
\hline  & 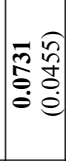 & $\begin{array}{ll}0 & f \\
0 & f \\
0 & 8 \\
& 8 \\
& 0\end{array}$ & $\begin{array}{l}0 \\
0 \\
0 \\
0 \\
0 \\
0 \\
0 \\
0\end{array}$ & $\left|\begin{array}{cc}* & 0 \\
4 & 0 \\
5 & 5 \\
0 & 0 \\
0 & 0\end{array}\right|$ & 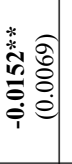 & & & 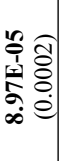 & 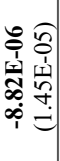 & & & & & & & & & F. & $\stackrel{?}{0}$ \\
\hline  & $\begin{array}{l}0 \\
\stackrel{0}{0} \\
\stackrel{0}{0} \\
\stackrel{0}{0} \\
\dot{0}\end{array}$ &  & 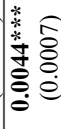 & $\begin{array}{ll}* & 0 \\
* & 0 \\
0 & 0 \\
0 & 8 \\
= & 0 \\
0 & 0\end{array} \mid$ & 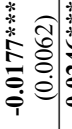 & 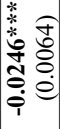 & 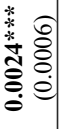 & & & & & & & & & & & & ๙ே. \\
\hline 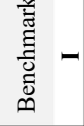 & 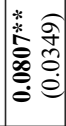 & 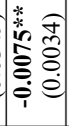 & 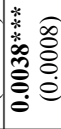 & 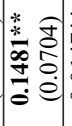 & 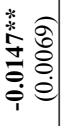 & & & & & & & & & & & & & & $\begin{array}{l}0 \\
0 \\
0 \\
0\end{array}$ \\
\hline 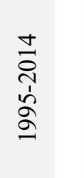 & $u$ & $\begin{array}{l}\text { ડ્ડ } \\
\Xi\end{array}$ & $\begin{array}{l}\text { हี } \\
\text { I" }\end{array}$ & 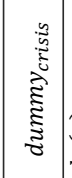 &  & $\equiv$ & 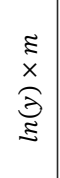 & $\Xi$ & 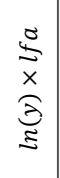 & $\delta_{0}^{2}$ & 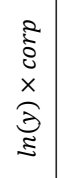 & 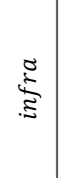 & 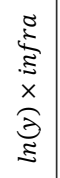 & है & 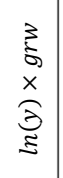 & है &  & $\approx 2$ & 2 \\
\hline
\end{tabular}


specification, we now investigate the impact of net migration, fiscal equalisation and structural funding on the convergence process, respectively.

\subsubsection{Migration}

The out-migration from East-Germany towards West-Germany started in the immediate aftermath of the border opening and only levelled off in recent years. We study the impact of net migration on growth and convergence of per capita incomes between German states, by including net migration lagged 4 years $\left(m_{t-T-4}\right)$ and its interaction with initial income in equation (5.6). ${ }^{11}$ The second column (II) of Table 5.1 shows the results. First, we observe that the explanatory power of the regression improves significantly compared to the benchmark specification (I), while the direct effect of initial income on growth (convergence parameter $b_{0}$ ) becomes insignificant. Second, the estimated direct effect of net migration on growth is negative and significant, indicating lower growth in states with positive migration rates. Given that low income states (East) experienced negative net migration and high-income states (West) positive net migration, our results support convergence through migration. This is consistent with Scheufele and Ludwig (2009) and Kubis and Schneider (2009) and with the hypothesised sign under the assumption of labour homogeneity. Third, the estimated coefficient on the interaction term is significantly positive. Hence, the direct (negative) migration effect is weakened by the interaction between migration and initial income. Sufficiently high income levels therefore tend to offset the initial negative migration effect. Overall, these findings suggest that net migration is able to capture a significant part of the unspecified convergence effect found in the benchmark specification.

The overall marginal effect equals $b_{1} \ln \left(y_{t-T}\right)+\gamma$ and is shown in Figure 5.2, which has the same layout as Figure 5.1. The figure shows that the marginal effect of net migration on growth is significantly negative for the Eastern low-income states (BB, TH, SN, ST, MV). Since these states have substantial negative net migration, it implies that they experience higher growth through the indirect migration effect. On the other side of the range, the marginal effect of net migration on growth is significantly positive for the two city states Bremen and Hamburg (HB and $\mathrm{HH}$ ) and Hesse (HE) and it is marginally significant for Baden-Württemberg and Bavaria (BW and BY). Only Bavaria and Hamburg experienced a substantial positive migration balance, suggesting that their growth rate was positively influenced by migration. In the other three, the migration balance is small and for Bremen it is even negative. Per capita income in

${ }^{11}$ We use lagged migration to avoid endogeneity bias. We tested five different lag-specifications and selected the one with the best fit. 
the other German states lies in the range where the marginal migration effect is insignificant. Overall, the results suggest that migration does not have a statistically significant effect on growth in Western states in general - Bavaria and Hamburg excluded - but contributes to faster growth and some catch-up in the five poorer Eastern states.

\section{Figure 5.2 Growth effect of net migration}

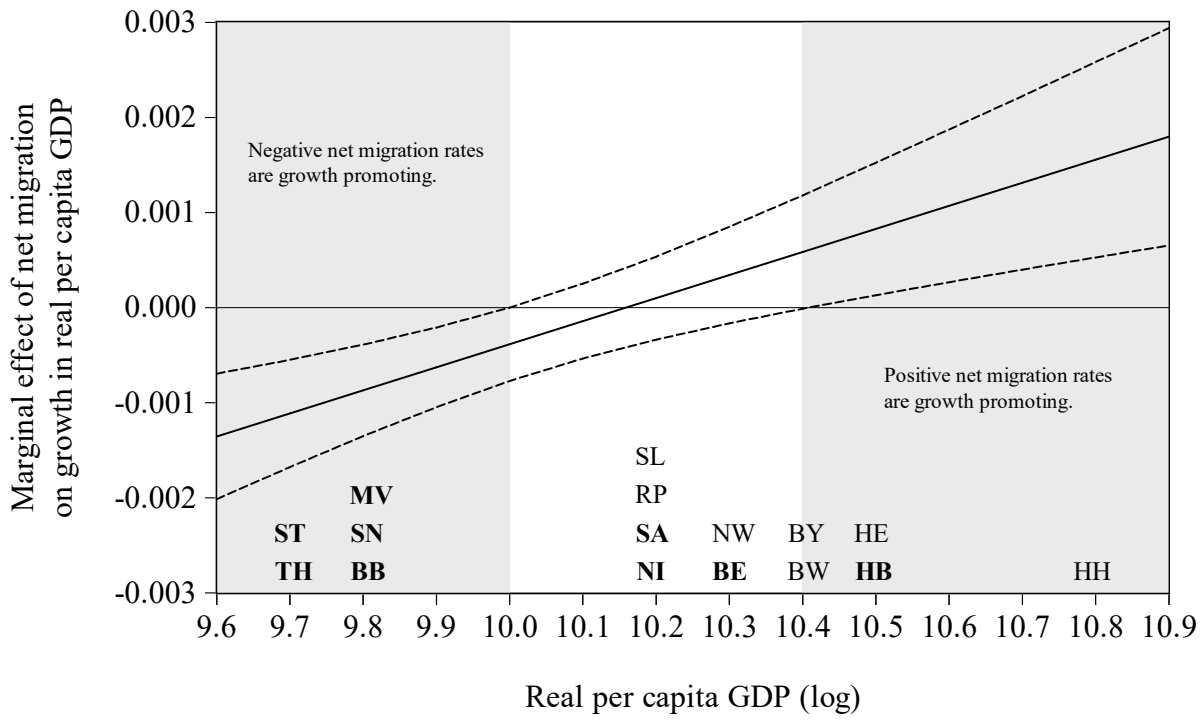

The solid line gives the marginal effect of net migration, the dashed lines indicate the $95 \%$ confidence interval. Bold prints of states' acronyms indicate negative net migration rates. The shaded areas indicate the ranges of significance.

\subsubsection{Fiscal equalisation}

Next, we investigate the impact of fiscal equalisation on growth and convergence between the various German states, using two proxies for fiscal equalisation, namely the horizontal tax redistribution and the sum of federal supplementary grants, in the starting year. ${ }^{12}$ The results are presented in columns III and IV of Table 5.1. When we use horizontal tax redistribution as our proxy for fiscal equalisation, we observe that both its direct and interaction effects are insignificant. Moreover, the coefficient estimates for initial income, trend, the crisis dummy and the crisis interaction effect remain virtually unchanged compared to the benchmark

\footnotetext{
${ }^{12}$ We cannot use lagged fiscal equalisation because the Eastern states entered the existing fiscal equalisation system only in 1995. The Eastern states benefitted from the fund "Deutsche Einheit" between 1990 and 1994. As a robustness check, we constructed a dummy variable which equals $1(0)$ if a state is on average a net recipient (contributor) of the fiscal equalisation in a 5-year period; all Eastern states are considered net recipients (1) over the period 1991-1995. Then, we include the lagged dummy and its interaction in the regression. The results are reported in Appendix I.
} 
regression, although the initial income coefficient becomes insignificant. There is no gain in explanatory power. ${ }^{13} \mathrm{We}$ conclude that tax redistribution is ineffective in promoting growth and convergence across states. Our findings correspond with Baskaran et al. (2017).

\section{Figure 5.3 Growth effect of fiscal equalisation (Federal supplementary grants)}

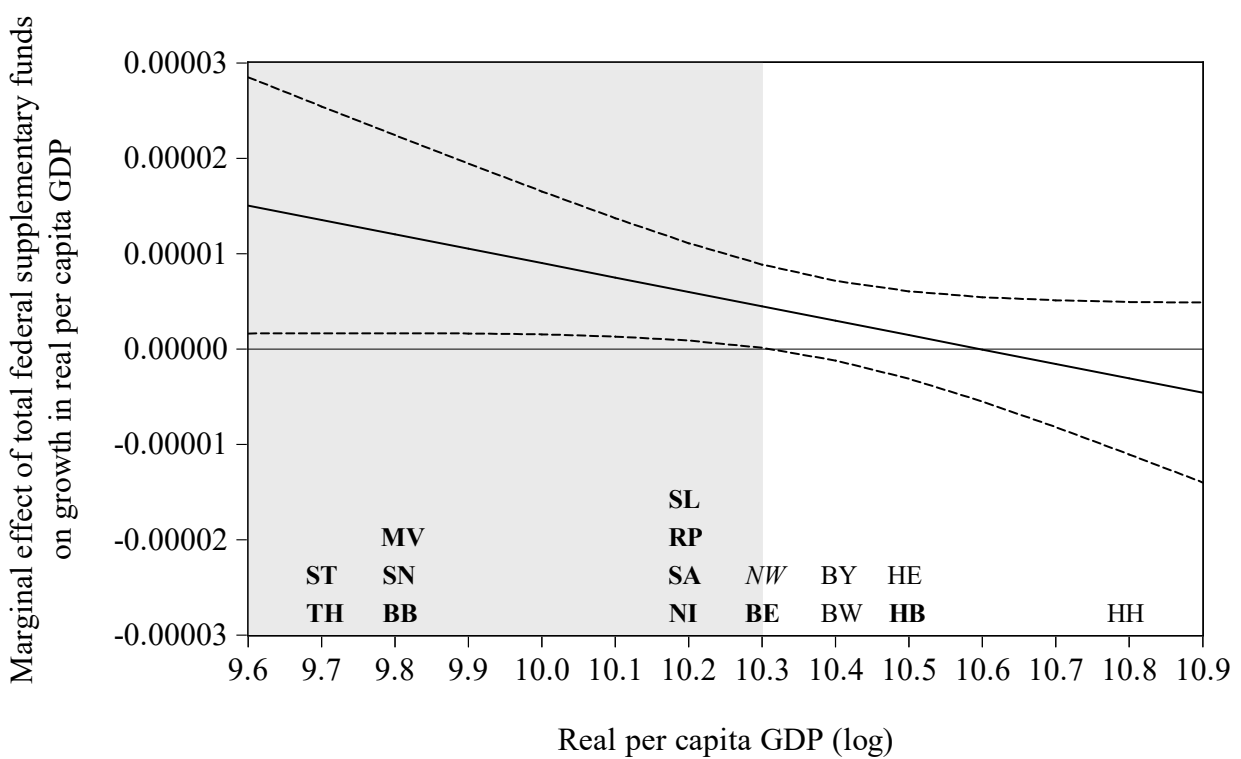

The solid line gives the marginal effect; the dashed lines indicate the $95 \%$ confidence interval. Bold prints of states' abbreviations indicate net recipients, cursive prints indicate that the state became a net recipient over the time horizon, normal prints are net contributors. The shaded area indicates the ranges of significance.

When we use federal supplementary grants as our fiscal equalisation proxy, the evidence is somewhat more supportive of a convergence effect. First, we find that both the direct and interaction effect of federal supplementary grants are marginally significant. Second, the initial income coefficient becomes virtually equal to zero and the adjusted $\mathrm{R}^{2}$ marginally increases. The other coefficients roughly remain the same. Figure 5.3 shows that the marginal effect of federal supplementary grants on growth is positive for lower income states and marginally significant. The effect is decreasing in initial income. All grant receiving states (BB, BE, MV, NI, RP, SA, SL, SN, ST, TH) except Bremen (HB) therefore experience a positive growth impetus from federal supplementary grants, which contributes somewhat to convergence between grant receiving and non-receiving states. This result contradicts especially the findings of Berthold et al. (2001), Berthold and Fricke (2005) and Berthold and Fricke (2007) who

\footnotetext{
${ }^{13}$ Due to the insignificant direct and interaction effects we do not show a marginal effects figure in this case.
} 
conclude that there are significantly negative effects of both horizontal and vertical redistribution. The variable of vertical fiscal redistribution in those studies includes both supplementary federal grants and payments within the framework of GRW funding. In this chapter, the impact of regional structural policy on economic growth is considered separately and will be discussed in the next section.

\subsubsection{Regional structural policy}

Finally, we investigate the impact of structural funds on growth and convergence between German states, and distinguish between the sources of funding (German, European, total) and the destinations of funding (corporate projects and economic infrastructure projects). Our data refer to the funds that were actually paid out according to the expenditure of funds. Funds that are paid out are assigned to the year in which the funds were granted. ${ }^{14}$ The underlying hypothesis is that structural funding leads to a capital inflow in the receiving state and is expected to temporarily increase growth towards the steady state (Alecke et al., 2013). However, which states qualify for structural funding and how much support they receive is determined on basis of several economic indicators. This may lead to simultaneity issues or reversed causality. To avoid this problem, we introduce the structural funding variables into the estimated equations with a lag (Eggert et al., 2007).

Columns V to VII in Table 5.1 display the results for total corporate funding and its German and European components, respectively. Here, we use funding in the year prior to the 5-year period as explanatory variable. ${ }^{15}$ The results for total funding and its German component are virtually identical. The direct effect of funding on growth is significantly positive, while the smaller interaction coefficient is significantly negative, indicating a marginal effect that decreases with initial income. The explanatory power of the regression rises substantially compared to the benchmark regression. The initial income coefficient virtually equals zero and is insignificant, while the other coefficients remain qualitatively unchanged. The results for European corporate funding are insignificant. Column VII provides no improvement at all compared to the benchmark specification.

\footnotetext{
${ }^{14}$ There is an apparent decrease in funding in some states over the past years, which may be related to the lack of data on confirmed actual expenditure.

${ }^{15}$ Some states are recipients of structural funding in some years and not in others. For robustness, we also estimate the equation using lagged 5-year averages for the respective funding variables. Overall, the results remain qualitatively unchanged (Appendix I).
} 


\section{Figure 5.4 Growth effect of structural funding}

Corporate structural funding
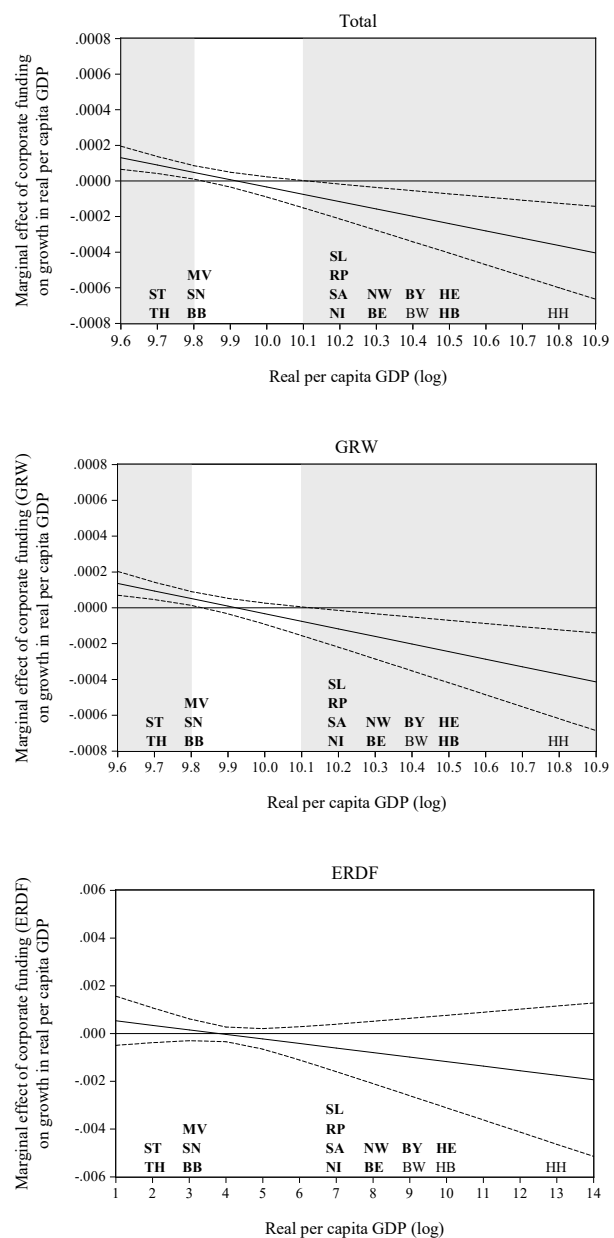

Structural funding to infrastructure
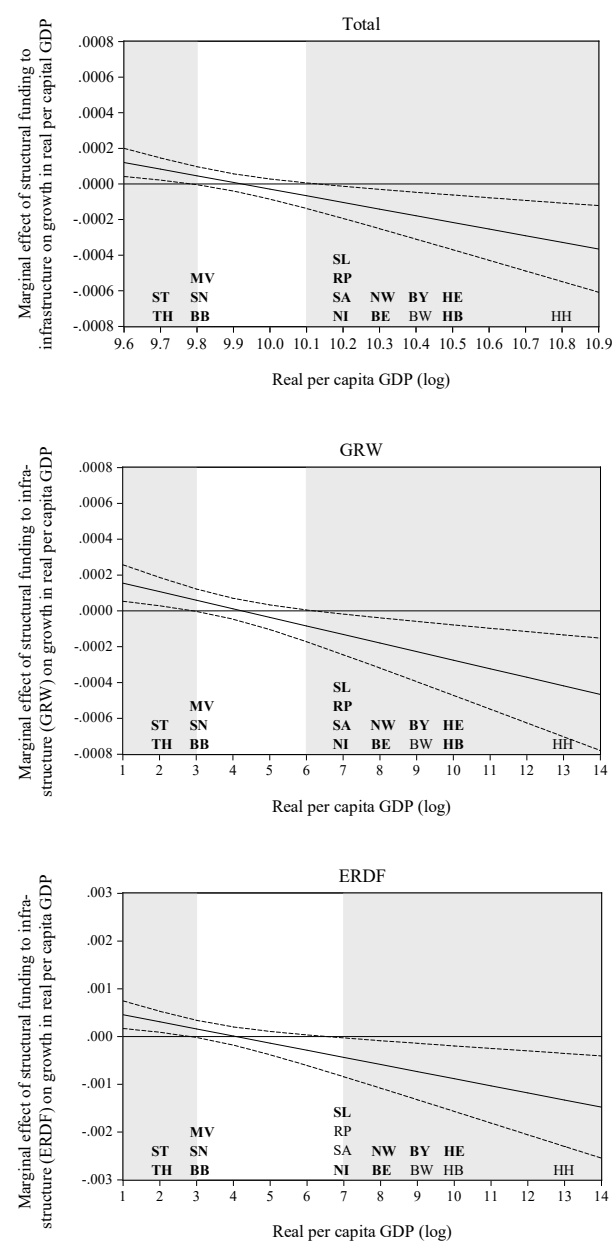

Solid lines give the marginal effect of structural funding, the dashed lines indicate the $95 \%$ confidence interval. Bold prints of states' abbreviations indicate that the state received a positive amount of structural funding. The shaded areas indicate the ranges of significance.

The three panels on the left in Figure 5.4 show the corresponding marginal effects in the usual way. Whereas the marginal effect of structural funding is significantly positive for the Eastern low income states (BB, MV, SN, ST, TH), it is found to be significantly negative in subsidised higher income states (BE, BY, HB, HE, NI, NW, RP, SA, SL). Note though that the latter states hardly receive any structural funding. The main economic impact, thus, is on the Eastern states. Overall, the evidence suggests that structural corporate funding by the German government contributes to convergence. On the other hand, the results for European corporate funding do 
not provide support for any convergence effect. Why the results differ so much for German versus European corporate funding is an unexplained puzzle that we leave for future research. Columns VIII to $\mathrm{X}$ in Table 5.1 show the regression results for structural funding in infrastructure. Again, funding in the previous year is used as explanatory variable. ${ }^{16}$ In column VIII we report the results for total funding, while in columns IX and X the results for the German and European funding component are displayed, respectively. For infrastructure investment, there is little difference between the total effect and the individual effects of German and European funding. In all cases, there is evidence of significant direct and indirect coefficients and a decrease in size and significance of the initial income effect. Overall, the explanatory power is larger than that of the benchmark equation, but less than is the case for corporate investment. The three panels on the right in Figure 5.4 graphically show the marginal effects. The decreasing marginal effects again provide evidence that this type of investment contributes to growth in the East, but hampers growth in recipient states in the West.

\subsubsection{Empirical results - Conditional convergence}

Our results so far show that, under the assumption of unconditional convergence between German states, the coefficient on initial income is significant but small in the benchmark specification. It becomes insignificant when additional explanatory variables are included into the estimated equation, providing suggestive evidence on the transmission channels through which the unconditional convergence works.

In this section, we relax the restriction of unconditional convergence and estimate a fixed effects model. This assumption is justified not only on the basis of expected persistent differences between the East and the West of the country, but more generally on additional differences between the North and the South and between city (BE, HB, HH) and area states. We include both cross-section and period fixed effects. The specification of cross-section fixed effects allows each German state to converge to its own steady state. Period fixed effects allow for a less restrictive specification in the time dimension than with the original trend and the crisis dummy. ${ }^{17}$ Obviously, the latter two variables need to be excluded in the presence of time fixed effects.

We estimate the fixed effects model for each of the specifications I - X in Table 5.1. In the benchmark specification for conditional convergence (Table 5.2), the coefficient on initial

\footnotetext{
${ }^{16}$ As with corporate funding, a robustness check with 5-year lagged infrastructure funding yields similar results. (Appendix I)

${ }^{17}$ The estimation of a model including only cross-section fixed effects yields similar results.
} 
income has the expected negative sign and is highly significant. The convergence parameter substantially exceeds the convergence parameter in the unconditional case, suggesting that the speed of convergence to the own steady state is significantly higher. More precisely, the speed of convergence towards the own steady state is about $10 \%$ per year and the half-life is 6.6 years. The coefficient on the interaction of the crisis dummy with initial income is also negative and highly statistically significant indicating a more severe (negative) impact of the crisis on the growth rate of higher income states. This translates into a higher speed of convergence of about $13.5 \%$ per year and a half-life of 4.8 years. Overall, the explanatory power of the regression significantly improves compared to the unconditional analysis. In all other specifications, the direct and interaction effects have small and insignificant coefficients, i.e. none of the variables under consideration contributes to the conditional convergence of German states. Both the coefficient on initial income and on its interaction with the crisis dummy are stable across specifications. $^{18}$

\section{Table 5.2 Panel estimation (cross-section and period fixed effects)}

\begin{tabular}{|c|c|}
\hline $1995-2014$ & $\begin{array}{c}\text { Benchmark } \\
\mathbf{- 0 . 0 8 1} 1^{* * *} \\
(0.016)\end{array}$ \\
\hline $\ln (y)$ & $\mathbf{- 0 . 0 1 7 ^ { * * * * }}$ \\
\hline $\ln (y) \times d u m m y_{\text {crisis }}$ & $0.004)$ \\
\hline$R^{2}$ & 0.83 \\
\hline $\bar{R}^{2}$ & 0.74 \\
\hline
\end{tabular}

Ordinary standard errors in parentheses.

${ }^{* * *}$ indicates significance at the $1 \%$.

In Table 5.3 we report the redundant fixed effects test results to evaluate the joint significance of the fixed effects. We perform three tests. First, we test for the significance of cross-section fixed effects compared to the restricted specification with only period fixed effects. Second, we do the reverse and test for the significance of the period fixed effects. Third, we test for the joint significance of all fixed effects compared to an estimated equation including only a single intercept. The table shows that all test statistics are highly statistically significant and, hence, strongly reject the null hypothesis that the fixed effects are redundant. Hence, econometrically, the conditional specification dominates the earlier unconditional specification.

Our results strongly support the assumption of conditional convergence between German states. Automatic convergence to a state dependent (conditional) steady state is found to be faster than

\footnotetext{
${ }^{18}$ The results for all other specifications are available on request.
} 
to a joint (unconditional) steady state, suggesting that structural differences between German states will prevail in the long run. The insignificance of the explanatory variables and interaction terms in the conditional specification furthermore suggest that migration and fiscal policy attempts do not succeed in speeding up convergence to the conditional steady state. The latter is quasi automatic. In contrast, the slow unconditional convergence between German states seems to be supported by fiscal policy measures and migration, in line with the attempts to equalise living conditions between German states.

Table 5.3 Redundant fixed effects test results

\begin{tabular}{|l|l|c|}
\hline \multicolumn{1}{|c|}{ Fixed effects } & \multicolumn{1}{|c|}{ Test } & Benchmark \\
\hline \multirow{3}{*}{ Cross-section } & F-test & $\mathbf{4 . 3 4}^{* * *}$ \\
& & $(15,43)$ \\
& Chi-square test & $\mathbf{5 9 . 0 0}^{* * *}$ \\
& F-test & $(15)$ \\
\hline & & $\mathbf{4 3 . 8 5}^{* * *}$ \\
Period & Chi-square test & $(3,43)$ \\
& & $\mathbf{8 9 . 6 7}^{* * *}$ \\
& F-test & $(3)$ \\
Cross-section and & & $\mathbf{9 . 9 0}^{* * *}$ \\
Period & Chi-square test & $(18,43)$ \\
& & $\mathbf{1 0 4 . 8 2}^{* * *}$ \\
& & $(18)$ \\
\hline Degrees of freedom in parentheses. \\
indicates significance at the $1 \%$.
\end{tabular}

What are the conclusions of these findings in view of the EA? These findings suggest that unconditional convergence between regions within a monetary union more generally is by no means either automatic or fast. Instead, it seems more likely that income differences between EA regions within will prevail in the long-run and that the regions converge to a region-specific steady state. In the light of these findings for Germany, the effectiveness of EA convergence policy, its extent and desirability need separate evaluation in view of the expected length of the convergence process.

\subsection{Conclusions}

In this chapter we study the presence and sources of growth and convergence in real per capita income between German states in the period 1995-2014. Our analysis starts from the standard neoclassical growth - initial income equation in a panel framework to which we add net 
migration, fiscal transfers and investment subsidies as potential determinants of growth and convergence.

We contribute to the literature in three directions. First, we use a long period to provide more robust results and to facilitate an analysis of the direct impact of the crisis on economic convergence. Second, we include a trend to pick up technological progress and avoid omitted variables bias. Third, we include interaction effects in the specification to allow the impact of explanatory variables to depend on initial conditions. A general, non-linear specification results. This is in contrast with the majority of earlier studies, which only consider the direct linear - effect of these variables on economic growth. Our analysis allows for the computation and interpretation of marginal effects, which sheds more light on the convergence dynamics between East and West.

We estimate unconditional and conditional convergence models. For the unconditional convergence model, our benchmark equation has satisfactory explanatory power and shows significant coefficients with expected signs for the -technology-driven - time trend, the crisis dummy and crisis interaction term. Accounting for these effects results in a small but significantly negative coefficient on lagged income. It provides support for slow convergence between East and West. An in-depth investigation of the marginal effect of the crisis dummy shows that the crisis period caused an additional convergence effect, driven by the negative impact of the crisis on real per capita GDP in the West rather than by a catch-up from the East. Overall, the empirical evidence for our additional explanatory variables to explain growth and convergence supports the relevance of non-linear interaction effects. While the direct initial income effect tends to become insignificant, the marginal effect of explanatory variables is found to depend strongly on initial income conditions. In our view, the results shed some light on the underlying transmission channels behind the initial income effect in the benchmark specification for unconditional convergence.

Net migration has a negative impact on growth for very low levels of income and a positive impact on growth for high levels of income. As a result of the internal migration patterns, Eastern states experience higher growth and some catch up with the West through the migration effect. Growth in the average West German states is not significantly affected by internal migration.

Despite the sizable amounts of fiscal redistribution across German states, the general findings of earlier studies suggest that the impact of fiscal equalisation on growth is at best absent. Our analysis distinguishes between horizontal tax redistribution and vertical redistribution 
(supplementary federal grants). Horizontal tax redistribution cannot explain growth differences between German states. However, we do find some evidence of significantly positive marginal effects of federal supplementary grants on the growth rates of the grant receiving states. This contributes to convergence between grant receiving and non-receiving states and provides supportive evidence of the effectiveness of at least some components of the fiscal redistribution scheme.

Our analysis of structural funding distinguishes between the sources (German and European) and the destination of funds (corporate and economic infrastructure projects). We find a positive direct impact of structural funding on growth in general, but this effect is crowded out by the indirect effect which becomes stronger with rising initial per capita income. The marginal effect of structural funding on growth is positive for the Eastern and negative for the Western German states, and the marginal effects of German funding dominate the marginal effects of funding from European sources. Structural funding therefore appears to be counterproductive in the West. For the East, it helps to speed up the convergence process.

Estimation of the fixed effects model significantly supports the hypothesis of conditional convergence between German states. Migration and fiscal policy attempts do not succeed in speeding up convergence to the conditional steady state. 


\section{References}

Alecke, B., Mitze, T., Untiedt, G., 2013. Growth effects of regional policy in Germany: results from a spatially augmented multiplicative interaction model. Annals of Regional Science $50(2), 535-554$.

Alecke, B., Untiedt, G., 2007. Makroökonometrische Untersuchungen zu den Wirkungen für die Ausgleichs- und Wachstumsregionen, in: Rosenfeld, M.T.W., Alecke, B., Franz, P., Heimpold, G., Kilper, H., Kunkel, K., Untiedt, G., Zillmer, S. (Eds.), Interregionale Ausgleichspolitik in Deutschland: Untersuchungen zu den Effekten ausgewählter Systeme zur Herstellung von "gleichwertigen Lebensverhältnissen", pp. 82-99.

Bade, F.-J., Alm, B., 2010. Endbericht zum Gutachten Evaluierung der Gemeinschaftsaufgabe "Verbesserung der regionalen Wirtschaftsstruktur" (GRW) durch einzelbetriebliche Erfolgskontrolle für den Förderzeitraum 1999-2008 und Schaffung eines Systems für ein gleitendes Monitoring. Technische Universität Dortmund, Dortmund.

Barro, R.J., Sala-i-Martin, X., 1991. Convergence across States and Regions. Brookings Papers on Economic Activity 1, 107-182.

Barro, R.J., Sala-i-Martin, X., 1992. Regional Growth and Migration: A Japan-United States Comparison. Journal of the Japanese and International Economies 6, 312-346.

Barro, R.J., Sala-i-Martin, X., 2004. Economic growth, 2nd ed. MIT Press, Cambridge, Massachusetts.

Baskaran, T., Feld, L.P., Necker, S., 2017. Depressing dependence?: Transfers and economic growth in the German states, 1975-2005. Regional Studies 51 (12), 1815-1825.

Baumol, W.J., 1986. Productivity Growth, Convergence, and Welfare: What the Long-Run Data Show. American Economic Review 76 (5), 1072-1085.

Berthold, N., Drews, S., Thode, E., 2001. Die föderale Ordnung in Deutschland - Motor oder Bremse des wirtschaftlichen Wachstums? Wirtschaftswissenschaftliche Beiträge des Lehrstuhls für VWL 42. Bayerische Julius-Maximilians-Universität Würzburg.

Berthold, N., Fricke, H., 2005. Föderalismus und Wachstum: Eine vernachlässigte Beziehung. Wirtschaftswissenschaftliche Beiträge des Lehrstuhls für VWL 83. Bayerische JuliusMaximilians-Universität Würzburg.

Berthold, N., Fricke, H., 2007. Volkswirtschaftliche Auswirkungen der finanziellen Ausgleichsysteme in Deutschland. Wirtschaftswissenschaftliche Beiträge des Lehrstuhls für VWL 93. Bayerische Julius-Maximilians-Universität Würzburg.

Berthold, N., Kullas, M., 2009. 20 Jahre Mauerfall - Konvergenz in Deutschland. Wirtschaftswissenschaftliche Beiträge des Lehrstuhls für VWL 105. Bayerische JuliusMaximilians-Universität Würzburg.

Boltho, A., Carlin, W., Scaramozzino, P., 2018. Why East Germany did not become a new Mezzogiorno. Journal of Comparative Economics 46 (1), 308-325.

Deutscher Bundestag, 2016. Regionalpolitischer Bericht der Bund-LänderGemeinschaftsaufgabe „Verbesserung der regionalen Wirtschaftsstruktur“. Drucksache $18 / 7500$.

Eberle, J., Brenner, T., 2016. More bucks, more growth, more justice? The effects of regional structural fund and regional economic growth and convergence in Germany. Working Papers on Innovation and Space 01.16. Universität Marburg. 
Eckey, H.-F., Kosfeld, R., 2005. Regionaler Wirkungsgrad und räumliche Ausstrahlungseffekte der Investitionsförderung. Volkswirtschaftliche Diskussionsbeiträge 55/04. Universität Kassel.

Eggert, W., von Ehrlich, M., Fenge, R., König, G., 2007. Konvergenz- und Wachstumseffekte der europäischen Regionalpolitik in Deutschland. Perspektiven der Wirtschaftspolitik 8 (2), $130-146$.

Eltges, M., 2013. Regionale Konvergenz und Divergenz - die Frage der Fragen. Informationen zur Raumentwicklung 1, 51-66.

Etzo, I., 2008a. Internal migration and growth in Italy. MPRA 8642.

Etzo, I., 2008b. Internal migration: a review of the literature. MPRA 8783. http://mpra.ub.unimuenchen.de/8783/.

Islam, N., 1995. Growth Empirics: A Panel Data Approach. The Quarterly Journal of Economics 110 (4), 1127-1170.

Islam, N., 2003. What have We Learnt from the Convergence Debate? Journal of Economic Surveys 17 (3), 309-362.

IWH, 2011. Wirtschaftlicher Stand und Perspektiven für Ostdeutschland: Studie im Auftrag des Bundesministeriums des Innern. Sonderheft 2. Institut für Wirtschaftsforschung Halle.

Koetter, M., Wedow, M., 2013. Transfer Payments without Growth: Evidence for German Regions, 1992-2005. International Journal of Urban and Regional Research 37 (4), 1438 1455.

Kubis, A., Schneider, L., 2009. Zum Zusammenhang von Abwanderung und regionaler Konvergenz. Wirtschaft im Wandel 10, 408-414.

Maseland, R., 2014. Does Germany have an East-West Problem? Regional Growth Patterns in Germany since Reunification. Regional Studies 48 (7), 1161-1175.

Sala-i-Martin, X., 1996. The Classical Approach to Convergence Analysis. The Economic Journal 106 (437), 1019-1036.

Scheufele, R., Ludwig, U., 2009. Der lange Weg der Konvergenz. Wirtschaft im Wandel 10, 400-407.

Schmidt, H., 1997. Konvergenz wachsender Volkswirtschaften: Theoretische und empirische Konzepte sowie eine Analyse der Produktionsniveaus westdeutscher Regionen. SpringerVerlag, Berlin Heidelberg.

Shioji, E., 2001. Composition Effect of Migration and Regional Growth in Japan. Journal of the Japanese and International Economies 15 (1), 29-49.

Sousa, C.T., Pereira, E.T., 2012. A Contribution to the Empirics of Convergence: the Case of the European State Members. MPRA 62017.

SVR, 2004. Wirtschaftspolitik für den Aufbau Ost: Königsweg nicht in Sicht. Jahresgutachten 2004/2005. Sachverständigenrat zur Begutachtung der gesamtwirtschaflichen Entwicklung. 


\section{Appendix I.}

\section{Table 5.4 Robustness analyses}

\begin{tabular}{|c|c|c|c|c|c|c|c|}
\hline $1995-2014$ & Fiscal & \multicolumn{3}{|c|}{ Corporate funding $(\operatorname{corp})$} & \multicolumn{3}{|c|}{ Funding to infrastructure (infra) } \\
\hline$c$ & $\begin{array}{c}\mathbf{0 . 0 7 0 8} \\
(0.0989)\end{array}$ & $\begin{array}{c}\mathbf{- 0 . 0 4 0 0} \\
(0.0530)\end{array}$ & $\begin{array}{l}\mathbf{- 0 . 0 4 0 9} \\
(0.0516)\end{array}$ & $\begin{array}{c}\mathbf{0 . 0 8 5 4} * * \\
(0.0401)\end{array}$ & $\begin{array}{c}\mathbf{0 . 0 2 4 5} \\
(0.0454)\end{array}$ & $\begin{array}{c}\mathbf{0 . 0 2 2 4} \\
(0.0439)\end{array}$ & $\begin{array}{l}\mathbf{0 . 0 7 2 0 *} \\
(0.0400)\end{array}$ \\
\hline $\ln (y)$ & $\begin{array}{l}\mathbf{- 0 . 0 0 6 4} \\
(0.0094) \\
\end{array}$ & $\begin{array}{c}\mathbf{0 . 0 0 4 0} \\
(0.0051) \\
\end{array}$ & $\begin{array}{c}\mathbf{0 . 0 0 4 1} \\
(0.0049) \\
\end{array}$ & $\begin{array}{c}-\mathbf{- 0 . 0 0 7 9 * *} \\
(0.0039)\end{array}$ & $\begin{array}{l}\mathbf{- 0 . 0 0 2 0} \\
(0.0044) \\
\end{array}$ & $\begin{array}{l}\mathbf{- 0 . 0 0 1 8} \\
(0.0042) \\
\end{array}$ & $\begin{array}{l}-\mathbf{- 0 . 0 0 6 6 *} \\
(0.0039) \\
\end{array}$ \\
\hline trend & $\begin{array}{c}\mathbf{0 . 0 0 3 8} * * * \\
(0.0008)\end{array}$ & $\begin{array}{c}\mathbf{0 . 0 0 4 7 * * *} \\
(0.0007)\end{array}$ & $\begin{array}{c}\mathbf{0 . 0 0 4 7 * * *} \\
(0.0008)\end{array}$ & $\begin{array}{c}\mathbf{0 . 0 0 4 2 * * *} \\
(0.0010)\end{array}$ & $\begin{array}{c}\mathbf{0 . 0 0 4 1 * * * *} \\
(0.0008)\end{array}$ & $\begin{array}{c}\mathbf{0 . 0 0 4 0 * * *} \\
(0.0008)\end{array}$ & $\begin{array}{c}\mathbf{0 . 0 0 4 2} * * * \\
(0.0008)\end{array}$ \\
\hline dummy $y_{\text {crisis }}$ & $\begin{array}{c}\mathbf{0 . 1 5 8 6 * * *}^{*} \\
(0.0714)\end{array}$ & $\begin{array}{c}\mathbf{0 . 2 2 0 8}^{* * *} \\
(0.0652)\end{array}$ & $\begin{array}{c}\mathbf{0 . 2 3 2 9} * * * \\
(0.0661)\end{array}$ & $\begin{array}{l}\mathbf{0 . 1 4 9 5 *}^{*} \\
(0.0767)\end{array}$ & $\begin{array}{c}\mathbf{0 . 1 8 4 9}^{* * *} \\
(0.0663)\end{array}$ & $\begin{array}{c}\mathbf{0 . 1 8 6 2} * * * \\
(0.0668)\end{array}$ & $\begin{array}{c}\mathbf{0 . 1 8 0 9} * * * \\
(0.0672)\end{array}$ \\
\hline $\begin{array}{l}\ln (y) \\
\times \text { dummy } \\
\end{array}$ & $\begin{array}{c}-\mathbf{- 0 . 0 1 5 8 * *} \\
(0.0070) \\
\end{array}$ & $\begin{array}{c}-\mathbf{- 0 . 0 2 1 8}^{* * * *} \\
(0.0064) \\
\end{array}$ & $\begin{array}{c}-\mathbf{- 0 . 0 2 2 9} * * * \\
(0.0064) \\
\end{array}$ & $\begin{array}{l}-\mathbf{- 0 . 0 1 4 9 *} \\
(0.0075) \\
\end{array}$ & $\begin{array}{c}-\mathbf{- 0 . 0 1 8 3} * * * \\
(0.0065) \\
\end{array}$ & $\begin{array}{c}-\mathbf{- 0 . 0 1 8 4} * * * * \\
(0.0065) \\
\end{array}$ & $\begin{array}{c}-\mathbf{- 0 . 0 1 7 9 * * * *} \\
(0.0066)\end{array}$ \\
\hline lfa & $\begin{array}{c}\mathbf{0 . 0 4 2 0} \\
(0.1043)\end{array}$ & & & & & & \\
\hline $\ln (y) \times l f a$ & $\begin{array}{l}\mathbf{- 0 . 0 0 4 3} \\
(0.0100) \\
\end{array}$ & & & & & & \\
\hline $\operatorname{corp}$ & & $\begin{array}{l}\mathbf{0 . 0 0 3 1 * *} \\
(0.0012)\end{array}$ & & & & & \\
\hline $\ln (y) \times \operatorname{corp}$ & & $\begin{array}{c}-\mathbf{- 0 . 0 0 0 3} * * \\
(0.0001)\end{array}$ & & & & & \\
\hline infra & & & & & $\begin{array}{c}\mathbf{0 . 0 0 5 4} * * * \\
(0.0016)\end{array}$ & & \\
\hline $\begin{array}{l}\ln (y) \\
\times \text { infra } \\
\end{array}$ & & & & & $\begin{array}{c}-\mathbf{- 0 . 0 0 0 5 * * *} \\
(0.0002) \\
\end{array}$ & & \\
\hline grw & & & $\begin{array}{l}\mathbf{0 . 0 0 3 1} \text { ** } \\
(0.0013)\end{array}$ & & & $\begin{array}{c}\mathbf{0 . 0 0 5 9} * * * \\
(0.0017)\end{array}$ & \\
\hline $\ln (y) \times g r w$ & & & $\begin{array}{c}-\mathbf{- 0 . 0 0 0 3}{ }^{* *} \\
(0.0001)\end{array}$ & & & $\begin{array}{c}-\mathbf{0 . 0 0 0 6 * * * *} \\
(0.0002)\end{array}$ & \\
\hline erdf & & & & $\begin{array}{c}\mathbf{0 . 0 1 0 4} \\
(0.0157)\end{array}$ & & & $\begin{array}{c}\mathbf{0 . 0 3 7 4} * * * \\
(0.0121)\end{array}$ \\
\hline $\ln (y) \times \operatorname{erd} f$ & & & & $\begin{array}{l}\mathbf{- 0 . 0 0 1 1} \\
(0.0016)\end{array}$ & & & $\begin{array}{c}-\mathbf{- 0 . 0 0 3 8} * * * \\
(0.0012)\end{array}$ \\
\hline$R^{2}$ & 0.42 & 0.54 & 0.54 & 0.41 & 0.51 & 0.51 & 0.49 \\
\hline $\bar{R}^{2}$ & 0.36 & 0.49 & 0.50 & 0.34 & 0.46 & 0.46 & 0.43 \\
\hline
\end{tabular}

Ordinary standard errors in parentheses. ${ }^{* * *} / /^{* *} /{ }^{*}$ indicate significance at the $1 \% / 5 \% / 10 \%$ level. 



\section{Nederlandse Samenvatting}

Zelfs zonder de Covid-19 crisis mee te tellen, heeft de eurozone sinds de oprichting al het hoofd moeten bieden aan ten minste twee grote economische uitdagingen, namelijk de financiële crisis en de resulterende Europese schuldencrisis. Natuurlijk is wel bekend dat het eurogebied niet voldoet aan de voorwaarden van een optimale muntzone (Optimum Currency Area, OCA). Dit leidde al lang voor de daadwerkelijke start van de Europese economische en monetaire unie tot een discussie over de economische motieven voor de invoering van een gemeenschappelijke valuta in Europa. In een muntzone kunnen nationale autoriteiten monetair beleid en het wisselkoersinstrument niet langer toepassen om schokken op te vangen waarmee de nationale economie te maken krijgt. Een centrale monetaire autoriteit richt zich op een gemeenschappelijk monetair beleid en ze streeft ernaar haar beleid voor alle landen in de muntzone te optimaliseren. Dat veronderstelt dat de landen die deel uitmaken van de muntzone zeer dicht bij elkaar liggen wat betreft hun conjunctuurcycli, of dat er alternative aanpassingsmechanismen zijn om schokken op te vangen. Empirisch onderzoek naar de OCAeigenschappen van de eurozone bestudeert voornamelijk de mate van symmetrie van schokken en conjunctuurcycli en richt zich dus vooral op de reële kant van de economie.

Hoewel macro-financiële verbanden in het verleden niet de focus van OCA studies waren, heeft de recente financiële crisis de onderzoeksinteresse in de verbanden tussen de financiële markten en de reële economie in het algemeen hernieuwd. Hiervoor zijn meerdere redenen. Ten eerste, werd als gevolg van de voortschrijdende Europese economische integratie en de invoering van de euro zowel een toename van de bilaterale handel als een algemene verdieping van de financiële markten waargenomen. Ten tweede, is de internationale integratie van de eurozone als geheel toegenomen door de wereldwijde globalisering. Dus er bestaan complexe reële en financiële interacties binnen de lidstaten, tussen de verschillende lidstaten en tussen de eurozone en de internationale handelspartners, die leiden tot de transmissie van schokken zowel over nationale grenzen als tussen reële en financiële markten.

Om schokken goed te kunnen opvangen is het heel belangrijk om zowel reële en financiële transmissiekanalen als de bestaande asymmetrieën in de eurozone te begrijpen. Dit proefschrift 
beoogt bij te dragen aan dit begrip. Het bestaat uit vier op zichzelf staande hoofdstukken en beantwoordt drie onderzoeksvragen. De eerste vraag analyseert de synchronisatie van reële en financiële markten in de eurozone (macro-financiële verbanden) en wordt in hoofdstuk 2 en hoofdstuk 3 besproken. De tweede vraag behandelt de transmissie van schokken in de eurozone en wordt in hoofdstuk 4 besproken. In het bijzonder wordt in dit hoofdstuk gekeken naar de effecten van symmetrische schokken op de handelsbalansen en het concurrentievermogen van individuele landen van het eurogebied. De derde vraag betreft de convergentie tussen Duitse deelstaten. Hoofdstuk 5 onderzoekt of het systeem van fiscale verevening tussen Duitse bondslanden convergentie tussen de regio's bevordert.

Hoofdstuk 2 onderzoekt macro-financiële verbanden tussen financiële cycli en conjunctuurcycli voor acht landen van de eurozone en aggregaten daarvan. De financiële cyclus is een synthetische maatstaf die wordt berekend op basis van krediet- en huizenprijsgegevens. Het hoofdstuk onderzoekt de overeenkomsten van de cycli binnen en tussen landen en het belang van overloopeffecten tussen landen en markten, met behulp van synchronisatiemaatstaven en van panel-OLS-schattingen. De resultaten van de empirische analyse onderstrepen het belang van binnenlandse macro-financiële verbanden en van de overloopeffecten tussen de landen en ze tonen aan dat de binnenlandse financiële en conjunctuurcycli worden beïnvloed door meerdere kanalen met een tegengesteld effect. De resultaten hebben gevolgen voor de uitvoering en de transmissie van het monetaire beleid in het eurogebied. Gezien de verschillende interacties kan worden aangenomen dat de effecten van het monetair beleid worden beïnvloed door de macro-financiële verbanden.

Hoofdstuk 3 onderzoekt macro-financiële verbanden in een Growth at Risk-raamwerk. De analyse maakt gebruik van de gegevens over de financiële cyclus uit hoofdstuk 2. De focus van de empirische analyse ligt op de eerste twee momenten - het conditioneel gemiddelde en de conditionele variantie - van de gefitte scheve t-verdeling en op de daaraan gerelateerde recessiekansen. In de analyse wordt het belang van binnenlandse macro-financiële verbanden voor elk land onderzocht. Verder onderzoekt dit hoofdstuk de synchronisatie van zowel het conditioneel gemiddelde en de conditionele variantie tussen verschillende landen, als van de gerelateerde recessiekansen. Er worden twee groepen landen onderscheiden: een 'kern' en een 'periferie'. Uit de analyse blijkt dat de financiële crisis in de perifere landen lange tijd op de loer heeft gelegen zonder dat dit tot uiting kwam in de feitelijke economische prestaties. De sterk groeiende financiële cycli in de vroege europeriode hebben geleid tot een continue afname van de conditionele gemiddelden, en een toename van zowel conditionele varianties als van 
recessiekansen in perifere landen. Voor de kernlanden zijn deze ontwikkelingen vóór de financiële crisis niet vast te stellen. De resultaten laten zien dat landen verschillen in gemiddelde groei en recessiekans. De asymmetrieën zijn het gevolg zowel van de verschillen in groei als een gebrek aan co-movement. Aangezien het gemeenschappelijk monetair beleid dit soort asymmetrieën niet aankan, zijn er andere mechanismen nodig om asymmetrische ontwikkelingen het hoofd te bieden en het verlies aan onafhankelijk monetair beleid en wisselkoersen te compenseren. Het hoofdstuk beveelt de een of andere vorm van begrotingsbeleid op supranationaal niveau, een effectieve Europese bankenunie, en internationale risicodeling via grensoverschrijdend kapitaalbezit aan om de stabiliteit van de eurozone te waarborgen en het welzijn te verhogen.

Hoofdstuk 4 onderzoekt de uiteenlopende handelsbalansen en de veranderingen in het concurrentievermogen van eurolanden. Om rekening to houden met de complexe internationale handelsomgeving van de eurozone wordt een GVAR-raamwerk geschat. De afzonderlijke beoordeling van intra-eurozone en extra-eurozone-handelsbalansen binnen dit model draagt bij aan het begrip van onevenwichtigheden in de Europese handelsbalansen. In dit hoofdstuk wordt onderzocht hoe symmetrische reële en monetaire schokken de handelsbalansen en het concurrentievermogen van eurolanden beïnvloeden. Er blijkt dat zowel de handelsbalansen als het concurrentievermogen grotendeels heterogeen op symmetrische schokken reageren. Dit geldt zowel binnen eurolanden (wanneer bijvoorbeeld de intra-eurozone handelsbalans en de extra-eurozone handelsbalans naar een schok in tegenstelde richtingen ontwikkelen) als ook tussen eurolanden. BBP-schokken zijn een belangrijke drijvende kracht achter de handelsbalansen en het concurrentievermogen in de eurozone. Wisselkoersschommelingen van de euro hebben geen permanent effect op de handelsbalansen. Verder beïnvloedt het monetaire beleid het concurrentievermogen van sommige landen, maar is het effect ervan op de handelsbalansen slechts tijdelijk. De algemene heterogeniteit van de reacties suggereert dat het verminderen van externe onevenwichtigheden binnen en tussen de eurolanden allesbehalve eenvoudig is. Gezien een asymmetrische transmissie van monetair beleid, kan coördinatie van het begrotingsbeleid nuttig blijken om onevenwichtigheden te verminderen.

In hoofdstuk 5 wordt de mate van $\beta$-convergentie tussen de Duitse deelstaten in de nasleep van de Duitse hereniging beoordeeld. In de analyse wordt het groeipercentage van het gemiddelde inkomen per hoofd gedurende een bepaalde periode gerelateerd aan het niveau van het inkomen per hoofd in de beginperiode. Deze relatie wordt uitgebreid om rekening te houden met voortgaande technologische verandering en met de financiële crisis. Bovendien worden 
migratie, fiscale verevening tussen de deelstaten en het regionaal structuurbeleid net zoals de interactie van deze variablen met het aanvangsinkomen als verklarende variabelen in de vergelijking opgenomen. De vergelijking wordt geschat met panel OLS. Zowel conditionele als onconditionele convergentie worden bestudeerd.

De empirische resultaten wijzen op een zeer langzame onconditonele convergentie tussen het oosten en westen van Duitsland en suggereren een heel lang convergentiepad. Met name blijkt uit de schattingen dat het automatische convergentie-effect niet significant wordt wanneer aanvullende verklarende variabelen in de analyse worden opgenomen. Migratie, verticale fiscale verevening en variabelen van het regionaal structuurbeleid dragen bij tot onconditionele convergentie tussen het oosten en het westen, terwijl horizontale fiscale verevening dat niet doet. Bovendien ondersteunen de empirische schattingen de relevantie van niet-lineaire interactie-effecten. De schatting van landendummies en periodedummies ondersteunt de hypothese van conditionele convergentie tussen de Duitse deelstaten. Conditionele convergentie lijkt quasi automatisch te zijn. De andere verklarende variabelen slagen er niet in het convergentieproces te versnellen. De resultaten suggereren dat de onconditionele convergentie tussen de regio's van een muntunie niet automatisch of snel is. Het lijkt waarschijnlijk dat de inkomensverschillen tussen de regio's op de lange termijn zullen blijven bestaan en dat de regio's zullen convergeren naar een regionale in plaats van een gemeenschappelijke steady state. Gezien deze resultaten moeten de doeltreffendheid, de omvang en de wenselijkheid van het convergentiebeleid in het eurogebied opnieuw afzonderlijk worden geëvalueerd vooral met het oog op het lange convergentieproces.

De resultaten in dit proefschrift tonen dus het belang van macro-financiële verbanden in het eurogebied aan en ze leveren bewijs van de verschillende kanalen die de binnenlandse reële en financiële markten beïnvloeden. Bovendien suggereren de aanwezigheid van asymmetrieën in conditionele groei en van asymmetrische transmissie van symmetrische schokken dat een gemeenschappelijk monetair beleid niet goed kan omgaan met de uiteenlopende economische ontwikkelingen. Dit vraagt om een aanvulling van fiscale en andere maatregelen om de stabiliteit van de EA te waarborgen. Ook moeten de doeltreffendheid, de omvang en wenselijkheid van het convergentiebeleid in het eurogebied nader worden geëvalueerd in het licht van de verwachte duur van het convergentieproces. 


\section{Curriculum Vitae}

Katharina Weddige-Haaf was born on 3 February 1974 in Quedlinburg (Germany). Between 1994 and 1996, she completed the Vordiplom of undergraduate studies in European Economics at Otto-Friedrich-Universität in Bamberg (Germany). From 1996 she continued her graduate studies at Maastricht University, Maastricht (The Netherlands) where she received her Master's Degree in International Economic Studies in May 1999. Between May 1999 and June 2000, she worked as economist at the Section Banking and supervisory strategies of the Directorate Supervision of the De Nederlandsche Bank in Amsterdam (The Netherlands). Starting in September 2000 until January 2003, she completed PhD level coursework and PhD comprehensive examinations at McGill University in Montreal (Canada). After moving to Brussels for family reasons, the subsequent thesis work was primarily pending until 2010. She became a PhD candidate at the University of Utrecht School of Economics in 2010. Working

part-time on her research project while raising her three children, she finished her doctoral dissertation in April 2021. 



\section{U.S.E. Dissertation Series}

USE 001 Bastian Westbrock (2010): Inter-firm networks: economic and sociological perspectives.

USE 002 Yi Zhang (2011): Institutions and International Investments: Evidence from China and Other Emerging Markets.

USE 003 Ryan van Lamoen (2011): The Relationship between Competition and Innovation Measuring Innovation and Causality.

USE 004 Martijn Dröes (2011): House Price Uncertainty in the Dutch Owner-Occupied Housing Market.

USE 005 Thomas van Huizen (2012): Behavioural Assumptions in Labour Economics: Analysing Social Security Reforms and Labour Market Transitions.

USE 006 Martijn Boermans (2012): International Entrepreneurship and Enterprise Development.

USE 007 Joras Ferwerda (2012): The Multidisciplinary Economics of Money Laundering.

USE 008 Federico D'Onofrio (2013): Observing the country: a history of Italian agricultural economics, 1900-1930.

USE 009 Saraï Sapulete (2013): Works Council Effectiveness: Determinants and Outcomes.

USE $010 \quad$ Britta Hoyer (2013): Network Formation under the Threat of Disruption.

USE 011 Coen Rigtering (2013): Entrepreneurial Orientation: Multilevel Analysis and Consequences.

USE 012 Beate Cesinger (2013): Context and Complexity of International Entrepreneurship as a Field of Research.

USE 013 Jan de Dreu (2013): Empirical essays on the governance of financial institutions.

USE 014 Lu Zhang (2013): Industrial Specialization: Determinants, Processes and Consequences. 
USE 015 Matthias Filser (2013): Strategic Issues in Entrepreneurship and Family Business Research.

USE 016 Mikko Pohjola (2013): A Compilation of Studies on Innovation in Firms: Capabilities, Strategies, and Performance.

USE 017 Han-Hsin Chang (2013): Heterogeneity in Development.

USE $018 \quad$ Suzanne Heijnen (2014): Analyses of sickness absence.

USE 019 Mark Kattenberg (2014): The Economics of Social Housing: Implications for Welfare, Consumption, and Labor Market Composition.

USE 020 Daniel Possenriede (2014): The Economics of Temporal and Locational Flexibility of Work.

USE 021 Dirk Gerritsen (2014): The Relevance of Security Analyst Opinions for Investment Decisions.

USE 022 Shiwei Hu (2014): Development in China and Africa.

USE 023 Saara Tamminen (2014): Heterogeneous Firms, Mark-Ups, and Income Inequality.

USE 024 Marcel van den Berg (2014): Does Internationalization Foster Firm Performance?

USE 025 Emre Akgündüz (2014): Analyzing maternal employment and child care quality.

USE 026 Jasper Lukkezen (2014): From Debt Crisis to Sovereign Risk.

USE 027 Vesile Kutlu (2015): Essays on Subjective Survival Probabilities, Consumption, and Retirement Decisions.

USE 028 Brigitte Crooijmans (2015): Leiden fusies tot efficiëntere woningcorporaties? Een exploratieve studie naar schaalvoordelen in de sociale huisvesting.

USE 029 Andrej Svorenčík (2015): The Experimental Turn in Economics: a History of Experimental Economics.

USE 030 Secil Danakol (2015): Foreign Direct Investment, Foreign Aid and Domestic Entrepreneurship.

USE 031 Ioana Deleanu (2015): Anti-Money Laundering Efforts: Failures, Fixes and the Future.

USE $032 \quad$ Jaap Oude Mulders (2016): Organizations, managers, and the employment of older workers after retirement.

USE 033 Malka de Castro Campos (2016): Private Consumption-Savings Behavior and Macroeconomic Imbalances. 
USE 034 Tahereh Rezai Khavas (2016): Fairness concerns and cooperation in context.

USE 035 Joyce Delnoy (2016): Auctions with Competing Sellers and Behavioral Bidders.

USE $036 \quad$ Krista Bruns (2017): Emergence and Diffusion of Institutions and their Effect on Economic Growth.

USE 037 Daan van der Linde (2017): Democracies under Rising Inequality: New Tests of the Redistributive Thesis.

USE 038 Swantje Falcke (2017): On the move: Analyzing immigration determinants and immigrant outcomes.

USE 039 Joep Steegmans (2017): House Prices and Household Mobility in The Netherlands: Empirical Analyses of Financial Characteristics of the Household.

USE $040 \quad$ Najmeh Rezaei Khavas (2017): Essays in Information Economics.

USE 041 Maryam Imanpour (2017): The Role of Social Networks for Combating Money Laundering.

USE 042 Ye Li (2018): Hydrogen Infrastructure Decisions through a Real Option Lens.

USE $043 \quad$ Li Lin (2018): Leadership across cultural contexts.

USE 044 Werner Liebregts (2018): Hidden entrepreneurship: Multilevel analyses of the determinants and consequences of entrepreneurial employee activity.

USE 045 Ian Koetsier (2018): Government debt: The economic consequences of natural disasters and pension funds' herding.

USE 046 Jordy Meekes (2019): Local Labour Markets, Job Displacement And Agglomeration Economies.

USE 047 Timur Pasch (2019): Essays On The Design Of The Management Accounting System: Determinants, Components And Effects.

USE 048 Jeroen Content (2019): The role of relatedness and entrepreneurship in regional economic development.

USE 049 Franziska Heinicke (2019): Essays on self-image and preferences for honesty.

USE 050 Rebean Al-silefanee (2019): Entrepreneurship and Private Sector Development: The Case of Kurdistan Region of Iraq.

USE 051 Markus Meinzer (2019): Countering cross-border tax evasion and avoidance: An assessment of OECD policy design from 2008 to 2018.

USE 052 Zornitza Kambourova (2019): Women's Adverse Health Events and Labor Market Participation. 
USE 053 Tim van der Valk (2019): Household finance in France and the Netherlands 1960-2000: An evolutionary approach.

USE 054 Milena Dinkova (2019): Brace yourselves, Pension is coming: Consumption, financial literacy and tailored pension communication.

USE 055 Lisa Dumhs (2019): Finding the right job: School-to-work transitions of vocational students in the Netherlands.

USE 056 Dea Tusha (2020): FDI spillovers in developing countries: channels, conditions, challenges.

USE 057 Jingyang Liu (2020): Money and credit dynamics in the euro area.

USE 058 An Thi Thuy Duong (2020): Financial integration, trade and productivity. 

This thesis contributes to the understanding of real and financial transmission channels, asymmetries and convergence in the euro area. First, based on country-specific business and financial cycles, the degree of cross-country synchronisation and the presence of macrofinancial linkages at the country and euro area levels are investigated. Second, the transmission of symmetric shocks and their impact on euro area countries' trade balances and competitiveness are examined. Third, income convergence in Germany, in the presence of migration and fiscal transfers, is studied.

The findings in this thesis show that asymmetries between countries in the EA continue to exist, both in real and financial markets. Macrofinancial linkages exist at the country and the euro area levels. Differences in economic structures and institutions result in the asymmetric transmission of symmetric shocks. The example of Germany shows that convergence of incomes within a currency union will be a lengthy process despite migration and fiscal transfer schemes. This finding suggests that income differences between EA countries and regions are likely to exist in the longer run. 